Modelagem gerativa para sumarização automática multidocumento

\author{
Maria Lucía del Rosario Castro Jorge
}




\title{
Modelagem gerativa para sumarização automática multidocumento
}

\author{
Maria Lucía del Rosario Castro Jorge
}

Orientador: Prof. Dr. Thiago Alexandre Salgueiro Pardo

Tese apresentada ao Instituto de Ciências Matemáticas e de Computação - ICMC-USP, como parte dos requisitos para obtenção do título de Doutor em Ciências de Computação e Matemática Computacional - VERSÃO REVISADA. 
Ficha catalográfica elaborada pela Biblioteca Prof. Achille Bassi e Seção Técnica de Informática, ICMC/USP, com os dados fornecidos pelo(a) autor(a)

\footnotetext{
(

Modelagem gerativa para sumarização automática multidocumento / Maria Lucía del Rosario Castro Jorge; orientador Thiago Alexandre Salgueiro Pardo. - - São Carlos, 2014.

Tese (Doutorado - Programa de Pós-Graduação em Ciências de Computação e Matemática Computacional) -Instituto de Ciências Matemáticas e de Computação, Universidade de São Paulo, 2014.

1. Processamento de Linguagem Natural. 2. Sumarização Multidocumento. 3. Aprendizado Gerativo. 4. Análise Discursiva. I. Pardo, Thiago Alexandre Salgueiro, orient. II. Título.
} 
Dedico este trabalho aos meus pais, irmã e avós. 


\section{Agradecimientos}

Agradeço primeiramente a Deus pela força para realizar este trabalho de doutorado durante todos esses anos.

À minha família, pelo carinho e apoio mesmo estando longe.

Ao meu orientador, Prof. Thiago Pardo, pela paciência, bondade e aprendizado tão valioso ao longo desses anos.

A todos os professores do NILC, que contribuíram muito para minha formação profissional.

Aos meus colegas e amigos do NILC, pelos momentos de alegria e aprendizado que nunca faltaram ao longo desses anos.

Ao meu colega Márcio Dias, pela colaboração no desenvolvimento do Modelo de Coerência.

A todos os colegas da equipe de sumarização, que enriqueceram minha formação profissional.

A Capes, pelo apoio financeiro.

Às minhas queridas amigas Merley, Lianet, Paula, Nathalie, Amanda, Nádia e Mapi pela amizade e carinho ao longo desses anos. 


\section{Resumo}

A Sumarização Multidocumento consiste na produção automática de um único sumário a partir de um conjunto de textos que tratam de um mesmo assunto. Essa tarefa vem se tornando cada vez mais importante, já que auxilia o processamento de grandes volumes de informação, permitindo destacar a informação mais relevante para o usuário. Nesse trabalho, são propostas e exploradas modelagens baseadas em Aprendizado Gerativo, em que a tarefa de Sumarização Multidocumento é esquematizada usando o modelo NoisyChannel e seus componentes de modelagem de língua, de transformação e decodificação, que são apropriadamente instanciados para a tarefa em questão. Essas modelagens são formuladas com atributos superficiais e profundos. Em particular, foram definidos três modelos de transformação, cujas histórias gerativas capturam padrões de seleção de conteúdo a partir de conjuntos de textos e seus correspondentes sumários multidocumento produzidos por humanos. O primeiro modelo é relativamente mais simples, pois é composto por atributos superficiais tradicionais; o segundo modelo é mais complexo, pois, além de atributos superficiais, adiciona atributos discursivos monodocumento; finalmente, o terceiro modelo é o mais complexo, pois integra atributos superficiais, de natureza discursiva monodocumento e semântico-discursiva multidocumento, pelo uso de informação proveniente das teorias RST e CST, respectivamente. Além desses modelos, também foi desenvolvido um modelo de coerência (ou modelo de língua) para sumários multidocumento, que é projetado para capturar padrões de coerência, tratando alguns dos principais fenômenos multidocumento que a afetam. Esse modelo foi desenvolvido com base no modelo de entidades e com informações discursivas. Cada um desses modelos foi inferido a partir do córpus CSTNews de textos jornalísticos e seus respectivos sumários em português. Finalmente, foi desenvolvido também um decodificador para realizar a construção do sumário a partir das inferências obtidas. $\mathrm{O}$ decodificador seleciona $\mathrm{o}$ subconjunto de sentenças que maximizam a probabilidade do sumário de acordo com as probabilidades inferidas nos modelos de seleção de conteúdo e o modelo de coerência. Esse decodificador inclui também uma estratégia para evitar que sentenças redundantes sejam incluídas no sumário final. Os sumários produzidos a partir dessa modelagem gerativa são comparados com os sumários produzidos por métodos estatísticos do estado da arte, os quais foram implementados, treinados e testados sobre o córpus. Utilizando-se avaliações de informatividade tradicionais da área, os resultados obtidos mostram que os modelos desenvolvidos neste trabalho são competitivos com os métodos estatísticos do estado da arte e, em alguns casos, os superam. 


\section{Abstract}

Multi-document Summarization consists in automatically producing a unique summary from a set of source texts that share a common topic. This task is becoming more important, since it supports large volume data processing, enabling to highlight relevant information to the users. In this work, generative modeling approaches are proposed and investigated, where the Multidocument Summarization task is modeled through the Noisy-Channel framework and its components: language model, transformation model and decoding, which are properly instantiated for the correspondent task. These models are formulated with shallow and deep features. Particularly, three main transformation models were defined, establishing generative stories that capture content selection patterns from sets of source texts and their corresponding human multi-document summaries. The first model is the less complex, since its features are traditional shallow features; the second model is more complex, incorporating single-document discursive knowledge features (given by RST) to the features proposed in the first model; finally, the third model is the most complex, since it incorporates multi-document discursive knowledge features (given by CST) to the features provided by models 1 and 2. Besides these models, it was also developed a coherence model (represented by the Noisy-Channel's language model) for multi-document summaries. This model, different from transformation models, aims at capturing coerence patterns in multi-document summaries. This model was developed over the Entity-based Model and incorporates discursive knowledge in order to capture coherence patterns, exploring multi-document phenomena. Each of these models was treined with the CSTNews córpus of journalistic texts and their corresponding summaries. Finally, a decoder to search for the summary that maximizes the probability of the estimated models was developed. The decoder selects the subset of sentences that maximize the estimated probabilities. The decoder also includes an additional functionality for treating redundancy in the decoding process by using discursive information from the CST. The produced summaries are compared with the summaries produced by state of the art generative models, which were also treined and tested with the CSTNews corpus. The evaluation was carried out using traditional informativeness measures, and the results showed that the generative models developed in this work are competitive with the state of the art statistical models, and, in some cases, they outperform them. 


\section{$\underline{\text { Índice de Conteúdo }}$}

\section{Resumo}

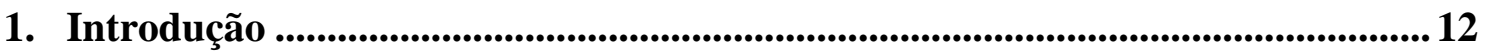

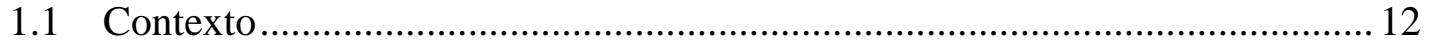

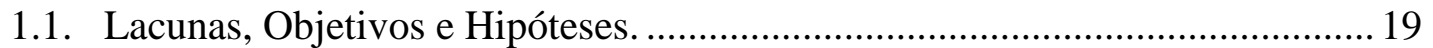

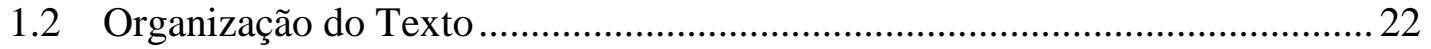

2. Aprendizado Gerativo e Aprendizado Discriminativo ............................................23

2.1. Aprendizado Gerativo: Definição e Métodos principais ................................ 23

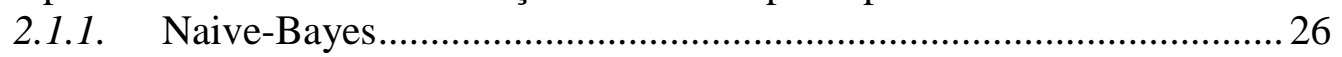

2.2. Aprendizado Discriminativo: Definição e Principais Modelos ........................ 27

2.2.1. Regressão Logística....................................................................... 27

2.2.2. Máquina de Vetor de Suporte (Support Vector Machine-SVM)....... 30

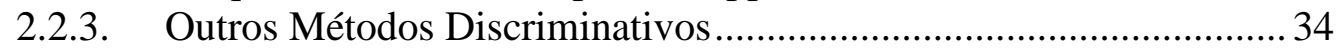

2.3. Abordagem Gerativa vs. Abordagem Discriminativa..................................... 34

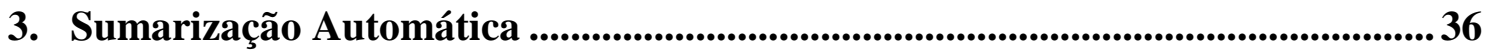

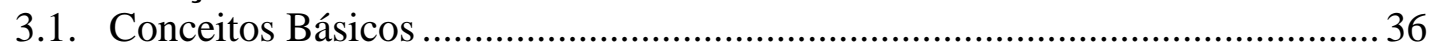

3.2. Avaliação de Sumários Automáticos ............................................................. 39

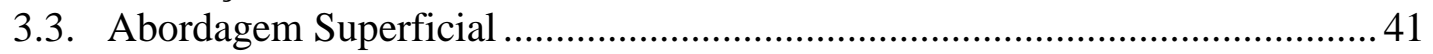

3.3.1. Trabalhos de Sumarização Automática na linha Superficial............. 42

3.4. Abordagem Profunda ................................................................................. 52

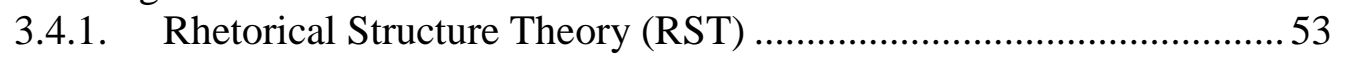

3.4.2. Cross-document Structure Theory (CST) ........................................55

3.4.3. Trabalhos de Sumarização Automática na linha profunda .................58

3.5. Síntese de trabalhos presentados do capítulo ................................................... 65

4. Anotação de Córpus.........................................................................................67

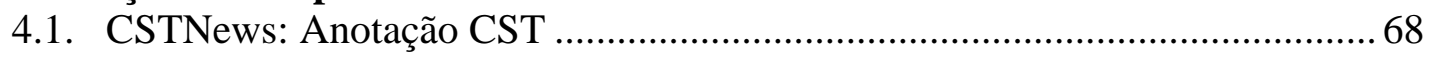

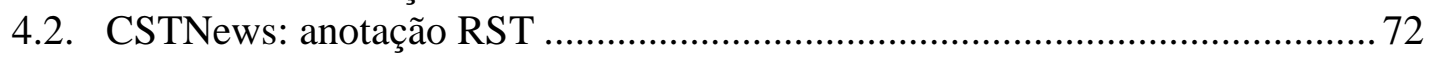

5. Aprendizado Gerativo para Sumarização Multidocumento................................. 76

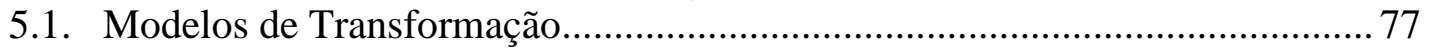

5.1.1. Modelo de Transformação1 ........................................................ 78

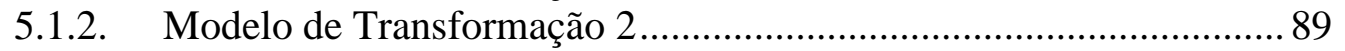

5.1.3. Modelo de Transformação 3 ........................................................ 93

5.2. Modelo de Coerência para Sumários Multidocumento .................................... 98

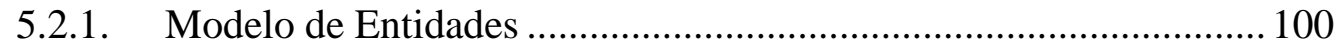

5.2.2. Modelo de Entidades e Informação Discursiva ............................. 102

5.2.3. Modelo de Coerência e a Modelagem Gerativa .............................. 106

5.3. Decodificação de Sumários Multidocumento ................................................ 107

5.3.1. Decodificação simples com o algoritmo A* ................................ 107

5.3.2. Decodificação com Tratamento de Redundância usando A* .......... 110

5.3.3. Modelo de Coerência e Decodificação ............................................. 113

5.3.4. Resumo do Capítulo e outros modelos relacionados ........................ 114

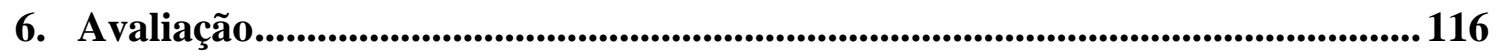


6.1. Modelo de Coerência na Classificação de Sumários coerentes e incoerentes 117

6.2. Impacto dos Atributos nos Modelos de Transformação ............................... 119

6.3. Impacto do Modelo de Coerência na Modelagem Gerativa ........................... 122

6.4. Impacto do tratamento de redundância na decodificação ............................... 125

6.5. Modelagem Gerativa e outros métodos estatísticos....................................... 127

6.6. Modelagem Gerativa e outros sumarizadores para Português ........................ 128

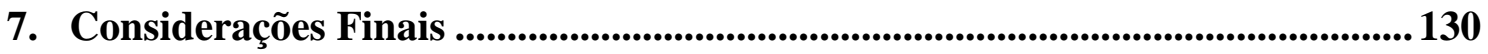

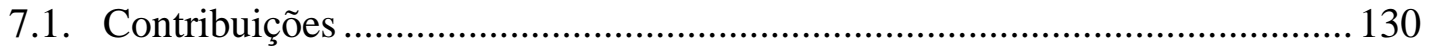

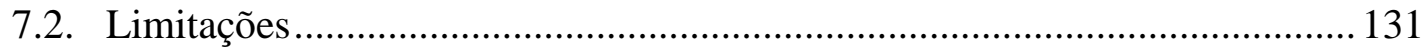

7.3. Trabalhos Futuros ........................................................................................ 132

Referências Bibliográficas...................................................................................... 134

APÊENDICE A - Relações CST refinadas para a anotação do córpus CSTNews......... 142

APÊENICE B - Relações RST para a anotação do córpus CSTNews .......................... 145 


\section{$\underline{\text { Índice de Figuras }}$}

Figura 1: Exemplo de sumário humano construído a partir de textos jornalísticos............... 12

Figura 2: Exemplo de sumário automático multidocumento .................................................. 13

Figura 3: Exemplo de sumário multidocumento com tratamento de informações .................. 14

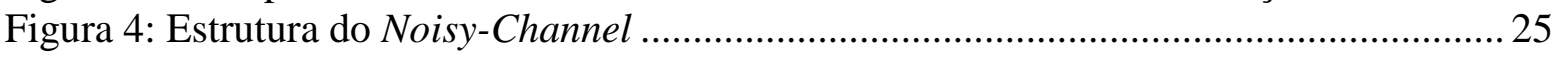

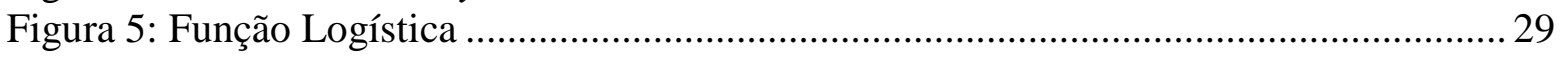

Figura 6: Fronteira de decisão do classificador SVM (Tan et al.,2006, p.258) .................... 31

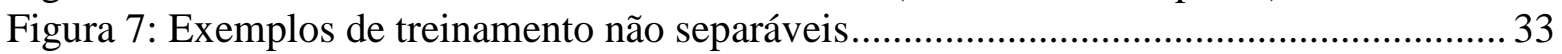

Figura 8: Arquitetura de um sistema de Sumarização Automática.......................................... 38

Figura 9: Árvore RST da relação Purpose entre dois segmentos .........................................55

Figura 10: Exemplo de relação RST Mononuclear................................................................. 55

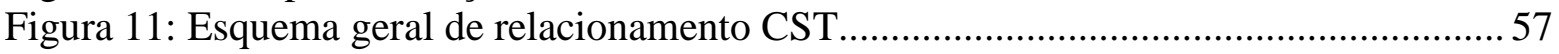

Figura 12: Tipologia de relações CST proposta por Maziero et al.(2010) ............................. 69

Figura 13: Esquema Noisy-Channel para modelagem gerativa de Sumarização

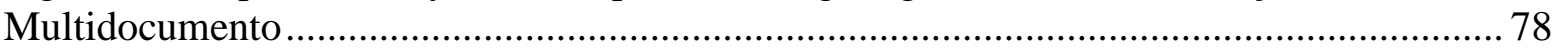

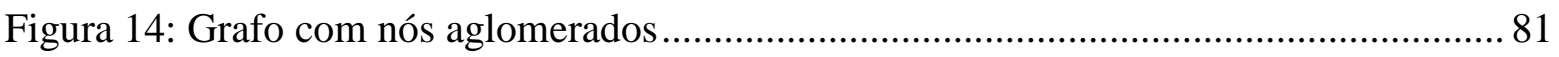

Figura 15: Exemplo de córpus de treinamento composto de textos-fonte e extrato humano 84

Figura 16: Exemplo de relações retóricas entre sentenças................................................. 92

Figura 17: Exemplo de redundância na relação Contradiction da CST ................................ 95

Figura 18: Exemplo de dois textos do córpus e suas relações CST ..................................... 97

Figura 19: Exemplo de coerência-texto original vs sumário Multidocumento....................... 100

Figura 20: Exemplo de Grade de Entidades extraído do trabalho de Barzilay e Lapata

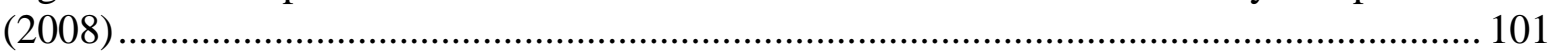

Figura 21: Exemplo de vetor de atributos extraído a partir da Grade de Entidades ............. 102

Figura 22: Exemplo de relações CST entre sentenças de um sumário ................................ 103

Figura 23: Exemplo de grade de entidades para o texto da Figura 22 ................................ 104

Figura 24: Exemplo de Matriz de relações CST para o texto da Figura 22 .......................... 104

Figura 25: Exemplo de vetor de atributos extraído a partir da grade de entidades e a

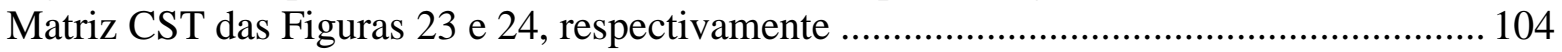

Figura 26: Matriz de Categorias CST do exemplo da Figura 22 .................................... 105

Figura 27: Exemplo de vetor de atributos integrando a grade de entidades da Figura 23 e

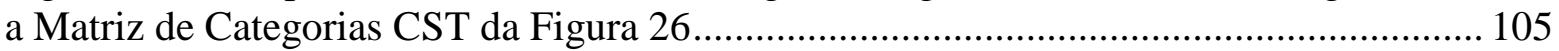

Figura 28: Matriz booleana CST correspondente ao exemplo da Figura 22 ...................... 106

Figura 29: Vetor de atributos que combina a grade de entidades da Figura 23 e a matriz

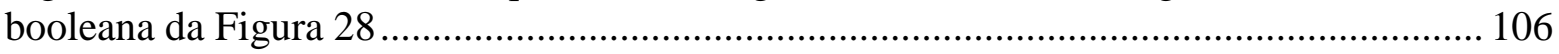

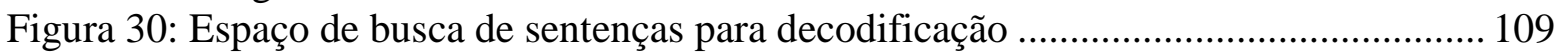

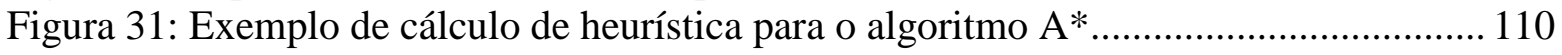

Figura 32: Espaço de busca com informações semântico-discursivas................................. 112

Figura 33: Exemplo de fila de prioridade para sub-soluções com redundância ................... 112

Figura 34: Esquema de experimentos realizados para a modelagem gerativa..................... 117

Figura 35: Exemplo de Sumários produzidos pelos modelos de transformação .................. 122

Figura 36 : Sumário produzido pelo modelo de transformação RST .................................. 123

Figura 37: Exemplos de sumários produzidos com os modelos de transformação e as variações do Modelo de Coerência ................................................................................ 126

Figura 38: Exemplo de sumários produzidos pelos modelos de transformação sem usar

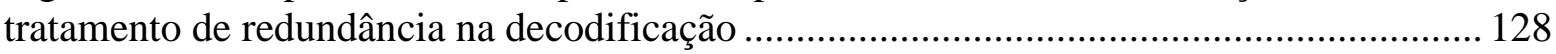




\section{Índice de Tabelas}

Tabela 1: Relações RST propostas no trabalho original de Mann e Thompson (1987) ........................54

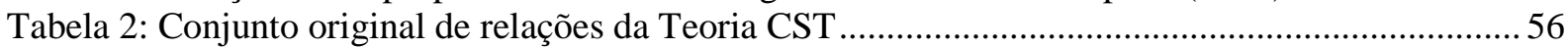

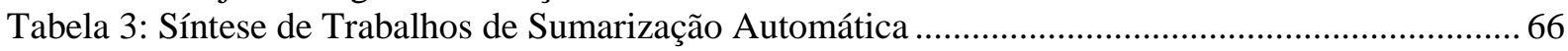

Tabela 4: Distribuição por categorias dos Clusters do córpus CSTNews ..............................................68

Tabela 5: Frequência das relações CST no córpus CSTNews ........................................................... 72

Tabela 6: Medida kappa da anotação CST no córpus CSTNews ......................................................... 72

Tabela 7: Porcentagem de concordância no córpus CSTNews ............................................................. 73

Tabela 8: Regras de Segmentação para anotação RST ........................................................................... 74

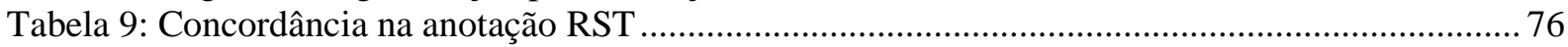

Tabela 10: Exemplo de frequência de palavras-chave........................................................................... 84

Tabela 11: Exemplo do atributo frequência de palavras-chave nas sentenças do córpus ....................... 85

Tabela 12: Exemplo de atributos frequência de palavras -chave e posição nas sentenças..................... 85

Tabela 13: Exemplo de atributos frequência de palavras -chave , posição e grau sentenças ................. 86

Tabela 14: Exemplo de atributos frequência de palavras -chave , posição, grau e similaridade ao

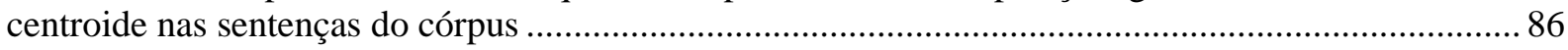

Tabela 15: Exemplo de atributos frequência de palavras -chave, posição, grau, similaridade ao centroide e coeficiente de aglomeração nas sentenças do córpus .......................................................... 87

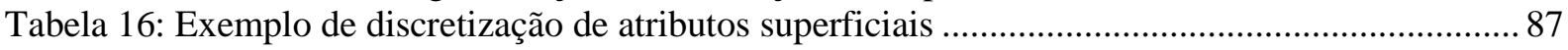

Tabela 17: Atributos discretizados das sentenças do extrato humano ................................................... 87

Tabela 18: Cálculo de probabilidade das sentenças a partir das probabilidades inferidas dos

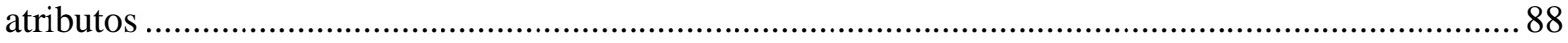

Tabela 19: Cálculo de probabilidade das sentenças usando a técnica de soma de logaritmos ..............89

Tabela 20: Atributos retóricos de cada sentença do córpus .................................................................. 93

Tabela 21: Cálculo de probabilidade das sentenças integrando as probabilidades inferidas do

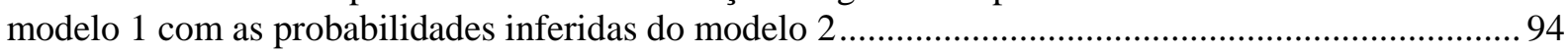

Tabela 22: Atributos do modelo 3 para cada sentença do córpus ......................................................... 97

Tabela 23: Cálculo de probabilidade das sentenças usando as probabilidades inferidas dos

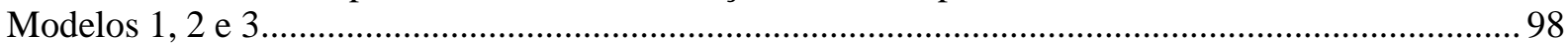

Tabela 24: Resultados do Modelo de Coerência para classificação de sumários ................................. 119

Tabela 25: Resultados da medida Rouge para Modelos de Transformação com tratamento de redundância na decodificação, sem Modelo de Coerência

Tabela 26: Resultados da medida Rouge para os modelos de transformações com as variações do

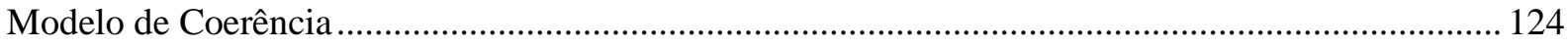

Tabela 27: Resultados da medida rouge para os modelos de transformação, com as variações do Modelo de Coerência, sem tratamento de redundância .................................................................... 127

Tabela 28: Resultados da medida rouge para os métodos do estado da arte....................................... 129

Tabela 29: Resultados da medida Rouge para sumarizadores do estado da arte em Português ........... 130 


\section{Introdução}

\subsection{Contexto}

Nas últimas décadas, muitas tecnologias novas têm surgido, trazendo com isso um crescente aumento no volume de informação. Hoje em dia, muitos recursos, tais como buscadores de notícias, blogs e redes sociais, fazem accessível uma enorme quantidade de informação e, em consequência, o processamento desta se faz cada vez mais difícil. Para se ter uma ideia, o informe recente da IDC $^{1}$ mostra que, entre 2013 e 2020, a informação digital vai crescer de 4.4 trilhões de gigabytes a 44 trilhões, ou seja, a quantidade de informação vai mais do que dobrar. Segundo esse mesmo informe, o mais interessante ainda é que, de todo esse universo digital apenas $1.5 \%$ é informação de alto valor ou relevante para análise.

Muita da informação digital na Web encontra-se em formato de texto, sendo que, alguns desses textos podem estar relacionados uns com os outros porque relatam temas similares. Por exemplo, ao se fazer uma busca no Google sobre a notícia do estado de saúde do ex-jogador Pelé, veremos que há milhares de fontes relatando a mesma notícia e, portanto, muito desse conteúdo é similar. Processar essa informação é uma tarefa muito custosa para o usuário. É neste contexto que a tarefa de Sumarização Automática Multidocumento (SAM) se mostra como um recurso importante. No exemplo da notícia da saúde do Pelé, seria interessante poder ter um texto que resuma as informações mais importantes da notícia, como mostrado na Figura 1.

O ex-jogador de futebol brasileiro Pelé sofreu um mal-estar na quarta feira dia 12 de novembro do presente ano, e foi levado de emergência para o hospital Albert Einstein, em São Paulo. O jogador foi sometido a uma bateria de exames para análise da necessidade de suporte renal, e logo foi levado para unidade de cuidados intensivos aonde vem recebendo antibiótico via intravenoso. A saúde da ex-estrela se mantêm estável desde então, mas ainda não foi emitido um boletim médico oficial.

Figura 1: Exemplo de sumário humano construído a partir de textos jornalísticos

\footnotetext{
1 "The Digital Universe of Oportunities: Rich Data and the Increasing Value of the Internet of Things", International Data Corporation (IDC) e EMC Digital Universe (Abril, 2014)
} 
A SAM consiste na produção de um sumário único a partir de um conjunto de documentos que versam sobre um mesmo assunto (Mani, 2001), sendo que esse sumário deve conter as informações mais relevantes do assunto que está sendo tratado. Essa tarefa surge como uma extensão da Sumarização Monodocumento, que visa à construção de um sumário a partir de um único documento.

A Sumarização Monodocumento foi bastante explorada e discutida por vários autores (p.ex. Luhn, 1958; Baxendale, 1958; Edmundson, 1969; O'Donnell, 1997; Marcu, 2000; Conroy e O' leary, 2001; Pardo e Rino, 2002; Pardo et al., 2003; Rino et al., 2004; Svore et al., 2007; Uzêda et al., 2010). Por outro lado, a SAM representa uma área mais nova que tem adquirido relevância nos últimos anos. As primeiras pesquisas datam dos anos 90 (p.ex. Mckeown e Radev, 1995; 1998; Carbonell e Goldstein, 1998) e as investigações continuam até os anos mais recentes (p.ex. Radev et al. 2000; Zhang et al., 2002; Otterbacher et al., 2002; Barzilay e Mckeown, 2005; Wan e Yan, 2006, Nenkova, 2005; Afantenos, 2007; Haghighi e Vanderwende, 2009; Jorge e Pardo, 2010, Aker et al., 2012; Li e Sujian, 2013). Recentemente têm surgido novas tendências, tais como Sumarização de Opiniões (p.ex., Hu e Liu, 2004; Esuli e Sebastiani, 2006; Dan, 2008; Pang e Lee, 2008; Lerman et al., 2009) e a Sumarização de Atualização (p.ex. Li et al., 2008; Du et al., 2010; Wang e Li, 2010). Na Sumarização de Opiniões, busca-se produzir um resumo das diversas opiniões dadas sobre um aspecto de algum tópico/assunto em particular, por exemplo, opiniões sobre o lançamento de um novo modelo de celular. No caso da Sumarização de Atualização, visa-se resumir as informações mais recentes sobre um assunto, dado que muitas informações já são conhecidas pelo leitor.

$\mathrm{O}$ avanço na SAM é motivado pela relevância desta em importantes sistemas de recuperação de informação, como buscadores de notícias (p.ex., Google News ${ }^{2}$, Wiki $N e w s^{3}$ ), bibliotecas digitais (p.ex.,, CiteSeer ${ }^{4}, \mathrm{DBLP}^{5}$ ) ou mídia social (p.ex., blogs, twitter, facebook). Por exemplo, poder-se-ia construir automaticamente um sumário contendo as informações mais relevantes noticiadas sobre o recente terremoto no Japão. Como ilustração, a Figura 2 mostra um sumário automático multidocumento produzido a partir de um grupo de três textos sobre o recente terremoto no Japão. O sumário foi gerado pelo sistema GistSumm (Pardo, 2005).

$\mathrm{O}$ tremor atingiu a região às $10 \mathrm{~h} 13$ (horário local, 22h13 de domingo, em Brasília) e seu epicentro foi localizado a $260 \mathrm{~km}$ da costa de Niigata, ao nordeste da capital, Tóquio, onde também foi sentido.

TÓQUIO - Um terremoto de 6,8 graus na escala Richter atingiu a costa noroeste do Japão nesta segunda-feira, 16, matando pelo menos sete pessoas na cidade de Kashiwazaki e deixando outros 700 feridos.

O terremoto de 7,4 graus, que pôde ser sentido em Tóquio, foi seguido por outro tremor de menor magnitude, de 4,2 graus na escala Ritcher, às 10h34m (22h34m de domingo em Brasília).

Figura 2: Exemplo de sumário automático multidocumento

\footnotetext{
${ }^{2}$ http://news.google.com.br/

3 http://pt.wikinews.org

${ }^{4}$ http://citeseerx.ist.psu.edu/

5 http://dblp.uni-trier.de/
} 
Diferente do exemplo de sumário humano da Figura 1, que é de fácil leitura e entendimento, o sumário automático da Figura 2 apresenta alguns problemas que dificultam a compreensão do texto. Por exemplo, é possível notar que a sentença que introduz o assunto principal do texto está no meio e não no começo do texto (segunda sentença). Além disso, a terceira e a última sentenças se contradizem ao indicar a magnitude do terremoto. Também se observam informações repetidas ao longo das três sentenças, por exemplo, as informações sobre o fato de que aconteceu um terremoto no Japão.

Todos esses problemas surgem porque no cenário multidocumento acontecem vários fenômenos, conhecidos como fenômenos multidocumento. Em princípio, entre diversas fontes de informação pode haver informação repetida ou redundante, contraditória, complementar e estilos de escrita diferentes. Todos esses fenômenos multidocumento constituem desafios na SAM, pois afetam a manutenção da coerência e coesão dos sumários. Por exemplo, para que um sumário seja coerente, é necessário que não tenha informações redundantes, que as informações complementares estejam bem ordenadas de modo que permitam um seguimento lógico ou temporal dos segmentos textuais, e que as informações contraditórias sejam evitadas ou corretamente contrastadas. Por sua vez, a coesão observa fatores de continuidade na superfície textual, como boa pontuação e uso de itens lexicais, e uso apropriado de anáforas, dentre outros fenômenos. Esses últimos fatores também interferem na coerência do texto.

A seguir, na Figura 3, é mostrado um sumário após o tratamento de alguns dos fenômenos multidocumento. O sumário foi gerado pelo sistema CSTSumm (Jorge e Pardo, 2010) a partir do mesmo conjunto de textos do qual foi extraído o sumário da Figura 2.

TÓQUIO - Um terremoto de 6,8 graus na escala Richter atingiu a costa noroeste do Japão nesta segunda-feira, 16, matando pelo menos sete pessoas na cidade de Kashiwazaki e deixando outros 700 feridos.

O terremoto, que pôde ser sentido em Tóquio, foi seguido por outro tremor de menor magnitude, de 4,2 graus na escala Ritcher, às $10 \mathrm{~h} 34 \mathrm{~m}(22 \mathrm{~h} 34 \mathrm{~m}$ de domingo em Brasília).

Chamas e rolos de fumaça preta foram vistos na usina nuclear de Kashiwazaki, que foi automaticamente fechada durante o terremoto.

Figura 3: Exemplo de sumário multidocumento com tratamento de informações

Nesse exemplo, é possível notar que as informações foram organizadas de modo que os eventos nelas relatados preservam uma ordenação coerente. Além disso, as informações redundantes foram eliminadas, o que deixou o texto mais coerente e também permitiu incluir mais informações relevantes.

Além desses desafios, também se deve considerar que os textos podem ser provenientes de fontes diferentes e, em geral, escritos por pessoas diferentes e, portanto, possuem estilos diversos. Finalmente, considera-se também a taxa de compressão aplicada ao sumário. A taxa de compressão indica o tamanho do sumário em relação aos textos de entrada (em termos de número de palavras), o que pode influenciar na informatividade do 
sumário. Quanto mais alta é a taxa de compressão, menor é o sumário e, portanto, menos informação é veiculada. Por exemplo, os sumários mostrados nas Figuras 2 e 3 foram gerados considerando uma taxa de compressão de $70 \%$ de palavras em relação ao tamanho do maior texto do conjunto de textos.

Uma distinção importante na área de Sumarização Automática (SA) (mono e multidocumento) diz respeito à forma do sumário produzido. Sumários produzidos pela extração e simples justaposição de segmentos do(s) texto(s)-fonte, sem operações de reescrita, são chamados extratos, e os métodos que os produzem são ditos extrativos. Por outro lado, se há alteração em sua forma, diferindo do texto original, o sumário é chamado abstract. É importante ressaltar que, no Brasil, a comunidade de pesquisa adotou esse termo em inglês.

Existem duas abordagens tradicionais para a SA em geral: a superficial (ou empírica/estatística) e a profunda (ou fundamental) (Mani e Maybury, 1999). A primeira abordagem é mais simples e barata, pois leva em consideração pouco ou nenhum conhecimento linguístico para o processamento. A segunda abordagem faz uso de mais conhecimento linguístico, tais como regras gramaticais, semântica, conhecimento discursivo e de mundo, o que faz com que o processamento seja geralmente mais caro. Em geral, os métodos de sumarização da abordagem superficial produzem extratos, enquanto os métodos de sumarização da linha profunda podem produzir abstracts. Apesar do desenvolvimento relativamente simples e de baixo custo, é consenso na área que os métodos superficiais comumente produzem sumários de qualidade inferior aos sumários produzidos por métodos profundos (Mani, 2001; Sparck Jones, 2007).

Os métodos de abordagem superficial destacam-se pelo uso de informações que se encontram na superfície textual, tais como frequência de palavras, $t f$-idf (term frequencyinverse document frequency), posição, similaridade lexical, e palavras-chave, entre outras, para determinar a importância das informações em um texto ou conjunto de textos. As técnicas superficiais têm sido estudadas há muitas décadas, mostrando resultados promissores tanto na sumarização mono quanto multidocumento (p.ex., Luhn, 1958; Baxendale, 1958; Edmunson, 1969; Sparck Jones, 1972; Kupiec et al., 1995; Radev et al., 2004; Nenkova, 2005; Schilder e Kondadadi, 2008; Ouyang et al.2010). Essas informações são usadas para destacar o conteúdo importante nos textos fonte. Por exemplo, a posição é uma informação que tem sido bastante usada, já que alguns gêneros textuais se caracterizam por condensar o conteúdo mais relevante em certos lugares do texto (p.ex. o gênero jornalístico tende a concentrar a informação principal no começo do(s) texto(s)); o tf-idf, bastante usado na área de Recuperação de Informação, destaca as palavras que são muito frequentes num texto e pouco frequentes numa coleção; as palavras-chave representam os termos mais destacados do texto e muitas vezes são descobertas por meio da frequência com que ocorrem no(s) texto(s). Esses exemplos são alguns dos mais conhecidos na linha superficial.

$\mathrm{Na}$ abordagem profunda, destaca-se o uso de ontologias, analisadores sintáticos, analisadores semânticos e discursivos (p.ex, Afantenos et al., 2004; Barzilay e Mckeown, 2005; Afantenos, 2007; Henning et al., 2008; Maziero et al., 2010; Jorge e Pardo, 2010). 
Um dos modelos que guiam a abordagem profunda na SA é a RST (Rhetorical Structure Theory) (Mann e Thompson, 1987). Por essa teoria, todo texto tem suas partes relacionadas por relações discursivas, ou seja, relações que se estabelecem entre o conteúdo de segmentos do texto, por exemplo, causa-efeito, contraste e elaboração. Tal teoria foi intensamente investigada para a Sumarização Monodocumento (por exemplo, Ono et al. 1994; O’Donnell, 1997; Marcu, 2000; Pardo e Rino, 2002; Seno e Rino, 2005; Uzêda et al, 2010), principalmente por sua característica de distinguir junto a cada relação estabelecida quais são os segmentos mais importantes. Na SAM é comumente usada a análise semântico-discursiva para estruturar um conjunto de textos que versam sobre um mesmo assunto, estabelecendo relações entre partes textuais que apontem similaridades ou diferenças entre elas. Nesse contexto, um dos principais modelos que guiam a linha profunda é a CST (Cross-document Structure Theory) (Radev, 2000). Esse modelo se inspira na RST e é o único dessa natureza para textos de qualquer domínio que se conhece. Nesse modelo, propõe-se um conjunto de relações que permitem identificar similaridades, diferenças, contradições e informações complementares entre partes de textos sobre um mesmo tópico. O modelo CST tem sido aplicado com sucesso na SAM (Radev et al., 2000, 2001a, 2001b; Zhang et al., 2002; Otterbacher et al., 2002; Afantenos et al., 2004, 2007; Jorge e Pardo, 2009, 2010, Ribaldo et al., 2012; Cardoso, 2014). Tais trabalhos utilizam-se do fato de que é possível tratar os desafios da SAM conhecendo-se as relações existentes entre os segmentos dos textos que estão sendo processados, como relações de equivalência semântica, elaboração e contextualização. Os resultados de alguns desses trabalhos mostram que é possível melhorar a informatividade e qualidade dos sumários.

Várias pesquisas em SA (mono e multidocumento) têm realizado essa tarefa via técnicas de Aprendizado de Maquina (AM) (p.ex., Kupiec et al., 1995; Mani e Bloedorn, 1998; Witbrock e Mittal, 1999; Daumé e Marcu, 2001; Knight e Marcu, 2002; Schilder e Kondadadi, 2008; Haghighi e Vanderwende, 2009; Jorge et al. 2011). A área de Aprendizado de Máquina é uma subárea da Inteligência Artificial que aborda a questão de construir sistemas computacionais que aprendam a modelar uma tarefa por meio da experiência de treinamento (Mitchell, 1997). Essa experiência é dada por meio de um conjunto de exemplos representativos da tarefa que se deseja modelar. Desse modo, a tarefa de aprendizado se torna um problema de busca em um espaço de funções, onde se pretende encontrar a função que melhor se ajuste aos exemplos de treinamento, e que logo possa ser generalizada eficientemente a outros exemplos novos. Em particular, o aprendizado na SA é realizado sobre exemplos de pares de textos fonte e sumários. A ideia é que, dados esses textos e os sumários correspondentes, a experiência de treinamento permita achar o modelo (função) que capture melhor os padrões de sumarização.

$\mathrm{Na}$ área de Aprendizado de Máquina, existem vários paradigmas de aprendizado (Mitchell, 1997). Os mais importantes são o Simbólico, o Estatístico, o Conexionista, o Baseado em exemplos e o Evolutivo. No paradigma Simbólico, busca-se aprender construindo representações simbólicas em forma de expressão lógica, regra ou rede semântica. Um exemplo clássico de algoritmo desse paradigma são as árvores de decisão (Quinlan, 1986, 1993). No paradigma Estatístico, utilizam-se modelos probabilísticos para encontrar uma aproximação do conceito induzido, por exemplo, Naive-Bayes (Duda e Hart, 
1973). O paradigma Conexionista é representado pelas Redes Neurais (McCulloch e Pitts, 1943; Hebb, 1949; Rosemblatt,1958), as quais são estruturas compostas de unidades simples que estão interconectadas entre si. $\mathrm{O}$ aprendizado em redes neurais é dado pela adaptação das unidades e suas conexões à tarefa que se deseja aprender. No paradigma baseado em exemplos, os dados novos são aprendidos a partir da sua similaridade com exemplos anteriores, por exemplo, o algoritmo k-vizinhos mais próximos (Cover e Hart, 1967). Finalmente, o paradigma Evolutivo é baseado em competição de elementos para fazer uma predição de modelo ou função. Esse paradigma pode ser exemplificado pelos algoritmos genéticos (Goldberg, 1989).

Os métodos de aprendizado também podem ser do tipo Supervisionado, não Supervisionado ou Semi-supervisionado. No Aprendizado Supervisionado, é fornecida a "classe", que é um atributo especial dos exemplos e que indica o que deve ser aprendido. No Aprendizado não Supervisionado, o elemento "classe" não é fornecido, portanto, os exemplos são agrupados explorando-se padrões em comum. No Aprendizado Semisupervisionado, é fornecida a classe de alguns elementos, mas não de todos. Nesse tipo de aprendizado, normalmente se procura propagar os rótulos da classe dos elementos que a possuem via algum tipo de associação com os elementos que não a possuem.

Outra classificação importante refere-se ao Aprendizado Gerativo e ao Aprendizado Discriminativo ( $\mathrm{Ng}$ e Jordan, 2002). No Aprendizado Gerativo, os modelos de classificação são aprendidos por meio do cálculo da probabilidade $\mathrm{p}(\mathrm{x}, \mathrm{y})$ entre os atributos x e a classe y. As predições sobre essa probabilidade são feitas por meio da aplicação da Regra de Bayes ${ }^{6}$ para calcular $\mathrm{p}(\mathrm{y} \mid \mathrm{x})$, e logo obter o valor de y mais provável para $\mathrm{o}$ conjunto de atributos x. No Aprendizado Discriminativo, a probabilidade $\mathrm{p}(\mathrm{x}, \mathrm{y})$ é calculada diretamente sem usar a regra de Bayes, ou seja, os atributos x são diretamente mapeados na classe y. Um exemplo representativo de classificador discriminativo é o método de Regressão Logística (Agresti, 1996). Um exemplo de classificador Gerativo é o Naive-Bayes. Muitos dos trabalhos de SA que usam Aprendizado de Máquina podem ser classificados nesses dois tipos de Aprendizado. Por exemplo, na abordagem discriminativa, destacam-se os trabalhos de Witbrock e Mittal (1999), Schilder e Kondadadi (2008), Jorge et al. (2011) e Aker et al. (2010,2012). Na abordagem gerativa destacam-se Daumé e Marcu (2001), Knight e Marcu (2002), Daumé e Marcu (2006) e Haghighi e Vanderwende (2009).

Em particular, a abordagem gerativa tem sido amplamente usada em várias áreas do Processamento de Língua Natural, usando-se o esquema Noisy-Channel (Shannon, 1948), por exemplo: Reconhecimento de Fala, Perguntas e Respostas, Correção Ortográfica, e Tradução Automática, entre outras. O esquema Noisy-Channel surgiu dentro da área de Teoria da Informação como um teorema de codificação de dados na linha telefônica. De acordo com esse teorema, incialmente assume-se que uma mensagem é enviada de um lado da linha telefônica e é transmitida por meio de um canal ruidoso, onde sofre um processo de transformação que corrompe a mensagem original, fazendo surgir do outro lado da linha

\footnotetext{
${ }^{6} \mathrm{Na}$ teoria das probabilidades, a regra de Bayes mostra a relação entre uma probabilidade condicional e a probabilidade condicional inversa: $P(y \mid x)=(P(x \mid y) \times P(y)) / P(x)$
} 
telefônica uma mensagem corrompida. Dado esse cenário, deseja-se recuperar a mensagem original por meio de um processo de decodificação. Nesse esquema, podem-se identificar três componentes principais: uma fonte (a que emite a mensagem original), um canal ruidoso (que contém um processo de transformação que corrompe a mensagem original) e um decodificador que recupera a mensagem mais provável. Os componentes desse esquema são mapeados na regra de Bayes, representando o modelo de língua da mensagem de saída (mensagem corrompida), o modelo de transformação, onde é modelado o ruído que ocorre no canal ruidoso e, finalmente, a própria decodificação. Esse esquema é interessante porque permite formalizar a história gerativa de uma tarefa, a qual é modelada como o componente principal do Noisy-Channel. Uma vantagem importante do NoisyChannel é que permite particionar a modelagem de uma tarefa de forma que é possível conceituar separadamente o modelo da história gerativa e o modelo de língua. Permite-se, assim, identificar os fatores envolvidos em cada componente de forma independente. Um exemplo clássico da aplicação do Noisy-Channel é na área de Tradução Automática, na qual a aplicação desse modelo produziu os tradutores do estado da arte de acordo com as avaliações do $\mathrm{NIST}^{7}$. Para instanciar o processo de tradução de uma língua qualquer para o inglês no esquema Noisy-Channel, assumiu-se que uma sentença em inglês era emitida por uma fonte e, ao passar por uma transformação, produzia-se uma sentença em outro idioma. Dado que o objetivo era recuperar a sentença em inglês original (a tradução), modelou-se o processo de transformação de forma contrária (como uma sentença em inglês se corrompe e vira uma sentença em outra língua), explorando uma história gerativa. Essa história gerativa consistiu basicamente em formalizar probabilisticamente todos os fatores envolvidos no processo de tradução, por exemplo, o mapeamento de palavras, a reordenação dessas palavras na sentença traduzida, o surgimento de novas palavras no idioma alvo, etc. Já no modelo de língua, utilizou-se um modelo de n-gramas para capturar os padrões de boa formação de uma sentença na língua alvo. Finalmente, um decodificador, que basicamente consistia em um algoritmo de busca sobre um conjunto de possíveis traduções de uma sentença, recuperava a tradução mais provável de acordo com o modelo de transformação e o modelo de língua conjuntamente.

Em particular, no caso da SAM, a história gerativa modelada no Noisy-Channel permitiria explorar os fatores envolvidos no processo de geração de um sumário. A modelagem gerativa seria entendida da seguinte forma: um sumário é emitido por uma fonte e logo em seguida sofre um processo de transformação, o que geraria um conjunto de textos fonte a partir dos quais esse sumário foi gerado. A ideia principal seria recuperar esse sumário original a partir da modelagem de transformação, o que representaria a história gerativa da SAM. Além disso, o modelo de coerência (que é representado pelo modelo de língua no Noisy-Channel) de um sumário multidocumento seria um modelo que capturaria os fatores de boa formação e coerência textual de um sumário multidocumento. O decodificador seria um algoritmo de busca no espaço de todos os possíveis sumários que podem ter sido gerados a partir do conjunto de textos, sendo que o objetivo seria achar o

\footnotetext{
${ }^{7}$ National Institute of Standards and Technology: http://www.nist.gov/
} 
sumário mais provável de acordo com o modelo de transformação e o modelo de coerência.

Independentemente da abordagem que se segue, Mani e Maybury (1999) sugerem que a tarefa de SA seja realizada em três etapas principais: 1) análise do conteúdo dos textos, 2) transformação/seleção de conteúdo relevante e 3) síntese/geração do sumário a partir do conteúdo selecionado. Na etapa de análise, os textos de origem são processados e seu conteúdo é representado em um ou mais níveis de análise linguística: morfológico, sintático, semântico e/ou discursivo; na etapa de transformação, o conteúdo representado é refinado, sendo que isto é feito por meio de operações de seleção de conteúdo relevante, combinação de informações, etc.; finalmente, na etapa de síntese, o conteúdo selecionado é organizado e expresso em língua natural, podendo-se utilizar métodos de geração textual.

Neste trabalho, foca-se em uma abordagem gerativa para SAM usando como base o esquema Noisy-Channel, no qual todas as etapas sugeridas por Mani e Maybury serão abordadas. A seguir, as lacunas na área da SAM são identificadas e detalhadas e, a partir delas, são estabelecidos os objetivos e as principais hipóteses deste trabalho.

\subsection{Lacunas, Objetivos e Hipóteses.}

Pesquisas recentes em Sumarização Multidocumento de textos em português tem abordado essa tarefa de diferentes formas, visando melhorar a qualidade dos sumários automáticos. A maioria das pesquisas tem explorado a tarefa por meio de estratégias pré-definidas para selecionar o conteúdo mais relevante (Pardo, 2005; Jorge e Pardo, 2009,2010; Ribaldo et al., 2012, Camargo, 2013; Cardoso, 2014). Apesar de essas pesquisas terem mostrado resultados promissores, esses resultados ainda estão longe de alcançar a qualidade dos sumários humanos. Além disso, apesar dos esforços de se tratar os fenômenos multidocumento, os sumários produzidos ainda apresentam problemas de redundância, contradição e ordenação de informações complementares. Todos esses problemas revelam a necessidade de que a informatividade e a qualidade dos sumários multidocumento sejam um assunto de pesquisa a ser explorado de novas formas, que se aproximem mais das decisões humanas de sumarização e, portanto, gerem sumários automáticos mais informativos.

Atualmente, vários métodos de SA visam aprender modelos automaticamente a partir de dados reais (textos e seus respectivos sumários), buscando-se descobrir padrões mais ricos e mais próximos aos critérios utilizados por humanos na elaboração de um sumário. Nesse sentido, alguns dos cenários que ainda foram pouco investigados na SAM são:

- o aprendizado automático de modelos de SAM de textos em português, a partir de córpus de textos e sumários;

- o uso de métodos de aprendizado que permitam modelar de forma adequada o processo de geração de um sumário multidocumento, abrangendo os fatores que o afetam; 
- uma exploração adequada da integração de conhecimentos superficial e profundo nos modelos de SAM que permita observar seu impacto no processo de geração de um sumário multidocumento;

- o tratamento dos fenômenos multidocumento por meio de modelos extraídos automaticamente.

Visando explorar mais a tarefa de geração de um sumário multidocumento e, assim, melhorar a qualidade dos sumários, o objetivo principal deste trabalho é o desenvolvimento e avaliação de modelos gerativos para SAM. Esses modelos gerativos são projetados usando o esquema Noisy-Channel, o que permite formular uma história gerativa para SAM. Essa história gerativa é formulada principalmente por meio de três modelos de transformação: o primeiro modelo é o modelo mais simples, pois incorpora apenas informações superficiais como posição de sentenças, frequência de palavras, etc.; o segundo modelo integra os atributos do primeiro modelo a atributos discursivos monodocumento, os quais são representados por informações da RST; o terceiro modelo integra os atributos dos modelos 1 e 2 e incorpora atributos semântico-discursivos, representados pela teoria CST. Também foi desenvolvido um modelo de coerência para sumários multidocumento, sendo que o objetivo desse modelo é capturar padrões de coerência textual para sumários multidocumento. Tal modelo é desenvolvido integrando, ao Modelo de Entidades de Barzilay e Lapata (2008) (bastante utilizado na área de coerência textual), informações discursivas monodocumento e semântico-discursivas multidocumento, representadas pelas teorias RST e CST, respectivamente. O decodificador proposto neste trabalho foi desenvolvido usando o algoritmo $A^{*}($ Russel et al., 1995), seguindo uma metodologia similar a Aker et al. (2010), mas incorporando informações semântico-discursivas da CST para tratar a redundância no processo de decodificação. A partir do objetivo principal, surgem os seguintes objetivos secundários:

- a partir dos modelos de transformação, formalizar a história gerativa da construção de um sumário multidocumento;

- investigar e definir os atributos adequados (da abordagem profunda e superficial) que permitam modelar mais apropriadamente o processo de seleção de conteúdo, identificando os diferentes níveis de informação considerados nesse processo;

- investigar o impacto de modelos discursivos (RST e CST) no modelo de coerência baseado no Modelo de Entidades;

- investigar o impacto do modelo de coerência na geração de sumários multidocumento;

- investigar o impacto do tratamento de redundância do processo de decodificação nos sumários produzidos. 
A tese principal deste trabalho é que uma modelagem gerativa de SAM, formulada a partir de atributos que representem os principais fatores da Sumarização, permitem explorar melhor o processo de construção de um sumário e, assim, produzir sumários automáticos mais informativos. Além disso, outras hipóteses secundárias são formuladas a partir da tese principal:

- a combinação de conhecimento profundo e superficial na formulação dos atributos tem um impacto positivo na qualidade e informatividade dos sumários;

- conhecimento discursivo tem um impacto positivo na modelagem da coerência para sumários multidocumento;

- o uso de informação semântico-discursiva (CST) no processo de decodificação ajuda a tratar efetivamente a redundância em sumários multidocumento.

Para este trabalho, foi utilizado conhecimento profundo via modelagens RST e CST, a partir das quais foram formulados os atributos que compõem os modelos gerativos desenvolvidos. A motivação para o uso dessas teorias é a existência de pesquisas que avaliam positivamente a influência destas na SA de textos em Português (Jorge e Pardo, 2010; Ribaldo et al.,2012; Cardoso, 2014). Para a língua portuguesa, conta-se com vários recursos baseados nessas teorias. Em particular, neste trabalho, usa-se o córpus CSTNews (Cardoso et al., 2011), que é composto de grupos de textos escritos em Português e anotados manualmente com CST e RST. Além disso, esse córpus também fornece dois tipos de sumários multidocumento, extratos e abstracts, para cada grupo de textos do córpus. Detalhes sobre a composição e construção desse córpus são apresentados no Capítulo 4. Na modelagem gerativa desenvolvida neste trabalho, foram usados os extratos e seus textos-fonte correspondentes para o treinamento e teste dos modelos.

A avaliação dos sumários produzidos foi feita usando a medida Rouge (Lin, 2004), que é a medida automática de informatividade mais utilizada para a avaliação de sumários. Os resultados dos métodos foram comparados com dois dos principais métodos estatísticos do estado da arte, TopicSum e HierSum (Haghighi e Vanderwende, 2009). Os resultados obtidos mostram que os atributos explorados são bons preditores de informação relevante para produzir sumários multidocumento. Além disso, observou-se que os modelos que incorporam informação profunda tem melhores resultados que os modelos mais simples, sendo competitivos com os modelos estatísticos do estado da arte. Também se observou que a aplicação do Modelo de Coerência contribui positivamente na formação de sumários multidocumento coerentes.

Esta pesquisa gerou o primeiro modelo de aprendizado automático que explora a história gerativa da SAM, integrando atributos superficiais e profundos. Outra contribuição importante é o estudo de um Modelo de Coerência para sumários multidocumento, explorando os fenômenos multidocumento via informações dadas pela CST e RST. O estudo e desenvolvimento de um decodificador com tratamento de redundância também são contribuições para a área. 


\subsection{Organização do Texto}

O trabalho está organizado da seguinte forma: no Capítulo 2, apresenta-se uma descrição e discussão sobre Aprendizado Gerativo e Aprendizado Discriminativo; no Capítulo 3, são estudados os principais conceitos de SAM e as mais importantes propostas da área com foco nos modelos baseados em AM; no Capítulo 4, descreve-se a anotação do córpus CSTNews; no Capítulo 5, apresenta-se a modelagem gerativa para SAM; no Capitulo 6, são discutidos os resultados dos métodos desenvolvidos; finalmente, no Capítulo 7 são feitas as considerações finais sobre este trabalho e alguns trabalhos futuros são discutidos. 


\section{Aprendizado Gerativo e Aprendizado Discriminativo}

Em muitas aplicações de Aprendizado de Máquina, o objetivo principal é mapear um vetor de atributos de entrada, que representam uma instância, a um valor de classe. Essa tarefa é referenciada como Classificação.

O aprendizado gerativo e o aprendizado discriminativo são duas visões diferentes para abordar a tarefa de classificação. Essas duas abordagens têm sido bastante utilizadas em diversas áreas, como a Tradução Automática (Brown et al. 1993), o Reconhecimento de Fala (Junqua e Haton, 1995), e Compressão Sentencial (Knight e Marcu, 2002), entre outras.

Neste capítulo, serão estudadas essas duas abordagens e seus principais modelos, destacando-se diferenças e aspectos relevantes dessas abordagens no âmbito da SAM.

\subsection{Aprendizado Gerativo: Definição e Métodos principais}

Dado um conjunto de atributos $X=\left\{X_{1}, X_{2}, \ldots, X_{N}\right\}$, que define o conjunto de exemplos de treinamento, e dada a variável $Y$ que define a classe destes exemplos, busca-se no Aprendizado Gerativo aprender um modelo desses dados a partir da probabilidade conjunta $\mathrm{P}(X, Y)$, a qual é inferida por meio da regra de Bayes (1). Aplicando-se a regra de Bayes, é possível calcular $\mathrm{P}(Y \mid X)$ e selecionar o valor de $Y$ mais provável (Ng e Jordan, 2002).

$$
P\left(Y \mid X_{1}, X_{2}, \ldots, X_{n}\right)=\frac{P\left(X_{1}, X_{2,}, \ldots, X_{n} \mid Y\right) \times P(Y)}{P\left(X_{1}, X_{2,}, \ldots, X_{n}\right)}
$$

Dada a equação (1), é preciso estimar as probabilidades a partir do conjunto de exemplos de treinamento. Um método muito utilizado na abordagem gerativa para a estimativa de probabilidades é o cálculo de Máxima Verossimilhança (Fisher, 1990). Esse método é baseado no cálculo da frequência relativa dos atributos do conjunto $X$ e a classe $Y$, em um conjunto de exemplos de treinamento. Em outras palavras, conta-se o número de vezes em que os atributos do conjunto $X$ e a classe $Y$ coocorrem no conjunto de exemplos de 
treinamento. Ao realizar esse cálculo, busca-se determinar quão provável é a ocorrência do padrão $\left(\mathrm{X}_{1}, \mathrm{X}_{2}, \ldots, \mathrm{X}_{\mathrm{n}}, Y\right)$ em um cenário real. Na equação (2), mostra-se a formulação dessa estimativa nas probabilidades da equação (1)

$$
P(Y \mid X 1, X 2, \ldots, X n)=\frac{\frac{F(X 1, X 2, \ldots, X n, Y)}{N} \times \frac{F(Y)}{N}}{\frac{F(X 1, X 2, \ldots, X n)}{N}}
$$

Nesta equação, $\mathrm{N}$ representa o numero total de exemplos no conjunto de treinamento; $\mathrm{F}\left(\mathrm{X}_{1}, \mathrm{X}_{2}, \ldots, \mathrm{X}_{\mathrm{n}} \mid Y\right)$ indica o número de vezes que os atributos $\mathrm{X}_{1}, \mathrm{X}_{2}, \ldots, \mathrm{X}_{\mathrm{n}}$ ocorreram conjuntamente com a classe $Y$, no conjunto de treinamento; $\mathrm{F}\left(\mathrm{X}_{1}, \mathrm{X}_{2}, \ldots, \mathrm{X}_{\mathrm{n}}\right)$ indica $\mathrm{o}$ número de vezes que os atributos $\mathrm{X}_{1}, \mathrm{X}_{2}, \ldots, \mathrm{X}_{\mathrm{n}}$ ocorreram juntos no conjunto de treinamento; $\mathrm{F}(Y)$ indica o número de vezes que a classe $\mathrm{Y}$ ocorreu no conjunto de treinamento. Para simplificar, sempre que sejam mencionadas as probabilidades que compõem a equação (1), assumiremos que estas são calculadas com base na frequência relativa.

A partir do cálculo das probabilidades, o método da Máxima Verossimilhança busca estimar o valor de Y que maximize a equação (1). Isso é expresso na equação (3).

$$
P(X 1, X 2, \ldots, X n \mid Y) \times P(Y)
$$

Observa-se que a probabilidade do denominador da equação (1) não foi considerada no cálculo da equação (3), pois o valor dessa probabilidade será o mesmo para todo $\mathrm{Y}$, portanto não afeta o cálculo da função argmax. Em particular, a equação (3) é conhecida como Máxima verossimilhança a Posteriori, pois é calculada com base na informação a priori dada por $\mathrm{P}(\mathrm{Y})$. $\mathrm{O}$ cálculo a priori da probabilidade $\mathrm{P}(\mathrm{Y})$ é uma característica da abordagem gerativa.

Um problema comum no cálculo da Máxima Verossimilhança é que a frequência relativa algumas vezes pode ser zero ou muito próxima de zero, implicando que o cálculo total da Máxima Verossimilhança pode ser zero também. Para resolver esse problema, existem várias técnicas de suavização de dados. Uma das técnicas mais conhecidas é o Estimador de Máxima Verossimilhança de Laplace ou Add-one smoothing (como é comumente referenciado em inglês) (Jeffreys, 1948). De acordo com esse estimador, o valor da frequência relativa é aumentada em 1, para ter o efeito de dar uma probabilidade pequena a eventos que nunca ocorrem no treinamento. Isso é formulado na equação (4).

$$
P_{\text {Lap }}\left(X_{1}, X_{2}, \ldots, X_{n} \mid Y\right)=\frac{F\left(X_{1}, X_{2}, \ldots, X_{n} \mid Y\right)+1}{N+F(Y)}
$$

Uma outra solução ao problema da frequência zero é o estimador $A d d-\delta$ smoothing (Johnson, 1932), que não adiciona 1 na contagem da frequência relativa, mas sim um valor menor, $\delta$. Outros tipos de técnicas de suavização também são: o Good-Turing smoothing (Good, 1953) e o Hold Out (Jelinek e Mercer, 1985), entre outros. 
Um esquema representativo da abordagem gerativa é o Noisy-Channel (Shannon, 1948). Esse esquema surgiu como um esquema de codificação de dados, no âmbito da Teoria da Informação. No entanto, o Noisy-Channel tem sido utilizado com bastante sucesso em áreas importantes como Tradução Automática, Reconhecimento de Fala, e Perguntas e Respostas, entre outras. Esse esquema foi inicialmente concebido para prever e corrigir erros ao longo das mensagens transmitidas pela linha telefônica. Em princípio, uma mensagem $y$ era emitida por uma fonte com uma probabilidade $\mathrm{P}(y)$, essa mensagem era transmitida por meio de um canal ruidoso onde acontecia algum processo de transformação que introduzia um ruído na mensagem original, produzindo uma mensagem corrompida $x$ com uma probabilidade $\mathrm{P}(x)$. A probabilidade de $y$ ter se transformado em $x$ é dada por $\mathrm{P}(x \mid y)$. De acordo com esse modelo, se $\mathrm{P}(y)$ e $\mathrm{P}(x \mid y)$ são conhecidos, é possível determinar $\mathrm{P}(y \mid x)$ por meio de um processo de decodificação, onde se busca pela mensagem original $y$ que maximize $\mathrm{P}(y \mid x)$. Esse cálculo é realizado por meio da Regra de Bayes mostrada na equação (5). Na Figura 4, é ilustrado o esquema Noisy-Channel com todos os seus componentes: fonte, canal-ruidoso e decodificador.

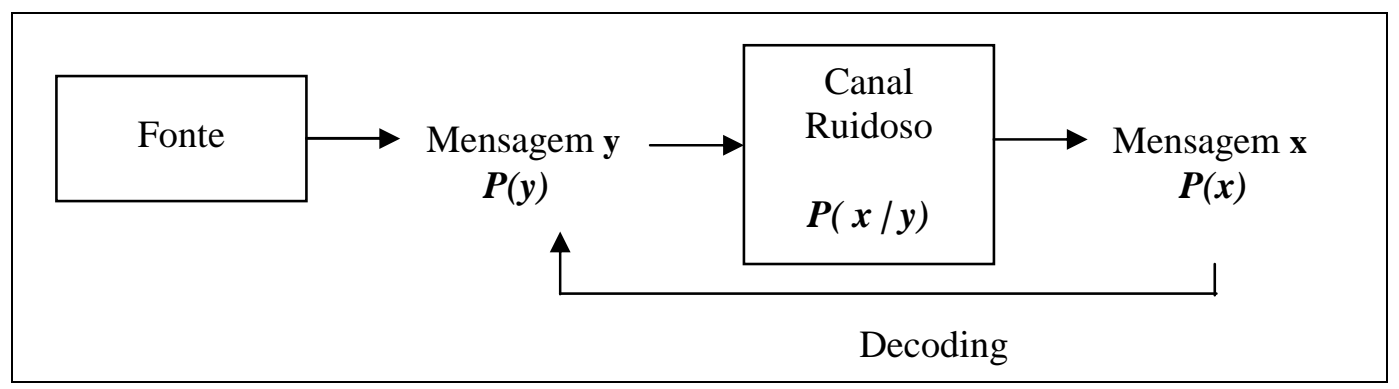

Figura 4: Estrutura do Noisy-Channel

$$
\underset{y}{\operatorname{argmax}} P(y \mid x)=\frac{P(x \mid y) \times P(y)}{P(x)}
$$

Dado que o que se deseja achar é o valor y que maximize $\boldsymbol{P}(\boldsymbol{y} \mid \boldsymbol{x})$, a probabilidade $\mathrm{P}(x)$ pode ser desconsiderada, já que é uma variável observada que não afeta ao cálculo da função argmax. Note que cada probabilidade que compõe a regra da Bayes (5) representa algum componente do esquema Noisy-Channel. Em particular, observa-se na Figura 4 que $\boldsymbol{P}(\boldsymbol{x} \mid \boldsymbol{y})$ é representado pelo ruído do canal. Nesse ponto, a história gerativa de qualquer tarefa é determinada pelo ruído introduzido no canal.

No contexto da SAM, pode-se imaginar que $y$ é um sumário multidocumento e $x$ é o grupo de textos a partir do qual foi produzido y. Seguindo a lógica do Noisy-Channel, pode-se calcular a probabilidade de $\boldsymbol{P}(\boldsymbol{y} \mid \boldsymbol{x})$ por meio da probabilidade $\boldsymbol{P}(\boldsymbol{x} \mid \boldsymbol{y})$ e da probabilidade $\boldsymbol{P}(\boldsymbol{y})$. Nesse caso, $\boldsymbol{P}(\boldsymbol{x} \mid \boldsymbol{y})$ é a probabilidade de que um grupo de textos y tenha gerado um sumário $\mathrm{x}$. Essa probabilidade estaria influenciada pelo ruído gerado no canal. $\mathrm{Na}$ SAM, esse ruído pode representar os fatores que influenciam o processo de geração de um sumário, ou dito de outro modo, os fatores que influenciam a história gerativa da SAM. 
Por outro lado, pode-se considerar que $\boldsymbol{P}(\boldsymbol{y})$ é um modelo de coerência para sumários. No caso da SAM, um modelo de coerência para sumários é uma distribuição probabilística dos elementos que descrevem a boa formação de um sumário. Essa boa formação pode estar influenciada por vários fatores como a coerência no fluxo de informações, a boa construção gramatical de sentenças, a coesão entre sentenças, etc. Neste trabalho, apresenta-se uma modelagem gerativa com base no esquema Noisy-Channel. Nessa modelagem, é especificada a probabilidade $\boldsymbol{P}(\boldsymbol{x} \mid \boldsymbol{y})$ que modela a história gerativa para SAM. $\boldsymbol{P}(\boldsymbol{y})$, por sua parte, especifica o modelo de coerência para sumários multidocumento.

A utilidade desse esquema é permitir a modelagem da história gerativa, por meio do modelo de transformação $\mathrm{P}(x \mid y)$, e, além disso, permitir modelar $\mathrm{P}(y)$ independentemente do modelo de transformação. Isso faz com que a tarefa possa se dividir em problemas menores que possam ser modelados separadamente, cada um com seus atributos particulares.

Existem vários métodos representativos do Aprendizado Gerativo, por exemplo, o Modelo de Mistura Gaussiana (em inglês, Gaussian Mixture Model) (Everit e Hand, 1981), o modelo de estados ocultos de Markov (em inglês, Hidden Markov Models) (Baum e Petri, 1966), e o classificador Naive-Bayes (Duda e Hart, 1973), entre outros. A seguir, será descrito o Naive-Bayes por ser um dos mais representativos desse tipo de aprendizado.

\subsubsection{Naive-Bayes}

Naive-Bayes é um classificador baseado na aplicação da regra de Bayes, fazendo a suposição de independência condicional entre os atributos do conjunto X. Essa suposição de independência é aplicada na estimativa da probabilidade condicional $\mathrm{P}\left(\mathrm{X}_{1}, \mathrm{X}_{2}, \ldots, \mathrm{X}_{\mathrm{n}}\right.$ | $\mathrm{Y})$. Desse modo, a probabilidade $\mathrm{P}\left(\mathrm{X}_{1}, \mathrm{X}_{2}, \ldots, \mathrm{X}_{\mathrm{n}} \mid \mathrm{Y}\right)$, pode ser formulada como segue:

$$
P(X \mid Y=y)=\prod_{i=1} P\left(X_{i} \mid Y=y\right)
$$

Dada a suposição de independência, é possível decompor a probabilidade $\mathrm{P}\left(\mathrm{X}_{1}, \mathrm{X}_{2}, \ldots, \mathrm{X}_{\mathrm{n}}\right.$ | Y) em vários parâmetros. A pesar de os atributos nem sempre serem verdadeiramente independentes, a suposição de independência ajuda muito no desempenho do algoritmo, pois é mais fácil estimar a probabilidade de um atributo independentemente do que estimar conjuntamente vários atributos. Quanto mais longo for o número de atributos que tenham que ser estimados conjuntamente, mais difícil é achar esses padrões nos exemplos de treinamento, o que poderia resultar em problemas de overfitting $^{8}$.

A probabilidade $\mathrm{P}(\mathrm{X} 1, \mathrm{X} 2, \ldots, \mathrm{Xn} \mid \mathrm{Y})$ na equação (3) pode ser substituída pela probabilidade da equação (6). Isso resulta na formulação do classificador Naive-Bayes, expressa na equação (7).

\footnotetext{
${ }^{8}$ Overfitting é a condição pela qual um modelo não pode se adequar a novos exemplos, diferentes dos exemplos observados na etapa de treinamento.
} 


$$
P(Y \mid X)=\mathrm{P}(Y=y) \times \prod_{i=1} P(X i=x i \mid Y=y)
$$

As probabilidades da equação (7) podem ser estimadas pelo cálculo da Máxima Verossimilhança, com a qual se busca o valor de y que maximize o valor da probabilidade $\mathrm{P}(\mathrm{Y} \mid \mathrm{X})$ da equação (7). Desse modo, o classificador Naive-Bayes é formulado de acordo com a equação (8).

$$
\hat{\mathrm{Y}}=\underset{\mathrm{y}}{\operatorname{argmax}} \mathrm{P}(Y=y) \times \prod_{i=1} P\left(X_{i}=x_{i} \mid Y=y\right)
$$

Estimar todas as probabilidades nem sempre é possível, já que muitas vezes se desconhece o valor da classe Y. Nesse cenário, uma forma de aproximar o cálculo da Máxima Verossimilhança é por meio do algoritmo Expectation-Maximization (EM) (Dempster et al., 1977). Esse algoritmo permite estimar a distribuição de probabilidades quando o valor da classe é desconhecido. O algoritmo segue quatro passos:

1) Estabelecem-se as probabilidades iniciais $\mathrm{P}\left(\mathrm{X}_{\mathrm{i}} \mid \mathrm{Y}\right)$ de maneira uniforme;

2) Calculam-se os valores de $Y$ para os exemplos de treinamento, a partir das probabilidades calculadas no passo anterior. Esse passo é chamado de Expectation;

3) Refina-se o modelo calculando as novas probabilidades, a partir dos resultados obtidos no passo anterior. Este passo é chamado de Maximization;

4) Repetem-se os passos 2 e 3 até o algoritmo convergir, isto é, até os valores das probabilidades se estabilizarem, ou até um número determinado de iterações.

Na seção seguinte, será estudada a abordagem discriminativa. Ao final do capítulo, serão discutidas as principais diferenças entre as duas abordagens na SAM.

\subsection{Aprendizado Discriminativo: Definição e Principais Modelos}

No aprendizado discriminativo, busca-se fazer um mapeamento direto entre um conjunto de atributos que descrevem os exemplos de treinamento, e a classe. Esse mapeamento é feito calculando-se diretamente $\mathrm{P}(\mathrm{Y} \mid \mathrm{X})$, ou seja, modela-se diretamente a dependência entre a classe $\mathrm{Y}$ e o atributo $\mathrm{X}$. Esse cálculo é direto, pois não são calculadas a probabilidade $\mathrm{P}(\mathrm{X} \mid \mathrm{Y})$ e a probabilidade $\mathrm{P}(\mathrm{Y})$ para se obter o valor de $\mathrm{P}(\mathrm{Y} \mid \mathrm{X})$.

Os métodos discriminativos utilizam diversas técnicas para determinar a classe a qual pertence uma instância. Uma das técnicas mais usadas é a busca de fronteiras de decisão que permitem separar os dados de diferentes classes. Outra técnica bastante usada é a aproximação de uma função de regressão. Nesta seção, serão estudados dois métodos de aprendizado discriminativo, os quais são comumente referenciados como os mais representativos dessas duas técnicas, respectivamente: SVM (Support Vector Machine) (Vapnik, 1995) e Regressão Logística (Agresti,1996).

\subsubsection{Regressão Logística}

Os modelos de regressão são comumente representados por equações matemáticas que descrevem a relação entre os atributos e a classe. Uma das formas mais comuns de 
regressão é a formulação de $\mathrm{Y}$ como sendo uma combinação linear de um conjunto $X=\left\{X_{1}, X_{2}, \ldots, X_{n}\right\}$ de atributos.

$$
Y=\beta_{0}+\beta_{1} X_{1}+\beta_{2} X_{2}+\ldots+\beta_{n} X_{n}=\beta_{0}+\sum_{i=1}^{n} \beta_{i} X_{i}
$$

Os valores $\beta_{i}$ da equação (9) são chamados de coeficientes de regressão e indicam se o atributo $\mathrm{X}_{\mathrm{i}}$ tem uma influência positiva ou uma influência negativa na predição da classe $\mathrm{Y}$. Por exemplo, se o coeficiente $\beta_{1}$ for negativo, significa que a variável $\mathrm{X}_{1}$ exerce uma mudança negativa no valor de $\mathrm{Y}$, pois ajuda a diminuí-lo.

Como se pode observar, o valor de Y num modelo de regressão linear como o da equação (9) será contínuo, ou seja, um número real. Isso nem sempre é adequado, pois em muitas tarefas o valor de Y é definido como categórico e assume dois valores (por exemplo, Sim ou Não, 1 ou 0). Nesse caso, será requerido outro tipo de tratamento da função de regressão. Em particular, o modelo de regressão logística permite resolver esse problema por meio do mapeamento do resultado da equação (9) numa função logística. Uma função logística simples é representada pela equação (10) e ilustrada na Figura 5. O resultado dessa função é um valor no intervalo entre 0 e 1.

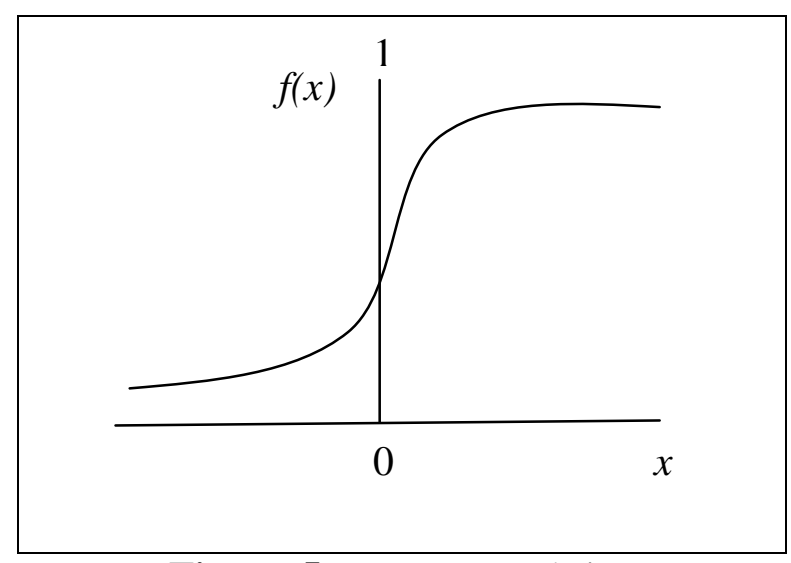

Figura 5: Função Logística

$$
f(x)=\frac{1}{1+e^{-x}}
$$

Por ser um valor no intervalo entre 0 e 1 , o valor de $f(x)$ pode ser considerado probabilístico. Nesse sentido, o valor de $f(x)$ pode ser correspondente a probabilidade $\mathrm{P}(\mathrm{Y} \mid \mathrm{X})$. Em outras palavras, $\mathrm{P}(\mathrm{Y} \mid \mathrm{X})$ é o resultado da função logística em (10). Em particular, dado que a classe $\mathrm{Y}$ pode assumir dois valores, $\mathrm{Y}=1$ e $\mathrm{Y}=0$, definem-se as probabilidades $\mathrm{P}(\mathrm{Y}=1 \mid \mathrm{X})$ e $\mathrm{P}(\mathrm{Y}=0 \mid \mathrm{X})$ como resultados de uma função logística:

$$
P\left(Y=1 \mid X_{1}, X_{2}, \ldots, X_{n}\right)=\frac{1}{1+e^{-\beta_{0}-\sum_{i=1}^{n} \beta_{i} X_{i}}}
$$


Dado que $\mathrm{P}(\mathrm{Y}=1 \mid \mathrm{X})$ e $\mathrm{P}(\mathrm{Y}=0 \mid \mathrm{X})$ são probabilidades complementares, ou seja, $\mathrm{P}(\mathrm{Y}=0 \mid \mathrm{X})$ é igual a 1-P(Y=1|X), a probabilidade $\mathrm{P}(\mathrm{Y}=0 \mid \mathrm{X})$ é definida como:

$$
P\left(Y=0 \mid X_{1}, X_{2}, \ldots, X_{n}\right)=1-\frac{1}{1+e^{-\beta_{0}-\sum_{i=1}^{n} \beta_{i} X_{i}}}=\frac{1}{1+e^{\beta_{0}+\sum_{i=1}^{n} \beta_{i} X_{i}}}
$$

A equação (11) ainda pode ser transformada para eliminar o fator negativo do expoente. Desse modo, por meio da aplicação de operações matemáticas simples, a equação em (11) é transformada na equação em (13)

$$
P\left(Y=1 \mid X_{1}, X_{2}, \ldots, X_{n}\right)=\frac{e^{\beta_{0}+\sum_{i=1}^{n} \beta_{i} X_{i}}}{1+e^{\beta_{0}+\sum_{i=1}^{n} \beta_{i} X_{i}}}
$$

Dadas as probabilidades (12) e (13), a tarefa de aprendizado consiste em estimar os parâmetros $\alpha$ e $\beta_{\mathrm{i}}$ que maximizem o valor da probabilidade condicional $\mathrm{P}(\mathrm{Y} \mid \mathrm{X}, \beta)$. Para fazer essa estimativa, pode-se realizar o cálculo da Máxima Verossimilhança, como é indicado na equação (14). Nota-se que essa Máxima Verossimilhança é diferente da Máxima Verossimilhança a Posteriori utilizada na abordagem gerativa, pois aquela era calculada com base na regra de Bayes. Nesse caso, o cálculo da Máxima verossimilhança é dado pelo produto das probabilidades em (12) ou (13), em todos os exemplos de treinamento. Em principio, os valores iniciais para os coeficientes $\beta_{i}$ são estabelecidos. Em cada iteração $l$, esses valores devem ir se adaptando para maximizar o resultado.

$$
\underset{\beta}{\operatorname{argmax}} \prod_{l=1}^{n} P\left(Y^{l} \mid X^{l}, \beta\right)=\prod_{l=1}^{n}\left[\left(\frac{e^{\beta_{0}+\sum_{i=1}^{p} \beta_{i} X_{i}^{l}}}{1+e^{\beta_{0}+\sum_{i=1}^{p} \beta_{i} X_{i}^{l}}}\right)^{Y^{l}}\left(\frac{1}{1+e^{\beta_{0}+\sum_{i=1}^{p} \beta_{i} X_{i}^{l}}}\right)^{1-Y^{l}}\right]
$$

Na equação (14), $Y^{l}$ denota o valor observado da classe $Y$ no l-ésimo exemplo de treinamento, e $X_{i}^{l}$ denota o valor observado do atributo $X_{\mathrm{i}}$ no l-ésimo exemplo de treinamento. Pode-se observar que os valores $Y^{l}$ e $1-Y^{l}$ determinam quais das probabilidades (12) ou (13) serão aplicadas em cada iteração. Por exemplo, se o valor de $Y^{l}$ for 1 , será utilizado o resultado da probabilidade descrita em (13); se $Y^{l}$ for 0 , será utilizado o resultado da probabilidade descrita em (12). A partir dessa equação, em cada iteração, deve-se estimar os valores de $\beta_{i}$ de forma que o produto final seja maximizado. Uma forma de estimar os coeficientes é por meio do uso do gradiente descendente:

$$
\frac{\partial l(\beta)}{\partial\left(\beta_{i}\right)}=\sum_{l} X_{i}^{l}\left(Y^{l}-P\left(Y^{l} \mid X^{l}, \beta\right)\right)
$$


O gradiente descendente é calculado a partir da derivada parcial da função do erro em relação aos valores dos coeficientes $\beta$. Nesse sentido, o gradiente descendente indica a direção oposta ao erro de classificação que é dado por $Y^{l}-\mathrm{P}\left(Y^{l} X^{l}, \beta\right)$. Portanto, o valor do coeficiente $\beta_{i}$ é atualizado em função do valor do gradiente descendente, como indicado na equação (16), onde $\eta$ é um valor constante pequeno (p.ex., 0.05) que indica o quanto será atualizado o valor de $\beta_{\mathrm{i}}$ em relação ao valor do gradiente descendente.

$$
\beta i=\beta i+\eta \sum_{l} X_{i}^{l}\left(Y^{l}-P\left(Y^{l} \mid X^{l}, \beta\right)\right)
$$

O modelo é treinado até o erro de classificação ser mínimo ou até um número pré-definido de iterações.

No contexto da SAM, pode-se assumir que os valores de $X_{i}$ representam os fatores que influenciam na presença ou ausência de uma unidade de informação (p.ex. sentenças) num sumário. Nesse cenário, os valores de $\mathrm{Y}$ podem ser 1 ou 0 , o que representa a presença ou ausência de uma unidade informativa no sumário. Nesse caso, estimar os valores dos coeficientes de regressão que maximizem a equação (14) implica poder determinar os fatores que ajudam a discriminar mais adequadamente as informações que devem compor ou não um sumário.

\subsubsection{Máquina de Vetor de Suporte (Support Vector Machine-SVM)}

Dado um problema de classificação, onde cada exemplo de treinamento é associado a uma de duas possíveis classes, existe mais de uma reta ou hiperplano capaz de separar os exemplos de classes diferentes. No entanto, quando são apresentados novos exemplos, diferentes dos exemplos de treinamento, nem todos os hiperplanos irão classificar os novos exemplos de forma satisfatória. Para ilustrar esse cenário, observe-se o problema de classificação mostrado na Figura 6, em que cada um dos exemplos de treinamento corresponde a uma de duas classes: a classe dos círculos e a classe dos quadrados.

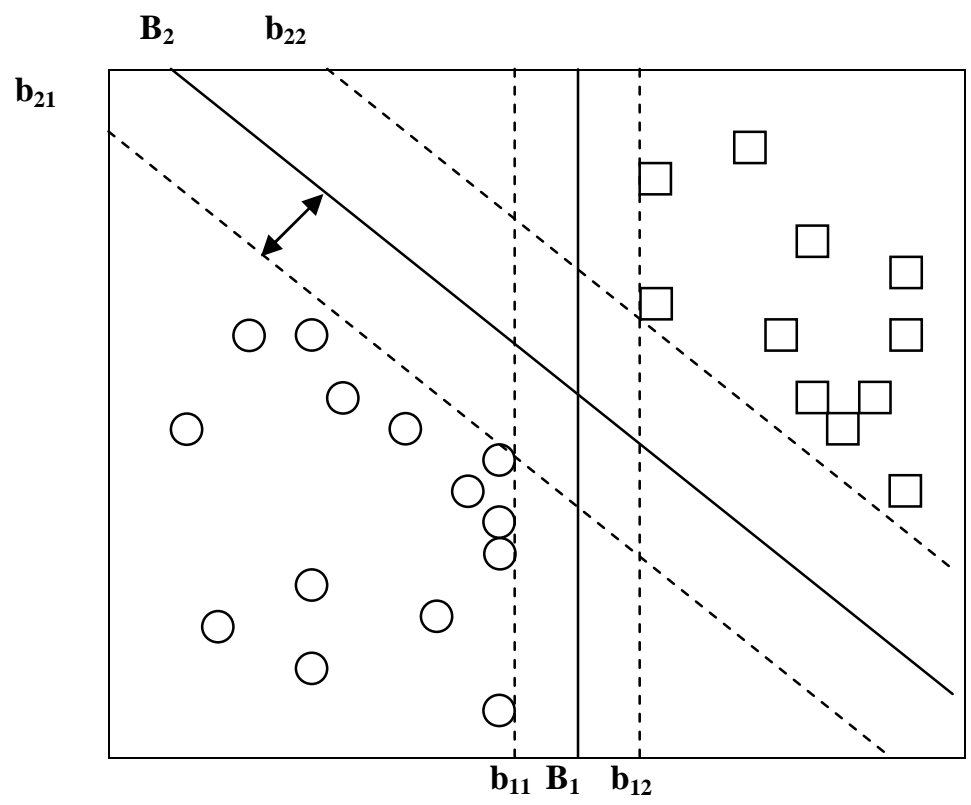

Figura 6: Fronteira de decisão do classificador SVM (Tan et al.,2006, p.258) 
Nessa Figura, pode-se observar duas retas que classificam corretamente os exemplos de treinamento: a reta $B_{1}$ e a reta $B_{2}$. A reta $B_{1}$ está associada às fronteiras $b_{11} e b_{12}$, as quais definem as margens que separam a reta $\mathrm{B}_{1}$ dos exemplos correspondentes de cada classe, que sejam mais próximos a $B_{1}$. De modo similar, a reta $B_{2}$ está associada às fronteiras $b_{21} e$ $\mathrm{b}_{22}$, as quais definem as margens que separam a reta $\mathrm{B}_{2}$ dos exemplos correspondentes de cada classe, que sejam mais próximos a $\mathrm{B}_{2}$. É possível notar que a reta $\mathrm{B}_{2}$ separa melhor os exemplos de diferentes classes, já que estabelece uma margem mais ampla entre as fronteiras $b_{11}$ e $b_{12}$. As retas que estabelecem margens maiores tendem a generalizar melhor do que as retas que estabelecem margens menores, pois estas últimas são mais suscetíveis a problemas de overfitting.

O SVM é um classificador que, dado um conjunto de exemplos de treinamento, busca pela reta ou hiperplano que melhor separe esses exemplos. Em particular, cada reta (ou hiperplano) $\mathrm{B}_{\mathrm{i}}$, é definida pela equação (17), onde w é um vetor de parâmetros que definem a inclinação da reta, e x é o vetor de atributos que descrevem os exemplos de treinamento.

$$
w \cdot x+b=0
$$

Por outro lado, as retas $b_{\mathrm{ij}}$ são definidas pelas equações (18) e (19) a seguir.

$$
\begin{aligned}
& w \cdot x_{s}+b=k, k>0 \\
& w \cdot x_{c}+b=k^{\prime}, k<0
\end{aligned}
$$

Observa-se que, de acordo com o cenário da Figura 5, para cada quadrado localizado acima da reta $B_{i}$, a equação (18) é satisfeita. Similarmente, para cada círculo localizado abaixo da reta $B_{i}$, a equação (19) é satisfeita.

Em particular, podemos dizer que, os exemplos representados pelos quadrados pertencem a classe +1 , e que os exemplos representados pelos círculos pertencem a classe 1. Desse modo, as classes de novos exemplos podem ser estimadas a partir da seguinte regra:

$$
\begin{array}{ll}
1 & \text { se } w \cdot x+b>0 \\
-1 & \text { se } w \cdot x+b<0
\end{array}
$$

Essa regra pode ser compactada em uma única expressão, como indicado em (21):

$$
y_{i}\left(w \cdot x_{i}+b\right) \geq 1, i=1,2, \ldots, \mathrm{N}
$$

As equações (18) e (19) podem ser transformadas em sua forma canônica e reescritas assim:

$$
\begin{aligned}
& w \cdot x+b=1 \\
& w \cdot x+b=-1
\end{aligned}
$$

A partir das equações (22) e (23), é possível determinar a longitude da margem entre as fronteiras $b_{i 1}$ e $b_{i 2}$. Essa longitude está dada pela distancia entre as retas (22) e (23): 


$$
d=\frac{|(w \cdot x+b-1)-(w \cdot x+b+1)|}{\|w\|}=\frac{2}{\|w\|}
$$

A partir do que já foi definido, podemos dizer que o objetivo do classificador SVM é buscar os parâmetros w que maximizem a distância expressa em (24), ou, o que é equivalente, minimizar a função expressa em (25):

$$
\min \frac{\|w\|^{2}}{2} \text {, sujeito a } y_{i}\left(w_{i} \cdot x_{i}+b\right) \geq 1
$$

A função e restrições em (25) podem ser expressas usando a técnica de multiplicadores de lagrange ${ }^{9}$, como indicado a seguir:

$$
\operatorname{minmax}_{w, b} f(x)=\frac{1}{2}\|w\|^{2}-\sum_{i=1}^{N} \lambda_{i}\left(y_{i}\left(w \cdot x_{i}+b\right)-1\right)
$$

Nesta última equação, os valores $\lambda$ são chamados multiplicadores de lagrange. $O$ componente quadrático da equação corresponde à função objetivo e o segundo componente expressa as restrições sobre essa função objetivo em termos dos multiplicadores de lagrange. A equação (26) pode ser entendida como um problema de otimização dupla (pois precisam ser realizadas duas funções de otimização: min e max) que pode ser resolvido usando técnicas de programação quadrática.

O caso hipotético da Figura 6 é um caso ideal, que nem sempre representa a situação real dos dados de treinamento. Na realidade, muitos dos casos reais correspondem a um cenário similar ao mostrado na Figura 7 , onde a fronteira de decisão $B_{1}$ não pode ser estabelecida sem se ter algumas classificações erradas.

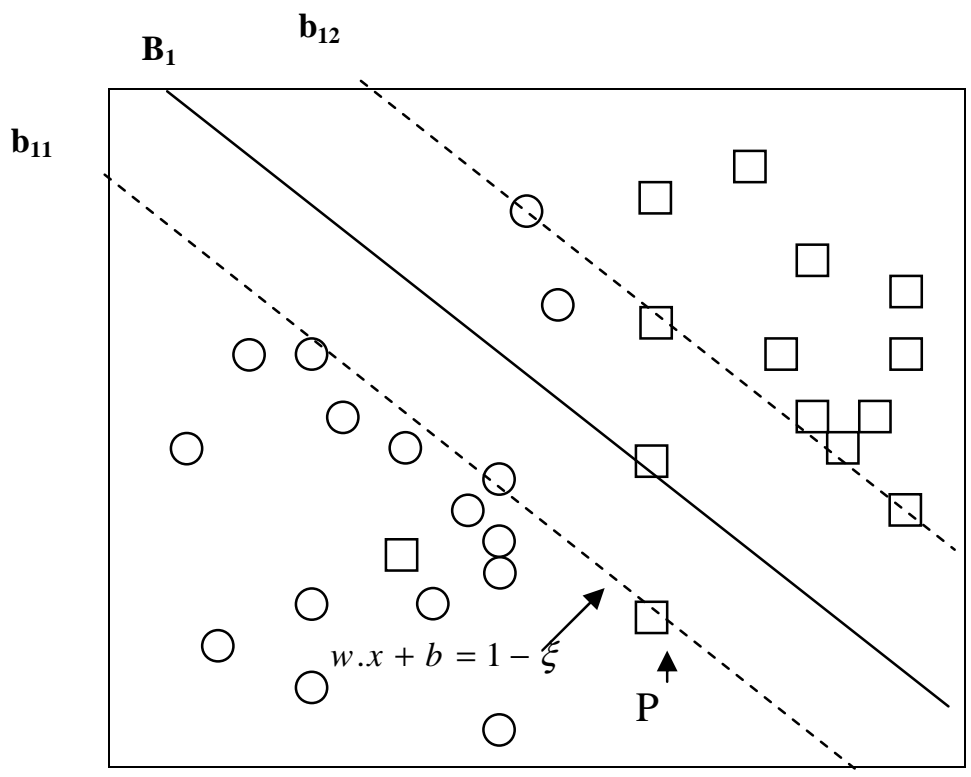

Figura 7: Exemplos de treinamento não separáveis

\footnotetext{
${ }^{9} \mathrm{O}$ método de multiplicadores de lagrange é um procedimento para encontrar os máximos e mínimos em uma função sujeita a restrições. O método simplifica uma função de n variáveis sujeitas a restrições, reduzindo-a numa função sem restrições de $n+k$ variáveis, onde $\mathrm{k}$ representa o número de restrições da função original.
} 
Para modelar esse cenário, faz-se uso de parâmetros chamados de slack ou variáveis de relaxamento $\xi$ que permitem adequar as fronteiras de decisão $b_{\mathrm{ij}}$ aos dados não separáveis linearmente. Em princípio, as restrições estabelecidas em (20) são adaptadas de modo que incluam as variáveis de relaxamento, como indicado a seguir:

$$
\begin{aligned}
& w \cdot x_{i}+b \geq 1-\xi_{i}, \text { se } y_{i}=1, \quad \forall \xi_{i}>0 \\
& w \cdot x_{i}+b \leq-1+\xi_{i}, \text { se } y_{i=-1,} \quad \forall \xi_{i}>0
\end{aligned}
$$

Para ilustrar melhor o funcionamento das variáveis $\xi$, é preciso referenciar o quadrado $\mathrm{P}$ da Figura 7, o qual viola as restrições em (20). Nesse caso, a variável de relaxamento $\xi$ permite que o elemento $\mathrm{P}$ seja classificado corretamente a pesar dele violar as restrições em (20). Em outras palavras, as variáveis de relaxamento permitem que alguns dados permaneçam entre as fronteiras $b_{11}$ e $b_{12}$. Desse modo, a função objetivo em (25) é modificada para incluir as variáveis de relaxamento, como indicado a seguir:

$$
f(w)=\frac{\|w\|^{2}}{2}+C\left(\sum_{i=1}^{N} \xi_{i}\right)^{k}
$$

$\mathrm{Na}$ equação (29), os parâmetros C e $k$, representam penalidades sobre as variáveis de relaxamento. Intuitivamente, isso sugere que o excesso de uso de variáveis de relaxamento pode prejudicar o desempenho do classificador. A partir desta equação, formula-se o problema de otimização com multiplicadores de lagrange, seguindo o mesmo critério que da equação (26), mas, dessa vez, incluindo as novas restrições:

$$
\begin{gathered}
f(x)=\frac{1}{2}\|w\|^{2}+C \sum_{i=1}^{N} \xi i-\sum_{i=1}^{N} \lambda i\{y i(\} w \cdot x i+b)-1+\xi i \\
-\sum_{i=1}^{N} \mu i \xi i
\end{gathered}
$$

Note-se que, nessa última equação, os dois primeiros componentes correspondem a função objetivo em (29), o terceiro componente corresponde as restrições em (27) e (28), e o quarto componente representa os requerimentos de não negatividade dos valores das variáveis de relaxamento.

Muitas vezes os exemplos de treinamento não são linearmente separáveis, e o uso de variáveis de relaxamento não resolve o problema. Nesse caso, os dados devem ser transformados em um novo espaço, por meio de uma função $\phi(x)$, de forma que nesse novo espaço possa ser definida uma fronteira linear que permita classificar os dados usando SVM.

O SVM é um classificador comumente referenciado como discriminativo, pois faz um mapeamento direto entre um conjunto de atributos e as classes dos exemplos. $\mathrm{O}$ 
classificador SVM se torna um modelo interessante para a SAM, já que esta tarefa pode ser modelada como um problema de classificação. Para este trabalho, já foram realizados alguns experimentos usando SVM. Nesses experimentos, consideraram-se as sentenças dos textos de entrada como exemplos de classificação. Essas sentenças foram definidas com base num conjunto de atributos, para logo serem classificadas com o SVM. Mais detalhes e resultados sobre esses experimentos em Jorge et al. (2011).

\subsubsection{Outros Métodos Discriminativos}

Além dos métodos estudados na seção anterior, outros métodos importantes, também comumente referenciados na linha discriminativa, são as Árvores de Decisão (Hunt et al., 1966), e as Redes Neurais Artificiais (McCulloch e Pitts, 1943; Hebb, 1949; Rosemblatt, 1958), entre outros. As árvores de Decisão definem fronteiras de decisão entre diferentes classes de dados. Essas fronteiras de decisão são representadas pela estrutura de uma árvore onde os nós representam os atributos, e o número de filhos dos nós corresponde aos valores que podem assumir esses atributos. A ideia desse método é que cada nó ou atributo represente uma fronteira de decisão. Desse modo, em cada nível da árvore são estabelecidas uma ou mais partições do espaço de dados. A seleção de atributos para cada nó em cada nível da árvore é feita calculando-se o ganho de informação do atributo. Geralmente, esse ganho de informação é determinado pelo valor da entropia ${ }^{10}$ do atributo.

Por outro lado, as redes neurais geralmente seguem a linha dos métodos de regressão. Por exemplo, em redes como perceptron simples ou perceptron multicamada, os componentes de uma função de regressão estão representados pelas conexões entre neurônios. Cada conexão representa um atributo ao qual está associado um valor $\beta$ i que representa o peso do atributo. A combinação linear desses atributos e seus pesos determinam a saída. A atualização dos valores $\beta$ i normalmente é feita usando o método do gradiente descendente.

\subsection{Abordagem Gerativa vs. Abordagem Discriminativa}

$\mathrm{O}$ aprendizado gerativo e o aprendizado discriminativo têm sido bastante explorados em diversas áreas da Computação. Basicamente, essas duas abordagens se diferenciam pela forma em que os modelos são extraídos a partir do conjunto de exemplos de treinamento. $\mathrm{Na}$ abordagem gerativa, estima-se a distribuição de probabilidade de todas as variáveis do modelo. Em particular, a probabilidade $\mathrm{P}(\mathrm{y} \mid \mathrm{x})$ é calculada por meio do calculo de $\mathrm{P}(\mathrm{x} \mid \mathrm{y}) \mathrm{e}$ de $\mathrm{P}(\mathrm{y})$. Na abordagem discriminativa, a relação entre os atributos e a classe é estabelecida diretamente, podendo-se utilizar uma função discriminativa (p.ex., uma reta ou hiperplano como no caso do SVM) ou se calculando $\mathrm{P}(\mathrm{y} \mid \mathrm{x})$ diretamente. Em outras palavras, faz-se um mapeamento direto entre a entrada e a saída. Em geral, os modelos discriminativos têm se mostrado com melhor desempenho em muitas áreas, em especial quando há uma quantidade considerável de dados de treinamento, pois os dados tendem a ser menos esparsos nesses casos. No caso da abordagem gerativa, os modelos gerativos podem ser

\footnotetext{
${ }^{10}$ A entropía de um atributo é uma medida de incerteza por meio da qual pode se determinar a quantidade de informação do atributo. Quanto menor é a entropia de um atributo, maior é seu ganho de informação.
} 
muito úteis quando os dados são muito esparsos, já que as suposições de independência permitem estimar vários parâmetros quando há poucos dados de treinamento. 


\section{Sumarização Automática}

\subsection{Conceitos Básicos}

A SA consiste na tarefa de condensar a informação mais importante de um texto ou um conjunto de textos, e apresentar essa informação de forma coerente e coesa ao usuário (Mani, 2001). De acordo com essa definição, a SA pode ser de dois tipos: monodocumento ou multidocumento. Na Sumarização Monodocumento, visa-se produzir um sumário a partir de um único texto. Na SAM, busca-se construir um resumo a partir de um conjunto de textos que versam sobre um mesmo assunto.

A construção de um sumário envolve vários desafios. Em princípio, é preciso identificar quais são as informações mais relevantes ao tópico que está sendo tratado. Além da identificação da informação relevante, é preciso organizar essa informação de modo que o significado em relação ao texto(s) original seja mantido de forma coerente. As informações não somente devem estar organizadas de uma forma coerente, mas também, devem ser expressas de forma correta, seguindo as regras gramaticais da língua, e mantendo a coesão entre as informações.

Em particular, na SAM, apresentam-se novos desafios, além dos já mencionados. Esses novos desafios são: a eliminação da redundância, o tratamento de informações complementares e o tratamento de informações contraditórias. Todos esses desafios devem ser tratados visando manter a coerência e a coesão do sumário final.

Independente do tipo de sumarização, os sumários automáticos podem ser classificados de acordo com a sua funcionalidade. Deste modo, um sumário pode ser classificado como:

- Indicativo: esse tipo de sumários contém apenas uma indicação dos tópicos essenciais do texto(s) original. Esse tipo de sumário não contem necessariamente detalhes dos argumentos do texto(s), portanto, nem sempre é mantido o significado original dos textos.

- Informativo: esse tipo de sumário contém os aspectos principais dos textos originais, e não apenas simples tópicos. Em geral, diz-se que os sumários informativos podem substituir a leitura dos textos originais, pois contêm os aspectos mais relevantes de cada tópico dos textos originais. 
- Critico: esse tipo de sumário tem a função de avaliar, além de resumir, os textos originais. Nesse tipo de sumário, apresentam-se análises, comparações, opiniões, etc., sobre o conteúdo dos textos originais.

Outra forma de classificar os sumários é pela sua forma. Em geral, os sumários podem ser de duas formas:

- Abstract: são sumários cuja informação foi processada a partir dos textos originais. Esse processamento inclui operações de seleção, combinação e reescrita de informações.

- Extratos: são sumários compostos pelas informações originais dos textos, sem serem reescritas ou combinadas, apenas selecionadas. Esse tipo de sumário geralmente é composto pelas sentenças dos textos originais.

Outros fatores que influenciam a construção de um sumário, além da sua função e sua forma, são: a taxa de compressão, a língua dos textos e o foco. A taxa de compressão é o valor porcentual que delimita o tamanho do sumário final, em termos de número de palavras, em relação ao tamanho do texto(s) de entrada. Normalmente, esse tamanho pode abranger entre $0 \%$ e $100 \%$, o que significa que um sumário pode ser tão grande quanto à própria entrada ou tão pequeno que não inclua informação nenhuma. Isso representa um limitante importante ao processo de sumarização, já que pode influenciar negativamente na qualidade do sumário. Se o sumário é muito pequeno, pode não ser tão informativo, ou, se é muito grande, perde sua utilidade. Além da taxa de compressão, outro fator de influência é a língua dos textos de entrada. Por exemplo, pode-se construir um sumário a partir de textos escritos em mais de uma língua, ou simplesmente se pode construir um sumário em uma língua diferente do(s) texto(s) de entrada. O foco do sumário é também um fator importante a se considerar. Um sumário pode ser construído de forma genérica, ou pode ser construído focado num tópico de preferência do usuário. Por exemplo, dado um texto(s) onde é relatado um acidente, poder-se-ia construir um sumário contendo as principais informações de todos os tópicos escritos sobre esse assunto no texto(s), ou poder-se-ia construir um sumário que relate apenas os detalhes em torno das vítimas do acidente.

Como já foi introduzido no Capítulo 1, Mani e Maybury (1999) propuseram uma arquitetura de três etapas a serem seguidas em um processo de sumarização. Na Figura 8, a seguir, são ilustradas essas etapas. 


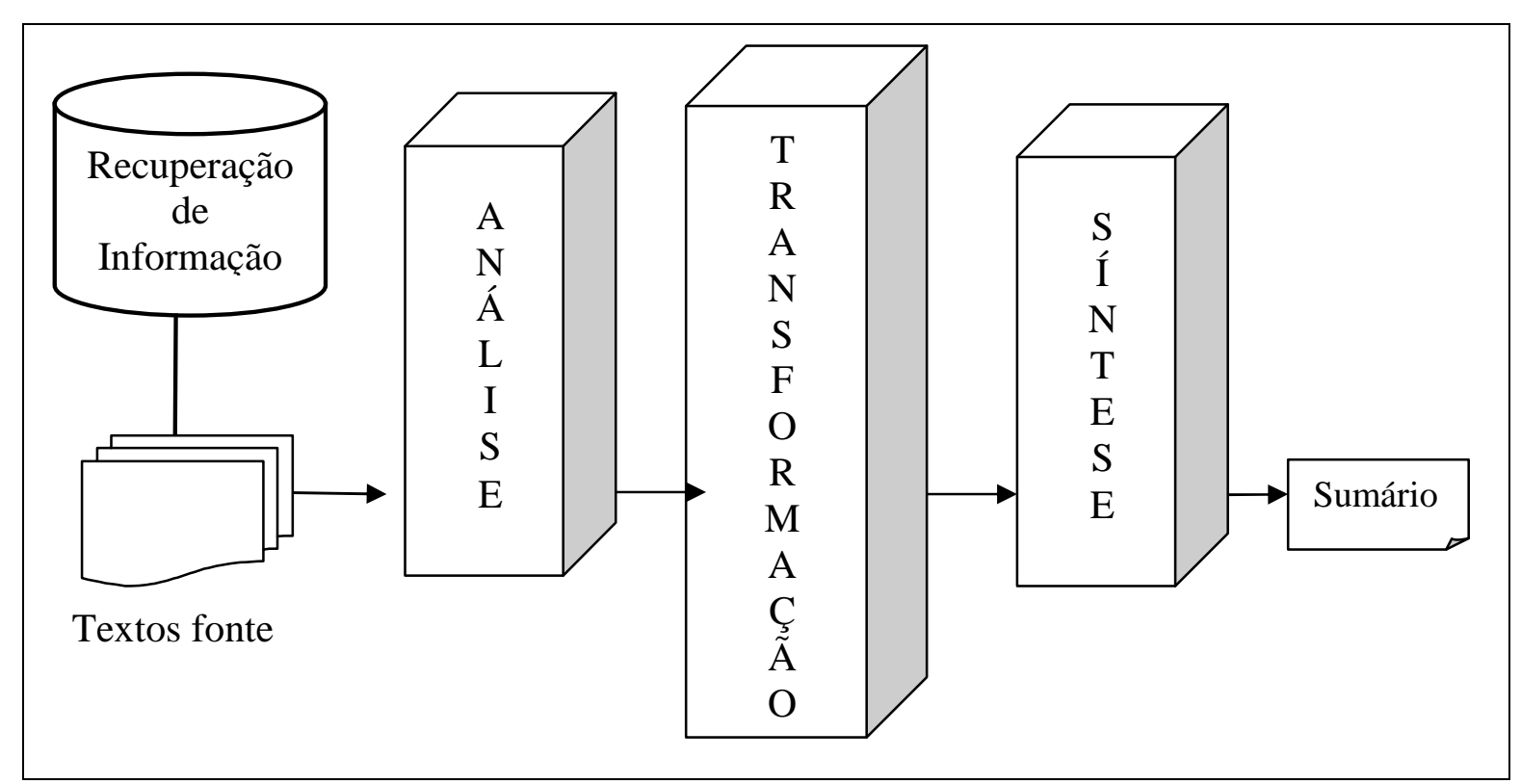

Figura 8: Arquitetura de um sistema de Sumarização Automática

$\mathrm{Na}$ etapa de análise, os textos de entrada são interpretados e uma representação computacional do conteúdo é feita. $\mathrm{Na}$ etapa de transformação, a representação computacional é processada para identificar e selecionar o conteúdo relevante. A saída da etapa de transformação é uma representação computacional condensada do texto(s). $\mathrm{Na}$ etapa de síntese, é gerado um texto expresso em língua natural, a partir da representação computacional condensada.

A SA também é influenciada por duas abordagens: profunda e superficial (mencionadas também no Capítulo 1). Na abordagem profunda, se faz uso de conhecimento linguístico profundo, sendo que, esse conhecimento pode ser dado em nível léxico, sintático, semântico ou discursivo. Na abordagem superficial, faz-se uso de pouco ou nenhum conhecimento linguístico, e sim de métodos estatísticos ou empíricos com base em elementos da superfície textual, visando descobrir padrões nos textos. Por exemplo, na etapa de análise da arquitetura mostrada na Figura 9, poder-se-ia criar uma representação do conteúdo do texto(s) seguindo uma abordagem profunda ou uma abordagem superficial. Em uma abordagem profunda, poder-se-ia construir a representação computacional utilizando informações linguísticas do conteúdo dos textos. No contexto da abordagem superficial, poder-se-ia criar uma representação textual a partir de distribuições estatísticas de palavras, sintagmas, orações ou sentenças.

Outro aspecto importante é como os sumários automaticamente produzidos são avaliados. Com o crescimento da área, novos e eficientes métodos de avaliação de sumários tem surgido. A seguir, nas seguintes seções, serão estudados os métodos de avaliação de 
sumários e as abordagens superficial e profunda, mostrando os métodos mais destacados de cada abordagem, assim como os trabalhos mais representativos de cada uma delas.

\subsection{Avaliação de Sumários Automáticos}

Existem dois aspectos principais que são o alvo da avaliação dos sumários produzidos automaticamente: a informatividade e a qualidade (Mani, 2001).

A informatividade diz respeito à quantidade de informação relevante que está contida nos sumários, este tipo de avaliação é geralmente realizada de forma automática. A qualidade do sumário diz respeito à gramaticalidade, a coesão, a coerência, etc., todos esses fatores são avaliados com critérios humanos.

Para a avaliação de informatividade, uma das medidas mais conhecidas e usadas amplamente pela comunidade é a medida Rouge (Recall-Oriented Understudy for Gisting Evaluation (Lin, 2004). O princípio dessa medida é basicamente comparar a quantidade de n-gramas de palavras em comum entre o sumário produzido automaticamente e um ou mais sumários humanos, também chamados sumários de referência. Essa medida fornece resultados em termos de Precisão, Cobertura e Medida-F. A precisão (31) diz respeito ao número de n-gramas de palavras em comum entre o(s) sumário(s) de referência e o sumário automático em relação ao total de n-gramas do sumário automático; a cobertura (32) diz respeito ao número de n-gramas de palavras em comum entre o(s) sumário(s) de referência e o sumário automático em relação ao total de n-gramas do(s) sumário(s) de referência. Em outras palavras, a precisão diz quanta informação do sumário de referência está no sumário automático, enquanto a cobertura diz quanta informação do sumário de referencia foi coberto pelo sumário automático. Essas duas medidas são complementares e são ponderadas pela Medida-f (33), que calcula a média harmônica das duas.

$$
\begin{gathered}
\text { Precisão }=\frac{\mathrm{n}-\text { gramas em comum sumário automático e sumário humano }}{\mathrm{n}-\text { gramas sumário automático }} \\
\text { Cobertura }=\frac{\mathrm{n} \text { - gramas em comum sumário automático e sumário humano }}{\mathrm{n}-\text { gramas sumário humano }} \\
\text { Medida }-F=\frac{2 \times \text { Precisão } \times \text { Cobertura }}{\text { Precisão } \times \text { Cobertura }}
\end{gathered}
$$

Essa medida é muito popular na comunidade, pois é rápida, barata e facilmente aplicável a qualquer tipo de sumário. Apesar de ser uma medida simples, Carenini e Cheung (2008) argumentam que a correlação entre a Rouge e o julgamento humano aumenta quando o número de sumários de referência aumenta também.

Uma desvantagem da Rouge é que, como apenas avalia correspondência de n-gramas de palavras, ignora todo aspecto relacionado à qualidade dos sumários. Para abordar essas 
questões, a TAC ${ }^{11}$ (Text Analysis Conference) sugeriu cinco aspectos linguísticos para medir a qualidade dos sumários automáticos:

- gramaticalidade, que se refere aos padrões de boa ortografia, pontuação e sintaxe;

- coerência, que se refere à manutenção da organização textual de forma que preserve o sentido do texto

- não redundância, que se refere ao fato de que não existam informações repetitivas no sumário

- foco, que se refere ao fato de que as partes do texto devem estar relacionadas com o todo

- clareza referencial, que se refere a presença adequada de componentes linguísticos que liguem apropriadamente os elementos do sumário

Para avaliar os sumários de acordo com esses critérios, a TAC sugere pontuar os sumários em cada um destes aspectos com valores entre 1-5, sendo que valores mais próximos de 1 significam muito ruim, e valores próximos de 5 significam muito bom.

Outra medida importante de avaliação de sumários é a pirâmide (Nenkova e Passonneau, 2004). Essa medida considera um conjunto de sumários de referência a partir dos quais são extraídas unidades de conteúdo do sumário (SCU). A ideia é dar maior valor às unidades de conteúdo que aparecem em mais sumários de referência. Para isso, é formada uma pirâmide onde o topo representam as unidades que aparecem em mais sumários de referência. As SCU são pontuadas de acordo com a posição na pirâmide, sendo que as SCU localizadas mais no topo são mais bem pontuadas que as que se localizam mais na base da pirâmide. Os sumários mais informativos são aqueles que têm maior número de SCU próximas do topo da pirâmide.

Outras medidas menos usadas são responsiveness e utilidade relativa. Responsiveness é uma medida de avaliação humana que mede informatividade e a qualidade linguística, dando uma pontuação para o sumario com valores entre 1 e 5 , sendo que valores próximos de 1 são mais ruins e valores próximos de 5 são muito bons. A utilidade relativa é uma medida de avaliação humana que fornece uma pontuação a todas as sentenças de um conjunto de textos de acordo com a sua utilidade para o usuário. A pontuação do sumário é dada com base nestas pontuações.

Esses métodos de avaliação humana têm sido relevantes na área, mas apesar disso sabe-se que o juízo humano é muito subjetivo e, portanto, nem sempre fornece um critério adequado.

Recentemente, Louis e Nenkova (2013) propuseram três formas novas de avaliar sumários, visando reduzir a influência da subjetividade humana na avaliação de sumários. $\mathrm{Na}$ primeira proposta, os autores sugerem medir a similaridade entre os textos fonte e os sumários automáticos, assumindo que um bom sumário é similar ao conjunto de textos do

\footnotetext{
${ }^{11}$ Conferência dedicada à competição e avaliação de sistemas de SA, antigamente chamada DUC (Document Analysis Conference)
} 
qual ele foi gerado. $\mathrm{Na}$ segunda proposta, os autores sugerem ampliar o conjunto de sumários de referência a partir de um conjunto pequeno de sumários de referência. Para isso, incorporam-se nesse conjunto, os sumários automáticos que tenham sido mais bem ranqueados com base na sua similaridade com os sumários de referência já existentes. A terceira proposta somente faz uso de sumários automáticos para construir o conjunto de sumários de referência, seguindo um critério similar ao método da pirâmide. Segundo esse critério, são consideradas informações relevantes àquelas que aparecem em mais sumários automáticos, e os sumários que possuam mais dessas informações relevantes serão os novos sumários de referência. As avaliações de Louis e Nenkova mostraram que esses métodos têm um comportamento similar aos métodos que usam sumários de referência na íntegra, tais como Rouge. Cabe destacar também que esses métodos apenas avaliam a informatividade dos sumários.

Neste trabalho de doutorado, usar-se-á medida Rouge para a avaliação dos sumários por ser à medida mais usada na área, o que facilita a comparação com outros métodos de sumarização do estado da arte.

\subsection{Abordagem Superficial}

Os métodos de sumarização de abordagem superficial caracterizam-se pelo uso de técnicas experimentais e métodos estatísticos para selecionar o conteúdo relevante de um ou vários textos. Várias dessas técnicas e métodos têm sido bastante utilizadas na SA, para identificar informação relevante. De acordo com Mani (2001), algumas das técnicas mais comuns da abordagem superficial são:

- Palavras-chave: essa técnica surgiu com o trabalho de Luhn (1958). Nesse trabalho, o autor afirma que as informações mais relevantes de um texto(s) podem ser identificadas por meio de um conjunto de palavras chave, as quais podem ser identificadas pela frequência de ocorrência no texto(s). A suposição na qual é baseada essa técnica é que as palavras mais frequentes são as mais representativas do texto(s). De acordo com esse critério, realiza-se o cálculo da frequência das palavras e, com base nessa frequência, extraem-se as sentenças que contenham as palavras melhor pontuadas. As sentenças são agrupadas a modo de compor um sumário final. Uma variação dessa técnica é a medida $t f$-idf (Term-Frequency Inverse-Document-Frequency) (Sparck Jones, 1972), a qual é comumente utilizada na área de Recuperação de Informação. Essa medida é caracterizada por considerar a importância de uma palavra em um conjunto de documentos dada a sua frequência nesse conjunto. A suposição na qual é baseada essa medida é que as palavras que ocorrem em muitos documentos tendem a ser palavras menos representativas de um texto em particular. Além disso, as palavras que ocorrem em poucos textos, mas ocorrem frequentemente em um texto em particular, tendem a ser as mais representativas daquele texto.

- Palavras-chave do Título: essa técnica é similar a anterior, mas se diferencia pelo fato de que as palavras-chave são indicadas pelo(s) título(s) de um texto(s). A 
suposição na qual se baseia essa técnica é que o título é representativo do tópico principal de um texto ou conjunto de textos (Edmunson, 1969). De acordo com esse método, as sentenças que contenham as palavras-chave são extraídas e agrupadas para compor o sumário final.

- Localização: essa técnica foi inicialmente explorada por Baxendale (1958). Segundo o autor, as primeiras e últimas sentenças de um texto contêm as informações mais relevantes de um tópico. Também as primeiras e últimas sentenças dos parágrafos são consideradas relevantes. Nesse sentido, para compor o sumário, selecionam-se as informações com base localização dessas no(s) texto(s).

- Palavras Sinalizadoras: de acordo com essa técnica, é utilizado um dicionário que contém as palavras mais relevantes do domínio ou tópico ao qual pertence o(s) texto(s) (Paice,1981). São atribuídos pesos positivos às sentenças que contêm essas palavras. Também são atribuídos pesos negativos as sentenças que não contêm palavras sinalizadoras. As sentenças que irão compor o sumário são selecionadas de acordo com os pesos obtidos a partir da soma dos pesos das suas palavras.

A seguir, são estudados alguns dos principais trabalhos da SA, que utilizaram os métodos descritos nesta seção. Destacam-se, em especial, aqueles trabalhos que utilizaram técnicas de aprendizado de máquina, tanto da abordagem gerativa quanto da abordagem discriminativa.

\subsubsection{Trabalhos de Sumarização Automática na linha Superficial}

Um dos trabalhos mais relevantes na abordagem superficial é o trabalho de Kupiec et al. (1995). Nesse trabalho, os autores focaram na seleção de conteúdo para Sumarização Monodocumento, utilizando métodos de Aprendizado de Máquina. Para isso, os autores abordam a tarefa de seleção de conteúdo como um problema de classificação de sentenças, onde a classe representa a inclusão ou não da sentença no sumário, em particular, no extrato. O classificador Naive-Bayes é usado para classificar as sentenças. Foram utilizados cinco atributos para descrever as sentenças. Um dos atributos utilizados foi o tamanho da sentença, cujo valor indica o tamanho da sentença em termos de número de palavras. Segundo os autores, esse atributo foi considerado devido à hipótese de que sentenças curtas não são comumente incluídas no sumário. Também foi utilizado o atributo de frases sinalizadoras, cujo valor indica a presença ou ausência de frases que pertencem a uma lista préestabelecida de frases. Essas frases seriam indicadores de informações importantes para se incluir num sumário (p.ex., "Este método", "Conclui-se que”). Outro atributo utilizado foi a localização das sentenças, o qual indica se uma sentença está no começo do parágrafo, no meio ou no fim. Também foi utilizado o atributo de palavras temáticas, que indica se uma sentença contém ou não palavras temáticas, as quais são determinadas pela sua frequência no texto. Finalmente, foi considerado o atributo de palavras maiúsculas, que indica se as palavras estão escritas em letras maiúsculas ou não. Segundo o autor, palavras maiúsculas referem-se, geralmente, a entidades importantes num texto. Para avaliar o método, os 
autores usaram um córpus de documentos técnicos com seus respectivos sumários (escritos manualmente). Nesse córpus, estabeleceram-se alinhamentos entre as sentenças do documento original e as sentenças do sumário manual. Foram considerados vários tipos de alinhamento, por exemplo: alinhamento exato (sentença a sentença), alinhamento conjunto (sentença a várias sentenças) e alinhamento não factível, quando não há correspondência nenhuma entre as sentenças do texto original e as sentenças do sumário. Para estabelecer os alinhamentos, seguiram-se duas etapas. $\mathrm{Na}$ primeira etapa, os alinhamentos foram estabelecidos automaticamente; na segunda etapa, completaram-se os alinhamentos automáticos com alinhamentos manuais. Avaliaram-se os resultados usando uma medida que calcula a proporção de sentenças produzidas corretamente pelo sumarizador. Foram consideradas corretas aquelas sentenças que tiveram um alinhamento exato, ou um alinhamento conjunto com as sentenças do texto original. De acordo com esta medida, os resultados mostraram que um $83 \%$ das sentenças produzidas tinham um alinhamento exato ou conjunto. Os autores também avaliaram o desempenho individual de cada um dos atributos, mostrando que o sistema desempenhava-se melhor usando apenas atributos como a posição da sentença no parágrafo e o atributo de frases sinalizadoras, obtendo $33 \%$ e $29 \%$ de acerto, segundo a medida descrita anteriormente.

Mani e Bloedorn (1998) utilizaram técnicas de aprendizado de máquina para descobrir quais são as combinações de atributos que contribuem na construção de um bom sumário. A diferença entre a pesquisa de Mani e Bloedorn e a de Kupiec et al. é que o método proposto por Mani e Bloedorn aprende sumários genéricos e também sumários focados no tópico. Os autores consideraram três tipos de atributos: atributos baseados na localização, por exemplo, a localização de sentença no parágrafo; atributos de informação do tópico, por exemplo, valor da sentença em função do $t f$-idf das suas palavras e também em função da presença de palavras do titulo; e finalmente, atributos de coesão, por exemplo, numero de links de sinonímia com outras sentenças. Os links de sinonímia são as conexões que se estabelecem entre sentenças, quando estas possuem um número de sinônimos e palavras relacionadas acima de um valor de threshold. Intuitivamente, sentenças que têm mais quantidade de links desse tipo tendem a ser mais informativas. Depois da seleção desses atributos, foram aplicados diversos algoritmos de aprendizado. Em particular, os autores utilizaram o método SCDF (Standard Canonical Discriminant Function), que é uma técnica de regressão que cria uma função linear para maximizar a discriminação entre sentenças boas para o sumário e sentenças ruins para o sumario. Além disso, os autores também utilizaram árvores de decisão para extrair regras de sumarização. Em particular, foi utilizado o algoritmo C4.5 (Quinlan, 1992). Os métodos de classificação foram utilizados em dois cenários: focado no tópico e não focado no tópico (ou genérico). Os sumários genéricos foram gerados usando os atributos descritos acima. No caso de sumários focados no tópico, foram gerados usando atributos extras. Em particular, usaram o número de palavras-chave do tópico, as quais foram determinadas a partir da sua frequência em uma coleção de textos, sendo que a escolha dos textos foi realizada pelo usuário de acordo aos seus interesses. A avaliação dos métodos foi realizada em um córpus de textos de Linguística Computacional, e os resultados mostraram um melhor desempenho com o algoritmo C4.5 para sumários focados no tópico, onde o algoritmo obteve um valor de $89 \%$ na medida-f. O método SCDF também mostrou 
um bom desempenho em sumários focados no tópico, obtendo $88 \%$ na medida-f. O algoritmo C4.5 obteve um valor de medida-f de $69 \%$ para sumários genéricos, enquanto o algoritmo SCDF obteve um valor de $62 \%$ na medida-f, para sumários genéricos.

Daumé III e Marcu (2005, 2006) propuseram o sistema Bayesum, baseado em técnicas de abordagem gerativa. Inicialmente, desenhou-se o sistema para Sumarização Monodocumento, e depois foi estendido para SAM. O sistema inicial consistiu em um modelo bayesiano de três componentes: modelo de tópico, modelo de documento e modelo de língua geral. O modelo de tópico era a distribuição probabilística das palavras de um tópico; o modelo do documento era a distribuição probabilística das palavras desse documento; o modelo de língua geral era a distribuição das palavras da língua em geral, sem nenhum contexto específico. A ideia do sistema inicial é que a cada sentença lhe fosse atribuída uma probabilidade que representasse a chance dessa sentença ser gerada por um dos três componentes. Por exemplo, se uma sentença tinha as seguintes probabilidades: $<0.9,0.1,0.1>$, sendo que a posição 1 desse vetor corresponde ao modelo do tópico principal, significa que essa sentença tinha $90 \%$ de chance de corresponder a um tópico principal e $10 \%$ de chance de corresponder a um assunto geral. Os três componentes foram integrados em um único modelo sobre o qual se calcularam as probabilidades das sentenças. Após o cálculo da distribuição de probabilidades, cada sentença nova foi pontuada com base na probabilidade obtida pelo modelo. Posteriormente, o sistema Bayesum foi adaptado para SAM. Nesse contexto, um novo fator foi adicionado no cálculo da pontuação da sentença. Esse fator refere-se à eliminação da redundância entre as sentenças, para a qual foi utilizada a medida de divergência Kullback-Lieber (KL) (Kullback e Leibler,1951). Essa divergência foi calculada entre a distribuição de probabilidade da sentença atual e a distribuição de probabilidade das sentenças que já foram selecionadas para o sumário anteriormente. Se a sentença atual era muito similar às sentenças que já foram selecionadas, o valor da divergência KL tendia a zero. Desse modo, a pontuação de uma sentença era dada pela soma da probabilidade bayesiana e o valor da divergência KL. O modelo foi avaliado na competição da DUC 2005. Os resultados mostraram que o sistema Bayesum obteve $44 \%$ de precisão.

Schilder e Kondadadi (2008) apresentaram o sistema FastSum, que utilizava um modelo de aprendizado discriminativo para SAM. Os atributos utilizados para o aprendizado se basearam em técnicas simples como a frequência de palavras na coleção de documentos, nos documentos e nos tópicos. Em particular, os atributos utilizados foram: a taxa de ocorrência de uma palavra no título e nas outras sentenças, taxa de ocorrência de uma palavra na sentença e na descrição do tópico, média da probabilidade de ocorrência da palavra na sentença e a média da probabilidade nos documentos (isto é, o produto das probabilidades das palavras correspondentes de cada documento). As sentenças dos documentos representadas por esses atributos foram ranqueadas por meio de um modelo de regressão. O sistema foi avaliado nas competições DUC 2006 e DUC 2007, usando a medida ROUGE-2. O sistema obteve o segundo e sexto lugar nas duas competições, com valores de medida-f de 9,2\% e 10\%, respectivamente. Também foi avaliado o desempenho individual dos atributos no processo de aprendizado. A avaliação mostrou que os atributos mais discriminativos foram às probabilidades das palavras nos documentos e a taxa de 
ocorrência da palavra no tópico, os quais obtiveram valores de medida-f 10,6\% e 10,4\%, respectivamente.

Em geral, os trabalhos apresentados até o momento mostram que os métodos superficiais fornecem informações que podem ser modeladas como atributos de um modelo de aprendizado automático. Em particular, a maior parte dos métodos coincide na utilização da frequência de palavras (em documentos e tópicos) e localização de sentenças no texto. Outros trabalhos que não usam aprendizado de máquina, também utilizam esses métodos superficiais. Nessa linha, um dos trabalhos mais importantes do estado da arte é Carbonel e Goldstein (1998). Os autores definem a Medida Maximal Marginal Relevance (MMR). Essa medida foi criada visando tratar o problema da redundância em sumários multidocumento. $\mathrm{O}$ objetivo foi minimizar a redundância para maximizar a originalidade da informação num sumário multidocumento. Para isso, o grau de similaridade entre as sentenças extraídas do conjunto de documentos era calculado. Assim, quando duas sentenças eram muito similares, de acordo com alguma medida (p.ex. similaridade lexical entre sentenças), a informação redundante era removida. A medida MMR é uma combinação linear de dois fatores, sendo que o primeiro fator corresponde à pontuação de uma sentença (ou outra unidade informativa como oração ou parágrafo) segundo a sua relevância em relação a um tópico definido. $\mathrm{O}$ segundo fator é dado pela similaridade dessa sentença com as outras sentenças dos textos. As sentenças melhor pontuadas de acordo com essa medida foram selecionadas para compor o sumário. Os autores avaliaram o sistema na conferência SUMMAC (Mani et al., 1999), na qual competiram com 15 sistemas de sumarização. A medida MMR obteve o primeiro lugar da competição, alcançando uma pontuação de $73 \%$ de medida-f e $70 \%$ de cobertura. A avaliação foi feita por juízes humanos que determinavam se uma sentença tinha ou não informação relevante dado um conjunto de perguntas chave relacionadas ao tópico.

Radev et al. (2000, 2001a, 2001b) apresentaram o sumarizador automático multidocumento MEAD. O sistema produzia sumários a partir de um conjunto de textos sobre um mesmo tópico, extraindo as sentenças mais importantes deles. O cálculo da importância (pontuação) de uma sentença baseou-se em três características: na distância em relação ao centróide do conjunto de textos (ou seja, o conjunto de palavras mais representativas do assunto tratado no conjunto de textos, as quais são extraídas a partir do cálculo da medida $t f$-idf), na distância lexical em relação ao início do documento (pode ser o título ou a primeira sentença do texto) e sua distância lexical em relação a primeira sentença do documento. Diversos parâmetros foram levados em consideração no processo. Dentre eles, destaca-se o parâmetro que indica o máximo de informação em comum que as sentenças que comporão o sumário podem ter. O uso de tal parâmetro tinha como objetivo identificar e tratar adequadamente a redundância. A ideia é que, se uma sentença S1 subsume $^{12}$ uma sentença $S 2$, então $S 2$ pode ser excluída do sumário, pois $\mathrm{S} 1$ já contém a informação toda de S1 e S2. Além disso, também foi calculada uma medida de similaridade lexical entre as sentenças. $\mathrm{O}$ valor da medida de similaridade foi introduzido como uma penalidade ao cálculo da pontuação da sentença. Os autores ainda apresentaram duas

\footnotetext{
${ }^{12}$ Uma sentença S1 subsume uma sentença S2 se S1 contém a informação de S2 e também contém informações novas.
} 
variações do MEAD: os sistemas NewsInEssence (Radev et al., 2001b) e WebInEssence (Radev et al., 2001c). Ambos os sistemas recuperavam informação da Web de acordo com a consulta realizada pelo usuário. Os textos recuperados formavam um grupo e, a partir dele, era elaborado o sumário multidocumento, extraindo-se as sentenças mais relevantes de acordo com os critérios do MEAD. A diferença entre os sistemas é que NewsInEssence selecionava os centróides e elaborava o resumo a partir de todo o grupo gerado pela consulta. O WebInEssence, por sua vez, selecionava os centróides e gerava o resumo somente a partir dos documentos selecionados pelo usuário de acordo com o critério do próprio usuário. Para avaliar o sistema MEAD, os autores usaram um córpus de 6 grupos de textos jornalísticos extraídos do Usenet Newsgroup. Cada grupo contém textos que versam sobre um mesmo assunto. Para avaliar os sumários, para cada grupo de textos, foi construído um extrato humano correspondente. Para comparar o desempenho do MEAD, foi usado um sistema baseline que seleciona as primeiras sentenças dos textos até atingir um tamanho determinado. Foram realizadas várias avaliações usando diferentes taxas de compressão para cada grupo de textos. A medida utilizada para a avaliação foi uma média das pontuações dadas por juízes humanos, para cada experimento. Os resultados mostraram que o sistema MEAD superou o desempenho do sistema baseline na maioria dos experimentos. Por exemplo, para taxa de compressão de $60 \%$, o sistema MEAD obteve uma pontuação de 0.9 , enquanto o sistema baseline obteve 0.36 .

Mihalcea e Tarau (2005) apresentam uma técnica de sumarização multidocumento baseada em percurso em grafos, independente de língua e com resultados bons. Os autores estudam dois algoritmos baseados em grafos: o algoritmo de Kleinberg (Kleinberg, 1999) e o algoritmo PageRank de Google (Brin e Page, 1999). O primeiro utiliza só as arestas de entrada num nó. A importância reside no número de arestas que apontam pra ele. $\mathrm{O}$ algoritmo PageRank considera arestas de entrada e saída, e faz uma ponderação. Para o processo de sumarização, as sentenças são representadas por nós, e os links entre os textos são representados pelas arestas. Esses links são determinados por uma medida de similaridade lexical que calcula o número de palavras em comum entre sentenças, e logo, esse número é dividido pelo total de palavras entre as duas sentenças. Dessa forma, cada aresta tem um peso associado. Na técnica de SAM proposta por Mihalcea e Tarau, primeiro era gerado um sumário monodocumento usando qualquer um dos algoritmos mencionados acima, ou seja, montando um grafo entre as sentenças de um mesmo texto e logo era aplicado ou o algoritmo Kleinberg ou o algoritmo PageRank. Após terem sido gerados os sumários monodocumento, novos links eram estabelecidos entre as sentenças dos sumários. Finalmente, aplicava-se de novo um dos algoritmos mencionados acima. No método proposto, também foi incluído o tratamento de redundância. Para as sentenças entre documentos que tinham um nível de similaridade acima de um threshold dado, não era estabelecido um link no grafo. O sistema foi avaliado na base de dados da DUC 2002, composta de 59 grupos de textos jornalísticos. Para avaliar os resultados, foi utilizada a medida ROUGE (Lin e Hovy, 2003). Os experimentos se realizaram utilizando uma base de dados de textos jornalísticos da DUC 2002. Os resultados foram comparados com os sistemas que participaram na mesma avaliação. O sistema de Milhacea e Tarau obteve 35\% de medida-f. 
Wan e Yang (2006) propuseram uma metodologia de SAM com base em grafos de afinidade, os quais representavam os textos e as relações entre as unidades informativas (sentenças) dos textos. No grafo, os nós representavam as sentenças e as arestas (não direcionadas) representavam links semânticos entre as sentenças, sendo que os links podiam ser inter-sentenciais ou intra-sentenciais. Os autores fizeram essa diferenciação para dar maior ênfase aos links inter-sentenciais, pois os autores consideravam que esses links são os mais informativos. A metodologia era composta de três etapas principais: na primeira etapa, se realizava a construção do grafo, identificando as relações entre as sentenças, o que é feito por meio da medida de similaridade coseno; na segunda etapa, aplicava-se um processo de difusão, que permitia calcular a similaridade semântica entre duas sentenças que não eram diretamente relacionadas, mas eram relacionadas por meio de outras sentenças. Esse processo de difusão era feito calculando-se a somatória dos produtos dos pesos em todos os caminhos de longitude $\mathrm{t}$ que começaram no nó i e terminavam no nó j. Isso dava como resultado uma nova matriz de pesos, correspondente a um novo grafo com novas arestas criadas a partir do processo de difusão. Após o processo de difusão no grafo, a informatividade de cada sentença era calculada com base em três critérios: 1) quanto mais vizinhos uma sentença tinha no grafo, mais informativa ela era; 2) quanto mais informativos eram os vizinhos de uma sentença, mais informativa ela era; 3) quanto mais alto era o valor da conexão semântica de uma sentença com outras sentenças informativas do grafo, mais informativa ela era. A partir destes critérios, a informatividade para cada sentença foi calculada por meio da soma dos links inter-sentenciais e dos links intra-sentenciais, sendo que os links inter-sentenciais tinham maior importância que os links intra-sentenciais. Para isso, cada um destes links tinha um coeficiente de penalidade, que, no caso dos links intrasentencias, era um valor muito pequeno. Finalmente, as sentenças com maiores pontuações foram selecionadas para compor o sumário final. O sistema foi avaliado na DUC 2002 e na DUC 2004, junto com outros sistemas que participaram na competição. O sistema foi avaliado com as medidas ROUGE-1, ROUGE-2 e ROUGE-L obtendo melhores resultados na informatividade em comparação com outros sistemas que também foram avaliados com as mesmas bases de dados. O melhor valor de medida-f foi $38 \%$ e foi obtido com ROUGE1 .

Seguindo o critério do trabalho anterior, Wan (2008), além de calcular a similaridade de cosseno entre duas sentenças, adicionaram-se dois novos fatores ao cálculo do peso de uma aresta no grafo: a importância do documento na coleção de textos e a importância da sentença dentro do documento ao qual pertence. Todos os fatores foram combinados linearmente para produzir o peso das arestas no grafo. $\mathrm{O}$ autor propôs três formas de calcular a importância do documento na coleção de documentos. A primeira forma baseou-se no cálculo da similaridade de cosseno entre o documento e o conjunto de documentos. $\mathrm{Na}$ segunda forma, considerou-se o cálculo da média dos cálculos de similaridade cosseno entre o documento e cada um dos documentos do conjunto. Por último, a terceira forma, baseouse no cálculo do algoritmo do algoritmo PageRank, a partir de um grafo de documentos. Além disso, para o cálculo da importância da sentença no documento, também foram propostas diversas formas. Em principio, todas as formas para calcular a importância da sentença no documento eram baseadas na posição da sentença no texto. Uma forma de 
calcular essa importância foi atribuir um valor de 1 ao cálculo, se a sentença estiver entre as três primeiras posições do texto e 0.5 caso contrário. Uma segunda forma foi dividir a posição da sentença pelo número de sentenças no texto. Finalmente, uma terceira forma foi calcular a similaridade cosseno entre a sentença e o documento todo. $\mathrm{O}$ autor avaliou sua proposta usando dois conjuntos de textos, um deles da DUC 2001 e o outro da DUC 2002. Cada grupo de documentos sobre um mesmo assunto tinha associado um sumário genérico de referência, de aproximadamente 100 palavras. Foram avaliadas todas as combinações entre as formas de calcular a importância do documento e a forma de calcular a importância da sentença dentro documento. Também foi avaliado um sistema baseline que extraia as primeiras sentenças do ultimo documento da coleção (os documentos estavam organizados cronologicamente). Os sumários produzidos foram avaliados pelas medidas ROUGE-1, ROUGE-2 e ROUGE-W. Os resultados obtidos mostraram que o valor mais alto de medidaf foi $38 \%$, usando a técnica da média do cálculo de similaridade cosseno entre um documento e o resto de documentos da coleção (para o cálculo da importância do documento), e usando a técnica mais simples da posição da sentença (para o cálculo da importância da sentença no documento). O método proposto superou amplamente ao sistema baseline que obteve apenas $29 \%$ de medida-f.

Aker et al. (2010) propuseram um sumarizador multidocumento extrativo de sentenças baseado no algoritmo A* e treinamento discriminativo. Para o treinamento, foi usado o algoritmo MERT (Minimum Error-Rate), o qual, anteriormente já tinha sido aplicado com sucesso na tradução automática (Och, 2003). Este algoritmo consistia em estimar um conjunto de parâmetros para cada atributo do modelo a fim de minimizar a função de perda, o que representava quanto um sumário automático era similar a um sumário humano ou gold-standard. Em particular, Aker et al. definiram essa função como sendo 1-R, onde R é o valor Rouge. Os atributos utilizados nesse modelo foram similaridade à query, similaridade ao centroide, posição da sentença, atributo binário indicando se a sentença estava ou não entre as 5 primeiras sentenças do texto, atributo binário indicando se a sentença começava com algum termo da query e, finalmente, um atributo indicando a probabilidade de uma sentença de acordo com algum modelo de língua baseado em n-gramas de palavras. Uma vez estimado o modelo era necessário decodificar para produzir o sumário de fato. Para isso, os autores usaram o algoritmo de busca A* para encontrar o sub-conjunto de sentenças que maximizem a pontuação final do sumário. De acordo com esse algoritmo, as sentenças eram incorporadas no sumário progressivamente com base na sua pontuação e uma heurística que indicava a possibilidade de chegar numa solução ótima (sumário ótimo) ao escolher essa sentença como caminho de busca. Essa heurística era dada com base nas pontuações das sentenças e o tamanho delas. Os autores aplicaram o método proposto sobre textos extraídos da Web e o compararam com um método baseline baseado em regressão usando SVR (Support Vector Regression), já que esse último método mostrou-se o melhor na DUC2005 e DUC2007. Os resultados dados pela medida Rouge mostraram que o método deles foi melhor que o baseline nas três medidas: Rouge-1, Rouge-2, Rouge-L. Em particular, neste trabalho, adota-se a estratégia de decodificação de Aker et al. como base para nossa etapa de decodificação. Essa escolha baseia-se no fato de que, diferente de outros métodos de decodificação que são gulosos e não garantem a solução ótima, o algoritmo A* permitiria 
encontrar uma solução ótima devido ao uso da heurística (a qual deve ser admissível ou seja, não deve superestimar o caminho a futuro no processo de busca). Isso é importante na SAM, pois o objetivo é achar o melhor sumário e, nesse contexto, um algoritmo guloso não seria adequado. No Capítulo 4, esse método de decodificação será explicado mais detalhadamente.

Pouco depois, os mesmos autores propuseram uma modificação ao algoritmo A* para SAM, incorporando o tratamento de redundância no processo de criação dos sumários (Aker et al., 2012). Esse novo algoritmo permitia excluir as sentenças que eram redundantes (até certo limite de threshold), verificando se a nova sentença a ser inserida era redundante às outras sentenças que já tinham sido inseridas no sumário ao longo do processo de decodificação (no estágio de busca do algoritmo $\mathrm{A}^{*}$ ). Em outras palavras, no processo de busca, não somente eram ignoradas as sentenças que ultrapassem o limite de tamanho, mas também as redundantes. A medida de redundância era dada pela soma de n-gramas de palavras em comum da sentença a ser incluída e todas as sentenças do sumário formado até o momento, tudo isso dividido pelo total de n-gramas de palavras do sumário. Os resultados da medida Rouge mostraram que o método de redundância supera o método original com A* simples. Nesse trabalho, foi proposto também um método para tratamento de redundância inédito a partir do algoritmo $\mathrm{A}^{*}$.

Como pode ter sido observado, muitos dos métodos relatados até o momento destacam-se pelo uso de medidas de similaridade entre sentenças para obter a pontuação destas. Um fator importante em vários desses trabalhos é que essas medidas estão dadas entre sentenças de um mesmo documento e também entre sentenças de diferentes documentos. Essas medidas podem fornecer informação relevante para a seleção de atributos num sistema de aprendizado automático.

Recentemente tem surgido uma nova linha na SAM que se baseia na produção de sumários a partir da modelagem probabilística de tópicos, que é uma forma de estimar a distribuição das frequências das palavras ao longo de coleções de textos que tratam de um assunto em comum. A Modelagem Probabilística de Tópicos (Blei et al., 2003) se baseia na ideia de que os documentos são compostos por uma mistura de tópicos, os quais, são uma distribuição probabilística sobre as palavras que compõem esses documentos. Um Modelo de Tópicos é um modelo gerativo que visa descobrir a distribuição dos tópicos que deram origem a um conjunto de documentos, ou seja, visa descobrir a associação entre as palavras e os tópicos (variáveis ocultas). Um dos Modelos de Tópico mais representativos é o LDA (Latent Dirichlet Allocation), o qual é comumente inferido via Expectation Maximization ou o algoritmo Gibbs Sampling.

Um dos trabalhos mais representativos de SAM que seguem a linha de Modelagem de Tópicos é o de Haghighi e Vanderwende (2009), que propuseram um conjunto de modelos probabilísticos para SAM. Em particular, os autores apresentam três modelos para extração de sumários multidocumento: SumBasic, KLSum, TopicSum e HierSum. De acordo com o modelo SumBasic, as sentenças eram selecionadas com base na frequência de palavras. Para isso, a pontuação de cada sentença era dada pela somatória normalizada das distribuições das palavras que compõem a sentença. O sumário era construído adicionando 
progressivamente as sentenças com maior pontuação. Para tratar a redundância, os autores propuseram um re-cálculo da distribuição dos n-gramas de palavras das sentenças que foram inseridas no sumário. O objetivo desse re-cálculo era diminuir o valor da probabilidade do n-grama cada vez que era inserido no sumário. No modelo KLSum, formulou-se a probabilidade de selecionar um sumário dado um conjunto de textos a partir da divergência $K L$ entre a distribuição unigramas no sumário e a distribuição de unigramas nos documentos. O sumário era construído progressivamente similar a SumBasic, e o tratamento de redundância seguiu o mesmo critério. O modelo TopicSum foi o primeiro modelo no qual os autores utilizaram Modelagem de Tópicos. Nesse modelo, as palavras dos documentos eram descritas a partir de três possíveis categorias: vocabulário geral da língua (Background); vocabulário de conteúdo representativo de uma coleção (Content), que representava o vocabulário particular do assunto que estava sendo tratado ao longo dos textos de uma coleção; e finalmente, a distribuição correspondente a cada documento (Document Specific), que representava o vocabulário local-específico de cada documento. Desse modo, os tópicos que davam origem as palavras representavam essas três categorias. Para descobrir a distribuição do vocabulário em $\mathrm{k}$ tópicos representativos dessas categorias era realizada a inferência via o algoritmo Gibbs sampling. A ideia principal era que a distribuição de palavras no tópico que representava o conteúdo do assunto principal dos textos (Content Distribution) devia ser similar a distribuição de unigramas do sumário. $\mathrm{O}$ sumário era construído progressivamente a partir do conjunto de sentenças dos textos fonte, de modo que a divergência $K L$ entre a distribuição das palavras do tópico de conteúdo e a distribuição de unigramas dos sumários fosse minimizada (estratégia gulosa). Finalmente, o modelo HierSum era apenas uma variação do modelo TopicSum. No HierSum consideravase uma subdivisão hierárquica na categoria de Content, onde as palavras podiam ser de conteúdo geral ou conteúdo específico. Desse modo, era introduzida uma nova distribuição binomial para decidir se uma palavra era de conteúdo específico ou geral (após ter decidido que era de conteúdo, via a distribuição descrita em TopicSum). A inferência era realizada usando Gibbs Sampling, e a construção do sumário era realizada usando a mesma estratégia que o TopicSum. Os modelos foram avaliados no conjunto de textos de avaliação da DUC 2006. Dois tipos de avaliação foram considerados. A primeira avaliação foi realizada usando a medida ROUGE-L. A segunda avaliação foi humana. O melhor valor de medida-f (43\%) foi obtido pelo modelo HierSum.

Wang et al.(2009) apresentaram um método de SAM que utilizava Modelagem de Tópico baseado em sentenças. A diferença entre esse método e os métodos tradicionais de Modelagem de Tópicos é que os tópicos não somente eram definidos como uma distribuição sobre as palavras de uma coleção de textos, mas também como uma distribuição sobre as sentenças de uma coleção de textos. A argumentação dos autores era que essa abordagem seria vantajosa, pois analisaria as sentenças em conjunto (já que a distribuição era inferida a partir da frequência ao longo de toda a coleção de sentenças) e não isoladamente como na maioria de métodos de sumarização extrativa. Nessa nova forma de modelagem de tópico, uma sentença podia ser gerada a partir de um tópico e, portanto, a probabilidade de uma palavra pertencer a um tópico era uma combinação da probabilidade da palavra pertencer a uma sentença e da probabilidade da sentença pertencer ao tópico. A probabilidade de uma 
palavra pertencer a uma sentença era dada por um modelo de língua, que era um modelo simples de n-gramas de palavras. Esse modelo era inferido via Expectation Maximization usando associações entre termos e documentos, termos e sentenças, documentos e tópicos, sentenças e tópicos, e palavras e tópicos. Ao final da inferência era obtida uma distribuição de sentenças para cada tópico. Para a construção do sumário utilizou-se a estratégia de incorporar a sentença mais provável de cada tópico. Nos experimentos foram utilizados os conjuntos de dados da DUC 2002 e DUC 2004. Os resultados, de acordo com a medida ROUGE, mostraram que o método proposto por Wang et al. superou vários métodos de SAM com a medida ROUGE-1, tais como o algoritmo LexPage Rank, LSA (Latent Semantic Analysis) e o DUC Best, obtendo um resultado de 0.48812 na Medida-F . Com as medidas ROUGE-2 e ROUGE-L não superou, mas obteve resultados próximos.

Li et al.(2011) desenvolveram um método de SAM orientado a aspectos, usando Modelagem de Tópicos. Na sumarização orientada a aspectos, o objetivo é produzir sumários que condensem a informação mais relevante dos aspectos nos quais o usuário está interessado, p.ex.: Onde, Como, Quando, etc. Estes aspectos são bem comuns em textos do gênero jornalístico, que foi o gênero utilizado pelos autores. $\mathrm{O}$ método proposto por $\mathrm{Li}$ et al. consistia em 3 etapas principais. Na primeira etapa, chamada de "Agrupamento de Sentenças", o objetivo era descobrir os aspectos num conjunto de documentos e agrupar as sentenças relacionadas com cada um desses aspectos. Foi assumido previamente que no conjunto de textos existiam tópicos, eventos e aspectos. Os eventos eram os fatos relatados ao longo dos textos, p.ex. Massacre de Columbine ou Abdução do Resort de Malásia; os tópicos eram um assunto mais geral que englobava os eventos, no caso do exemplo o tópico seria "Ataques"; os aspectos eram informações mais pontuais relacionadas com os eventos, p.ex. Como, Quando, Onde. De acordo com isso, as palavras do conjunto de textos podiam ser de 4 tipos: stopwords ou palavras comuns a todas as coleções de textos, palavras de conteúdo geral de cada aspecto, palavras de conteúdo específico de cada aspecto para eventos específicos e palavras específicas de um documento. Com base nisso, assumia-se que as palavras podiam ser geradas a partir de 4 tipos de distribuições que representem essas categorias. Para descobrir a distribuição do vocabulário em $\mathrm{k}$ tópicos correspondentes a essas categorias, foi realizada a inferência via o algoritmo Gibbs sampling. Após a inferência, obtiveram-se as distribuições das palavras nas categorias conteúdo geral, conteúdo geral dos aspectos e conteúdo específico dos aspectos. Na segunda etapa, foi construído um grafo de sentenças onde as arestas das sentenças eram dadas pela probabilidade que as duas sentenças representem a mesma categoria de conteúdo específico dos aspectos ou conteúdo geral dos aspectos. Após a construção do grafo, era construído um ranque de sentenças via o algoritmo LexRank (Erkan e Radev, 2004). Na ultima etapa, o conjunto de sentenças a compor o sumário final foi selecionado usando Programação Linear inteira, considerando restrições sobre o tamanho e a redundância entre as sentenças. $\mathrm{O}$ método foi comparado com vários métodos do estado da arte como o HierSum, métodos tradicionais baseados em ranque, entre outros. O córpus usado para os experimentos foi o conjunto de dados da Sumarization Task da TAC2010. Os resultados mostraram que, em geral, para todas as medidas Rouge (Rouge-1, Roug-e2 e Rouge-L), o método deles superou os métodos do estado da arte. 
Li e Sujian (2013) propuseram um método para SAM baseado em query, usando um modelo combinado de tópicos e atributos. A ideia dessa proposta era melhorar o desempenho da Modelagem de Tópicos, enriquecendo-a com atributos das sentenças dos textos. Em uma Modelagem de Tópicos tradicional, cada tópico inferido é uma distribuição sobre as palavras que compõem o conjunto de documentos, e essa distribuição é inferida a partir da associação entre tópicos e palavras ao longo dos documentos. Na proposta de Li e Sujian, a distribuição das palavras para cada tópico era inferida a partir da associação entre tópicos e sentenças, tópicos e atributos de sentenças e tópicos e palavras. Os autores assumiram que cada sentença era vinculada apenas a um tópico e, portanto, as palavras que componham essa mesma sentença também estavam vinculadas a esse tópico. Foi assumido também que, para cada sentença, corresponde um conjunto de atributos. Os atributos considerados para as sentenças foram: grau da sentença (número de arestas que conectam a sentença com outras sentenças), palavra específica do documento (valor 1 se a sentença tem ao menos uma palavra específica do documento, 0 caso contrário), probabilidade média de unigramas (soma das probabilidades das palavras da sentença, dividido pelo número de palavras da sentença), similaridade cosseno da sentença com a query. A inferência dos tópicos, dadas as associações mencionadas anteriormente, foi feita via o algoritmo Expectation Maximization. Após a inferência, foram obtidas as distribuições sobre as sentenças, as palavras e os atributos. Uma vez realizada essa inferência, os valores dos pesos dos atributos eram aprendidos da seguinte forma: cada sentença obtinha uma pontuação via avaliação humana, indicando se a sentença era boa para o sumário. As pontuações eram num rango de -2 a 2 (valores menores indicavam uma pontuação ruim e valores maiores indicavam boa pontuação). Desse modo, utilizou-se a distribuição das sentenças que, correspondem a cada um desses valores para cada tópico k, e buscou-se otimizar a função de divergência KL entre cada uma dessas distribuições e a distribuição de unigramas da query, obtendo assim os pesos para os atributos em cada tópico. Após isso, com os pesos corretos e as distribuições inferidas, procurava-se pelo sub-conjunto de sentenças que minimize a divergência KL com a query. Os autores avaliaram o método deles com o conjunto de dados da DUC 2007, TAC 2008 e TAC 2009. O método foi comparado com os métodos gerativos do estado da arte: KLSum e Hiersum. Os resultados mostraram que o método proposto superou os outros métodos nas medidas Rouge-1, Rouge-2 e Rouge-L. O melhor valor de Rouge obtido foi Rouge1 sendo 0.3724 .

\subsection{Abordagem Profunda}

Apesar dos métodos da abordagem superficial terem sido estudados em vários trabalhos e, muitas vezes, obtiveram resultados satisfatórios, ainda possuem algumas desvantagens. Em princípio, em uma abordagem superficial, as decisões de seleção de conteúdo apenas envolvem tarefas de identificação, seleção e exclusão de segmentos textuais. No entanto, esses métodos não abordam (ou abordam de forma muito superficial) vários dos desafios tanto da Sumarização Monodocumento quanto da SAM. Por exemplo, alguns desafios pouco tratados pelos métodos superficiais são: a organização de informações complementares, o tratamento de informações redundantes e contraditórias, a coesão entre segmentos textuais, entre outras. 
$\mathrm{Na}$ abordagem profunda, foca-se no uso de conhecimento linguístico para análise, seleção de conteúdo e geração de sumários. Os métodos correspondentes a essa abordagem envolvem, por exemplo, o uso de regras gramaticais, ontologias ou outras informações semânticas, discursivas e intencionais.

$\mathrm{Na}$ abordagem profunda, várias teorias que abordam a semântica, ou discurso e até a intenção nos textos têm sido propostas. Algumas dessas teorias são, por exemplo: Grosz e Sidner (1986), que propuseram uma teoria discursiva baseada em intencionalidade; Jordan (1992), que propôs um conjunto de relações semânticas para capturar as noções ou vínculos semânticos entre duas proposições de um texto; Kheler (2002), que também investigou a linha de relacionamento semântico, mas, diferente do Jordan, ele apenas propôs três relações semânticas: resemblance, cause-effect e contiguity. Mann e Thompson (1987), que propuseram a teoria discursiva RST (Rhetorical Structure Theory). Essa teoria, além de fornecer um conjunto de relações retóricas, também determina o conceito de nuclearidade, o qual define que há partes dos textos que são mais importantes do que outras.

Para o tratamento de múltiplos textos, vários métodos para estabelecimento de relações semânticas entre partes de textos diferentes também foram explorados. Por exemplo, Trigg (1983) e Trigg e Weiser (1986) propuseram uma tipologia de links semânticos, os quais podiam ser de dois tipos: conteúdo e comentário. Links de conteúdo estabeleciam relações entre segmentos onde se argumentava, apresentava ou especificava o conteúdo de um tópico. Links de comentário eram estabelecidos entre segmentos onde havia comentários, criticas ou apoio. Allan (1996) também propôs um conjunto de links semânticos para múltiplos textos. Os links propostos incluiam desde relações simples (p.ex., similaridade lexical entre segmentos) até relações mais complexas como causa-efeito, propósito, entre outras. Radev (2000) propôs a teoria CST (Cross-document Structure Theory) para relacionamento entre múltiplos documentos, com base num conjunto de relações semântico-discursivas. Afantenos et al.(2007), com base na CST, propuseram uma nova classificação das relações semânticas, dividindo-as em dois tipos: sincrônicas e diacrônicas. As relações sincrônicas modelavam os eventos similares relatados em vários textos; as relações diacrônicas modelavam a evolução de um evento ao longo de uma mesma fonte de informação.

Em particular, as teorias RST e CST têm sido bastante exploradas para Sumarização Monodocumento e SAM em português. Atualmente, conta-se com vários recursos ${ }^{13}$ disponíveis em RST e CST para textos em Português. Neste Capítulo, serão apresentadas brevemente essas duas teorias, as quais podem fornecer informação muito útil para a construção de modelos de SAM.

\subsubsection{Rhetorical Structure Theory (RST)}

A RST foi proposta por Mann e Thompson (1987) como uma teoria de organização do texto, que identifica unidades elementares do discurso (EDU- Elementary Discourse Unit) subjacentes a um texto e estabelece um conjunto de relações retóricas entre estas. A teoria é baseada na hipótese de que essas proposições são organizadas pelo autor com a intenção de

\footnotetext{
${ }^{13}$ http://www.icmc.usp.br/ taspardo/sucinto/index.html
} 
transmitir uma mensagem ao leitor. As EDUs consideradas na teoria RST são unidades mínimas de sentido lógico, que comumente são expressas em orações ou sentenças. As relações se estruturam em forma de árvore, sendo que as EDUs de tamanho menor se localizam nas folhas da árvore e as EDUs maiores se encontram mais ao topo da árvore. $\mathrm{Na}$ Tabela 1, são listadas as relações do conjunto original proposto por Mann e Thompson (1987). Os nomes das relações foram mantidos em inglês como na obra original.

Tabela 1: Relações RST propostas no trabalho original de Mann e Thompson (1987)

\begin{tabular}{|c|c|c|}
\hline Circumstance & Volitional Cause & Otherwise \\
\hline Solutionhood & Non-Volitional Cause & Interpretation \\
\hline Elaboration & Volitional Result & Evaluation \\
\hline Background & Non-Volitional Result & Restatement \\
\hline Enablement & Purpose & Summary \\
\hline Motivation & Antithesis & Sequence \\
\hline Evidence & Concession & Contrast \\
\hline Justify & Condition & Joint \\
\hline
\end{tabular}

Posteriormente, outros trabalhos, como Marcu (1997), adicionaram novas relações como List, Means, Explanation, Comparison, Conclusion, Attribution, Parenthetical e Same-Unit.

Um conceito importante da teoria RST é o conceito de nuclearidade. Segundo a teoria RST, existem proposições nucleares e proposições satélites. As EDUs nucleares são as que contêm as informações mais importantes segundo a intenção do autor. Por outro lado, as relações satélites são as que fornecem informação complementar. As EDUs que têm apenas um núcleo e um satélite são ditas mononucleares, enquanto as proposições que têm mais de um núcleo são chamadas de multinucleares. Por exemplo, considere-se a seguinte sentença:

- [A polícia oficializou a criação de um grupo especial $]^{1}$ [para investigar o acidente. $]^{2}$

Nesse exemplo, pode-se observar duas EDUs na da sentença, sendo que a EDU 1 é o núcleo e a EDU 2 é satélite, pois a informação principal está em 1 e a informação complementar em 2. Em particular, a proposição 2 representa o propósito da EDU 1, portanto, a relação entre as duas proposições é Purpose. A árvore RST para essas duas EDUs é ilustrada na Figura 9.

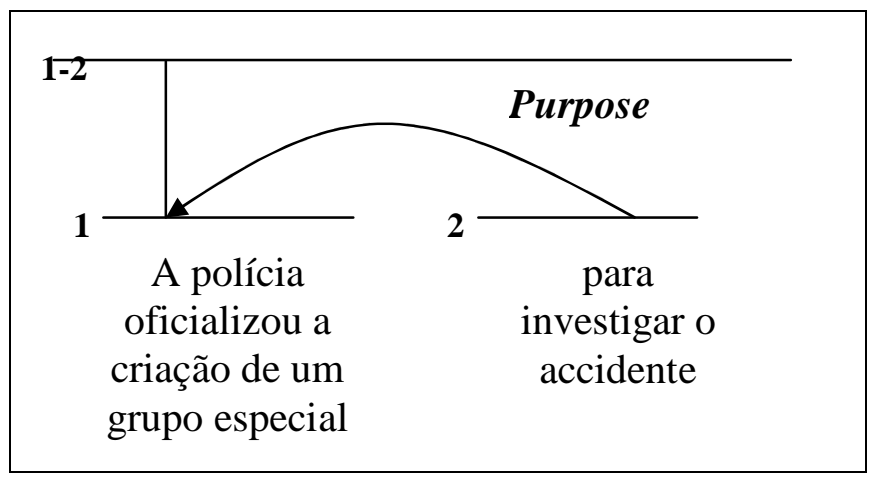

Figura 9: Árvore RST da relação Purpose entre dois segmentos 
A linha horizontal acima da relação indica que há uma subárvore envolvendo dois ou mais segmentos. Nas relações mononucleares, o satélite aponta sempre para o núcleo, como ilustrado na Figura 8. No caso das relações multinucleares, não há direcionamento entre satélite e núcleo, como ilustrado na Figura 10, em que é mostrada a árvore RST para as duas proposições mostradas a seguir.

- $\quad[\text { Pedro comeu um lanche }]^{1}[\text { e bebeu refrigerante }]^{2}$

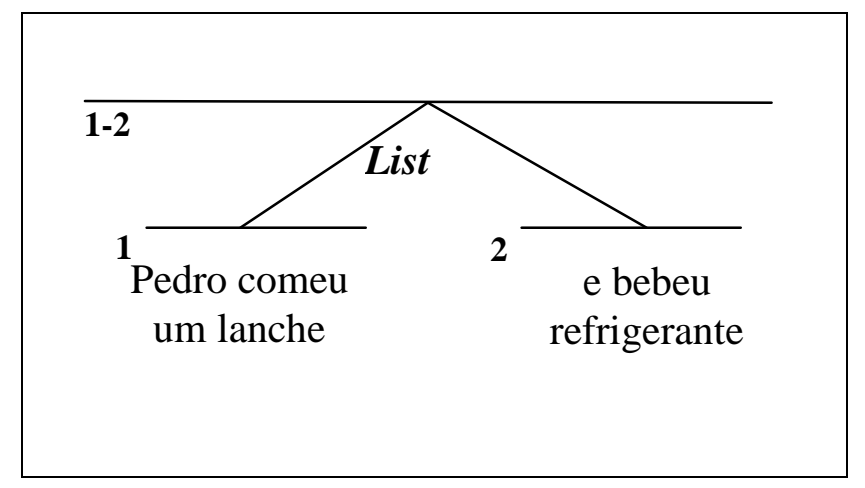

Figura 10: Exemplo de relação RST Mononuclear

Uma condição importante da análise de textos segundo a teoria RST é que o analisador deve ter conhecimento do tópico do texto, para poder estabelecer as relações. Além disso, a análise RST do texto envolve muita subjetividade, já que depende do critério de quem está fazendo a análise. Essa subjetividade pode levar à discordância entre vários analisadores sobre a identificação das relações estabelecidas entre as proposições e, também, a identificação dessas proposições dentro do texto. A tarefa de identificação de proposições é também conhecida como segmentação.

Com o intuito de reduzir a ambiguidade da análise RST, Carlos e Marcu (2001) propuseram um conjunto de regras claras de segmentação baseadas na sintaxe. Apesar do uso dessas regras, a análise RST continua sendo subjetiva podendo existir mais de uma árvore retórica para um mesmo texto. No entanto, vários trabalhos têm mostrado que se pode obter um bom nível de concordância na análise dos textos (Cardoso et al., 2011; Carlson e Marcu, 2001).

\subsubsection{Cross-document Structure Theory (CST)}

A teoria CST (Radev, 2000) surge como um modelo de estruturação de vários textos, que estabelece relações entre diferentes unidades informativas. Essas relações modelam os atributos ou fenômenos multidocumento tais como: similaridades, diferenças, contradições e informações complementares. Essa teoria se inspira na RST e em outros trabalhos anteriores como os trabalhos de Trigg, (1983), Trigg e Weiser (1986) e Radev e McKeown (1998), que exploram o relacionamento semântico entre documentos. 
Originalmente a teoria foi proposta com um conjunto de 24 relações semânticodiscursivas, as quais são mostradas na Tabela 2. O nome das relações foi mantido em inglês como na obra original.

Tabela 2: Conjunto original de relações da Teoria CST

\begin{tabular}{|c|c|c|}
\hline Identity & Modality & Judgement \\
\hline Equivalence & Attribution & Fullfilment \\
\hline Translation & Summary & Reader Profile \\
\hline Subsumption & Follow-up & Contrast \\
\hline Contradiction & Elaboration & Parallel \\
\hline Historical background & Indirect speech & Description \\
\hline Cross-reference & Refinement & Generalization \\
\hline Citation & Agreement & Change of Perspective \\
\hline
\end{tabular}

Segundo a teoria CST, pode-se relacionar proposições expressas por palavras, expressões multipalavra, sintagmas, orações, sentenças, parágrafos ou blocos de textos maiores. Esse esquema geral de relacionamento é ilustrado na Figura 11. Pode-se perceber que o resultado da análise CST é um grafo, ou seja, um conjunto de elementos/nós relacionados, sem restrição quanto à forma de relacionamento.

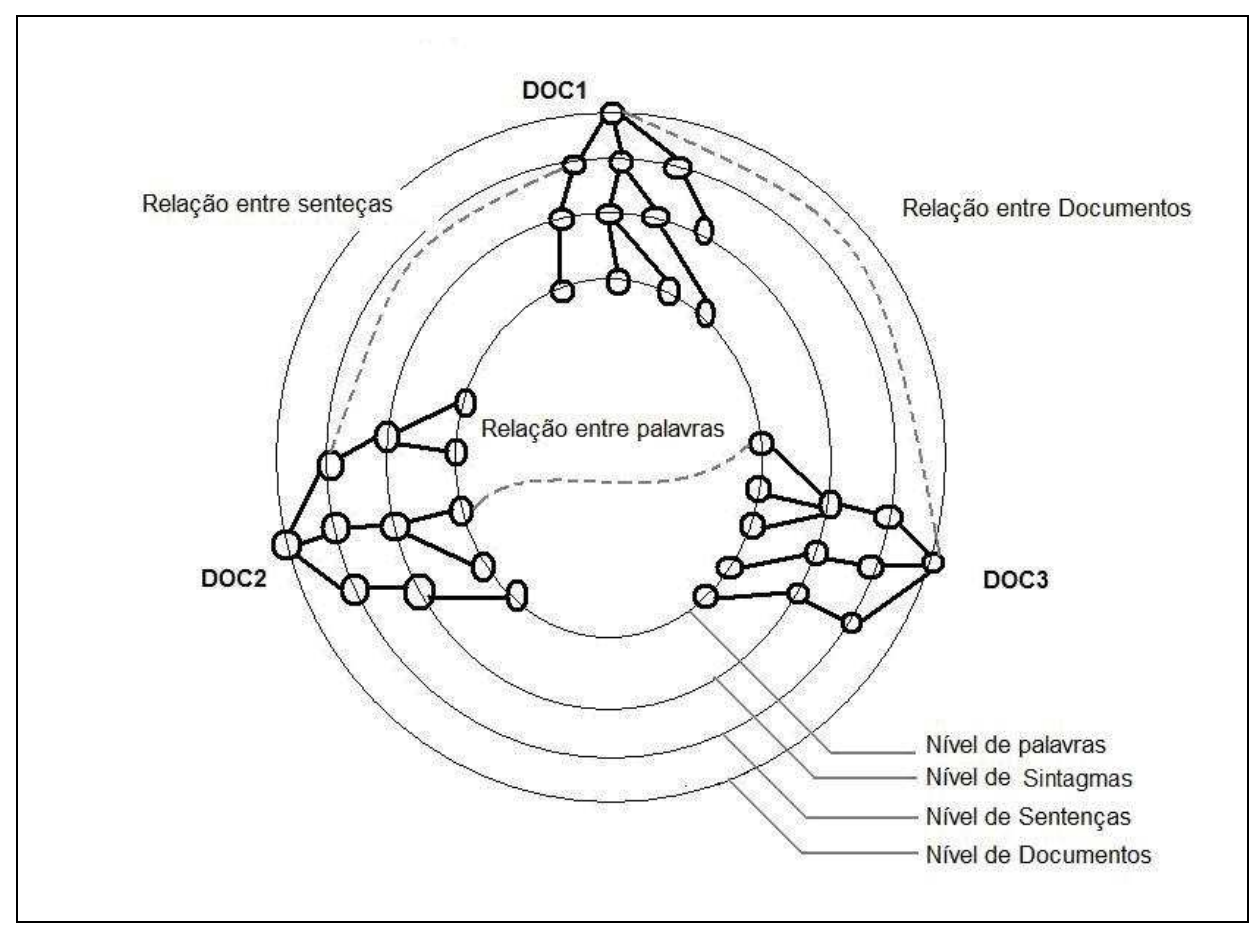

Figura 11: Esquema geral de relacionamento CST

De acordo com a figura, os documentos similares são representados em uma hierarquia de palavras, sintagmas, sentenças e o documento completo. Em cada nível dessa hierarquia, pode-se estabelecer relações CST. São considerados todos esses níveis, pois, apesar de 
orações e sentenças serem tradicionalmente os segmentos mais utilizados, tarefas particulares podem exigir um relacionamento entre unidades menores. Por exemplo, para sumarização, o relacionamento de sintagmas pode ser mais adequado do que orações ou sentenças. Também se deve considerar que nem todas as unidades informativas contidas nos textos têm relações CST com outras unidades, portanto, é possível que o grafo seja desconexo.

Segundo vários autores, como Maziero et al. (2010) e Zhang et al.(2002), as relações CST somente são estabelecidas entre segmentos de texto similares lexicalmente, já que tentar estabelecer relações CST entre todos os segmentos possíveis resulta uma tarefa muito trabalhosa que poderia gerar ambiguidade.

Similar à RST, a CST também envolve muita subjetividade na análise, o que pode levar à discordância. Analisadores humanos diferentes podem identificar diferentes relações entre os mesmos segmentos de texto ou, ainda, podem selecionar segmentos diferentes para relacionar.

Nesse sentido, algumas pesquisas têm encontrado algumas deficiências na teoria CST. Por exemplo, Afantenos et al. (2004) e Afantenos (2007) destacam a baixa concordância na anotação das relações dada a subjetividade das relações. Afantenos et al. também consideram que nem todas as relações são utilizadas e que somente segmentos do mesmo nível na taxonomia podem ser conectados por meio das relações (sentenças com sentenças, palavras com palavras, etc.). Segundo o critério dos autores, isso se deve ao fato de que a CST se inspira na RST, sem levar em conta que, no caso monodocumento, assume-se a coerência no texto. No caso multidocumento, têm-se diversas fontes de informação e não faz sentido se falar em coerência. Outra crítica de Afantenos et al. é que a CST deveria focar em um tópico em particular, para evitar a generalização das relações.

No trabalho de Zhang et al. (2002), os pesquisadores também concluíram que houve um baixo nível de concordância na anotação de relações. Eles argumentam que isso se deve às ambiguidades de algumas relações e à subjetividade própria da língua. Por exemplo, as relações elaboration e refinement têm definições similares, o que geraria ambiguidade e reduziria a concordância entre os anotadores. Para reduzir a ambiguidade, Zhang e colaboradores propuseram um refinamento do conjunto de relações do modelo original, considerando somente 18 relações. As relações consideradas similares na sua definição foram reduzidas a uma relação só, por exemplo, as relações equivalence e paraphrase têm definições similares, portanto, paraphrase foi eliminada e equivalence permaneceu. Para avaliar o nível de concordância entre vários anotadores, Zhang e colaboradores observaram um conjunto de 88 pares de sentenças, para as quais, um grupo de juízes anotou relações CST. Os anotadores concordaram, pelo menos em uma relação em 51 pares de sentenças, ou seja, obtive-se um 58\% de concordância.

Recentemente, Maziero et al. (2010) também fizeram um refinamento das relações propostas por Radev (2000), como parte do projeto de anotação do córpus CSTNews. Os detalhes desse refinamento serão descritos no Capítulo 4. 


\subsubsection{Trabalhos de Sumarização Automática na linha profunda}

Um dos primeiros trabalhos que integram informação profunda em modelos de aprendizado de sumários é Witbrock e Mittal (1999). Os autores apresentam um modelo estatístico de sumarização monodocumento. O modelo envolve as tarefas de seleção de conteúdo e geração do texto, sendo que o foco do trabalho é a construção de abstracts. Na proposta dos autores, seguiu-se o critério dos trabalhos da Tradução Automática (Brown et al., 1993). O sistema consistiu de três etapas principais. Na primeira etapa, era feito um préprocessamento dos textos de entrada e os respectivos sumários (os sumários eram considerados títulos de documentos). Esse pré-processamento consistiu na identificação de tokens, os quais podiam não apenas ser palavras, mas etiquetas semânticas, etiquetas morfossintáticas, informação estrutural do texto, relações entre palavras etc. Esses tokens representam os atributos do modelo. Na segunda etapa, foi modelada estatisticamente a relação entre a ocorrência dos atributos nos textos fonte e a ocorrência dos atributos nos sumários. Também foi projetada uma modelagem probabilística de bigramas, que computava a probabilidade de sequência de uma palavra dada a ocorrência de uma palavra anterior. Na terceira etapa, foram gerados vários sumários, entre os quais, buscava-se identificar aquele que maximizasse o valor da combinação linear dos dois modelos da segunda etapa. Os autores avaliaram a proposta em um córpus de textos extraídos da Reuters e compararam os sumários produzidos pelos modelos com os títulos dos documentos que foram testados. Os resultados mostraram que a sobreposição entre os sumários produzidos e os títulos dos documentos alcançou valores superiores a $80 \%$.

Knight e Marcu (2002) propuseram um modelo de compressão de sentenças para sumarização monodocumento, usando o esquema Noisy-Channel. Ao instanciar a tarefa de compressão de sentenças nesse esquema, assumiu-se que as sentenças comprimidas seriam introduzidas no canal ruidoso produzindo assim sentenças maiores. Por meio da regra de Bayes, a qual é instanciada no esquema Noisy-Channel, calculava-se a probabilidade de uma sentença menor expandir-se em uma sentença maior. No treinamento, as sentenças eram representadas por meio de árvores sintáticas, produzidas pelo parser de Collins (Collins, 1997). Para cada componente da arvore sintática da sentença menor, computava-se a probabilidade do componente ser expandido em um componente maior da árvore correspondente à sentença maior. Na etapa de decodificação, procurava-se pela sentença comprimida que maximizasse a regra de Bayes. O modelo foi treinado no córpus Ziff Davis, que é um córpus paralelo de documentos e seus respectivos sumários. Nesse córpus, as sentenças dos textos eram alinhadas com suas respectivas versões comprimidas no sumário. A avaliação realizada foi humana, sendo que os juízes deviam atribuir uma pontuação entre 1 e 5 às sentenças produzidas pelo sistema. Os resultados da avaliação mostraram que o método produzia sentenças relevantes e gramaticalmente boas com resultados bem próximos da compressão humana. Em particular, na avaliação da gramaticalidade, o sistema de compressão proposto obteve uma média de pontuação de 4.34 , enquanto as sentenças comprimidas manualmente obtiveram uma média de pontuação de 4.92. Em termos de informatividade, as sentenças produzidas automaticamente obtiveram uma média de pontuação de 3.38 , e as sentenças comprimidas manualmente obtiveram uma pontuação de 4.24 . 
Seguindo a linha do trabalho anterior, Daumé III e Marcu (2002), abordaram o problema da compressão de um documento (ou sumarização monodocumento), por meio de uma modelagem gerativa usando o esquema Noisy-Channel. O modelo foi projetado por meio de uma estrutura combinada de árvore retórica RST e árvore sintática. Em princípio, a árvore retórica era construída sobre as diferentes unidades discursivas do texto. Para cada folha da árvore retórica era construída a árvore sintática correspondente. A partir dessa estrutura era modelada a probabilidade de um sumário ser expandido em um texto completo. Em outras palavras, a probabilidade de expansão de cada componente da árvore retórica do sumário. Simultaneamente, essa probabilidade foi combinada com a probabilidade de expansão dos componentes sintáticos. Finalmente, buscava-se pelo sumário que maximizasse a regra de Bayes. Para o treinamento e teste foi utilizado o córpus Mitre (Hirschman et al., 1999). A avaliação realizada foi humana considerando fatores como gramaticalidade, qualidade e coerência, sendo que os juízes deviam atribuir uma pontuação entre 1 e 5 aos sumários gerados. Os resultados obtidos foram comparados com os resultados de alguns sistemas baseline, como a concatenação de sentenças comprimidas até atingir o limite da taxa de compressão. Esses resultados mostraram que o uso de informação retórica ajuda a melhorar a qualidade e informatividade dos sumários. Em particular, o sistema obteve uma média de pontuação de $3.61 \mathrm{em}$ termos de gramaticalidade, $3.2 \mathrm{em}$ termos de coerência e 2.95 em termos de qualidade. Por outro lado, o sistema baseline obteve $1.6,1.58$ e 2.13 , respectivamente.

Além desses trabalhos, existem outros, também importantes, que utilizam conhecimento linguístico, mas não utilizam técnicas de Aprendizado de Máquina. Por exemplo, na linha da RST, destacam-se várias pesquisas como a de Ono et al. (1994). Nesse estudo, os autores propuseram um método de geração de sumários com base na teoria RST. A proposta baseava-se na idéia de que os núcleos de uma árvore RST contêm as ideias principais de um texto. Para extrair as informações principais, a árvore RST era percorrida em profundidade, atribuindo-se uma pontuação para cada nó em cada nível da árvore. O nó raiz tinha uma pontuação igual à profundidade da árvore, e para cada nó filho satélite, atribuía-se uma pontuação diminuída em uma unidade com respeito ao nó pai; para cada nó filho núcleo atribui-se a mesma pontuação que o nó pai. Esse procedimento era aplicado recursivamente até as folhas da árvore. Finalmente, os nós eram ordenados pela sua pontuação final, sendo que os nós com maior pontuação tinham preferência para compor o sumário final. Após a identificação da informação relevante, era produzido um abstract. $\mathrm{O}$ método foi avaliado em dois conjuntos de textos. O primeiro conjunto corresponde a textos jornalísticos extraídos de um jornal Japonês; o segundo conjunto corresponde a reportes técnicos extraídos da revista "Toshiba Review". Para a avaliação do método, os sumários produzidos foram comparados por sentenças extraídas por juízes humanos, os quais selecionaram a sentença mais importante e as sentenças relevantes do texto. Os resultados mostraram que foi obtido um valor de $60 \%$ de cobertura sobre a sentença principal e um valor de $41 \%$ de cobertura sobre as sentenças mais relevantes.

O’Donnel (1997) apresentou um modelo similar a Ono et al., que introduzia o valor da relação na pontuação de cada nó da árvore. De acordo com o critério humano, a cada relação RST foi atribuído um valor entre 0 e 1 . Em principio, foi atribuído o valor de 1 ao nó raiz da 
árvore, na sequencia, a árvore era percorrida em profundidade onde a cada nó satélite era atribuído o valor do nó pai multiplicado pelo valor da relação RST correspondente ao arco que os unia. Ao final do percorrido, os nós eram ordenados pela pontuação final. O método não foi avaliado.

Marcu (1998), seguindo a linha dos métodos anteriores, propôs um método para geração de sumários monodocumento com base na RST. No método de Marcu, associava-se a cada nó da árvore um conjunto chamado promotion set. Esse conjunto continha os núcleos dos filhos, desde o nível das folhas até o nó da árvore que estava sendo avaliado. $\mathrm{O}$ promotion set de um nó folha era composto por um único elemento, que era ele mesmo. Para cada nó intermediário (não folha), o promotion set era composto pelos elementos do promotion set dos filhos nucleares. Após o estabelecimento desses conjuntos, a árvore era percorrida em profundidade em busca de um segmento em particular a cada iteração. Atribuía-se ao nó raiz uma pontuação correspondente ao valor da profundidade da árvore. Após disso, a árvore era percorrida em direção ao segmento procurado, e, se o nó do segmento não estivesse no promotion set de um nó do caminho até ele, a pontuação desse nó era a pontuação do pai diminuída em um. O autor avaliou o método usando um conjunto de 5 textos da revista Scientific American Magazine. As unidades mais importantes geradas por esse método foram comparadas com unidades geradas por juízes humanos. Os resultados mostraram que se logrou um $70 \%$ de precisão e cobertura.

Uzeda et al. (2009) propuseram um método para Sumarização Monodocumento, que integrou os conceitos das propostas de Ono et al. (1994), O’Donnel (1997) e Marcu (1998). Em principio, foi atribuído ao nó raiz um valor de duas vezes o valor da profundidade da árvore. Após isso, para cada segmento, a árvore era percorrida em direção àquele segmento. Para cada nó visitado nesse caminho, se o segmento não pertencia ao promotion set, a pontuação do nó era diminuída pelo complemento do valor da relação RST que conectava aquele nó. Se o nó visitado era satélite, o valor do nó era diminuído em 1. Para avaliar o método, os autores utilizaram o RST Discourse Tree Bank (Carlson et al.,2003), que é um córpus de textos em inglês, anotados de acordo com a teria RST. O método foi avaliado usando a medida ROUGE. Os resultados mostraram que o método proposto alcançou um valor de $38 \%$ de medida-f. Além do método proposto, os autores fizeram alguns experimentos utilizando aprendizado de máquina. Foram extraídos vários atributos a partir das informações RST, por exemplo: nível da árvore, porcentagem de núcleos encontrados no caminho desde a raiz até o segmento, porcentagem de satélites encontrados no caminho desde a raiz até o segmento, entre outros. Os autores usaram o algoritmo J48 e o algoritmo Naive-Bayes para treinar o modelo. Os resultados revelaram valores de $31 \%$ de medida-f para o algoritmo J48 e $41 \%$ de medida-f para o algoritmo Naive-Bayes.

$\mathrm{Na}$ linha multidocumento, vários trabalhos também utilizam informações profundas como relações semânticas entre documentos. Nessa linha, um dos trabalhos mais relevantes da área é o trabalho de Radev e McKeown (1995,1998), que propuseram o sumarizador multidocumento chamado SUMMONS (Summarizing Online News Articles), para sumarização de artigos jornalísticos que falam sobre terrorismo. Os dados de entrada para o sistema consistem em um conjunto de informações salientes em cada artigo organizadas em 
templates, ou seja, informações na forma atributo-valor. Esses templates eram extraídos a partir das informações dos textos. Para extrair essas informações, o sistema possuia módulos de extração de entidades, planificação e geração de texto. Por exemplo, os templates eram preenchidos com atributos do tipo: vítimas, lugar do crime, etc. No total, cada template timha 25 campos. Após a construção dos templates, o sumarizador aplicava uma série de operadores sobre os templates, atribuindo-lhes pontos de acordo com sua importância (em função da repetição de informação em diferentes templates e do tipo de informação que continham), combinando-os em novos templates mais genéricos ou específicos (dependendo do operador aplicado), excluindo templates, etc. Ao final, os templates mais bem pontuados eram selecionados e, com base nos dados contidos neles, o sistema produzia o sumário final utilizando técnicas de geração de língua natural. Os operadores aplicados sobre os templates eram de diversos tipos e eram ativados por heurísticas que identificavam as relações entre os templates. Essas relações eram do tipo semântico-discursivo, similares às relações propostas na CST, por exemplo, "Contradiction", "Refinement", "Agreement", etc. Por exemplo, dados dois templates, para aplicar o operador "Contradiction", verificava-se primeiro se o valor do atributo "Location" (atributo que representava o lugar onde aconteceu o atentado terrorista) era o mesmo nos dois templates; se for verdade que o valor de "Location" era igual, e algum dos outros atributos tinham valor diferente, então o operador "Contradiction" era aplicado e os templates eram combinados. Os autores não avaliaram o método, já que a proposta deles foi uma das primeiras e não existia outra proposta com a qual pudesse ser comparada.

Radev (2000), o autor da teoria CST, propôs um modelo de sumarização de 4 etapas. Na primeira etapa, era realizado o agrupamento de textos de conteúdo similar. Na segunda etapa, era realizada uma análise interna dos textos, levando em conta as sentenças, sintagmas ou palavras contidas no texto. Na terceira etapa, procedia-se ao estabelecimento das relações de CST. Por último, na quarta etapa, extraia-se o sumário final. O autor sugeriu a criação de operadores ativados por preferências de sumarização do usuário, que percorressem o grafo formado pelos documentos e suas relações, e selecionassem os segmentos textuais que estejam ligados às relações de preferência do usuário. Exemplos de preferências sugeridas pelo autor eram: preferência sobre "contradição", que reportava as contradições encontradas nos documentos e suas respectivas fontes, ou preferência sobre "informações de contexto" de um evento, entre outras. O autor apenas fez a proposta de sumarização, mas não avaliou o método.

Zhang et al. (2002) propuseram o enriquecimento de sumários multidocumento produzidos automaticamente, por meio do uso de relações CST. A metodologia apresentada pelos autores consistia em identificar sentenças do sumário que tivessem uma baixa pontuação (pontuação era determinada por qualquer método de sumarização que tenha sido utilizado, por exemplo, o método do sistema MEAD), aumentar a sua pontuação de acordo com o número de relações CST, e, finalmente, re-ranquear as sentenças de acordo com a nova pontuação. Os autores executaram alguns experimentos e demonstraram que os sumários cujas sentenças eram mais relacionadas (pelas relações CST) ajudaram a incrementar a informatividade do sumário final. O método de avaliação utilizado foi humano, sendo que os juízes deviam atribuir um valor de utilidade às sentenças do sumário 
de acordo com o critério proposto em Radev et al. (2000). A ponderação final dos valores atribuídos pelos juízes era um valor entre 0 e 1 , sendo que os valores mais próximos de 1 denotam maior utilidade na informação do sumário. De acordo com os resultados, os sumários resultantes após a aplicação de CST obtiveram um valor de utilidade de 0.293 para uma taxa de compressão de $20 \%$. Por outro lado, os sumários produzidos sem aplicar CST obtiveram um valor de utilidade de 0.287 , ligeiramente menor. Os autores também observaram que as inclusões de sentenças relacionadas por diferentes relações CST afetavam de formas diversas a qualidade do sumário, sendo que algumas relações melhoraram (por exemplo, as relações Equivalence e Subsumption) e outras pioraram a qualidade do sumário (por exemplo, as relações Historical background e Description).

Jorge e Pardo $(2009,2010)$ propuseram um sistema de sumarização multidocumento com base no modelo CST, chamado CSTSumm. Os autores modelaram o conjunto de documentos de entrada como um grafo, em que os nós eram as sentenças dos textos e as arestas representavam as relações CST entre as sentenças. Definiu-se um conjunto de operadores de seleção de conteúdo que representavam possíveis preferências de sumarização, tais como preferências de autoria, de informações de contexto, de informações contraditórias ou simplesmente informações gerais. No método proposto pelos autores, um ranque inicial de sentenças era construído a partir das informações contidas no grafo, sendo que as sentenças com maior número de conexões eram as que ficavam mais bem pontuadas no ranque. A partir desse ranque, a função dos operadores consistia em re-ranquear algumas sentenças em função da preferência especificada. Por exemplo, dada a preferência de informação de contexto, as sentenças que forneciam informações de contexto ou complementarias a informação principal subiam posições no ranque. Após o re ranqueamento, as primeiras sentenças do ranque eram selecionadas para o sumário final de acordo com os limites da taxa de compressão. O modelo foi avaliado nos textos do córpus CSTNews e os resultados foram comparados com os resultados de sumarizadores como MEAD e GistSumm. Essa avaliação foi feita usando a medida ROUGE. Os resultados mostraram um bom desempenho em relação aos outros sumarizadores. Por exemplo, ao avaliar as diversas estratégias de seleção de conteúdo, obteve-se um valor de medida-f de $54 \%$. Os sistemas que não usaram CST obtiveram um valor de medida-d de $47 \%$.

Ribaldo et al. (2012) apresentaram vários métodos de seleção de conteúdo para sumários multidocumento, baseados em grafos. Os autores inspiraram-se em métodos de redes complexas, similares ao trabalho de Antiqueira et al.(2007) e, também, nos métodos de seleção de conteúdo baseados em grafos de Salton et al. (1999), que propuseram esses métodos para sumarização monodocumento. De acordo com a metodologia de Ribaldo et al., um grafo era construído a partir de todas as sentenças dos documentos de um conjunto, e as arestas eram construídas a partir da similaridade lexical entre as sentenças, dada pela medida de similaridade cosseno. Apenas os $1.5^{*} \mathrm{~N}$ melhores links eram mantidos (onde $\mathrm{N}$ é o número de nós), seguindo as diretrizes de Salton et al. Dos métodos sugeridos por Salton et al., os autores aplicaram dois, Bushy-Path e Depth-First Path. No Bushy-Path, selecionavase os nós com maior numero de links, até atingir uma taxa de compressão. No Depth-First Path, selecionava-se o primeiro nó de acordo com o critério de maior número de links. Em diante, selecionava-se um nó do conjunto de nós que estavam conectados com o nó 
selecionado anteriormente, e que estivesse localizado após ele no mesmo texto, também se considerava aquele que tinha mais links. Se o conjunto de sentenças não era do mesmo texto, então apenas olhava-se o grau do nó como critério de seleção. Para tratar a redundância, apenas foram selecionadas sentenças que não eram similares mais do que um limite (o limite era a media do maior e menor valor de similaridade cosseno do grafo). Os autores também propuseram uma variação do grafo mencionado anteriormente, em que também foram incluídas as relações CST das sentenças. Para isso foram adotadas duas estratégias: a primeira era simplesmente somar o número de relações CST aos links já estabelecidos a uma sentença sem olhar para o significado das relações, a segunda estratégia consistiu em atribuir scores para cada tipo de relação CST que ocorre em uma sentença, e somar esses valores ao numero de links já existentes. Nesse sentido, as relações de conteúdo levavam um score maior (0.5-1) do que outros tipos de relações. As sentenças eram selecionadas da mesma forma que na primeira metodologia em que apenas eram considerados os links com base na similaridade cosseno. Finalmente, os autores também aplicaram medidas de redes complexas sobre o grafo construído com links que representavam a similaridade cosseno. As métricas usadas foram: grau, coeficiente de agrupamento ou aglomeração e menor caminho. Com base nessas métricas, as sentenças foram ranqueadas e as melhor ranqueadas eram levadas ao sumário final. Os métodos desenvolvidos por Ribaldo et al. foram implementados usando o córpus CSTNews. Os métodos foram avaliados usando a medida Rouge e comparados com outros sumarizadores de textos em português, tais como CSTSumm, Mead e GistSumm. A medida de grau e Bushy-Path mostraram ter os melhores resultados com valores de Rouge-1 0.53 e 0.48 , respectivamente.

Camargo (2013) apresentou um estudo no qual se investigou sumários multidocumento humanos visando identificar as estratégias que os humanos usam para resumir um conjunto de textos. Para realizar esta investigação, Camargo tomou como base o córpus CSTNews e alinhou manualmente, em nível sentencial, os sumários multidocumento humanos com seus respectivos textos-fonte, isso com o objetivo de revelar de onde foram originadas as informações que compõem esses sumários. Nesses alinhamentos, e também nas sentenças não alinhadas, foram analisados os atributos recorrentes, os quais foram representados por informações superficiais, profundas e extralinguísticas. Os atributos superficiais foram: localização das sentenças, esse atributo podia assumir três valores: "inicio", "meio" e "fim", sendo que, "inicio" era a primeira sentença do texto, "fim" a ultima, e todas as outras sentenças eram "meio"; palavras chave, esse atributo indicava a soma das frequências das palavras mais importantes da coleção de textos numa sentença, sendo que, uma palavra era das mais importantes, se estava no conjunto dos $10 \%$ de palavras com maior frequência na coleção de textos; frequência, esse atributo indicava a soma das frequências das palavras que compunham a sentença, na coleção de textos; tamanho da sentença, esse atributo indicava o número de palavras da sentença. Enquanto aos atributos profundos, foram consideradas como atributos as categorias da CST: redundância, complementaridade, contradição e forma. Em particular, cada sentença foi caracterizada pelo número de relações de cada categoria. Todos os valores dos atributos foram normalizados. O atributo extralinguístico correspondia à fonte de onde foi extraída a 
informação, e destacava as fontes de informação mais usadas pelos humanos para selecionar a informação. Com base nesses atributos, foi realizada uma análise manual e um aprendizado de máquina para inferir regras a partir dos dados. De acordo com a análise manual, os humanos selecionavam mais as sentenças cuja localização era ao início do texto, e também, as sentenças que tinham redundância com outras sentenças dos textos-fonte, o que indicaria a importância dessa informação. Enquanto as regras aprendidas, essas foram testadas no mesmo CSTNews e também em um novo córpus de textos jornalísticos. No CSTNews obteve-se um valor de $71 \%$ de precisão e no novo córpus $70 \%$. As regras extraídas automaticamente confirmaram a análise manual.

Cardoso (2014) realizou uma investigação de métodos de SAM com base em conhecimento semântico-discursivo (dados pela RST e CST) e de tópicos. O objetivo de Cardoso era formalizar métodos que integrassem esses conhecimentos, a fim de que o sumário cobrisse a distribuição das informações mais relevantes ao longo de um conjunto de textos. No trabalho de Cardoso foram propostos 4 tipos/categorias de métodos de SAM: os baseados em informação discursiva monodocumento (RST), em informação de sub-tópicos, em informação discursiva mondocumento e semântico-discursiva multidocumento (RST e CST), e em informação monodocumento, multidocumento e de sub-tópicos. No primeiro grupo de métodos, identificaram-se as edu's mais importantes (ou seja, as mais nucleares) e atribuía-se uma nota a essas edu's, e a pontuação de uma sentença era a soma de essas notas. Com essa pontuação montou-se um ranque de sentenças, do qual progressivamente foram-se extraindo sentenças para compor o sumário final, sendo que, as que tinham similaridade alta (medida de cosseno) em relação àquelas que já foram inseridas no sumário eram puladas. Deve-se destacar que as sentenças não eram inseridas completas no sumário, pois os satélites das sentenças eram eliminados. Nesse primeiro grupo de métodos, desenvolveramse também duas variações: (i) a primeira variação implicava normalizar as notas das sentenças pela altura da sua árvore RST correspondente, e, (ii) na segunda variação eram eliminadas apenas as sentenças satélites. No segundo grupo de métodos, consideraram-se duas estratégias: sub-tópico denso e maior sub-tópico. No sub-tópico denso era selecionada uma sentença de cada sub-tópico do conjunto de textos, e, no maior sub-tópico recuperavam-se apenas as sentenças do sub-tópico com maior número de sentenças. No terceiro grupo de métodos, foram consideradas 4 variações. Primeiramente, as sentenças foram ranqueadas pelo número de relações CST, e, ao inserir progressivamente as sentenças no sumário, descartaram-se as que tivessem redundância com as outras sentenças já inseridas, sendo que a redundância era medida com base nas relações CST. As sentenças eram inseridas eliminando seus satélites. O segundo método era uma variação do primeiro, no qual, era dado um peso para as relações CST, e, a soma dos pesos era a nota da sentença. Outra variação implicava que as sentenças satélite formadas de uma única proposição deviam ser eliminadas. Na ultima variação desse grupo de métodos, a pontuação da sentença era dada pela nota CST e pela nota RST (como nos métodos do primeiro grupo). Finalmente, no quarto grupo de métodos apresentaram-se 4 variações também. No primeiro método, a nota da sentença era dada pela RST, CST, e, em cada sub-tópico as sentenças eram organizadas por essa nota para depois aplicar a estratégia de sub-tópico denso. Uma segunda variação desse método consistia em eliminar as sentenças de uma única proposição que 
fossem satélites. Na terceira e quarta variação, modificava-se a nota RST normalizando-a pela altura da árvore RST; na terceira variação eliminavam-se apenas as proposições satélite, enquanto na quarta variação eliminavam-se as sentenças de uma única proposição que sejam satélites. Os métodos propostos pela autora foram avaliados usando a medida Rouge, e comparados com os principais métodos de SAM para textos em português. Os resultados mostraram que a combinação de RST e CST gerava melhores sumários. Nesse grupo de métodos chegou a se obter um valor de medida-f de 0.44 na Rouge, superando muitos métodos de estado da arte para o português, como CSTSumm.

Além de todos os trabalhos apresentados nesta seção, destacam-se também os trabalhos que usam ontologias e outras informações profundas como Afantenos et al. (2004), Afantenos (2007), Barzilay e Mckeown (2005), Henning et al.(2008), entre outros.

Os trabalhos estudados nesta seção apresentam diversos métodos, os quais fornecem informação linguística tanto em nível monodocumento (RST) quanto em nível multidocumento (CST). As informações linguísticas fornecidas pelas duas teorias se mostram relevantes para seleção de atributos.

\subsection{Síntese de trabalhos presentados do capítulo}

Na Tabela 3, é mostrada uma síntese dos trabalhos apresentados neste capítulo. Na tabela são incluídos detalhes como: o nome do autor (es), ano de publicação, paradigma utilizado (gerativo, discriminativo ou nenhum), abordagem (superficial ou profunda), tipo de sumarização (mono ou multidocumento) e, métodos e informações utilizadas.

Tabela 3: Síntese de Trabalhos de Sumarização Automática

\begin{tabular}{|c|c|c|c|c|c|}
\hline Autor & Ano & Paradigma & Abordagem & Tipo & Métodos/Informações \\
\hline Ono et al. & 1994 & & Profunda & Monodocumento & RST \\
\hline Kupiec et al. & 1995 & Gerativo & Superficial & Monodocumento & $\begin{array}{c}\text { Naive-Bayes, posição } \\
\text { de palavras, etc. }\end{array}$ \\
\hline O'Donnell & 1997 & & Profunda & Monodocumento & RST \\
\hline $\begin{array}{l}\text { Carbonell e } \\
\text { Goldstein }\end{array}$ & 1998 & & Superficial & Monodocumento & $\begin{array}{c}\text { MMR, similaridade } \\
\text { lexical. }\end{array}$ \\
\hline $\begin{array}{c}\text { Mani e } \\
\text { Bloedorn }\end{array}$ & 1998 & Discriminativo & Superficial & Monodocumento & $\begin{array}{l}\text { Árvores de Decisão } \\
\text { (C 4.5), tf-idf, } \\
\text { posição de sentenças, } \\
\text { etc. }\end{array}$ \\
\hline Marcu & 1998 & & Profunda & Monodocumento & RST \\
\hline $\begin{array}{l}\text { Radev e } \\
\text { Mckeown }\end{array}$ & 1998 & & Profunda & Multidocumento & $\begin{array}{c}\text { Relações Semântico- } \\
\text { Discursivas }\end{array}$ \\
\hline $\begin{array}{c}\text { Witbrock e } \\
\text { Mittal } \\
\end{array}$ & 1999 & Gerativo & Superficial & Monodocumento & $\begin{array}{c}\text { Probabilidade de } \\
\text { ocorrência de tokens }\end{array}$ \\
\hline Radev & 2000 & & Profunda & Multidocumento & CST, Grafos \\
\hline Radev et al. & $\begin{array}{l}2000 \\
2001 \mathrm{a}\end{array}$ & & Superficial & $\begin{array}{l}\text { Monodocumento e } \\
\text { Multidocumento }\end{array}$ & $\begin{array}{c}t f-i d f, \text { medida de } \\
\text { similaridade coseno }\end{array}$ \\
\hline
\end{tabular}




\begin{tabular}{|c|c|c|c|c|c|}
\hline & $\begin{array}{l}2001 b, \\
2001 c\end{array}$ & & & & \\
\hline Zhang et al. & 2002 & & Profunda & Multidocumento & CST \\
\hline Knight e Marcu & 2002 & Gerativo & Profunda & Monodocumento & $\begin{array}{c}\text { Árvores Sintáticas, } \\
\text { Noisy-Channel. }\end{array}$ \\
\hline $\begin{array}{c}\text { Daumé III e } \\
\text { Marcu }\end{array}$ & 2001 & Gerativo & Profunda & Monodocumento & $\begin{array}{l}\text { Árvores Sintáticas, } \\
\text { Noisy-Channel, RST }\end{array}$ \\
\hline $\begin{array}{c}\text { Mihalcea e } \\
\text { Tarau }\end{array}$ & 2005 & & Superficial & Multidocumento & $\begin{array}{c}\text { Similaridade lexical, } \\
\text { Grafos. }\end{array}$ \\
\hline $\begin{array}{l}\text { Daumé III e } \\
\text { Marcu }\end{array}$ & 2006 & Gerativo & Superficial & Multidocumento & $\begin{array}{c}\text { Regra de Bayes, } \\
\text { probabilidade de } \\
\text { ocorrência de } \\
\text { palavras }\end{array}$ \\
\hline Wan e Yang & 2006 & & Superficial & Multidocumento & $\begin{array}{c}\text { Grafos, similaridade } \\
\text { coseno. }\end{array}$ \\
\hline $\begin{array}{l}\text { Schilder e } \\
\text { Kondadadi }\end{array}$ & 2008 & Discriminativo & Superficial & Multidocumento & $\begin{array}{l}\text { Freqüência de } \\
\text { palavras, SVM }\end{array}$ \\
\hline Wan & 2008 & & Superficial & Multidocumento & $\begin{array}{c}\text { Grafos, similaridade } \\
\text { coseno. }\end{array}$ \\
\hline $\begin{array}{l}\text { Haghighi e } \\
\text { Vanderwende }\end{array}$ & 2009 & & Superficial & Multidocumento & $\begin{array}{c}\text { Distribuição de n- } \\
\text { gramas e Modelagem } \\
\text { de Topicos }\end{array}$ \\
\hline Uzeda et al. & 2009 & & Profunda & Monodocumento & RST \\
\hline Wang et al. & 2009 & Gerativo & Superficial & Multidocumento & $\begin{array}{c}\text { Modelagem de } \\
\text { Tópicos }\end{array}$ \\
\hline Li et al. & 2011 & Gerativo & Superficial & Multidocumento & $\begin{array}{c}\text { Modelagem de } \\
\text { Tópicos }\end{array}$ \\
\hline Jorge e Pardo & 2010 & & Profunda & Multidocumento & CST, grafos \\
\hline Aker et al. & 2010 & Discriminativo & Superficial & Multidocumento & $\begin{array}{c}\text { Posição, Frequência, } \\
\text { similaridade, MERT, } \\
\text { A* }\end{array}$ \\
\hline Aker et al. & 2012 & Discriminativo & Superficial & Multidocumento & $\begin{array}{c}\text { Posição, Frequência, } \\
\text { similaridade, MERT, } \\
\text { A }^{*}\end{array}$ \\
\hline Ribaldo et al. & 2012 & & $\begin{array}{c}\text { Superficial/Pro } \\
\text { funda }\end{array}$ & Multidocumento & CST,grafos \\
\hline Camargo & 2013 & & $\begin{array}{l}\text { Superficial/Pro } \\
\text { funda } \\
\end{array}$ & & $\begin{array}{l}\text { Frequência, palavras- } \\
\text { chave, posição, RST }\end{array}$ \\
\hline Li e Sujian & 2013 & Gerativo & Superficial & Multidocumento & $\begin{array}{c}\text { Modelagem de } \\
\text { Tópicos } \\
\end{array}$ \\
\hline Cardoso & 2014 & & Profunda & Multidocumento & CST,RST,Subtópicos \\
\hline
\end{tabular}




\section{Capítulo}

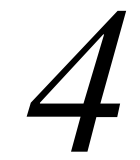

\section{Anotação de Córpus}

O córpus CSTNews é um dos principais recursos usados para pesquisa em SAM de textos em português. Esse córpus consiste em um conjunto de 50 grupos (também chamados clusters) de textos jornalísticos, sendo que os textos em cada grupo versam sobre um mesmo assunto. Esses textos foram extraídos dos principais jornais do Brasil como: Folha de São Paulo, Estadão, O Globo, Jornal do Brasil e Gazeta do Povo. Os grupos do córpus estão distribuídos em seis categorias: Mundo, Economia, Esportes, Ciência, Política e Cotidiano. A distribuição de clusters por cada categoria é mostrada na Tabela 4.

Tabela 4: Distribuição dos Clusters por categorias do córpus CSTNews

\begin{tabular}{|c|c|c|}
\hline Categoria & $\begin{array}{c}\text { \% de Clusters } \\
\text { por Categoria }\end{array}$ & $\begin{array}{c}\text { Nro. de Clusters } \\
\text { por categoria }\end{array}$ \\
\hline Mundo & 28 & 14 \\
\hline Economia & 2 & 1 \\
\hline Esportes & 20 & 10 \\
\hline Ciência & 2 & 1 \\
\hline Política & 22 & 11 \\
\hline Cotidiano & 26 & 13 \\
\hline
\end{tabular}

No total, o córpus contém 140 textos, 2,088 sentenças e 47,240 palavras, isso é, em media, 2.8 textos, 41.76 sentenças e 944.8 palavras por cluster.

O córpus é bastante rico, pois contém vários recursos úteis para a tarefa de SA. Para cada grupo de textos, estão associadas às anotações de acordo com a teoria CST e, também, para cada texto do córpus, estão associadas às anotações de acordo com a teoria RST. As anotações dos textos foram realizadas em duas etapas. Na primeira etapa, foi realizada a anotação CST e, na segunda etapa, foi realizada a anotação RST. Nas seguintes subseções, serão detalhadas as anotações CST e RST, respectivamente. 


\subsection{CSTNews: Anotação CST}

A anotação CST foi realizada no ano 2009, como parte do trabalho de mestrado que precede a este trabalho. A anotação foi realizada por uma equipe de 4 pessoas da área de Linguística Computacional. A tarefa de anotação foi realizada em duas etapas: o treinamento e a anotação de fato. A etapa de treinamento durou aproximadamente três meses, período em que os anotadores estudaram a teoria e experimentaram a anotação de alguns textos não pertencentes ao córpus. Durante essa etapa, surgiram discussões que resultaram em um refinamento das relações da teoria. Esse refinamento consistiu na eliminação de algumas relações da teoria original e a junção de outras. A decisão da eliminação de algumas relações (p.ex., Reader Profile, Change of Perspective) foi tomada sobre a hipótese de que essas relações não iriam acontecer no córpus. A decisão de junção de algumas relações (p.ex. Elaboration, Description e Refinement) foi tomada sobre a hipótese de que algumas das relações tinham definições muito similares, o que foi percebido pelos anotadores. No total, foram mantidas 14 relações da teoria CST, as quais foram classificadas em uma tipologia Maziero et al. (2010), que também resultou do processo de treinamento. Na Figura 12, é mostrada a classificação das 14 relações de acordo com essa tipologia.

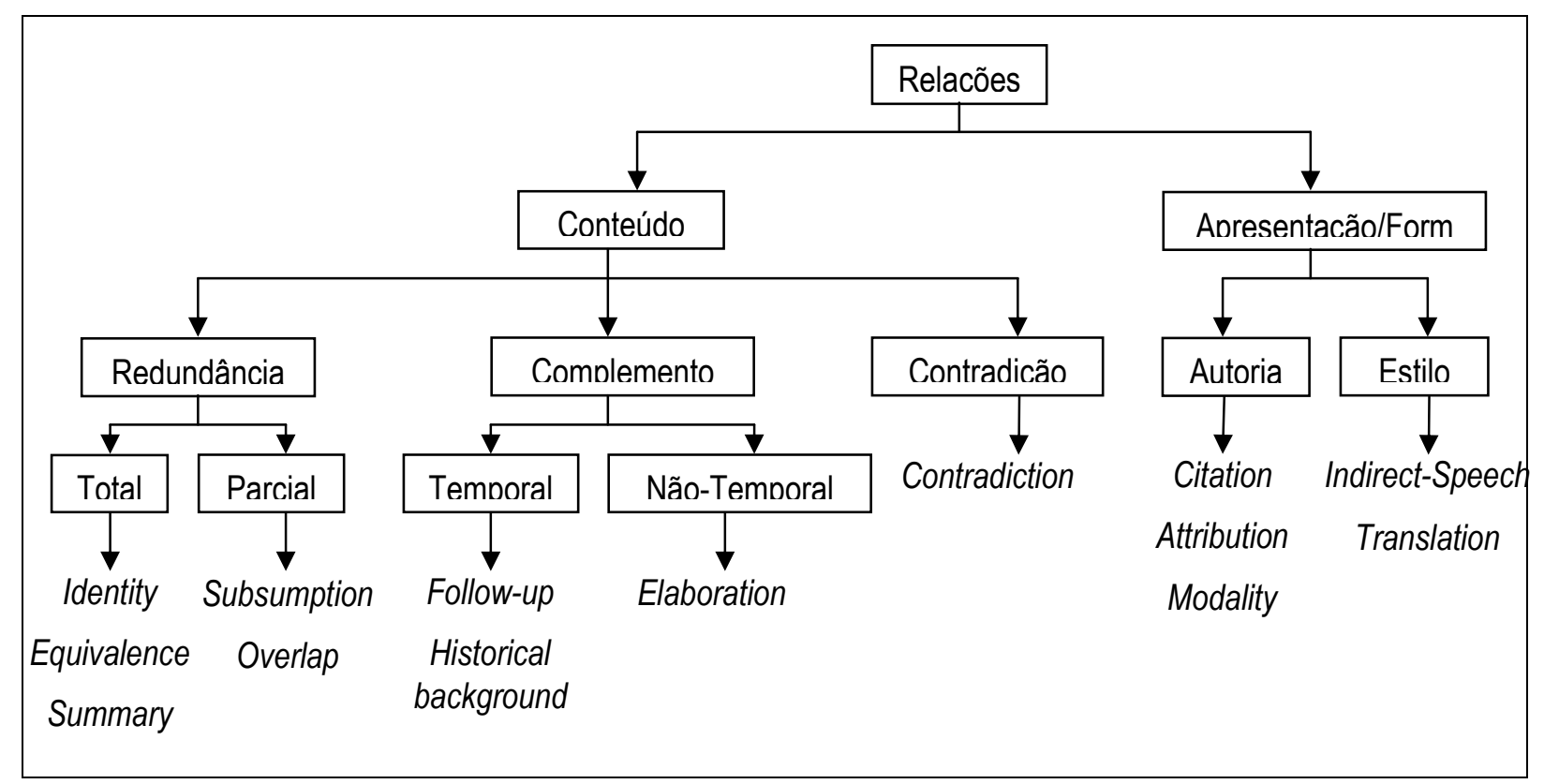

Figura 12: Tipologia de relações CST proposta por Maziero et al.(2010)

Pode-se observar que, no primeiro nível, a tipologia tem duas subdivisões principais: relações de conteúdo e relações de apresentação/forma. Na categoria de conteúdo, estão as relações que expressam similaridade, contradição ou complementaridade entre as informações textuais, ou seja, relações que, de fato, referem-se ao conteúdo dos segmentos relacionados. Essa categoria se divide, por sua vez, em três subcategorias: redundância, complemento e contradição. Na subcategoria redundância, incluem-se as relações que 
expressam similaridade parcial ou total das informações. Por exemplo, as relações Identity, Equivalence e Summary expressam similaridade total entre segmentos, já que as informações podem ser idênticas ou equivalentes; as relações Overlap e Subsumption indicam certa similaridade entre as informações, já que pode haver informações diferentes nos segmentos que estão sendo relacionados. Na subcategoria complemento, incluem-se todas as relações que elaboram as informações principais, quer seja com informações históricas, fatos que dão continuidade a um evento, ou com informação contextual. As relações que indicam informações históricas e de fatos que dão continuidade a um evento (Historical background e Follow-up) são consideradas temporais, enquanto as relações que indicam contexto de um fato (atual, em geral) são consideradas não temporais. A última subcategoria da categoria conteúdo é Contradição, em que está a relação Contradiction, que indica informações contraditórias entre dois segmentos.

A segunda categoria no primeiro nível da tipologia é Apresentação/Forma, na qual são incluídas todas as relações que lidam com aspectos secundários da informação, como a atribuição de uma informação a determinado autor ou fonte (Attribution, Citation), o estilo de escrita e o posicionamento do autor do texto (Indirect Speech, Modality) e a língua utilizada (Translation).

É importante dizer que, de acordo com essa tipologia, mais de uma relação pode ser estabelecida entre um mesmo par de unidades informativas, se e somente se, as relações pertencerem a diferentes categorias. Por exemplo, a relação Attribution pode ocorrer com qualquer relação que pertence à categoria conteúdo: Subsumption, Overlap, etc. O que não pode ocorrer é que, mais de uma relação de uma mesma categoria seja estabelecida para um mesmo par de unidades informativas. Tal decisão ajuda a evitar a ambigüidade e a controlar, na medida do possível, a subjetividade envolvida na anotação textual.

Além do refinamento e da classificação das relações, as definições das relações foram formalizadas. Essa definição é dada com base em dois atributos principais: direcionalidade e restrições. Dado um par de sentenças, S1 e S2, a direcionalidade pode ser nula (S1-S2), à esquerda $(\mathrm{S} 1 \leftarrow \mathrm{S} 2)$ ou à direita $(\mathrm{S} 1 \rightarrow \mathrm{S} 2)$. As restrições especificam as situações em que se deve estabelecer a relação indicada. A seguir é mostrado um exemplo de definição de relação CST. Além da direcionalidade e das restrições, também é incluído um exemplo que ajuda a entender melhor a definição em cada caso. A definição de todas as relações consideradas neste trabalho é mostrada no Apêndice A.

Quadro 1: Definição formal da relação Overlap

\begin{tabular}{|l|}
\hline Nome da Relação: Overlap \\
\hline Direcionalidade: Nula \\
\hline $\begin{array}{l}\text { Restrições: } \mathrm{S} 1 \text { e S2 apresentam informações em comum e ambas apresentam } \\
\text { informações adicionais distintas entre si. }\end{array}$ \\
\hline Comentários: $\mathrm{S} 1$ contém as informações X e Y,e, S2 contém as informações X e Z. \\
\hline
\end{tabular}

Exemplo de relação Overlap entre duas sentenças: 
S1. Um terremoto de 6.8 graus na escala Richter, com epicentro a 17 quilômetros de profundidade, atingiu a costa noroeste do Japão às 10h13m desta segunda-feira ( 22h13m de domingo em Brasília).

S2. Um forte terremoto matou ao menos cinco pessoas no noroeste do Japão nesta segunda-feira.

No exemplo, as sentenças S1 e S2 apresentam informação em comum sobre um terremoto no Japão, mas a sentença S1 apresenta informações particulares sobre a magnitude, lugar de origem e horário de acontecimento do terremoto; a sentença S2 apresenta informações particulares do número de mortos.

Para a anotação do córpus, foi utilizada a ferramenta CSTTool (Aleixo e Pardo, 2008). A CSTTool é uma ferramenta semiautomática para a anotação de múltiplos textos de acordo com a teoria CST. Com essa ferramenta, é possível realizar duas tarefas: a segmentação e a anotação de fato. A tarefa de segmentação é realizada automaticamente pela ferramenta, a qual, pela sua vez, utiliza o sistema de segmentação SENTER (Pardo, 2006), para segmentar os textos em sentenças. Após a segmentação dos textos, a ferramenta determina automaticamente as sentenças candidatas a serem relacionadas pela CST. Para determinar quais são as sentenças que têm maior chance de se relacionar via CST, a CSTTool calcula a similaridade lexical das sentenças por meio da medida Word Overlap, indicada na equação (34) a seguir.

$$
\text { word_overl ap }\left(S_{1}, S_{2}\right)=\frac{\text { nro. de palavras em comum entre } S_{1} \text { e } S_{2}}{\text { nro. de palavras em } S_{1}+\text { nro. de palavras em } S_{2}}
$$

O resultado dessa equação é um valor entre 0 e 1, sendo que valores mais próximos de zero indicam sentenças com menos palavras em comum, e valores mais próximos de 1 indicam maior número de palavras em comum. Para selecionar os pares de sentenças candidatas, estabelece-se um valor threshold, que indica o valor mínimo de word-overlap para considerar as sentenças de um par devam ser conectadas por uma relação CST. Para anotação do córpus CSTNews, o valor de threshold estabelecido foi 0.12 , assim como foi estabelecido por Zhang e Radev (2002). É importante destacar que, apesar da ferramenta CSTTool selecionar automaticamente os pares de sentenças candidatas, isso não impede ao anotador adicionar mais pares ou mudar outros de acordo com o seu critério.

Após a anotação dos textos foram extraídas as freqüências com as quais as relações CST ocorreram no córpus. Isso é mostrado na Tabela 5, a seguir.

Tabela 5: Frequência das relações CST no córpus CSTNews

\begin{tabular}{|c|c|}
\hline Relação & Frequência \\
\hline Overlap & 467 \\
\hline
\end{tabular}




\begin{tabular}{|c|c|}
\hline Elaboration & 343 \\
\hline Follow-up & 293 \\
\hline Subsumption & 207 \\
\hline Identity & 85 \\
\hline Historical background & 77 \\
\hline Attribution & 69 \\
\hline Contradiction & 46 \\
\hline Equivalence & 39 \\
\hline Indirect Speech & 18 \\
\hline Summary & 4 \\
\hline Translation & 2 \\
\hline Modality & 1 \\
\hline Citation & 0 \\
\hline
\end{tabular}

Essas frequências mostram que as relações mais observadas no córpus são aquelas que representam redundância, complementaridade e contradição entre as informações dos textos, ou seja, aquelas que modelam os principais fenômenos multidocumento.

Para a anotação, foi avaliada a concordância entre os anotadores usando a medida kappa (Carletta, 1996), que é uma medida estatística que mede o nível de concordância, excluindo a concordância do acaso. Foi calculada a medida kappa de três parâmetros: as relações, a direcionalidade e as relações agrupadas (isto é, relações que pertencem a uma mesma categoria de acordo com a tipologia de Maziero et al. (2010)). Na Tabela 6, são mostrados os resultados da medida kappa, os quais são valores entre 0 e 1 , sendo que, valores mais próximos de 1 indicam maior nível de concordância, e os valores mais próximos de zero indicam baixo nível de concordância.

Tabela 6: Medida kappa da anotação CST no córpus CSTNews

\begin{tabular}{|c|c|}
\hline $\begin{array}{c}\text { Parâmetros de } \\
\text { concordância }\end{array}$ & Valor Kappa \\
\hline Relações & 0.50 \\
\hline Direcionalidade & 0.44 \\
\hline Relações agrupadas & 0.61 \\
\hline
\end{tabular}

Além da medida kappa, também foi utilizada uma medida de porcentagem para avaliar a concordância. Com essa medida foram avaliados três tipos de concordância: a concordância total (isto é, todos os anotadores indicavam a mesma relação, direcionalidade ou relações 
agrupadas), concordância parcial (isto é, a maioria dos anotadores indicavam a mesma relação, direcionalidade ou relações agrupadas) e concordância nula (isto é, nenhum dos anotadores indicava a mesma relação, direcionalidade ou relações agrupadas). Na Tabela 7 , mostra-se a medida de porcentagem de concordância no córpus CSTNews.

Tabela 7: Porcentagem de concordância no córpus CSTNews

\begin{tabular}{|c|c|c|c|}
\hline $\begin{array}{c}\text { Parâmetros de } \\
\text { concordância }\end{array}$ & $\begin{array}{c}\text { Concordância } \\
\text { Total }\end{array}$ & $\begin{array}{c}\text { Concordância } \\
\text { Parcial }\end{array}$ & $\begin{array}{c}\text { Concordância } \\
\text { Nula }\end{array}$ \\
\hline Relações & 54 & 27 & 18 \\
\hline Direcionalidade & 58 & 27 & 14 \\
\hline Relações agrupadas & 70 & 21 & 9 \\
\hline
\end{tabular}

Esses resultados mostraram que há $81 \%$ de concordância parcial ou total para as relações, $85 \%$ de concordância parcial ou total para a direcionalidade e um $91 \%$ de concordância parcial ou total para as relações agrupadas. Esses resultados se mostram melhores que os resultados obtidos por Zhang et al. (2002), que obtiveram apenas 58\% de concordância parcial ou total das relações, para textos anotados na língua inglesa.

\subsection{CSTNews: anotação RST}

A anotação RST foi realizada no ano 2011, no escopo deste trabalho de doutorado. A anotação RST foi realizada por 8 anotadores, sendo que 4 deles tinham um conhecimento mais profundo da teoria RST e mais experiência na anotação. A tarefa de anotação foi realizada em duas etapas: treinamento e anotação de fato. Na etapa de treinamento, foi realizado um estudo profundo da teoria RST, tendo como base o relato técnico de Mann e Thompson (1987) e o manual de Carlson e Marcu (2001). Durante a etapa de treinamento, foram estudadas as regras de segmentação de Carlson e Marcu, e também foram adaptadas algumas delas para o Português. Inicialmente, as regras de Carlson e Marcu foram projetadas para a língua inglesa. No entanto, na tentativa de adaptar essas regras, observouse que algumas delas não se adequavam ao Português do Brasil. Por esse motivo, algumas regras foram adaptadas. Em particular, determinou-se que todas as orações relativas deveriam ser segmentadas, e não apenas as não restritivas. O motivo dessa nova regra foi a dificuldade de distinguir as orações restritivas das não restritivas para textos em português. Também foi determinado que os complementos de verbos atributivos deveriam ser segmentados somente se o sujeito correspondente fosse animado (p.ex. pessoas, instituições ou grupos de pessoas). Discursos internos também deveriam ser segmentados, se algumas das outras regras de segmentação fossem aplicáveis. Por exemplo, um discurso entre aspas pode ser segmentado se alguma regra é aplicável. Também devem ser segmentadas todas as orações que tivessem verbo elíptico ou sujeito implícito. Além disso, foram estabelecidos alguns marcadores fortes para o Português, já que os marcadores fortes também indicam segmentação. Em particular, alguns dos marcadores fortes considerados para a anotação do 
córpus CSTNews foram: "porque", "por meio de", "além de", "após", "apesar de", "durante", "mas", entre outros.

As regras de segmentação utilizadas para a anotação do córpus CSTNews são listadas na Tabela 8. O símbolo “"” é utilizado para indicar o ponto em que ocorre a segmentação.

Tabela 8: Regras de Segmentação para anotação RST

\begin{tabular}{|c|c|c|}
\hline \#Regra & Descrição da Regra & Exemplo \\
\hline 1 & $\begin{array}{l}\text { Segmentam-se as sentenças que } \\
\text { terminam em: ".", “!" ou "?”. }\end{array}$ & A menina foi para a escola. \\
\hline 2 & $\begin{array}{l}\text { Segmentam-se orações com verbo } \\
\text { explícito ou orações sem verbo } \\
\text { explícito, mas com marcador forte } \\
\text { (p.ex., mas, apesar de, etc.). }\end{array}$ & $\begin{array}{l}\text { O aluno foi bem em } \\
\text { matemática,| mas reprovou } \\
\text { física.| }\end{array}$ \\
\hline 3 & $\begin{array}{l}\text { Não se segmentam complementos de } \\
\text { verbo ou sujeito. }\end{array}$ & $\begin{array}{l}\text { É muito raro alguém perder } \\
\text { o jogo e arrancar a } \\
\text { classificação no campo do } \\
\text { adversário. }\end{array}$ \\
\hline 4 & $\begin{array}{l}\text { Segmentam-se orações conjuntas onde } \\
\text { o sujeito está implícito ou o verbo é } \\
\text { elíptico. }\end{array}$ & $\begin{array}{l}\text { Maria lavou a roupal e a } \\
\text { louça.| }\end{array}$ \\
\hline 5 & $\begin{array}{l}\text { Segmentam-se orações em particípio } \\
\text { se estiver bem delimitado (p.ex., por } \\
\text { meio do uso da vírgula). }\end{array}$ & $\begin{array}{l}\text { Terminada a tarefa, } \mid \text { João } \\
\text { voltou para casa. }\end{array}$ \\
\hline 6 & $\begin{array}{l}\text { Segmentam-se orações relativas tanto } \\
\text { restritivas quanto explicativas. }\end{array}$ & $\begin{array}{l}\text { A menina dos olhos azuis } \\
\text { que ganhou o premio, mora } \\
\text { em São Paulo. }\end{array}$ \\
\hline 7 & $\begin{array}{l}\text { Segmentam-se orações com verbos } \\
\text { atributivos (p.ex., disse que, anunciou, } \\
\text { explicou que) e que tenham sujeito } \\
\text { animado (e.g. instituições, pessoas, } \\
\text { etc.). }\end{array}$ & $\begin{array}{l}\text { A presidenta disse que } \mid \text { criará } \\
\text { programas de inversão } \\
\text { estrangeira.| }\end{array}$ \\
\hline 8 & $\begin{array}{l}\text { Segmentam-se quaisquer trechos de } \\
\text { texto que sejam informação contida } \\
\text { entre parênteses. }\end{array}$ & $\begin{array}{l}\text { Seja qual for a escolha dela| } \\
\text { (da Maria) } \mid \text { será boa. }\end{array}$ \\
\hline 9 & $\begin{array}{l}\text { Segmentam-se todas as orações que } \\
\text { estiverem dentro de aspas ou qualquer } \\
\text { outra forma de citação, utilizando }\end{array}$ & $\begin{array}{l}\text { "Torço pelo Rodrigo, } \text { que } \\
\text { é meu amigo,| mas todos }\end{array}$ \\
\hline
\end{tabular}




\begin{tabular}{|l|l|l|}
\hline & $\begin{array}{l}\text { qualquer uma das regras acima, se for } \\
\text { o caso. }\end{array}$ & são merecedores." $\mid$ \\
\hline
\end{tabular}

Após uma semana de estudo e treinamento das regras de segmentação, incorporou-se ao treinamento a tarefa de anotação das relações RST. Tanto para a segmentação quanto para a anotação das relações RST, foi utilizada a ferramenta RSTTool (O'Donnell, 2000), que possui um ambiente gráfico que permite segmentar e anotar os segmentos de acordo com a teoria RST.

Após duas semanas de treinamento, começou a etapa de anotação dos textos do córpus CSTNews. Essa etapa durou aproximadamente dois meses, durante os quais, a anotação foi realizada por períodos de 5 dias semanais. A cada dia, um texto era anotado por um grupo de 2 ou 3 pessoas. No total, cada dia eram 3 ou 4 grupos que anotavam textos diferentes. Todos os dias os grupos eram reorganizados para evitar possíveis tendências. A cada 10 textos anotados, todos os grupos trabalhavam no mesmo texto, com o objetivo de calcular a concordância na segmentação e na anotação.

A tarefa foi realizada incrementalmente, ou seja, primeiro eram anotados os segmentos dentro das sentenças, logo as sentenças adjacentes dentro de um parágrafo, e finalmente, os parágrafos adjacentes. Esse padrão de anotação nem sempre foi possível, já que, dependendo do discurso, essa forma de anotação nem sempre era aplicável.

A concordância foi calculada usando a ferramenta RSTeval (Maziero e Pardo, 2009) . A metodologia usada por essa ferramenta baseia-se na comparação de duas ou mais árvores retóricas para um mesmo texto. Para essa comparação, uma das árvores correspondentes ao texto é selecionada como "ideal" e as outras árvores são comparadas com ela, em cada um dos seguintes elementos:

- segmentos textuais simples;

- segmentos textuais mais complexos (p.ex., dois ou mais segmentos ligados por uma mesma relação);

- núclearidade de cada segmento;

- relação RST entre segmentos.

As medidas Precisão, Cobertura e Medida-F são calculadas para cada um dos elementos listados acima, em cada uma das árvores RST e, desse modo, determina-se quão similares são as árvores entre si. A medida de Precisão indica o número de elementos corretos (C) de uma árvore $\mathrm{T}$ (em comparação com a árvore "ideal"), dividido pelo número total de elementos da árvore T. A medida de cobertura indica o número de elementos corretos (C) da árvore T, dividido pelo número de elementos da árvore "ideal" I. A Medida-F representa a média harmônica entre Precisão e Cobertura. Estas medidas são expressas nas equações a seguir: 


$$
\begin{gathered}
\text { Precisão }=\frac{\mathrm{C}}{|\mathrm{T}|} \\
\text { Cobertura }=\frac{\mathrm{C}}{|\mathrm{I}|} \\
\text { Medida }-\mathrm{F}=\frac{2 \times \text { Precisão } \times \text { Cobertura }}{\text { Precisão }+ \text { Cobertura }}
\end{gathered}
$$

Na Tabela 9, mostra-se a concordância obtida na anotação RST do córpus CSTNews, usando as medidas descritas acima.

Tabela 9: Concordância na anotação RST

\begin{tabular}{|c|c|c|c|}
\hline Elemento avaliado & Precisão & Cobertura & Medida-F \\
\hline Segmento Simple & 0.91 & 0.91 & 0.91 \\
\hline Segmento Complexo & 0.78 & 0.78 & 0.78 \\
\hline Núcleo & 0.78 & 0.78 & 0.78 \\
\hline Relação RST & 0.66 & 0.66 & 0.66 \\
\hline
\end{tabular}

De acordo com esses resultados, a concordância mais alta é atingida pela tarefa de segmentação, na qual foi obtido um valor $91 \%$ de Precisão, Cobertura e Medida-F. Por outro lado, a concordância nas relações entre segmentos foi mais baixa, obtendo apenas $66 \%$ de concordância. Dada a subjetvidade da tarefa, os resultados são considerados satisfatórios. 


\section{Aprendizado Gerativo para Sumarização Multidocumento}

A história gerativa da criação de um sumário multidocumento é representada usando o modelo Noisy-Channel, que esquematiza a Regra de Bayes (38). Noisy-Channel tem sido amplamente usado na modelagem gerativa de outras áreas importantes do Processamento de Linguagem Natural.

De acordo com esse esquema (mostrado na Figura 13), inicialmente assume-se que a fonte produz um sumário multidocumento, que é modelado por $\mathrm{P}(\mathrm{S})$. Após o sumário ter sido produzido pela fonte, este passa pelo canal ruidoso (Noisy-channel), em que algum tipo de ruído é introduzido, produzindo um conjunto maior de textos. O modelo do canal é representado pela probabilidade condicional $\mathrm{P}(\mathrm{C} \mid \mathrm{S})$, que é a probabilidade de um grupo de textos serem gerados a partir de um sumário multidocumento. $\mathrm{Na}$ arquitetura geral do processo de sumarização descrita por Mani (2001), o canal ruidoso representaria a etapa de transformação, em que a seleção de conteúdo ocorre; desse modo, $\mathrm{P}(\mathrm{C} \mid \mathrm{S})$ modela os padrões de seleção de conteúdo via diversos atributos que representam os fatores que influenciam o processo de sumarização. Em particular, neste trabalho, a modelagem gerativa é realizada em nível sentencial, o seja, todos os atributos que compõem o modelo são formulados para descrever as sentenças do córpus. Essa característica será descrita em mais detalhe nas seguintes seções. Daqui em diante o modelo que descreve o Canal Ruidoso é chamado Modelo de Transformação. $\mathrm{P}(\mathrm{S})$, que é a probabilidade do sumário, descreve o modelo que captura padrões da boa construção de um sumário multidocumento em termos de coerência.

Finalmente, na etapa de decodificação, que é representada por $\mathrm{P}(\mathrm{S} \mid \mathrm{C})$, faz-se a busca pelo melhor sumário de acordo com $\mathrm{P}(\mathrm{C} \mid \mathrm{S})$ e $\mathrm{P}(\mathrm{S})$, o seja, pelo sumário com maior probabilidade de acordo com os modelos $\mathrm{P}(\mathrm{C} \mid \mathrm{S})$ e $\mathrm{P}(\mathrm{S})$, os quais são inferidos a partir de um córpus de textos-fonte e seus correspondentes extratos humanos multidocumento. $\mathrm{O}$ processo de decodificação é descrito por um algoritmo de busca, o qual tem como objetivo identificar a combinação de sentenças que gere o sumário com maior probabilidade. $\mathrm{O}$ modelo de decodificação desenvolvido neste trabalho é baseado no algoritmo de busca $\mathrm{A}^{*}, \mathrm{e}$ será descrito em mais detalhes em seções posteriores. 


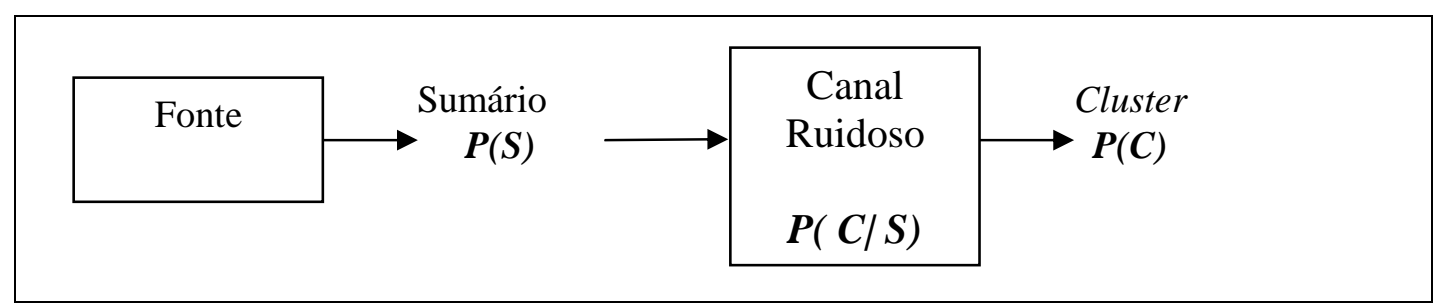

Figura 13: Esquema Noisy-Channel para modelagem gerativa de Sumarização Multidocumento

$$
P(S \mid C)=\frac{P(C \mid S) \times P(S)}{P(C)}
$$

Pode-se formalizar o processo gerativo da SAM como descrito a seguir:

- Um sumário é o conjunto de sentenças $\mathrm{SS}=\left\{\mathrm{SS}_{1}, \ldots, \mathrm{SS}_{\mathrm{n}}\right\}$

- O grupo de textos ou Cluster é o conjunto de todas as sentenças dos textos originais $\mathrm{CC}=\left\{\mathrm{CS}_{1}, \ldots, \mathrm{Cs}_{\mathrm{m}}\right\}$

- Existe um conjunto de fatores que influenciam a expansão das sentenças $F=\left\{F_{1}\right.$, $\left.\ldots, \mathrm{F}_{\mathrm{z}}\right\}$

Com esses critérios iniciais, o algoritmo que formaliza a história gerativa de qualquer modelo de transformação é como mostrado a seguir:

Para cada sentença $\mathbf{S S}_{\mathbf{i}}$ do sumário

Para cada Atributo do Modelo de Transformação

Se Atributo aplica a $\mathbf{S S}_{\mathrm{i}}$ então

Criam-se $\mathbf{N}$ sentenças para $\mathbf{S S}_{\mathbf{i}}$ que representem a Atributo

Incluem-se as $\mathbf{N}$ sentenças no conjunto $\mathbf{C S}$

Neste Capítulo, são apresentados os modelos desenvolvidos para cada componente do Noisy-Channel. Na primeira seção, são descritos os modelos de transformação; na segunda seção, é descrito o modelo de coerência para sumários multidocumento e, finalmente, é descrito o algoritmo de decodificação.

\subsection{Modelos de Transformação}

$\mathrm{Na}$ modelagem gerativa desenvolvida neste trabalho, entende-se o Modelo de Transformação como o modelo probabilístico que, por meio da combinação de atributos profundos e superficiais, captura os principais padrões de seleção de sentenças que comporão um sumário multidocumento. Ao longo dos anos de pesquisa na área de SA, tem se estudado vários atributos presentes no processo de sumarização, desde os mais simples, como a contagem básica de frequência de palavras, até informações mais complexas, que envolve semântica e discurso. Cada um desses atributos permite abordar, de ângulos 
diferentes, o problema da identificação de informação relevante em um conjunto de textos. Por esse motivo, no presente trabalho, desenvolveram-se três Modelos de Transformação que abordam os atributos mais simples e os mais complexos, de forma incremental. Em outras palavras, em cada modelo, incrementa-se a complexidade e profundidade dos atributos a fim de integrar, em um último modelo (Modelo 3), atributos de diferente natureza que identificam de forma diferente as informações relevantes. A seguir, são descritos os modelos de transformação 1,2 e 3 :

\subsubsection{Modelo de Transformação1}

No primeiro modelo gerativo são explorados atributos superficiais, tais como posição das sentenças, frequência de palavras e similaridade lexical entre sentenças. O objetivo desse modelo é formular a probabilidade de uma sentença de sumário ter sido gerada com base em certos atributos superficiais nos textos-fonte. Tem-se mostrado ao longo de várias pesquisas (Luhn, 1958; Baxendale, 1958; Edmunson, 1969; Sparck Jones, 1972; Kupiec et al., 1995; Radev et al., 2004; Nenkova, 2005; Schilder e Kondadadi, 2008; Ouyang et al.2010), que, por meio desses atributos simples, é possível descobrir informação relevante em um conjunto de textos. Recentemente, a pesquisa sobre caracterização de sumários multidocumento realizada por Camargo (2013) para a língua portuguesa, mostrou que atributos superficiais tais como palavras-chave ou palavras mais frequentes e a posição das sentenças nos textos-fonte se correlacionam fortemente com a decisão de incluir uma sentença dos textos originais no sumário final.

Seguindo as hipóteses de que a frequência de palavras em um conjunto de textos e a posição de sentenças em textos jornalísticos são indicadores de informações relevantes, esses atributos são considerados no Modelo de Transformação 1 como descrito a seguir:

- Palavras mais frequentes ou Top-Words. São as palavras de conteúdo mais frequentes em um conjunto de textos. As palavras únicas dos textos originais são ranqueadas com base na sua respectiva frequência na coleção de textos. Desse ranque, apenas um subconjunto de palavras (as mais bem ranqueadas) é considerado palavras-chave ou palavras-top, sendo que, neste trabalho, foi considerado que, as palavras-top seriam as que pertencem ao topo do ranque (10\% do tamanho do ranque), seguindo o critério de (Camargo, 2013). Esse subconjunto é também denominado toplist. A partir dessa informação, cada sentença do córpus obtém uma pontuação com base no número de palavras-chave que contém.

- Posição de sentenças no texto. No gênero jornalístico, as primeiras e últimas sentenças tendem a condensar a ideia central dos textos. Pode-se, inclusive, sugerir que a posição das sentenças dentro de um tópico ou subtópico em um conjunto de textos pode indicar informação relevante. Segundo pesquisas recentes (Boros et al., 2001; Ercan e Cicekli, 2008; Camargo, 2013; Cardoso, 2014), cada parágrafo tende a representar um subtópico diferente do assunto que está sendo tratado em um ou vários textos. Inclusive, segundo essas pesquisas, as primeiras sentenças em um tópico tendem a ser consideradas informação relevante. Seguindo esse critério, consideramos a hipótese de que a posição da sentença em 
cada parágrafo é indicador de relevância da informação. Assim, toda primeira sentença de um parágrafo diferente é etiquetada como 'Começo'; toda última sentença de um parágrafo é etiquetada como 'Fim' e o resto de sentenças do parágrafo são etiquetadas como 'Meio'.

Os atributos apresentados até o momento tem um escopo limitado e não enxergam a relação de cada sentença com as demais sentenças. De fato, como estudado no Capítulo 3, várias pesquisas têm modelado a tarefa de sumarização como um grafo em que os nós representam sentenças de um conjunto de textos e as arestas entre os nós representam algum tipo de relação: léxica, sintática, semântica ou discursiva. Para os fins do modelo 1, seguiram-se algumas estratégias apresentadas no trabalho de Ribaldo et al. (2012) com base em medidas sobre grafos complexos, que mostraram bons resultados para sumarização de textos em português. Assim, cada grupo de textos é descrito por um grafo em que cada nó representa uma sentença do conjunto de textos e as arestas são estabelecidas a partir de um valor de threshold=0.12 (seguindo o critério estabelecido por Zhang e Radev(2002)) de similaridade lexical, qué é obtido pela medida de Word-Overlap:

$$
\text { word_overl ap }\left(S_{1}, S_{2}\right)=\frac{\text { nro. de palavras em comum entre } S_{1} \text { e } S_{2}}{\text { nro. de palavras em } S_{1}+\text { nro. de palavras em } S_{2}}
$$

Em particular, neste trabalho foi utilizado o grafo CST (Ver Cap. 3 Seção 3), pois, apesar de ser um grafo de informações profundas, as arestas foram construídas usando o critério de similaridade lexical, com a medida Word-Overlap, e neste estágio do modelo 1 não se considerou a semântica subjacente a cada aresta, mas apenas a existência delas entre um par de nós. A partir desse grafo, foram construídos mais dois atributos, os quais foram incorporados na formulação do modelo 1. Esses atributos baseiam-se em duas medidas de redes complexas descritas no trabalho de Ribaldo et al.(2012). A seguir, descrevem-se o Coeficiente de Aglomeração e a Similaridade ao Centroide com base na medida de grau:

- Similaridade ao Centroide. De acordo com Radev et al. (2000), o centroide de um texto ou um conjunto de textos é a palavra ou conjunto de palavras que melhor representam um tópico. No contexto do presente trabalho, o centroide foi definido como a sentença mais representativa do conjunto de textos. Para determinar qual sentença é centroide, escolhe-se a sentença/nó de maior grau no grafo (medida de grafo complexo), as demais sentenças não são consideradas centroide. Se o centroide é a sentença mais representativa de um conjunto de textos, então as sentenças similares ao centroide serão bastante representativas dos textos. A similaridade entre uma sentença e o centroide é dada pelo cálculo de similaridade lexical, que computa o número de coincidências lexicais dividido pela soma do número de palavras do centroide e o número de palavras da sentença (medida de Word-Overlap). Os valores dessa medida são entre 0 e 1. 
- Coeficiente de Aglomeração. Em teoria de redes complexas, o valor dessa medida diz quanto os nós de um grafo tendem a se agrupar. Por exemplo, observese o grafo da Figura 14.

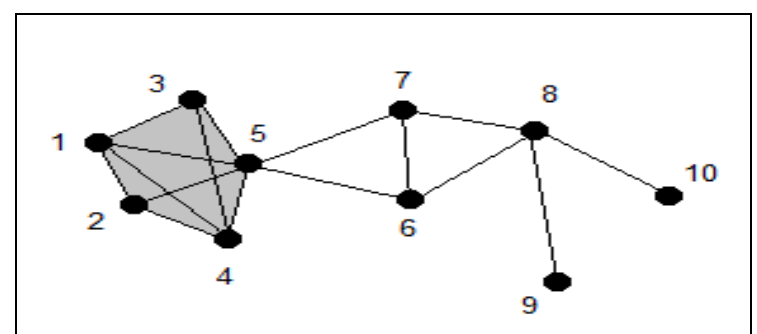

Figura 14: Grafo com nós aglomerados

Nessa figura, pode-se observar que os nós 1, 2, 3, 4 e 5 estão bem agrupados e formam uma pequena comunidade de nós. Para SAM, isso é muito interessante, já que as sentenças que tendem a se agrupar mais podem expressar a relevância de um tópico nos textos. O valor desse nível de agrupamento é dado na equação:

$$
C C=\frac{3 \times \# \text { triangulos }}{\# \text { triplas }}
$$

Nessa equação, as triplas se referem aos conjuntos de três nós que estão conectados por duas ou três arestas. Os triângulos se referem aos conjuntos de nós que estão conectados por exatamente três arestas. Essa característica assume valores entre 0 e 1 .

Pode parecer que esses atributos têm alguma redundância entre eles. Em princípio, todos os atributos poderiam destacar a relevância das mesmas sentenças (p.ex. os atributos posição e frequência de palavras-chave poderiam privilegiar sempre as primeiras sentenças de um texto). No entanto, os dois atributos buscam privilegiar a informação relevante, mas a partir de óticas diferentes. Por exemplo, a posição das sentenças pode privilegiar fortemente sentenças no começo dos parágrafos, enquanto a frequência das top-words pode privilegiar também sentenças em outras posições, já que, sentenças que contenham as palavras mais relevantes podem não sempre (ou unicamente) estar localizadas no começo de um texto ou de um parágrafo. Do mesmo modo, os dois atributos baseados no grafo de similaridade lexical abordam, de óticas diferentes, a relevância de uma sentença. A similaridade ao centroide destaca sentenças similares a um único centroide, enquanto o coeficiente de aglomeração destaca sentenças ligadas a grupos de sentenças que tenham um alto grau de informação em comum, o que envolve vários centros ou pontos de concentração da informação, e não apenas um como é no caso da similaridade ao centroide. 
É importante dizer que, para o cálculo de cada um destes atributos foi realizado um pré-processamento dos textos. Esse preprocessamento consistiu basicamente em remover stopwords e realizar stemming sobre as palavras do conjunto de textos.

Outro ponto importante a considerar é que os valores desses atributos são contínuos e podem chegar a ser muito granulares e variados entre cada sentença. Por esse motivo, resolveu-se aplicar o método de discretização de valores baseado em entropia dos intervalos (Clarke and Barton, 2000), similar ao usado na ferramenta Weka. Esse método é supervisionado e, inicialmente, assume-se que cada valor contínuo é um intervalo diferente. Recursivamente, intervalos contíguos são mesclados até identificar a divisão de intervalos com a que se obtenha o maior valor de ganho de informação para todo o conjunto de dados. Continua-se mesclando intervalos até que o ganho de informação não melhore.

No caso do atributo posição de sentenças, não se aplica discretização, pois os valores desse atributo são categóricos.

\section{Formulação Estatística do Modelo de Transformação 1}

De acordo com a formulação de Bayes, para obter o valor de $\mathrm{P}(\mathrm{S} \mid \mathrm{C})$, deve-se inferir primeiro o valor de $\mathrm{P}(\mathrm{C} \mid \mathrm{S})$. $\mathrm{P}(\mathrm{C} \mid \mathrm{S})$ é a probabilidade de que as sentenças de uma coleção de textos tenham sido geradas com certos valores dos atributos descritos anteriormente, dado que elas também são sentenças que compõem o sumário.

Seguindo este critério, a formulação do modelo é mostrada na equação a seguir:

$$
\begin{gathered}
P(C \mid S)=\prod_{i} P\left(\text { CoefAgl }=N_{a} \quad: N_{a} \in\left[I_{w 1}, I_{w 2}[\mid \text { SSi }) \times P\left(\text { SimCentr }=N_{b} \quad: N_{b} \in\left[I_{x 1}, I_{x 2}[\mid \text { SSi })\right.\right.\right.\right. \\
\times P\left(\text { PalChave }=N_{c} \quad: N_{c} \in\left[I_{y 1}, I_{y 2}[\mid \text { SSi }) \times P\left(\text { Começo }=N_{x} \mid \text { SSi }\right)\right.\right. \\
\times P\left(\text { Meio }=N_{y} \mid \text { SSi }\right) \times P\left(\text { Fim }=N_{z} \mid \text { SSi }\right)
\end{gathered}
$$

Nessa formulação, $P\left(\right.$ CoefAgl $=N a: N a \epsilon\left[I_{w 1}-I_{w 2}\left[\mid S S_{i}\right)\right.$ é a probabilidade de uma sentença do texto ter sido gerada com um valor $N a$ para o atributo coeficiente de aglomeração, sendo que esse valor $N a$ esteja no intervalo de valores [Iw1-Iw2[. Com o mesmo critério, pode-se interpretar as probabilidades para os atributos similaridade ao centroide e palavras-chave. No caso do atributo Posição, $P\left(\right.$ Começo $\left.=N_{x} \mid S S_{i}\right)$, por exemplo, expressa a chance de uma sentença ser gerada com um valor $N x$ para esse atributo, ou, expresso de outra forma, a chance de uma sentença ser gerada sendo que ocorreu $N x$ vezes na posição "Começo" nos textos-fonte. O mesmo critério é aplicado para calcular as probabilidades dos outros dois valores para o atributo posição, "Meio" e "Fim".

O cálculo das probabilidades do modelo 1 na equação (41) é realizado dividindo o número de sentenças do sumário (SS) que são geradas de acordo com o padrão correspondente a cada atributo, pelo número total de sentenças de sumário. 


\section{Treino e Teste}

O córpus CSTNews foi usado para o treinamento e teste desse modelo e dos demais modelos gerativos que serão descritos nas seções posteriores. Esse treinamento consistiubasicamente em inferir o valor das probabilidades do modelo a partir de extratos humanos e os seus correspondentes textos-fonte. Em particular, o treinamento foi realizado em um subconjunto de clusters do córpus usando o esquema 10-fold cross validation. Desse modo, o córpus foi dividido em 10 subconjuntos. Cada um desses subconjuntos tem 45 clusters diferentes que foram usados para treinar o modelo e inferir as probabilidades, os 5 clusters restantes são usados para testar o modelo inferido. Em outras palavras, para cada subconjunto, foram produzidos 5 sumários a partir das probabilidades inferidas nos outros 45 clusters. Fazendo esse processo para os 10 subconjuntos revezados, obteve-se um total de 50 sumários correspondentes aos 50 clusters do córpus.

\section{Exemplo de Inferência e Teste do Modelo de Transformação 1}

Considerem-se os seguintes dois textos e o correspondente extrato humano multidocumento, extraídos do Cluster 31 do córpus CSTNews, como se fossem um córpus de treinamento e teste. O extrato, além de estar composto pelas sentenças extraídas, também contém o alinhamento correspondente à sentença(s) dos textos-fonte.

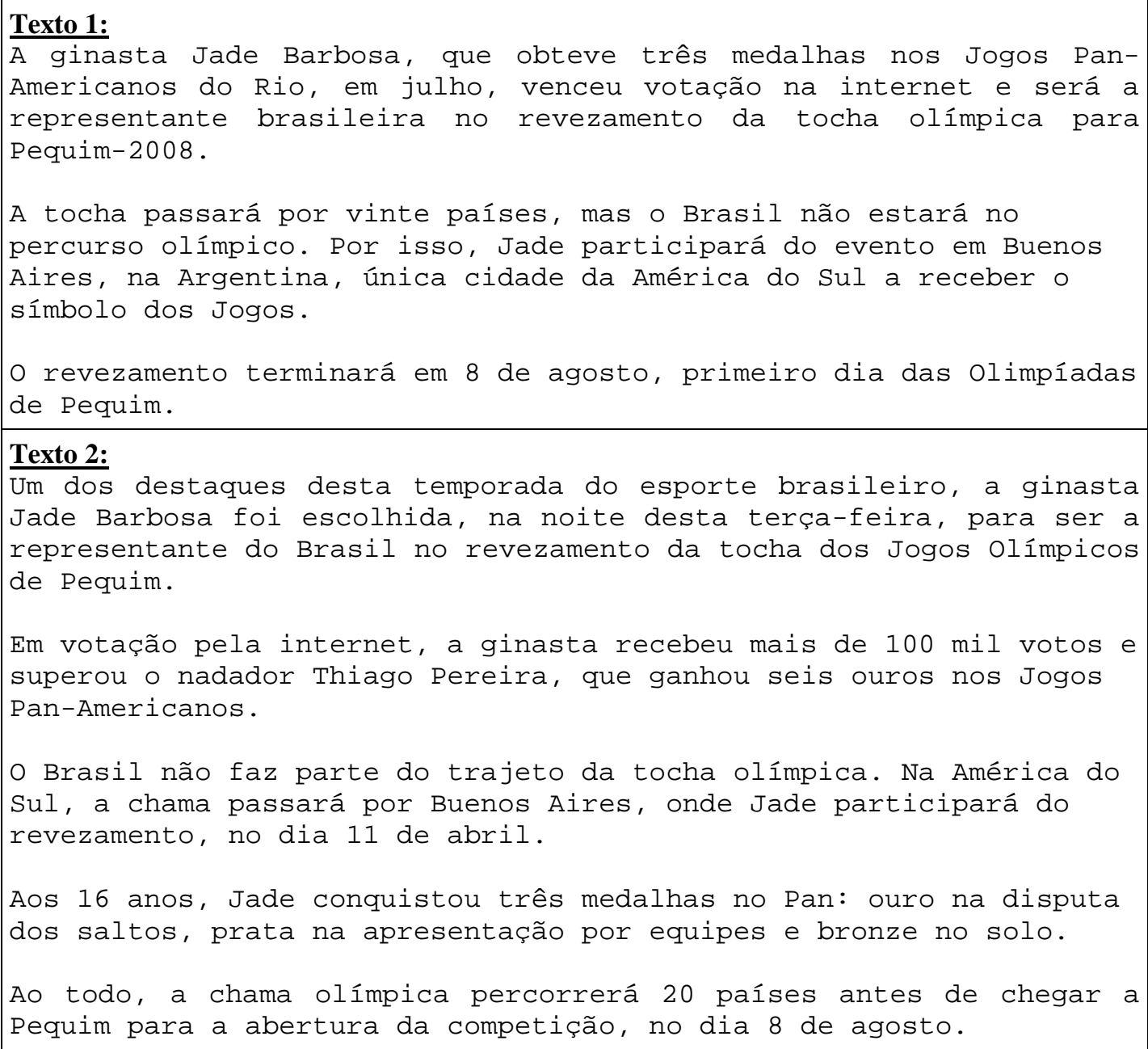




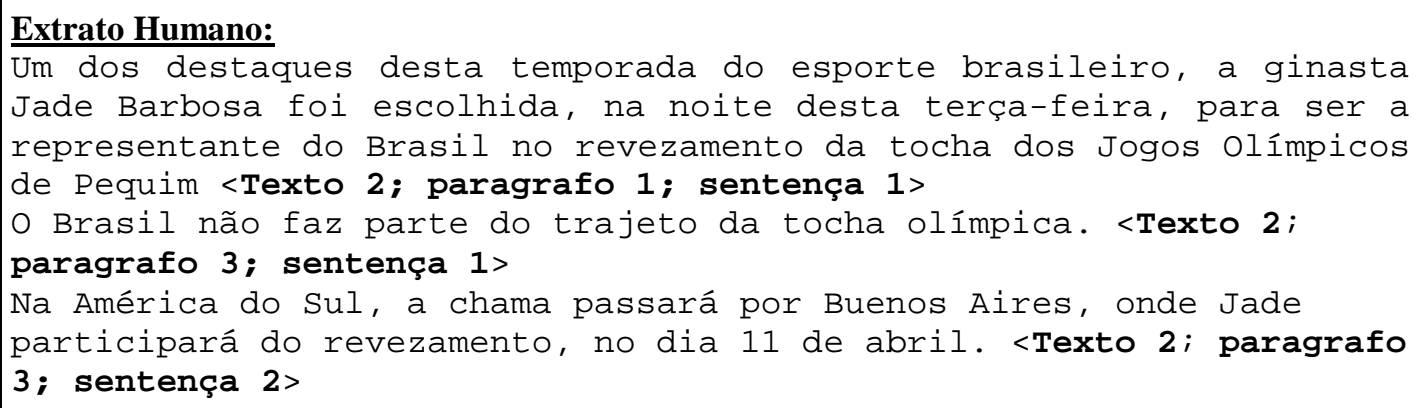

Figura 15: Exemplo de córpus de treinamento composto de textos-fonte e extrato humano

A partir dos textos-fonte forma-se um conjunto de sentenças para o treinamento. No conjunto todo, calculam-se as palavras chave, que, no caso, são 9 (10\% do total de sentenças de treinamento) para os textos do exemplo. A seguir, são mostradas as palavras-chave do exemplo, com seu respectivo valor de frequências:

Tabela 10: Exemplo de frequência de palavras-chave

\begin{tabular}{|c|c|}
\hline Palavras & Frequência \\
\hline Jade & 5 \\
Jogos & 4 \\
Revezamento & 4 \\
Tocha & 4 \\
ginasta & 3 \\
olímplica & 3 \\
Brasil & 3 \\
Dia & 3 \\
Pequim & 3 \\
\hline
\end{tabular}

Na sequência, calcula-se a frequência das palavras-chave em cada sentença do conjunto, o que resulta em: 
Tabela 11: Exemplo do atributo frequência de palavras-chave nas sentenças do córpus

\begin{tabular}{|c|c|}
\hline Id Sentença & $\begin{array}{c}\text { Frequência } \\
\text { Palavras Chave }\end{array}$ \\
\hline Sentença1_Texto1 & 6 \\
Sentença2_Texto1 & 2 \\
Sentença3_Texto1 & 2 \\
Sentença4_Texto1 & 3 \\
Sentença1_Texto2 & 7 \\
Sentença2_Texto2 & 2 \\
Sentença3_Texto2 & 3 \\
Sentença4_Texto2 & 3 \\
Sentença5_Texto2 & 1 \\
Sentença6_Texto2 & 3 \\
\hline
\end{tabular}

Identifica-se também a posição de cada sentença no texto, como descrito anteriormente:

Tabela 12: Exemplo dos atributos frequência de palavras-chave e posição das sentenças do córpus

\begin{tabular}{|c|c|c|}
\hline Id Sentença & $\begin{array}{c}\text { Frequência } \\
\text { Palavras Chave }\end{array}$ & Posição \\
\hline Sentença1_Texto1 & 6 & Começo \\
Sentença2_Texto1 & 2 & Começo \\
Sentença3_Texto1 & 2 & Fim \\
Sentença4_Texto1 & 3 & Começo \\
Sentença1_Texto2 & 7 & Começo \\
Sentença2_Texto2 & 2 & Começo \\
Sentença3_Texto2 & 3 & Começo \\
Sentença4_Texto2 & 3 & Fim \\
Sentença5_Texto2 & 1 & Começo \\
Sentença6_Texto2 & 3 & Começo \\
\hline
\end{tabular}

A partir do grafo CST (que para fins desse exemplo assume-se que já está pronto), é calculado o grau de cada sentença e, assim, determina-se qual é a sentença centroide. 
Tabela 13: Exemplo dos atributos frequência de palavras-chave, posição e grau das sentenças do córpus

\begin{tabular}{|c|c|c|c|}
\hline Id Sentença & $\begin{array}{c}\text { Frequência } \\
\text { palavras-chave }\end{array}$ & Posição & Grau \\
\hline Sentença1_Texto1 & $\mathbf{6}$ & Começo & $\mathbf{2}$ \\
Sentença2_Texto1 & 2 & Começo & 2 \\
Sentença3_Texto1 & 2 & Fim & 1 \\
Sentença4_Texto1 & 3 & Começo & 2 \\
Sentença1_Texto2 & 7 & Começo & 2 \\
Sentença2_Texto2 & 2 & Começo & 1 \\
Sentença3_Texto2 & 3 & Começo & 1 \\
Sentença4_Texto2 & 3 & Fim & 2 \\
Sentença5_Texto2 & 1 & Começo & 0 \\
Sentença6_Texto2 & 3 & Começo & 1 \\
\hline
\end{tabular}

Como existem várias sentenças com o mesmo valor de grau, há vários critérios para selecionar a sentença centroide, por exemplo: (i) aleatoriedade ou (ii) a posição da sentença, dando preferência à sentença localizada no começo do texto . Nesse caso, escolhemos como centroide a sentença com posição mais no começo do texto que foi lido primeiro, o seja, a Sentença1_Texto1. A partir desse cálculo, computa-se a similaridade das demais sentenças com a sentença centroide.

Tabela 14: Exemplo dos atributos frequência de palavras-chave, posição, grau e similaridade ao centroide nas sentenças do córpus

\begin{tabular}{|c|c|c|c|}
\hline Id Sentença & $\begin{array}{c}\text { Frequência } \\
\text { palavras-chave }\end{array}$ & Posição & $\begin{array}{c}\text { Similaridade ao } \\
\text { Centroide }\end{array}$ \\
\hline Sentença1_Texto1 & 6 & Começo & 1.000 \\
Sentença2_Texto1 & 2 & Começo & 0.022 \\
Sentença3_Texto1 & 2 & Fim & 0.038 \\
Sentença4_Texto1 & 3 & Começo & 0.023 \\
Sentença1_Texto2 & 7 & Começo & 0.118 \\
Sentença2_Texto2 & 2 & Começo & 0.098 \\
Sentença3_Texto2 & 3 & Começo & 0.051 \\
Sentença4_Texto2 & 3 & Fim & 0.040 \\
Sentença5_Texto2 & 1 & Começo & 0.058 \\
Sentença6_Texto2 & 3 & Começo & 0.018 \\
\hline
\end{tabular}

A seguir, computa-se o valor de Coeficiente de Aglomeração também com base no grafo CST. 
Tabela 15: Exemplo dos atributos frequência de palavras-chave, posição, grau, similaridade ao centroide e coeficiente de aglomeração das sentenças do córpus

\begin{tabular}{|c|c|c|c|c|}
\hline Sentença & $\begin{array}{c}\text { Frequência } \\
\text { Palavras Chave }\end{array}$ & Posição & $\begin{array}{c}\text { Similaridade } \\
\text { com o Centroide }\end{array}$ & $\begin{array}{c}\text { Coeficiente de } \\
\text { Aglomeração }\end{array}$ \\
\hline Sentença1_Texto1 & 6 & Começo & 1.000 & 0.950 \\
Sentença2_Texto1 & 2 & Começo & 0.022 & 0.000 \\
Sentença3_Texto1 & 2 & Fim & 0.038 & 0.000 \\
Sentença4_Texto1 & 3 & Começo & 0.023 & 0.000 \\
Sentença1_Texto2 & 7 & Começo & 0.118 & 0.750 \\
Sentença2_Texto2 & 2 & Começo & 0.098 & 0.500 \\
Sentença3_Texto2 & 3 & Começo & 0.051 & 0.000 \\
Sentença4_Texto2 & 3 & Fim & 0.040 & 0.750 \\
Sentença5_Texto2 & 1 & Começo & 0.058 & 0.000 \\
Sentença6_Texto2 & 3 & Começo & 0.018 & 0.000 \\
\hline
\end{tabular}

Finalmente, aplica-se o algoritmo de discretização, obtendo os seguintes intervalos para os atributos: Frequência de palavras-chave, similaridade ao centroide e coeficiente de aglomeração:

Tabela 16: Exemplo de discretização dos atributos superficiais

\begin{tabular}{|l|l|l|}
\hline Frequência de Palavras Chave & \multicolumn{1}{|c|}{ Similaridade Centroide } & Coef. Aglomeração \\
\hline$[0,3]$ & {$[0,0.0408163[$} & {$[0,0.23[$} \\
{$[3,7]$} & {$[0.0408163,0.058823[$} & {$[0.23,0.040[$} \\
& {$[0.0588235,0.118644[$} & {$[0.040,0.051[$} \\
& {$[0.118644,0.47619[$} & {$[0.051,0.118[$} \\
& {$[0.47619,1]$} & {$[0.118,1.000]$} \\
\hline
\end{tabular}

Uma vez que se obtiveram os valores dos atributos para cada sentença, e os intervalos discretizados, pode-se inferir a probabilidade de cada sentença do sumário ter sido gerada a partir desses fatores. $\mathrm{Na}$ tabela a seguir, mostra-se atributos já discretizados para as sentenças do extrato humano.

Tabela 17: Atributos discretizados das sentenças do extrato humano

\begin{tabular}{|l|l|l|l|l|}
\hline Sentença do Sumário & $\begin{array}{c}\text { Frequência de } \\
\text { Palavras Chave }\end{array}$ & Similaridade Centroide & Coef. Aglomeração & Posição \\
\hline Sentença1_Texto2 & {$[3,7]$} & {$[0.118644,0.47619[$} & {$[0.118,1.000]$} & 1-Começo \\
Sentença3_Texto2 & {$[3,7]$} & {$[0.0408163,0.058823[$} & {$[0,0.23[$} & 1-Começo \\
Sentença4_Texto2 & {$[3,7]$} & {$[0.0408163,0.058823[$} & {$[0.118,1.000]$} & 1-Fim \\
\hline
\end{tabular}


A partir dessa tabela pode-se inferir que:

- 3 sentenças de sumário são geradas a partir de um padrão de palavras-chave= (FreqPalCh $=7: 7 \in[3,7]$ ); portanto, $\mathrm{P}($ FreqPalCh $€[3,7] \mid \mathrm{SSi})=3 / 3=1$

- 1 sentença do sumário é gerada a partir do padrão de similaridade ao centroide $=(\operatorname{SimCentr}=0.118: 0.118 \epsilon[0.118644,0.47619[)$ e as outras 2 são geradas a partir do padrão: (SimCentr=0.051 : $0.051 \in[0.0408163,0.058823[$ ) e (SimCentr=0.040: $0.040 \in[0.0408163,0.058823[)$; por tanto, $\mathrm{P}(\operatorname{SimCentr} \epsilon$ $[0.118644,0.47619[\mid \mathrm{SSi})=1 / 3=0.33$ e $\mathrm{P}($ SimCentr $\in \quad[0.0408163,0.058823[]$ $\mathrm{SSi})=2 / 3=0.66$

- 2 sentenças do sumário são geradas a partir do padrão de coeficiente de aglomeração $=($ CoefAgl $=0.750: 0.750 \in[0.118,1.000])$ e a outra sentença é gerada a partir do padrão (CoefAgl $=0: 0 \in[0,0.23[)$; portanto, $\mathrm{P}(\mathrm{CoefAgl} \in[0.118,1.000] \mid \mathrm{SSi})$ $=2 / 3=0.66$ e $\mathrm{P}($ CoefAgl $\epsilon[0,0.23[\mid \mathrm{SSi})=1 / 3=0.33$

- 2 sentenças do sumário são geradas dado ocorreram 1 vez no começo nos textosfonte, portanto, $\mathrm{P}(\mathrm{Começo}=1 \mid \mathrm{SSi})=2 / 3=0,66$; e 1 sentença do sumário ocorreu $1 \mathrm{vez}$ no Fim, portanto, $\mathrm{P}(\mathrm{Fim}=1 \mid \mathrm{SSi})=1 / 3=0,33$

No exemplo, ao se analisar os padrões aprendidos através da inferência, pode-se deduzir que as sentenças que têm maior valor de similaridade ao centroide e maior valor de coeficiente de aglomeração, tendem a compor um sumário multidocumento. Do mesmo modo, as sentenças que ocorrem 1 vez na posição Começo nos textos-fonte, têm uma alta probabilidade de compor o sumário multidocumento.

$\mathrm{Na}$ fase de teste, utilizar-se-ão essas probabilidades inferidas para calcular o score de cada sentença candidata a compor um sumário. Na tabela seguinte, é mostrado o cálculo das probabilidades das sentenças a partir do modelo inferido.

Tabela 18: Cálculo da probabilidade das sentenças a partir das probabilidades inferidas dos atributos

\begin{tabular}{|c|c|}
\hline Sentença & Probabilidade \\
\hline Sentença1_Texto1 & $\begin{array}{l}\mathrm{P}\left(\mathrm{S} 1 \_\mathrm{T} 1\right)=\mathrm{P}(\mathrm{P} \text { chave } \in[3,7]) * \mathrm{P}(\text { SimCent } r \in[0.47619,1]) \\
\in[0.118,1.000]) * \mathrm{P}(\text { Começo }=1)=1 * 0.0001 * 0.66 * 0.66=0,00004356\end{array}$ \\
\hline Sentença2_Texto1 & $\begin{array}{l}\mathrm{P}\left(\mathrm{S} 2 \_\mathrm{T} 1\right)=\mathrm{P}(\mathrm{P} \text { chave } \in[0,3[) * \mathrm{P}(\text { SimCent } r \in[0,0.0408163[) * \mathrm{P}(\text { CoefAg }] \\
\in\left[0,0.23[) * \mathrm{P}(\text { Começo }=1)=0.0001 * 0.0001 * 0.33 * 0.66=22 \times 10^{-9}\right.\end{array}$ \\
\hline Sentença3_Texto1 & $\begin{array}{l}\mathrm{P}\left(\mathrm{S} 3 \_\mathrm{T} 1\right)=\mathrm{P}(\mathrm{P} \text { chave } \in[0,3[) * \mathrm{P}(\text { SimCent } r \in[0,0.0408163[) * \mathrm{P}(\text { CoefAg }] \\
\in\left[0,0.23[) * \mathrm{P}(\text { Fim }=1)=0.0001 * 0.0001 * 0.33 * 0.33=11 \times 10^{-9}\right.\end{array}$ \\
\hline Sentença4_Texto1 & $\begin{array}{l}\mathrm{P}\left(\mathrm{S} 4 \_\mathrm{T} 1\right)=\mathrm{P}(\mathrm{P} \text { chave } \in[3,7]) * \mathrm{P}\left(\text { SimCent } r \in\left[0,0.0408163[)^{*} \mathrm{P}(\text { CoefAg } 1\right.\right. \\
\in[0,0.23[) * \mathrm{P}(\text { Começo }=1)=1 * 0.0001 * 0.33 * 0.66=0,00002178\end{array}$ \\
\hline Sentença1_Texto2 & $\begin{array}{l}\mathrm{P}\left(\mathrm{S} 1 \_\mathrm{T} 2\right)=\mathrm{P}(\mathrm{P} \text { chave } \in[3,7]) * \mathrm{P}(\mathrm{SimCent} r \in[0.118644,0.47619[) \\
* \mathrm{P}(\text { CoefAgl } \in[0.118,1.000]) * \mathrm{P}(\text { Começo }=1)=1 * 0.33 * 0.66 * 0.66=0,143748\end{array}$ \\
\hline Sentença2_Texto2 & $\begin{array}{l}\mathrm{P}\left(\mathrm{S} 2 \_\mathrm{T} 2\right)=\mathrm{P}(\mathrm{P} \text { chave } \in[0,3[) * \mathrm{P}(\text { SimCent } r \in[0.0588235,0.118644[) \\
* \mathrm{P}(\text { CoefAg }] \in[0.118,1.000]) * \mathrm{P}(\text { Começo }=1)=0.0001 * 0.0001 * 0.66 * 0.66=44 \mathrm{x} \\
10^{-9}\end{array}$ \\
\hline Sentença3_Texto2 & $\mathrm{P}\left(\mathrm{S} 3 \_\mathrm{T} 2\right)=\mathrm{P}(\mathrm{P}$ chave $\in[3,7]) * \mathrm{P}($ SimCent $r \in[0.0408163,0.058823[)$ \\
\hline
\end{tabular}




\begin{tabular}{|c|c|}
\hline & $* \mathrm{P}($ CoefAg $l \in[0.118,1.000]) * \mathrm{P}($ Começo $=1)=1 * 0.66 * 0.66 * 0.66=0,2875$ \\
\hline Sentença4_Texto2 & $\begin{array}{l}\mathrm{P}\left(\mathrm{S} 4 \_\mathrm{T} 2\right)=\mathrm{P}(\mathrm{P} \text { chave } \in[3,7]) * \mathrm{P}(\text { SimCent } r \in[0.0408163,0.058823[) \\
* \mathrm{P}(\text { CoefAg } l \in[0.118,1.000]) * \mathrm{P}(\mathrm{Fim}=1)=1 * 0.66 * 0.66 * 0,33=0,1437\end{array}$ \\
\hline Sentença5_Texto2 & $\begin{array}{l}\mathrm{P}\left(\mathrm{S} 5 \_\mathrm{T} 2\right)=\mathrm{P}(\mathrm{P} \text { chave } \in[0,3[) * \mathrm{P}(\mathrm{S} \text { imCent } r \in[0.0588235,0.118644[) \\
* \mathrm{P}\left(\text { CoefAg } l \in\left[0,0.23[) * \mathrm{P}(\mathrm{Começo}=1)=0.0001 * 0.0001 * 0.33 * 0.66=22 \times 10^{-9}\right.\right.\end{array}$ \\
\hline Sentença6_Texto2 & $\begin{array}{l}\mathrm{P}\left(\mathrm{S} 6 \_\mathrm{T} 2\right)=\mathrm{P}(\mathrm{P} \text { chave } \in[3,7]) * \mathrm{P}(\text { SimCent } r \in[0,0.0408163[) \\
* \mathrm{P}\left(\text { CoefAg } l \in\left[0,0.23[) * \mathrm{P}(\mathrm{Começo}=1)=1 * 0.0001 * 0.0001 * 0.66=66 \times 10^{-9}\right.\right.\end{array}$ \\
\hline
\end{tabular}

Com base na Tabela 18, nota-se que as sentenças que obtiveram melhor probabilidade de acordo com o modelo inferido são as mesmas sentenças do extrato humano usado para a inferência; logicamente, em um cenário real de treinamento e teste, usando 10-fold cross validation, esse overfitting não deveria acontecer.

Outro detalhe importante a se notar é que as probabilidades de cada atributo podem ser muito baixas e, ao se multiplicar, podem gerar um underflow no valor final da probabilidade da sentença. Para resolver esse problema, aplicou-se a técnica da probabilidade aritmética logarítmica, que foi utilizada com sucesso na área de Tradução Automática (Brown et al. 1993) para resolver o problema do underflow em pontos flutuantes. De acordo com essa técnica, considera-se a soma dos logaritmos das probabilidades ao invés da multiplicação das probabilidades em si, da seguinte maneira:

$$
\begin{gathered}
\log _{2}(P(C \mid S))=\log _{2}\left(\prod _ { i } P \left(\text { CoefAgl }=N a \quad: N_{a} \in\left[I_{w 1}, I_{w 2}[\mid \text { SSi }) \times P\left(\text { SimCentr }=N_{b} \quad: N b \in\left[I_{x 1}, I_{x 2}[\mid \text { SSi })\right.\right.\right.\right.\right. \\
\times P\left(\text { PalChave }=N_{c} \quad: N_{c} \in\left[I_{y 1}, I_{y 2}[\mid \text { SSi }) \times P\left(\text { Começo }=N_{x} \mid S S i\right)\right.\right. \\
\left.\times P\left(\text { Meio }=N_{y} \mid S S i\right) \times P\left(\text { Fim }=N_{z} \mid \text { SSi }\right)\right) \\
\log _{2}(P(C \mid S))=\prod_{i} \log _{2}\left(P \left(\text { CoefAgl }=N a \quad: N_{a} \in\left[I_{w 1}, I_{w 2}[\mid \text { SSi })\right)+\log _{2}\left(P \left(\text { SimCentr }=N_{b} \quad: N_{b} \in\left[I_{x 1}, I_{x 2}[\mid \text { SSi })\right)\right.\right.\right.\right. \\
+\log _{2}\left(P \left(\text { PalChave }=N_{c} \quad: N_{c} \in\left[I_{y 1}, I_{y 2}[\mid S S i)\right)+\log _{2}\left(P\left(\text { Começo }=N_{x} \mid \text { SSi }\right)\right)\right.\right. \\
+\log _{2}\left(P\left(\text { Meio }=N_{y} \mid S S i\right)\right)+\log _{2}\left(P\left(\text { Fim }=N_{z} \mid \text { SSi }\right)\right)
\end{gathered}
$$

\begin{tabular}{|c|c|}
\hline Sentença & Probabilidade \\
\hline Sentença1_Texto1 & $\begin{array}{l}\mathrm{P}\left(\mathrm{S} 1 \_\mathrm{T} 1\right)=\log _{2}(\mathrm{P}(\mathrm{Pchave} \in[3,7]))+\log _{2}(\mathrm{P}(\mathrm{SimCent} r \in[0.47619,1]))+\log _{2}(\mathrm{P}(\mathrm{Coef} \\
\mathrm{Ag} l \in[0.118,1.000]))+\log _{2}(\mathrm{P}(\text { Começo=1) })=-14.48\end{array}$ \\
\hline Sentença2_Texto1 & $\begin{array}{l}\mathrm{P}\left(\mathrm{S} 2 \_\mathrm{T} 1\right)=\log _{2}\left(\mathrm{P}\left(\mathrm{Pchave} \in[0,3[))+\log _{2}\left(\mathrm{P}\left(\text { SimCent } r \in[0,0.0408163[))+\log _{2}(\mathrm{P}(\mathrm{Co}\right.\right.\right.\right. \\
\text { efAgl } \in[0,0.23[))+\log _{2}(\mathrm{P}(\text { Começo }=1))=-28.77\end{array}$ \\
\hline
\end{tabular}

A formulação da equação (43) é equivalente à formulação da equação (42) que, por sua vez, é equivalente à formulação inicial do modelo de transformação 1 (41).

De acordo com essa nova formulação, o cálculo para cada sentença na fase de teste seria como mostrado a seguir:

Tabela 19: Cálculo da probabilidade das sentenças usando a técnica de soma de logaritmos 


\begin{tabular}{|c|c|}
\hline Sentença3_Texto1 & $\begin{array}{l}\mathrm{P}\left(\mathrm{S} 3 \_\mathrm{T} 1\right)=\log _{2}\left(\mathrm{P}\left(\mathrm{Pchave} \in[0,3[))+\log _{2}\left(\mathrm{P}\left(\mathrm{S} \text { imCent } r \in[0,0.0408163[))+\log _{2}\right.\right.\right.\right. \\
\left(\mathrm{P}\left(\text { CoefAgl } \in[0,0.23[))+\log _{2}(\mathrm{P}(\mathrm{Fim}=1))=-33.09\right.\right.\end{array}$ \\
\hline Sentença4_Texto1 & $\begin{array}{l}\mathrm{P}\left(\mathrm{S} 4 \_\mathrm{T} 1\right)=\log _{2}(\mathrm{P}(\mathrm{P} \text { chave } \in[3,7]))+\log _{2}\left(\mathrm{P}\left(\text { SimCent } r \in[0,0.0408163[))+\log _{2}\right.\right. \\
\left(\mathrm{P}\left(\text { CoefAgl } \in[0,0.23[))+\log _{2}(\mathrm{P}(\text { Começo=1 }))=-15.49\right.\right.\end{array}$ \\
\hline Sentença1_Texto2 & $\begin{array}{l}\mathrm{P}\left(\mathrm{S} 1_{-} \mathrm{T} 2\right)=\log _{2}(\mathrm{P}(\mathrm{P} \text { chave } \in[3,7]))+\log _{2}(\mathrm{P}(\text { SimCent } r \in[0.118644,0.47619[))+ \\
\log _{2}(\mathrm{P}(\mathrm{CoefAg} \in[0.118,1.000]))+\log _{2}(\mathrm{P}(\text { Começo }=1))=-2.79\end{array}$ \\
\hline Sentença2_Texto2 & $\begin{array}{l}\mathrm{P}\left(\mathrm{S} 2 \_\mathrm{T} 2\right)=\log _{2}\left(\mathrm{P}\left(\mathrm{P} \text { chave } \in[0,3[))+\log _{2}(\mathrm{P}(\mathrm{S} \text { imCent } r \in[0.0588235,0.118644[))\right.\right. \\
+\log _{2}(\mathrm{P}(\text { CoefAgl } 1 \in[0.118,1.000]))+\log _{2}(\mathrm{P}(\text { Começo=1 }))=-27.77\end{array}$ \\
\hline Sentença3_Texto2 & $\begin{array}{l}\mathrm{P}\left(\mathrm{S} 3 \_\mathrm{T} 2\right)=\log _{2}(\mathrm{P}(\mathrm{P} \text { chave } \in[3,7]))+\log _{2}(\mathrm{P}(\mathrm{S} \text { imCent } r \in[0.0408163,0.058823[)) \\
+\log _{2}(\mathrm{P}(\mathrm{CoefAg} \in[0.118,1.000]))+\log _{2}(\mathrm{P}(\text { Começo }=1))=-1.79\end{array}$ \\
\hline Sentença4_Texto2 & $\begin{array}{l}\mathrm{P}\left(\mathrm{S} 4 \_\mathrm{T} 2\right)=\log _{2}(\mathrm{P}(\mathrm{P} \text { chave } \in[3,7]))+\log _{2}(\mathrm{P}(\mathrm{S} \text { imCent } r \in[0.0408163,0.058823[)) \\
+\log _{2}(\mathrm{P}(\mathrm{CoefAg} l \in[0.118,1.000]))+\log _{2}(\mathrm{P}(\mathrm{Fim}=1))=-2.79\end{array}$ \\
\hline Sentença5_Texto2 & $\begin{array}{l}\mathrm{P}\left(\mathrm{S} 5 \_\mathrm{T} 2\right)=\log _{2}\left(\mathrm{P}\left(\mathrm{P} \text { chave } \in[0,3[))+\log _{2}(\mathrm{P}(\mathrm{S} \text { imCent } r \in[0.0588235,0.118644[))\right.\right. \\
+\log _{2}\left(\mathrm{P}(\mathrm{CoefAg}] \in[0,0.23[))+\log _{2}(\mathrm{P}(\text { Começo }=1))=-28.77\right.\end{array}$ \\
\hline Sentença6_Texto2 & $\begin{array}{l}\mathrm{P}\left(\mathrm{S} 6 \_\mathrm{T} 2\right)=\log _{2}(\mathrm{P}(\mathrm{P} \text { chave } \in[3,7]))+\log _{2}(\mathrm{P}(\mathrm{S} \text { imCent } r \in[0,0.0408163[)) \\
+\log _{2}\left(\mathrm{P}\left(\text { CoefAg } l \in[0,0.23[))+\log _{2}(\mathrm{P}(\text { Começo }=1))=-27.17\right.\right.\end{array}$ \\
\hline
\end{tabular}

Com base na Tabela 19, nota-se que, após aplicar os logaritmos, os valores para cada sentença se tornam negativos, mesmo assim, por propriedade dos logaritmos, a ordem de comparação continua sendo a mesma, o seja, as sentenças com maior pontuação são as que têm mais chance de comporem um sumário final.

A seguir, descreveremos o Modelo de Transformação 2.

\subsubsection{Modelo de Transformação 2}

O Modelo de Transformação 1 é um modelo baseado nos atributos mais tradicionais e simples. Esses atributos superficiais modelam de alguma forma o estágio inicial em um processo de sumarização, em que, em uma primeira leitura (geralmente rápida), extraem-se os detalhes mais ressaltantes da superfície textual.

Já no modelo 2, pretende-se caracterizar um segundo estágio no processo de sumarização, um estágio que envolve análise e entendimento mais profundos dos textos. Neste trabalho, modelou-se essa análise mais profunda via RST. Na SA tem se explorado amplamente o uso da RST mostrando resultados satisfatórios (ver Capítulo 3). A RST, diferente do modelo 1, permite identificar informação saliente de cada texto explorando a estrutura retórica correspondente. Essa saliência é dada principalmente pelas relações retóricas e a atribuição de nuclearidade às EDU's. Em particular, nesse modelo, consideraram-se atributos baseados na nuclearidade das sentenças. A hipótese subjacente é que, uma sentença que é categorizada muitas vezes como nuclear em um texto, tende a conter informações salientes, o que torna a sentença relevante para compor um sumário. Desse modo, os atributos considerados nesse modelo são dois:

- Número de vezes que uma sentença é nuclear em um texto

- Número de vezes que uma sentença é satélite em um texto 
Tanto os atributos do Modelo de Transformação 1 como os atributos do Modelo de Transformação 2 visam detectar as informações mais relevantes de um conjunto de textos. A diferença básica entre os dois modelos é que, com os atributos baseados na RST, tenta-se modelar essa saliência da informação com base na estrutura discursiva do texto, o que pode revelar informações importantes que os atributos da superfície textual podem não seriam capazes de captar até o momento.

\section{Formulação Estatística do Modelo de Transformação 2}

Como foi mencionado no começo deste capítulo, os modelos aqui apresentados são incrementais, assim, a formulação do Modelo 2 é a formulação do Modelo 1 incrementada com a formulação probabilística dos atributos baseados na RST. A formulação é dada na seguinte equação:

$$
\begin{gathered}
P(C \mid S)=\prod_{i} P\left(\text { CoefAgl }=N a \quad: N_{a} \in\left[I_{w 1}, I_{w 2}[\mid S S i) \times P\left(\text { SimCentr }=N_{b} \quad: N_{b} \in\left[I_{x 1}, I_{x 2}[\mid \text { SSi })\right.\right.\right.\right. \\
\times P\left(\text { PalChave }=N_{c} \quad: N_{c} \in\left[I_{y 1}, I_{y 2}[\mid \text { SSi }) \times P\left(\text { Começo }=N_{x} \mid \text { SSi }\right)\right.\right. \\
\times P\left(\text { Meio }=N_{y} \mid S S i\right) \times P\left(\text { Fim }=N_{z} \mid \text { SSi }\right) \\
\times P\left(\text { Satelite }=N_{\text {Sat }} \mid \text { SSi }\right) \times P\left(\text { Nucleo }=N_{\text {Nuc }} \mid \text { SSi }\right)
\end{gathered}
$$

Nessa nova formulação, foram adicionados os fatores correspondentes aos atributos de Núcleo e Satélite da RST. Desse modo, os dois últimos componentes da formulação expressam a probabilidade de uma sentença ser gerada dado que seja satélite $N_{\text {sat }}$ vezes nos textos-fonte e núcleo $N_{\text {nuc }}$ vezes.

O cálculo dessas probabilidades é realizado da mesma forma que no modelo 1, o seja, dividindo o número de sentenças do sumário (SS) que são geradas com esses atributos, pelo número total de sentenças de sumário.

O treinamento e teste do modelo 2 é realizado usando 10-fold cross validation, da mesma forma que no Modelo de Transformação 1, e a formulação é transformada na soma de logaritmos de base 2, como foi feito no Modelo 1 também.

\section{Exemplo de Inferência e Teste do Modelo de Transformação 2}

Utilizando o mesmo exemplo do Modelo 1, consideram-se as duas árvores retóricas correspondentes aos textos 1 e 2 do exemplo do Modelo 1, as quais, são mostradas na Figura 16. Como na formulação do modelo 2 somente interessam as informações de Núcleo e Satélite das sentenças, as árvores retóricas mostradas na Figura 16 são árvores simplificadas que mostram apenas as relações retóricas entre sentenças e não todas as relações entre todas as EDU's dos textos. 


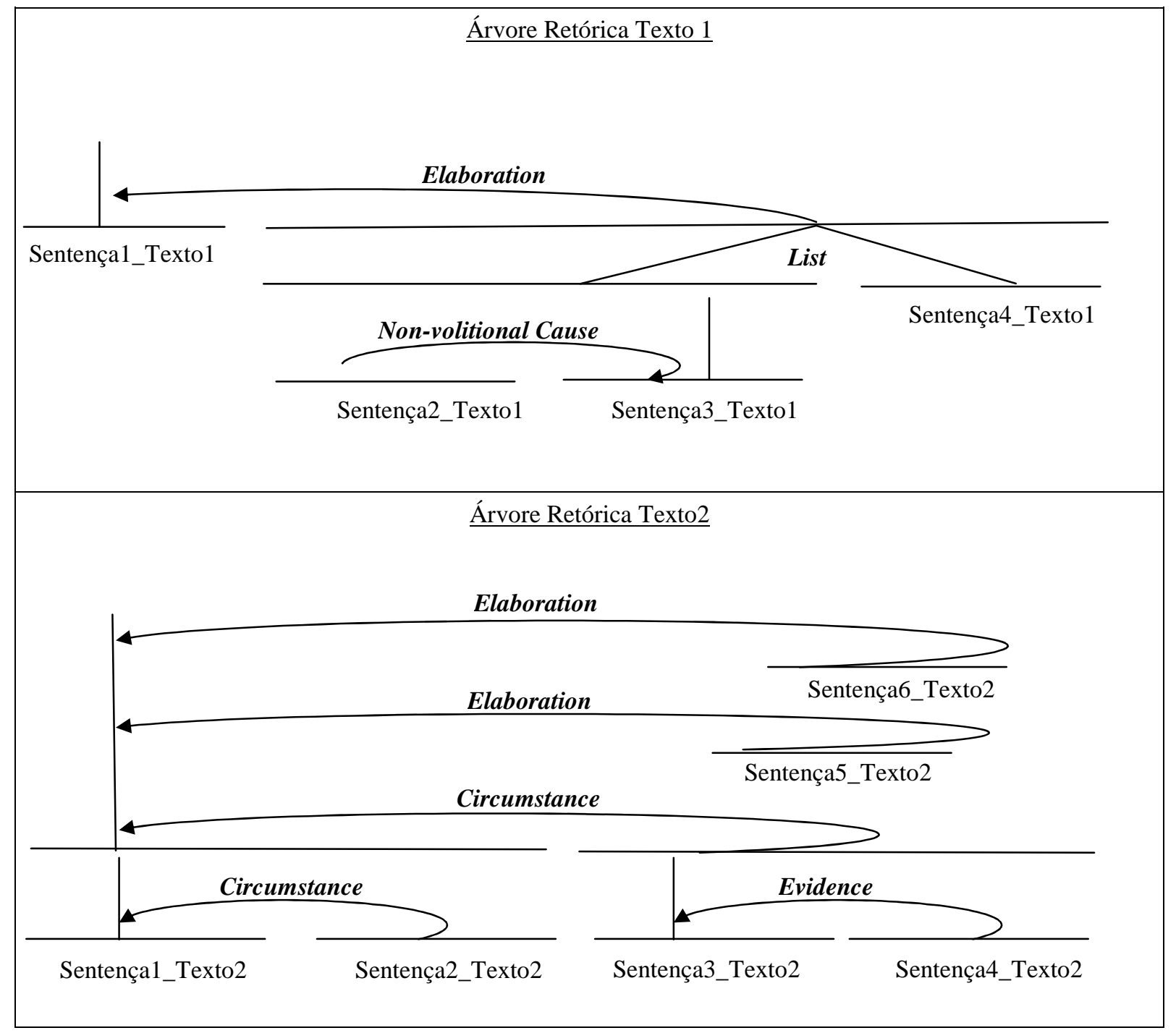

Figura 16: Exemplo de relações retóricas entre sentenças

A partir dessas duas árvores retóricas, extraem-se as informações de nuclearidade para todas as sentenças. Essa informação é sintetizada e mostrada na Tabela 20. 
Tabela 20: Atributos retóricos de cada sentença do córpus

\begin{tabular}{|c|c|c|}
\hline Sentença & Número de vezes Núcleo & Número de vezes Satélite \\
\hline Sentença1_Texto1 & 1 & 0 \\
Sentença2_Texto1 & 0 & 1 \\
Sentença3_Texto1 & 2 & 1 \\
Sentença4_Texto1 & 1 & 1 \\
Sentença1_Texto2 & 4 & 0 \\
Sentença2_Texto2 & 0 & 1 \\
Sentença3_Texto2 & 1 & 1 \\
Sentença4_Texto2 & 0 & 1 \\
Sentença5_Texto2 & 0 & 1 \\
Sentença6_Texto2 & 0 & 1 \\
\hline
\end{tabular}

Para extrair estas informações, foram consideradas todas as relações nas quais as sentenças estão presentes, e para cada uma de essas relações observou-se quantas vezes a sentença foi Núcleo e quantas vezes foi Satélite. É importante notar que, para poder determinar os Núcleos e Satélites das relações que estão mais no topo da árvore foram consideradas as sentenças mais nucleares das subárvores que compõem essas relações correspondentes. Por exemplo, observe-se que a Sentença1_Texto2 é componente das relações mais embaixo da árvore até as relações mais no topo da árvore, isto é devido a que em cada subárvore correspondente a cada relação, ela é a sentença mais nuclear.

A partir das informações dadas na Tabela 20, podemos inferir algumas probabilidades:

- 1 sentença do sumário é gerada dado que foi 4 vezes núcleo nos textos-fonte; portanto, $\mathrm{P}(4 \mid \mathrm{SSi}$, Núcleo $)=1 / 3=0.33$

- 1 sentença do sumário é gerada dado que foi 0 vezes satélite nos textos-fonte; portanto, $\mathrm{P}(0 \mid \mathrm{SSi}$, Satélite $)=1 / 3=0.33$

- 1 sentença do sumário é gerada dado que foi 1 vez núcleo nos textos-fonte; portanto, $\mathrm{P}(1 \mid \mathrm{SSi}$,Núcleo $)=1 / 3=0.33$

- 1 sentença do sumário é gerada dado que foi 0 vezes núcleo nos textos-fonte; portanto, $\mathrm{P}(0 \mid \mathrm{SSi}$, Núcleo $)=1 / 3=0.33$

- 2 sentenças do sumário são geradas dado que foram 1 vez satélite nos textosfonte; portanto, $\mathrm{P}(1 \mid \mathrm{SSi}$, Satélite $)=2 / 3=0.66$

A partir das inferências do modelo 2 no exemplo, se pode deduzir que as sentenças que geram padrões de poucos satélites nos textos-fonte, tem mais chance de ser geradas no sumário final. Para a etapa de teste aplicamos estas probabilidades inferidas nas sentenças dos textos do exemplo: 
Tabela 21: Cálculo de probabilidade das sentenças integrando as probabilidades inferidas do modelo $1 \mathrm{com}$ as probabilidades inferidas do modelo 2

\begin{tabular}{|c|c|}
\hline Sentença & Probabilidade \\
\hline Sentença1_Texto1 & $\begin{array}{l}\mathrm{P}\left(\mathrm{S} 1 \_\mathrm{T} 1\right)=\operatorname{Modelo1}\left(\mathrm{S} 1 \_\mathrm{T} 1\right)+\log _{2}(\mathrm{P}(\mathrm{Núcleo}=1 \mid))+\log _{2}(\mathrm{P}(\text { Satélite }=0))=-14.48- \\
1.599-1.599=-17.68\end{array}$ \\
\hline Sentença2_Texto1 & $\begin{array}{l}\mathrm{P}\left(\mathrm{S} 2 \_\mathrm{T} 1\right)=\operatorname{Modelo1}\left(\mathrm{S} 2 \_\mathrm{T} 1\right)+\log _{2}(\mathrm{P}(\text { Núcleo }=0))+\log _{2}(\mathrm{P}(\text { Satélite }=1))=-28.77- \\
1.599-0.599=-30.97\end{array}$ \\
\hline Sentença3_Texto1 & $\begin{array}{l}\mathrm{P}\left(\mathrm{S} 3 \_\mathrm{T} 1\right)=\text { Modelo1 }\left(\mathrm{S} 3 \_\mathrm{T} 1\right)+\log _{2}(\mathrm{P}(\mathrm{Núcleo}=2))+\log _{2}(\mathrm{P}(\text { Satélite }=1))=-33.09- \\
13.287-0.599=-46.98\end{array}$ \\
\hline Sentença4_Texto1 & $\begin{array}{l}\mathrm{P}\left(\mathrm{S} 4 \_\mathrm{T} 1\right)=\text { Modelo1 }\left(\mathrm{S} 4 \_\mathrm{T} 1\right)+\log _{2}(\mathrm{P}(\text { Núcleo }=1))+\log _{2}(\mathrm{P}(\text { Satélite }=1))=-15.49- \\
1.599-0.599=-17.69\end{array}$ \\
\hline Sentença1_Texto2 & $\begin{array}{l}\mathrm{P}\left(\mathrm{S} 1 \_\mathrm{T} 2\right)=\text { Modelo1 }\left(\mathrm{S} 1 \_\mathrm{T} 2\right)+\log _{2}(\mathrm{P}(\text { Núcleo=4 }))+\log _{2}(\mathrm{P}(\text { Satélite }=0))=-2.79- \\
1.599-1.599=-5.99\end{array}$ \\
\hline Sentença2_Texto2 & $\begin{array}{l}\mathrm{P}\left(\mathrm{S} 2 \_\mathrm{T} 2\right)=\text { Modelo1 }\left(\mathrm{S} 2 \_\mathrm{T} 2\right)+\log _{2}(\mathrm{P}(\text { Núcleo=0 }))+\log _{2}(\mathrm{P}(\text { Satélite=1 }))=-27.77- \\
1.599-0.599=-29.97\end{array}$ \\
\hline Sentença3_Texto2 & $\begin{array}{l}\mathrm{P}\left(\mathrm{S} 3 \_\mathrm{T} 2\right)=\operatorname{Modelo} 1\left(\mathrm{~S} 3 \_\mathrm{T} 2\right)+\log _{2}(\mathrm{P}(\text { Núcleo=1 }))+\log _{2}(\mathrm{P}(\text { Satélite }=1))=-1.79- \\
1.599-0.599=-3.99\end{array}$ \\
\hline Sentença4_Texto2 & $\begin{array}{l}\mathrm{P}\left(\mathrm{S} 4 \_\mathrm{T} 2\right)=\text { Modelo1 }\left(\mathrm{S} 4 \_\mathrm{T} 2\right)+\log _{2}(\mathrm{P}(\text { Núcleo=0 }))+\log 2(\mathrm{P}(\text { Satélite=1 }))=-2.79- \\
1.599-0.599=-4.99\end{array}$ \\
\hline Sentença5_Texto2 & $\begin{array}{l}\mathrm{P}\left(\mathrm{S} 5 \_\mathrm{T} 2\right)=\text { Modelo1 }\left(\mathrm{S} 5 \_\mathrm{T} 2\right)+\log _{2}(\mathrm{P}(\text { Núcleo }=0))+\log _{2}(\mathrm{P}(\text { Satélite }=1))=-28.77- \\
1.599-0.599=-30.97\end{array}$ \\
\hline Sentença6_Texto2 & $\begin{array}{l}\mathrm{P}\left(\mathrm{S} 6 \_\mathrm{T} 2\right)=\text { Modelo1 }\left(\mathrm{S} 6 \_\mathrm{T} 2\right)+\log _{2}(\mathrm{P}(\text { Núcleo=0 }))+\log _{2}(\mathrm{P}(\text { Satélite=1 }))=-27.17- \\
1.599-0.599=-29.37\end{array}$ \\
\hline
\end{tabular}

Um ponto importante a se discutir é que os atributos do Modelo de Transformação 2 podem ter alguma redundância com os atributos do Modelo de Transformação 1. Por exemplo, observa-se que a sentença 1 do texto 2 (sentença do sumário) gera muitos núcleos, ao mesmo tempo tem um dos valores mais altos de similaridade ao centroide, o maior no número de palavras-chave, o maior valor de coeficiente de aglomeração e está localizada no começo do parágrafo. Aparentemente, isso significaria que se poderia utilizar um modelo ou o outro para o aprendizado, mas, apesar de ter essa redundância, cada um dos atributos também é capaz de destacar outras sentenças diferentes. Por exemplo, nota-se que a sentença 3 do texto 2 é destacada pelo Modelo de Transformação 2 e não tanto pelos atributos do Modelo de Transformação 1, em que ela obtém baixos valores.

A seguir, descreve-se o Modelo de Transformação 3.

\subsubsection{Modelo de Transformação 3}

Seguindo a lógica incremental dos modelos de transformação apresentados neste trabalho, introduz-se o Modelo de Transformação 3, que envolve o entendimento dos textos-fonte como um conjunto todo, analisando os diversos fenômenos envolvidos em um cenário de múltiplos textos. Para isso, os atributos do Modelo 3 são representados por meio da CST, a qual modela adequadamente os fenômenos multidocumento. Em particular, os atributos são descritos com base na tipologia apresentada em Cardoso et al. (2011) (descrita no Capítulo 
4), já que essa tipologia agrupa as relações CST pela sua semântica, o que permite explicitar os fenômenos multidocumento. No Modelo de Transformação 3, incorporam-se três atributos novos que correspondem às categorias do segundo nível hierárquico, esses atributos são descritos a seguir:

- Complementaridade: esse atributo indica o número de sentenças nos textos-fonte que são geradas via alguma das relações correspondentes à categoria Complementaridade: Historical background, Elaboration ou Follow-up.

- Redundância: indica o número de sentenças nos textos-fonte que são geradas via alguma das relações correspondentes à categoria Redundância: Identity, Equivalence, Overlap, Summary ou Subsumption.

- Contradição: indica o número de sentenças nos textos-fonte que são geradas via a relação Contradiction, que é a única relação que representa a categoria Contradição.

Foi observado que a relação Contradiction acontece poucas vezes, e muitas dessas vezes, além de apontar uma contradição, também traz consigo muita redundância. Os dois exemplos a seguir evidenciam como sentenças contraditórias são também as que contêm informação redundante.

S1. Todos morreram quando o avião, prejudicado pelo mau tempo, não conseguiu chegar à pista de aterrissagem e caiu numa floresta a $15 \mathrm{Km}$ do aeroporto de Bukavu.

S2. A aeronave se chocou com uma montanha e caiu, em chamas, sobre uma floresta a 15 quilômetros de distância da pista do aeroporto.

S3. Às 9 horas, a cidade tinha $113 \mathbf{~ k m}$ de lentidão, sendo que a média para o horário é de 82 km, segundo a Companhia de Engenharia de Tráfego (CET).

S4. O congestionamento esteve ainda maior às $9 \mathrm{~h}$, quando chegou a $113 \mathrm{~km}$ de extensão para uma média de $32 \mathrm{~km}$.

Figura 17: Exemplo de redundância na relação Contradiction da CST

No caso das sentenças S1 e S2 (extraídas dos documentos 1 e 2 do Cluster 3 do córpus CSTNews ), que relatam como aconteceu um acidente aéreo, há uma diferença no relato de como o avião caiu, mas o contexto do assunto é o mesmo. No caso das sentenças S3 e S4 (extraídas dos documentos 2 e 3 do Cluster 4 do córpus CSTNews), que relatam a notícia de um alagamento na cidade de São Paulo, a informação referente ao horário e o número de quilômetros do congestionamento coincide e somente a informação referente à media de lentidão difere.

Por esse motivo, integrou-se a relação Contradiction à categoria de redundância. Dessa forma, somente seriam dois os atributos que representam os fenômenos multidocumento, o que também contribuiria para reduzir a esparcidade dos dados. 
Além de atributos que representam os fenômenos multidocumento, deve-se considerar a possibilidade de que uma sentença ter sido gerada sem estar vinculada a nenhum fenômeno multidocumento. Para isso, incorporou-se o atributo None, que indica o número de sentenças que são geradas nos textos-fonte sem ter nenhuma ligação com alguma relação das categorias mencionadas acima.

\section{Formulação Estatística do Modelo de Transformação 3}

Seguindo com a lógica incremental dos Modelos de Transformação 1 e 2, a formulação estatística do Modelo 3 é a seguinte:

$$
\begin{gathered}
P(C \mid S)=\prod_{i} P\left(\text { CoefAgl }=N_{a} \quad: N_{a} \in\left[I_{w 1}, I_{w 2}[\mid \text { SSi }) \times P\left(\text { SimCentr }=N_{b} \quad: N_{b} \in\left[I_{x 1}, I_{x 2}[\mid S S i)\right.\right.\right.\right. \\
\times P\left(\text { PalChave }=N_{c} \quad: N_{c} \in\left[I_{y 1}, I_{y 2}[\mid S S i) \times P\left(\text { Começo }=N_{x} \mid \text { SSi }\right)\right.\right. \\
\times P\left(\text { Meio }=N_{y} \mid S S i\right) \times P\left(\text { Fim }=N_{z} \mid \text { SSi }\right) \\
\times P\left(\text { Satelite }=N_{\text {Sat }} \mid S S i\right) \times P\left(\text { Nucleo }=N_{\text {Nuc }} \mid \text { SSi }\right) \\
\times P\left(\text { Complementaridade }=N_{\text {Cmpl }} \mid S S i\right) \times P\left(\text { Redundância }=N_{\text {Redund }} \mid \text { SSi }\right) \\
\times P\left(\text { None }=N_{\text {none }} \mid \text { SSi }\right)
\end{gathered}
$$

Os três últimos componentes dessa formulação se referem aos atributos do Modelo de Transformação 3, e indicam a probabilidade de uma sentença ser gerada $N_{\text {comp }}$ vezes nos textos-fonte via o fenômeno de Complementaridade, $N_{\text {red }}$ vezes via o fenômeno de Redundância e $N_{\text {none }}$ vezes não relacionadas a nenhum fenômeno multidocumento.

A inferência das probabilidades (treinamento) e o teste do Modelo de Transformação 3 são realizados da mesma forma que nos Modelos de Transformação 1 e 2.

\section{Exemplo de inferência do Modelo de Transformação 3}

Continuando a análise do exemplo dos Modelos de Transformação 1 e 2, mostra-se, na Figura 18, a seguir, a modelagem CST dos textos do exemplo. 


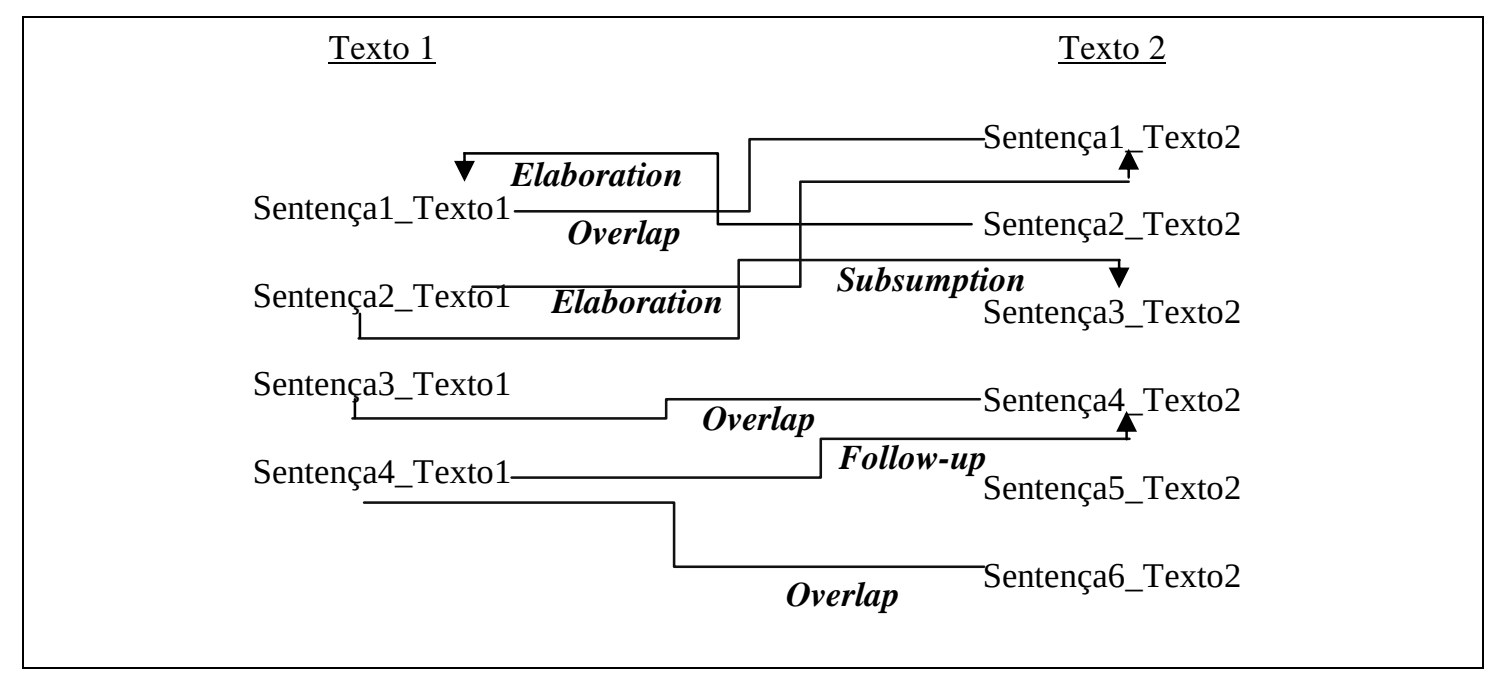

Figura 18: Exemplo de dois textos do córpus e suas relações CST

A partir dessa modelagem, mostra-se a seguinte tabela indicando, para cada sentença, quantas sentenças são geradas via cada fenômeno multidocumento:

Tabela 22: Atributos do modelo 3 para cada sentença do córpus

\begin{tabular}{|c|c|c|c|}
\hline Sentença & Complementaridade & Redundância & None \\
\hline Sentença1_Texto1 & 1 & 1 & \\
Sentença2_Texto1 & 1 & 1 & \\
Sentença3_Texto1 & 1 & 1 & \\
Sentença4_Texto1 & 1 & 1 & \\
Sentença1_Texto & 1 & & \\
2 & & 1 & \\
Sentença2_Texto2 & 1 & 1 & \\
Sentença3_Texto & & & \\
2 & & & \\
Sentença4_Texto & 2 & & \\
Sentença5_Texto2 & & & \\
Sentença6_Texto2 & & & \\
\hline
\end{tabular}

Um detalhe importante de se mencionar é que, para calcular esses valores em cada sentença, é importante considerar a redundância de cada uma delas. Por exemplo, se a Sentença2_Texto1 subsume a Sentença3_Texto2, então, para calcular a complementaridade e a redundância, deve-se considerar quantas sentenças redundantes e complementares geram tanto a Sentença2_Texto1 e a Sentença3_Texto2. Mais especificamente, essas considerações são feitas quando a redundância dada é total, o seja, quando é dada via as relações Identity, Equivalence ou Subsumption. Nesse cálculo, não é considerada a relação Overlap, pois essa 
implica que também há informações diferentes nas duas sentenças, o que não é apropriado considerar nesse caso.

A partir das informações dadas na Tabela 22, pode-se inferir algumas probabilidades:

- 2 sentenças do sumário geram 1-Complementaridade; portanto, $\mathrm{P}\left(\right.$ Complementaridade $\left.=1 \mid \mathrm{SS}_{\mathrm{i}}\right)=2 / 3=0,66$

- 1 sentença do sumário gera 0-Complementaridade; portanto, $\mathrm{P}\left(\right.$ Complementaridade $\left.=0 \mid \mathrm{SS}_{\mathrm{i}}\right)=1 / 3=0,33$

- 3 sentenças do sumário geram 1-Redundância; portanto, $\mathrm{P}\left(\right.$ Redundância $\left.=1 \mid \mathrm{SS}_{\mathrm{i}}\right)=3 / 3=1$

- 3 sentenças do sumário geram 0-None; portanto, $\mathrm{P}\left(\right.$ None $\left.=0 \mid \mathrm{SS}_{\mathrm{i}}\right)=3 / 3=1$

A partir dessas probabilidades inferidas, pode-se deduzir que, sentenças que geram redundância e complementaridade são preferidas para compor um sumário. Sentenças que são geradas via nenhum fenômeno tem pouca (ou nenhuma) chance de compor um sumário multidocumento.

Para o teste do modelo, calcula-se a probabilidade das sentenças integrando as inferências dos modelos 1,2 e 3.

Tabela 23: Cálculo da probabilidade das sentenças usando as probabilidades inferidas dos Modelos 1, 2 e 3

\begin{tabular}{|c|c|}
\hline Sentença & Probabilidade \\
\hline Sentença1_Texto1 & $\begin{array}{l}\mathrm{P}\left(\mathrm{S} 1 \_\mathrm{T} 1\right)=\text { Modelo} 2\left(\mathrm{~S} 1 \_\mathrm{T} 1\right)+\log _{2}(\mathrm{P}(\text { Complementaridade }=1))+\log _{2}(\mathrm{P}(\text { Redundância }=1)) \\
+\log _{2}(\mathrm{P}(\text { None }=0))=-17.68-0.599+0+0=-18.28\end{array}$ \\
\hline Sentença2_Texto1 & $\begin{array}{l}\mathrm{P}\left(\mathrm{S} 2 \_\mathrm{T} 1\right)=\mathrm{Modelo} 2\left(\mathrm{~S} 2 \_\mathrm{T} 1\right)+\log _{2}(\mathrm{P}(\text { Complementaridade }=1))+\log _{2}(\mathrm{P}(\text { Redundância }=1)) \\
+\log _{2}(\mathrm{P}(\text { None }=0))=-30.97-0.599+0+0=-31.57\end{array}$ \\
\hline Sentença3_Texto1 & $\begin{array}{l}\mathrm{P}\left(\mathrm{S} 3 \_\mathrm{T} 1\right)=\mathrm{Modelo} 2\left(\mathrm{~S} 3 \_\mathrm{T} 1\right)+\log _{2}(\mathrm{P}(\text { Complementaridade }=0))+\log _{2}(\mathrm{P}(\text { Redundância }=1)) \\
+\log _{2}(\mathrm{P}(\text { None }=0))=-46.98-1.599+0+0=-48.58\end{array}$ \\
\hline Sentença4_Texto1 & $\begin{array}{l}\mathrm{P}\left(\mathrm{S} 4 \_\mathrm{T} 1\right)=\text { Modelo2 }\left(\mathrm{S} 4 \_\mathrm{T} 1\right)+\log _{2}(\mathrm{P}(\text { Complementaridade }=1))+\log _{2}(\mathrm{P}(\text { Redundância }=0)) \\
+\log _{2}(\mathrm{P}(\text { None }=0))=-17.69-0.599-13.287+0=-31.58\end{array}$ \\
\hline Sentença1_Texto2 & $\begin{array}{l}\mathrm{P}\left(\mathrm{S} 1 \_\mathrm{T} 2\right)=\text { Modelo2 }\left(\mathrm{S} 1 \_\mathrm{T} 2\right)+\log _{2}(\mathrm{P}(\text { Complementaridade }=1))+\log _{2}(\mathrm{P}(\text { Redundância }=1)) \\
+\log _{2}(\mathrm{P}(\text { None }=0))=-5.99-0.599+0+0=-6.59\end{array}$ \\
\hline Sentença2_Texto2 & $\begin{array}{l}\mathrm{P}\left(\mathrm{S} 2 \_\mathrm{T} 2\right)=\text { Modelo2 }\left(\mathrm{S} 2 \_\mathrm{T} 2\right)+\log _{2}(\mathrm{P}(\text { Complementaridade }=1))+\log _{2}(\mathrm{P}(\text { Redundância }=0)) \\
+\log _{2}(\mathrm{P}(\text { None }=0))=-29.97-0.599-13.287+0=-43.86\end{array}$ \\
\hline Sentença3_Texto2 & $\begin{array}{l}\mathrm{P}\left(\mathrm{S} 3 \_\mathrm{T} 2\right)=\text { Modelo2 }\left(\mathrm{S} 3 \_\mathrm{T} 2\right)+\log _{2}(\mathrm{P}(\text { Complementaridade }=0))+\log _{2}(\mathrm{P}(\text { Redundância }=1)) \\
+\log _{2}(\mathrm{P}(\text { None }=0))=-3.99-1.599+0+0=-5.59\end{array}$ \\
\hline Sentença4_Texto2 & $\begin{array}{l}\mathrm{P}\left(\mathrm{S} 4 \_\mathrm{T} 2\right)=\text { Modelo} 2\left(\mathrm{~S} 4 \_\mathrm{T} 2\right)+\log _{2}(\mathrm{P}(\text { Complementaridade }=1))+\log _{2}(\mathrm{P}(\text { Redundância }=1)) \\
+\log _{2}(\mathrm{P}(\text { None }=0))=-4.99-0.599+0+0=-5.59\end{array}$ \\
\hline Sentença5_Texto2 & $\begin{array}{l}\mathrm{P}\left(\mathrm{S} 5 \_\mathrm{T} 2\right)=\text { Modelo2 }\left(\mathrm{S} 5 \_\mathrm{T} 2\right)+\log _{2}(\mathrm{P}(\text { Complementaridade }=0))+\log _{2}(\mathrm{P}(\text { Redundância }=0)) \\
+\log _{2}(\mathrm{P}(\text { None }=1))=-30.97-1.599-13.287-13.287=-59.14\end{array}$ \\
\hline Sentença6_Texto2 & $\begin{array}{l}\mathrm{P}\left(\mathrm{S} 5 \_\mathrm{T} 2\right)=\text { Modelo2 }\left(\mathrm{S} 5 \_\mathrm{T} 2\right)+\log _{2}(\mathrm{P}(\text { Complementaridade }=0))+\log _{2}(\mathrm{P}(\text { Redundância }=1)) \\
+\log _{2}(\mathrm{P}(\text { None }=0))=-29.37-1.599+0+0=-30.97\end{array}$ \\
\hline
\end{tabular}




\subsection{Modelo de Coerência para Sumários Multidocumento}

Os modelos descritos até o momento são construídos com o fim de capturar os principais padrões de seleção de conteúdo para compor sumários multidocumento. A informatividade em um sumário multidocumento é um dos desafios mais importantes da área, mas, também, a coerência é importante para ter sumários finais de qualidade.

Uma das definições mais clássicas de Coerência Textual, dada por Koch e Travaglia (2002), é a qualidade de um texto que o permite ser comprensível ao leitor dado um cenário de comunicação. Mais ainda, Dijk e Kintsch (1983) dividiram o conceito de coerência em dois tipos: Local e Global. A Coerência Local se refere a partes do texto, tais como sentenças ou sequências de sentenças, e ocorre quando há conteúdo relacionado e o uso de elementos linguísticos que conectam essas partes de forma que tenham sentido para a comunicação. A Coerência Global, por outro lado, refere-se a mensagem do texto como um todo e depende da Coerência Local.

Muitos trabalhos recentes focam no estudo da Coerência Local, já que esta pode ser analisada em porções pequenas do texto, o que facilita o tratamento computacional. Um dos trabalhos mais relevantes sobre a Coerência Local é o Modelo de Entidades de Barzilay e Lapata (2008), que captura as principais propriedades da Coerência Local por meio da distribuição dos atributos sintáticos das entidades que compõem um texto. Essa pesquisa inspirou outras que usaram o modelo de entidades para modelar a coerência textual em outros idiomas (Filippova e Strube, 2007), para detectar relações semânticas entre as entidades (Strube e Ponzetto, 2006), ou para incorporar outras informações, como a discursiva, para melhorar o desempenho do modelo (Lin et al., 2011).

O Modelo de Entidades também foi aplicado na SAM. De fato, o modelo de Barzilay e Lapata foi avaliado em vários cenários, um deles, SAM. Apesar de o modelo ter obtido resultados promissores, o fato de tratar a coerência apenas com base na distribuição de padrões sintáticos das entidades dos textos pode não ser o mais adequado, pois não são considerados os fenômenos multidocumento que afetam a coerência de um sumário automático de múltiplos textos. Para ilustrar isso, observa-se o exemplo a seguir, extraído do córpus CSTNews, e do mesmo Cluster do exemplo usado nos Modelos de Transformação 1, 2 e 3. 


\begin{tabular}{|c|c|}
\hline $\begin{array}{l}\text { Texto Original } \\
\text { A ginasta Jade Barbosa, que obteve } \\
\text { três medalhas nos Jogos Pan- } \\
\text { Americanos do Rio, em julho, } \\
\text { venceu votação na internet e será } \\
\text { a representante brasileira no } \\
\text { revezamento da tocha olímpica para } \\
\text { Pequim-2008. } \\
\text { A tocha passará por vinte países, } \\
\text { mas o Brasil não estará no } \\
\text { percurso olímpico. Por isso, Jade } \\
\text { participará do evento em Buenos } \\
\text { Aires, na Argentina, única cidade } \\
\text { da América do Sul a receber o } \\
\text { símbolo dos Jogos. } \\
\text { o revezamento terminará em } 8 \text { de } \\
\text { agosto, primeiro dia das } \\
\text { Olimpíadas de Pequim. }\end{array}$ & $\begin{array}{l}\text { Sumário Multidocumento } \\
\text { Por isso, Jade participará do evento } \\
\text { em Buenos Aires, na Argentina, única } \\
\text { cidade da América do Sul a receber o } \\
\text { símbolo dos Jogos. } \\
\text { Um dos destaques desta temporada do } \\
\text { esporte brasileiro, a ginasta Jade } \\
\text { Barbosa foi escolhida, na noite } \\
\text { desta terça-feira, para ser a } \\
\text { representante do Brasil no } \\
\text { revezamento da tocha dos Jogos } \\
\text { Olímpicos de Pequim. } \\
\text { Aos } 16 \text { anos, Jade conquistou três } \\
\text { medalhas no Pan: ouro na disputa dos } \\
\text { saltos, prata na apresentação por } \\
\text { equipes e bronze no solo }\end{array}$ \\
\hline
\end{tabular}

Figura 19: Exemplo de coerência-texto original vs sumário Multidocumento

Nesse exemplo, são mostrados dois textos, um deles é um texto do conjunto de textos-fonte e o outro é o sumário automático multidocumento do mesmo Cluster. Pode-se observar como as informações apresentadas no texto original seguem uma sequência lógica, e cada sentença do texto está conectada apropriadamente com as informações dadas previamente no texto. Já no sumário multidocumento observam-se informações desconexas e redundantes, por exemplo, a primeira sentença aparece sem ter introdução prévia ou complementar ao assunto que está tratando e, além disso, tem informação redundante.

Um Modelo de Coerência de sumários multidocumento deve ser capaz de capturar os padrões de coerência de um sumário, explorando os diversos fatores que a afetam. Dado que a informação contida nos sumários é proveniente de diversas fontes que narram um mesmo assunto, é comum que haja informação redundante, complementar, contraditória, diversos estilos de escrita, etc. Um bom sumário não deveria conter informação redundante, a informação complementar deveria estar organizada de forma que o texto tenha sentido e a informação contraditória deveria ser evitada ou discutida apropriadamente.

Neste trabalho, além dos Modelos de Transformação apresentados na Seção 1 deste Capítulo, também foi desenvolvido um Modelo de Coerência em parceria com o colega e aluno de doutorado do NILC Márcio Dias Souza, cujo trabalho de doutorado envolve o estudo da coerência em sumários multidocumento. Esse modelo integra o conhecimento discursivo das teorias CST e RST ao conhecimento fornecido pelo Modelo de Entidades de Barzilay e Lapata (2008). Antes de incorporar o Modelo de Coerência na modelagem gerativa, esse foi avaliado na tarefa de classificação de sumários coerentes e incoerentes. Nesta seção, descreve-se primeiro o Modelo de Entidades original; na sequência, descrevese o modelo integrado de entidades e informação discursiva e, finalmente, integra-se o modelo desenvolvido na modelagem gerativa para SAM. No Capitulo 6, são discutidos os resultados do modelo proposto na tarefa de classificação de sumários coerentes e incoerentes. 


\subsubsection{Modelo de Entidades}

O Modelo de Entidades baseia-se na hipótese de que textos coerentes apresentam padrões regulares de transição de entidades entre sentenças. O método consiste na criação de uma matriz bidimensional, também chamada grade de entidades, em que as linhas representam as sentenças do texto, as colunas representam as entidades e as células da grade representam a função sintática da entidade correspondente na sentença correspondente. Um exemplo dessa grade é mostrado na Figura 20. Nessa Figura, a grade de entidades está associada a seu texto-fonte. Esse exemplo foi extraído do trabalho original de Barzilay e Lapata e mantido na língua original, o inglês.

\section{$\underline{\text { Texto }}$}

1 [The Justice Department $]_{\mathrm{S}}$ is conducting an [anti-trust trial $]_{\mathrm{O}}$ against [Microsoft Corp. $]_{\mathrm{X}}$ with [evidence $]_{\mathrm{X}}$ that [the company $]_{\mathrm{S}}$ is increasingly attempting to crush [competitors $]_{\mathrm{O}}$.

2 [Microsoft $]_{\mathrm{O}}$ is accused of trying to forcefully buy into [markets $]_{\mathrm{X}}$ where [its own products $]_{\mathrm{S}}$ are not competitive enough to unseat [established brands $]_{\mathrm{O}}$.

$3[\text { The case }]_{S}$ revolves around $[\text { evidence }]_{O}$ of $[\text { Microsoft }]_{S}$ aggressively pressuring $[\text { Netscape }]_{O}$ into merging [browser software $]_{\mathrm{O}}$.

$4[\text { Microsoft }]_{S}$ claims [its tactics $]_{S}$ are commonplace and good economically.

$5[\text { The government }]_{S}$ may file $[\text { a civil suit }]_{\mathrm{O}}$ ruling that $[\text { conspiracy }]_{\mathrm{S}}$ to curb $[\text { competition }]_{\mathrm{O}}$ through [collusion $]_{\mathrm{X}}$ is [a violation of the Sherman Act $]_{\mathrm{O}}$.

$6[\text { Microsoft }]_{\mathrm{S}}$ continues to show [increased earnings $]_{\mathrm{O}}$ despite $[\text { the trial }]_{\mathrm{X}}$

\section{Grade de Entidades}

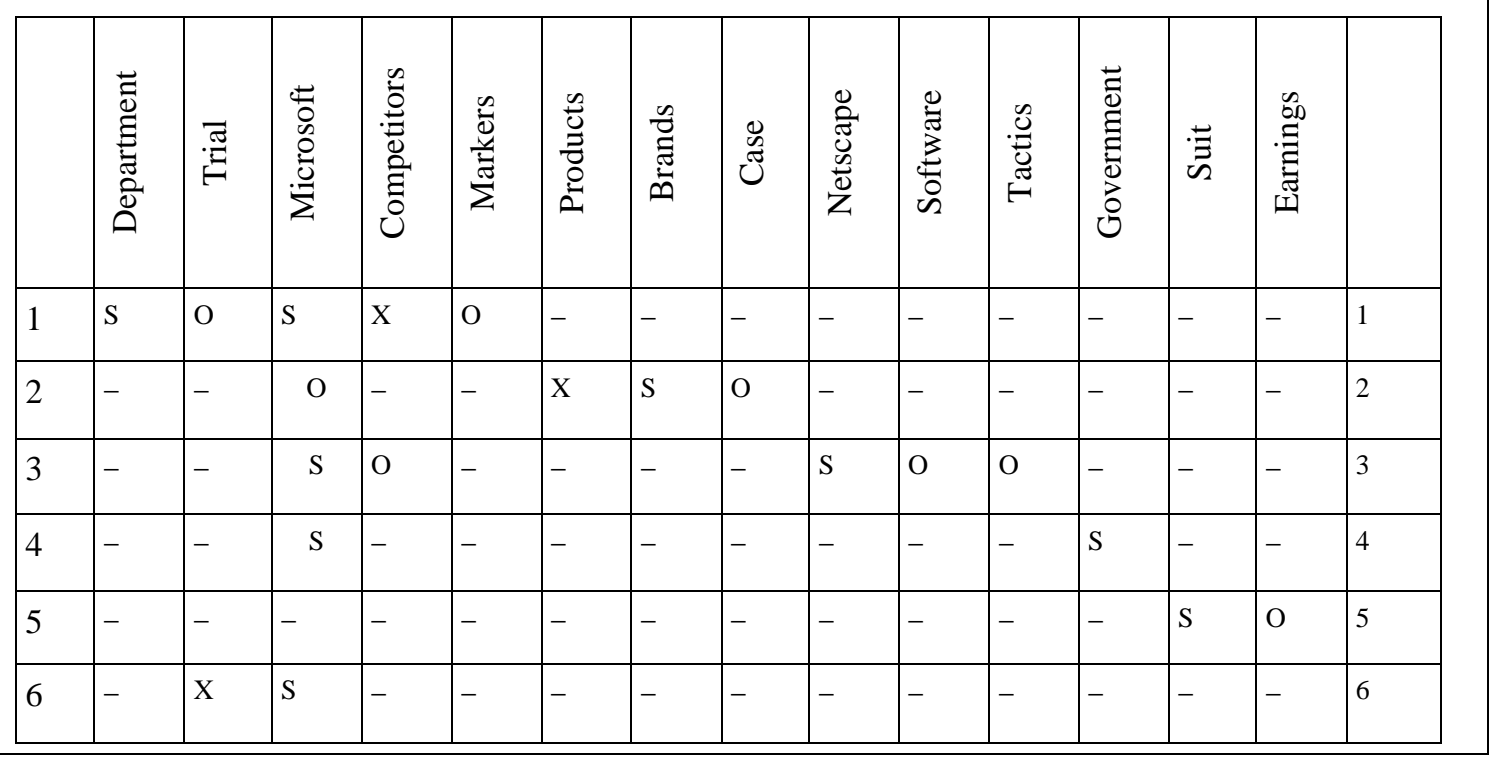

Figura 20: Exemplo de Grade de Entidades extraído do trabalho de Barzilay e Lapata (2008)

A partir da grade, pode-se computar o número de vezes que cada possível transição ocorre na grade e, assim, sua probabilidade pode ser calculada. As transições de entidades podem ser de diferentes tamanhos (entenda-se como transição o número de sentenças no qual se observa a mudança de uma dada entidade), mas, no trabalho original, considera-se que utilizar transições de tamanho 2 é o mais adequado. O cálculo de probabilidades das 
transições de entidades é baseado em três tipos de informação: sintática, referencial e saliência de informação. Quando a informação sintática é considerada, as células da grade são preenchidas com valores como 'S' (sujeito), 'O' (objeto) e X(nem sujeito nem objeto) ou '-'. Quando a informação sintática não é considerada, a grade é preenchida com valores 'X' ou '-'. Quando informação referencial é considerada, cada coluna da grade de entidades se refere a um conjunto de entidades correferentes e a célula da grade tem informação sintática de acordo com a prioridade sintática, por exemplo, sujeitos tem maior prioridade que objetos e objetos tem maior prioridade que o resto. Uma ilustração desse caso pode ser observada no exemplo da Figura 20, em que a entidade Microsoft é mencionada duas vezes na sentença 1 com papéis sintáticos diferentes: 'X' (no caso de Microsoft Corp.) e 'S' (no caso de company), mas somente é representada com 'S' na grade. As autoras também propuseram uma opção alternativa quando as correferencias não podiam ser extraídas. Nesse caso, cada substantivo nos sintagmas nominais representava uma entidade diferente na grade de entidades. Quando informação saliente é considerada, podem ser usadas duas ou mais grades de entidades baseadas na frequência das entidades. Uma grade de entidades baseada em frequência de entidades é construída com entidades que tem ocorrência maior ou igual à certa quantidade no texto (normalmente maior ou igual a dois).

Pode-se observar no exemplo da Figura 20 que informação sintática e referencial foi usada para construir a grade de entidades, e todas as entidades foram consideradas. Por exemplo, o termo Microsoft refere-se a todas as ocorrências do termo Company. De fato, na primeira sentença aparece como sujeito, na segunda como objeto, e assim por diante.

As probabilidades das transições da grade são computadas dividindo a frequência de ocorrência de uma transição específica e o número total de transições da grade (transições de tamanho 2, no caso). Por exemplo, a probabilidade da transição 'S-'(isto é, entidade que aparece primeiro como sujeito e logo na sentença contígua não aparece) é 0.09 , pois ocorre 6 vezes em meio a 75 possíveis transições.

Cada possível transição e a sua respectiva probabilidade formam um vetor de atributos que será parte de um conjunto de instâncias em um processo de Aprendizado de Máquina, usando SVMlight. Na Figura 21, mostra-se o vetor de atributos extraído da grade de entidades do exemplo da Figura 20.

\begin{tabular}{|l|c|c|c|c|c|c|c|c|c|c|c|c|c|c|c|c|}
\hline & SS & SO & SX & S- & OS & OO & OX & O- & XS & XO & XX & X- & - S & $-\mathrm{O}$ & $-\mathrm{X}$ & -- \\
\hline d1 & 0.01 & 0.01 & 0.00 & 0.08 & 0.01 & 0.00 & 0.00 & 0.09 & 0.00 & 0.00 & 0.00 & 0.03 & 0.05 & 0.07 & 0.03 & 0.59 \\
\hline
\end{tabular}

Figura 21: Exemplo de vetor de atributos extraído a partir da Grade de Entidades

Foram produzidos 8 modelos considerando o uso e o não uso das informações de saliência, sintática e referencial. Os modelos gerados foram usados para avaliar coerência em sumários multidocumento. Compararam-se os ranques obtidos pelos modelos e os ranques produzidos por humanos para os mesmos sumários. O modelo que apresenta alta concordância com o julgamento humano é o mais adequadamente captura as propriedades de coerência de sumários. Nessa tarefa, o melhor modelo foi o que usa informação sintática, que obteve um valor de $83 \%$ de acurácia, sendo que essa acurácia é medida pelo o número de pares de 
sumários ranqueados corretamente (pares de textos corretamente identificados como coerente ou incoerente), no conjunto de teste.

\subsubsection{Modelo de Entidades e Informação Discursiva Mono e Multidocumento}

Um modelo híbrido, além de analisar as transições sintáticas das entidades em um sumário, também analisa a informação discursiva que ocorre entre sequências de sentenças. Em outras palavras, visa-se descobrir a distribuição da coocorrência de conhecimento discursivo e informação sintática de entidades em sumários coerentes. A hipótese subjacente é que as relações discursivas que acontecem entre sentenças contíguas em um sumário coerente apresentam certos padrões de ocorrência, por exemplo, as informações complementares tendem a ocorrer em sentenças contíguas ou que não há redundância entre as sentenças do sumário. Esses padrões de ocorrência da informação discursiva complementam e enriquecem os padrões de ocorrência das transições sintáticas das entidades, e produzem um modelo de coerência com melhor acurácia que o modelo de entidades original.

Para ilustrar esta ideia, mostra-se na Figura 22 o extrato humano multidocumento do Cluster 1 do córpus CSTNews, que relata a queda de um avião no Congo. Na Figura, podese observar a ocorrência de informações sintáticas das entidades e a ocorrência de informação discursiva (relações) dada pela CST, em princípio.

1. Ao menos 17 [pessoas $]_{\mathbf{S}}$ morreram após a [queda $]_{\mathbf{X}}$ de um [avião] $\mathbf{X}$ de passageiros na [República Democrática do Congo $]_{\mathbf{X}}$.

2. As [vítimas $]_{\mathbf{S}}$ do acidente foram 14 [passageiros $]_{\mathbf{X}}$ e três [membros $]_{\mathbf{X}}$

da [tripulação $]_{\mathbf{X}}$.

Elaboration

3. Segundo [fontes $]_{\mathbf{X}}$ aeroportuárias, os [membros $]_{\mathbf{S}}$ da [tripulação $]_{\mathbf{S}}$ eram de [nacionalidade $]_{\mathbf{X}}$ russa.

4. O [avião]s explodiu e se incendiou, acrescentou o porta-voz da ONU em Kinshasa, Jean-Tobias Okala.

5. [Ele $]_{\mathbf{S}}$ havia saído da [cidade $]_{\mathbf{x}}$ mineira de Lugushwa em direção a Bukavu, numa [distância] $\mathbf{x}$ de 130 [quilômetros] $\mathbf{x}$.

Figura 22: Exemplo de relações CST entre sentenças de um sumário

Nesse exemplo, há três relações CST entre sentenças contíguas, por exemplo, entre as sentenças 1 e 2 ocorre a relação Elaboration, o que indica que a sentença 2 fornece informação complementar aos fatos principais apresentados na sentença 1. O mesmo ocorre entre as sentenças 2 e 3 . Entre as sentenças 4 e 5, ocorre a relação Follow-up que indica que os fatos narrados na sentença 4 aconteceram depois dos fatos narrados na sentença 5 . Não há sentenças redundantes no sumário

A partir desse exemplo pode-se gerar duas matrizes: a grade de entidades e uma matriz que mostra as relações CST entre sentenças. Isso é ilustrado nas Figuras 23 e 24. 


\begin{tabular}{|c|c|c|c|c|c|c|c|c|c|c|c|c|c|c|}
\hline & 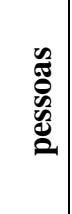 & 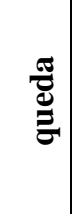 & 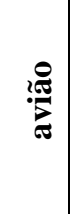 & 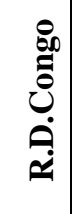 & 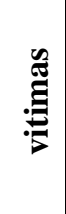 & 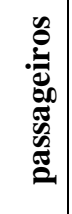 & 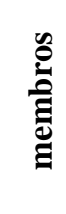 & 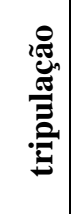 & 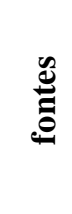 & 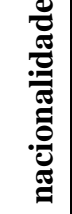 & $\stackrel{0}{0}$ & 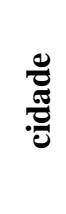 & 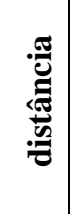 & 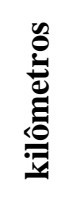 \\
\hline $\mathbf{S}_{1}$ & $S$ & $X$ & $X$ & $X$ & - & - & - & - & - & - & - & - & - & - \\
\hline $\mathbf{S}_{\mathbf{2}}$ & - & - & - & - & $S$ & $X$ & $X$ & $X$ & - & - & - & - & - & - \\
\hline $\mathbf{S}_{\mathbf{3}}$ & - & - & - & - & - & - & $S$ & $\mathrm{~S}$ & $X$ & $X$ & - & - & - & - \\
\hline $\mathbf{S}_{\mathbf{4}}$ & - & - & $S$ & - & - & - & - & - & - & - & - & - & - & - \\
\hline $\mathrm{S}_{5}$ & - & - & - & - & - & - & - & - & - & - & $S$ & $X$ & $X$ & $X$ \\
\hline
\end{tabular}

Figura 23: Exemplo de grade de entidades para o texto da Figura 22

\begin{tabular}{|l|c|c|c|c|c|}
\hline & $\mathbf{S}_{\mathbf{1}}$ & $\mathbf{S}_{\mathbf{2}}$ & $\mathbf{S}_{\mathbf{3}}$ & $\mathbf{S}_{\mathbf{4}}$ & $\mathbf{S}_{\mathbf{5}}$ \\
\hline $\mathbf{S}_{\mathbf{1}}$ & - & Elaboration & - & - & - \\
\hline $\mathbf{S}_{\mathbf{2}}$ & - & - & Elaboration & - & - \\
\hline $\mathbf{S}_{\mathbf{3}}$ & - & - & - & - & - \\
\hline $\mathbf{S}_{\mathbf{4}}$ & - & - & - & - & Follow-up \\
\hline $\mathbf{S}_{\mathbf{5}}$ & - & - & - & - & - \\
\hline
\end{tabular}

Figura 24: Exemplo de Matriz de relações CST para o texto da Figura 22

Nota-se que, na Matriz de relações CST, cada célula é preenchida com o nome da relação CST que há entre as duas sentenças correspondentes e, caso no haja relação, a célula é preenchida com um traço '-'.

A partir dessas duas matrizes, é possível produzir o vetor de atributos que condensa ambas as informações: sintática e discursiva. Por exemplo, entre as sentenças 1 e 2, ocorrem os padrões 'S-', 'X-', 'X-', '-S', '-X', '- -', e também ocorre a relação Elaboration. Nesse caso, para cada transição sintática, calcula-se o número de vezes em que cada transição ocorre junto com alguma relação CST. Logo, esses valores são divididos pelo número total de transições de tamanho 2 na grade de entidades. Desse modo, o vetor de atributos é produzido a partir das duas matrizes, resultando no vetor mostrado a seguir:

\begin{tabular}{|c|c|c|c|c|c|c|c|c|c|c|c|c|c|c|c|c|c|c|}
\hline & 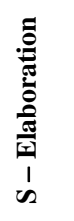 & 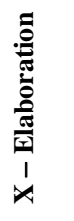 & 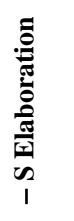 & 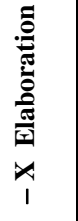 & 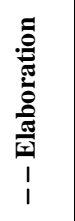 & 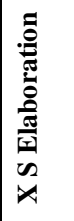 & 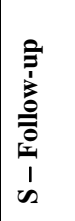 & 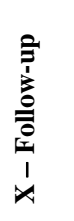 & 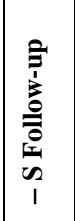 & 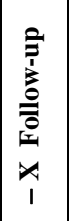 & 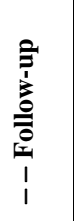 & 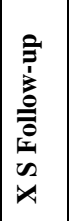 & $\begin{array}{l}1 \\
1 \\
\text { n }\end{array}$ & $\begin{array}{l}1 \\
1 \\
x\end{array}$ & $\begin{array}{l}1 \\
0 \\
1\end{array}$ & 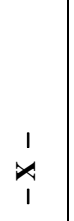 & $\begin{array}{l}1 \\
1 \\
1\end{array}$ & $\ddot{x}$ \\
\hline d & 0.03 & 0.07 & 0.01 & 0.08 & 0.25 & 0.03 & $\mid 0.01$ & 0.00 & 0.01 & 0.05 & 0.16 & 0.00 & 0.03 & 0.03 & 0.01 & 0.00 & 0.16 & 0.0 \\
\hline
\end{tabular}

Figura 25: Exemplo de vetor de atributos extraído da grade de entidades e a Matriz CST das Figuras 23 e 24, respectivamente.

Nesse vetor de atributos correspondente ao exemplo da Figura 22, foram consideramos apenas os atributos das transições que ocorrem nas matrizes das Figuras 23 e 24, com o 
propósito de ilustrar como o vetor de atributos é criado. Em um cenário real, o número de atributos seria 224, que é o resultado de multiplicar 16 (isto é, o número de todas as possíveis combinações de transições sintáticas de tamanho 2) vezes 14 (isto é, o número total de relações CST). No exemplo, os valores das probabilidades são o resultado de dividir a frequência correspondente a cada padrão pelo total de possíveis transições da grade de entidades da Figura 23, nesse caso 56. Por exemplo, o padrão 'S-Elaboration' ocorre 2 vezes no texto, portanto, a probabilidade desse padrão é $2 / 56=0.03$.

No cenário real, o número de atributos é muito grande, o que pode gerar dados muito esparsos e, em consequência, degradar o desempenho na tarefa de classificação de sumários coerentes e incoerentes. Para melhorar essa deficiência, fez-se uma variação do primeiro modelo, considerando apenas as categorias que representam as relações CST (de acordo com a taxonomia de Cardoso et al.(2011)). A vantagem de usar as categorias e não o conjunto inteiro das relações CST é que se tem um conjunto menor de atributos que condensam a semântica dos principais tipos de relações CST. Ao total, 5 categorias foram consideradas: Complemento, Redundância, Contradição, Autoria e Estilo. Considerando essas categorias, o número de atributos se reduz a 80 . A nova matriz CST de categorias e seu correspondente vetor de atributos são mostrados nas Figuras 26 e 27.

\begin{tabular}{|c|c|c|c|c|c|}
\hline & $\mathbf{S}_{\mathbf{1}}$ & $\mathbf{S}_{\mathbf{2}}$ & $\mathbf{S}_{\mathbf{3}}$ & $\mathbf{S}_{\mathbf{4}}$ & $\mathbf{S}_{\mathbf{5}}$ \\
\hline $\mathbf{S}_{\mathbf{1}}$ & - & Complemento & - & - & - \\
\hline $\mathbf{S}_{\mathbf{2}}$ & - & - & Complemento & - & - \\
\hline $\mathbf{S}_{\mathbf{3}}$ & - & - & - & - & - \\
\hline $\mathbf{S}_{\mathbf{4}}$ & - & - & - & - & Complemento \\
\hline $\mathbf{S}_{\mathbf{5}}$ & - & - & - & - & - \\
\hline
\end{tabular}

Figura 26: Matriz de Categorias CST do exemplo da Figura 22

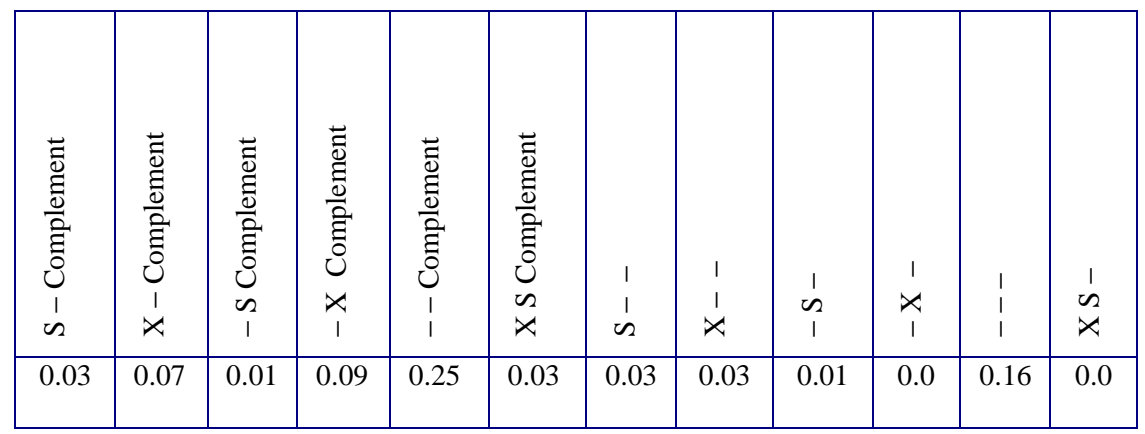

Figura 27: Exemplo de vetor de atributos integrando a grade de entidades da Figura 23 e a Matriz de Categorias CST da Figura 26

Novamente, por motivos de illustração, os atributos mostrados na Figura 27 somente são os que aparecem no exemplo da Figura 22. Apesar de se ter, nessa nova versão do modelo, uma quantidade de atributos menor, 80 é ainda um número grande de atributos, especialmente ao se considerar que um córpus de treinamento anotado com relações discursivas pode não ser muito grande e conter poucos dados para análise. Por isso, considerou-se um terceiro modelo em que apenas informações booleanas são consideradas. Em outras palavras, 
somente será considerada a ocorrência ou não ocorrência de uma relação CST, o que reduz o número de atributos a 32. Nesse contexto, a matriz CST e o vetor de atributos resultante são como mostrados a seguir.

\begin{tabular}{|l|l|l|l|l|l|}
\hline & $\mathbf{S}_{\mathbf{1}}$ & $\mathbf{S}_{\mathbf{2}}$ & $\mathbf{S}_{\mathbf{3}}$ & $\mathbf{S}_{\mathbf{4}}$ & $\mathbf{S}_{\mathbf{5}}$ \\
\hline $\mathbf{S}_{\mathbf{1}}$ & 0 & 1 & 0 & 0 & 0 \\
\hline $\mathbf{S}_{\mathbf{2}}$ & 0 & 0 & 1 & 0 & 0 \\
\hline $\mathbf{S}_{\mathbf{3}}$ & 0 & 0 & 0 & 0 & 0 \\
\hline $\mathbf{S}_{\mathbf{4}}$ & 0 & 0 & 0 & 0 & 1 \\
\hline $\mathbf{S}_{\mathbf{5}}$ & 0 & 0 & 0 & 0 & 0 \\
\hline
\end{tabular}

Figura 28: Matriz booleana CST correspondente ao exemplo da Figura 22

\begin{tabular}{|c|c|c|c|c|c|c|c|c|c|c|c|}
\hline $\begin{array}{l}7 \\
1 \\
n\end{array}$ & $\begin{array}{l}7 \\
1 \\
x\end{array}$ & $\bar{n}$ & $\bar{x}$ & $\vec{\imath}$ & $\bar{n} \bar{x}$ & $\begin{array}{l}0 \\
1 \\
n\end{array}$ & $\begin{array}{l}0 \\
\dot{1}\end{array}$ & $\begin{array}{l}0 \\
\text { in } \\
1\end{array}$ & $\underset{x}{0}$ & $\begin{array}{l}0 \\
1 \\
1\end{array}$ & $\begin{array}{l}\dot{0} \\
\dot{n} \\
x\end{array}$ \\
\hline 0.03 & 0.07 & 0.01 & 0.08 & 0.25 & 0.03 & 0.03 & 0.03 & 0.01 & 0.0 & 0.16 & 0.0 \\
\hline
\end{tabular}

Figura 29: Vetor de atributos que combina a grade de entidades da Figura 23 e a matriz booleana da Figura 28

Um detalhe importante dos sumários multidocumento é que as sentenças que os compõem podem ser provenientes de diferentes documentos, ou de um mesmo documento. As sentenças advindas de um mesmo documento também podem ter relações discursivas entre si, as quais não estariam representadas pela CST. Essas relações discursivas monodocumento (relações entre sentenças de um mesmo texto) também podem representar padrões de coerência, pelo que deveriam ser incluídas nos modelos descritos até o momento. Para representar essas relações monodocumento, usou-se a informação fornecida pela teoria RST. Particularmente, incorporamos essa informação na matriz de informação booleana da CST mostrada na Figura 28, o seja, preencheram-se as células da matriz com 1 ou 0 caso houvesse ou não alguma relação discursiva da RST ou da CST. Essa abordagem incorpora informação mono e multidocumento.

Das três variações do modelo de coerência que foram descritas nesta seção, somente o modelo que usa a matriz de informação booleana da CST foi complementado com informação da RST. O motivo para essa decisão foi o fato de que complementar a matriz de categorias requereria a classificação das relações RST nas categorias utilizadas (o que não iria ser viável, pois as relações CST e RST são de natureza diferente) ou a proposição de uma nova classificação para relações monodocumento, o que fugia do escopo deste trabalho. No caso da matriz de relações da CST, o fato de complementar com as relações RST geraria um vetor de atributos muito grande, o que degradaria o desempenho na classificação. 


\subsubsection{Modelo de Coerência e a Modelagem Gerativa}

Relembrando a fórmula de Bayes representada no esquema Noisy-Channel, o Modelo de Coerência para sumários é representado por $\mathrm{P}(\mathrm{S})$, que modela a probabilidade de um sumário multidocumento ser coerente. Essa probabilidade está determinada pela distribuição dos atributos da combinação do Modelo de Entidades e a Matriz booleana CST. Escolheu-se o modelo booleano porque, na tarefa de classificação de sumários, foi o que mostrou melhor desempenho. Isso será discutido em detalhe no seguinte Capítulo. Em outras palavras, incorpora-se na modelagem gerativa a probabilidade de um sumário ter certos padrões de coerência, sendo que estes padrões são representados pelos atributos produzidos a partir da combinação das informações da matriz booleana e a grade de entidades. A formulação de $\mathrm{P}(\mathrm{S})$ é dada a seguir:

$$
\begin{gathered}
P(S)=P(S S 1=N a) \times P(S S 0=N b) \times P(S O 1=N c) \times P(S O 0=N d) \times P(S X 1=N e) \times P(S X 0=N f) \\
\times P(S-1=N g) \times P(S-0=N h) \times P(O S 1=N i) \times P(O S 0=N j) \times P(O O 1=N k) \times P(O O 0=N l) \\
\times P(O X 1=N m) \times P(O X 0=N n) \times P(O-1=N o) \times P(O-0=N p) \times P(X S 1=N q) \times P(X S 0=N r) \\
\times P(X O 1=N s) \times P(X O 0=N t) \times P(X-1=N u) \times P(X-0=N v) \times P(-S 1=N w) \times P(-S 0=N x) \\
\quad \times P(-O 1=N y) \times P(-O 0=N z) \times P(--1=N a 1) \times P(--0=N b 1)
\end{gathered}
$$

De acordo com essa formulação, cada probabilidade representa a chance de um sumário multidocumento ter certos valores para cada atributo ou padrão de coerência. Por exemplo, $\mathrm{P}\left(\mathrm{SS} 1=\mathrm{N}_{\mathrm{a}}\right)$ representa a probabilidade de um sumário ter $\mathrm{N}_{\mathrm{a}}$ transições correspondentes ao padrão "SS1", $\mathrm{P}\left(\mathrm{SSO}=\mathrm{N}_{\mathrm{b}}\right)$ é a probabilidade de sumário ter $\mathrm{N}_{\mathrm{b}}$ transições "SS0", e assim por diante. $\mathrm{O}$ valor de cada probabilidade é calculado de acordo com a seguinte fórmula:

$$
P(\text { PadraoCoerencia }=N)=\frac{\text { NúmerodesumárioscomPadraoCoerência }=N}{\text { NúmeroTotaldeSumáriosdetreinamento }}
$$

Os dados para a construção do Modelo de Coerência são os 50 extratos humanos correspondentes aos 50 clusters do córpus CSTNews. O método de treinamento e teste do Modelo de Coerência é 10-fold cross validation.

O Modelo de Coerência resultante do treinamento pode ser testado na integração com os modelos de transformação durante a fase de decodificação (busca pelo melhor sumário de acordo com $\mathrm{P}(\mathrm{C} \mid \mathrm{S}) * \mathrm{P}(\mathrm{S})$ ) ou pela aplicação de $\mathrm{P}(\mathrm{S})$ sobre um conjunto dos $\mathrm{M}$ melhores sumários já decodificados. Nessa última opção, o Modelo de Coerência funciona como um seletor do sumário mais coerente dentre os M sumários de melhor conteúdo (ou dito de outro modo, sumários mais informativos) segundo os modelos de transformação. Essas estratégias de aplicação do Modelo de Coerência serão explicadas em mais detalhes, quando o algoritmo de decodificação seja explicado. 


\subsection{Decodificação de Sumários Multidocumento}

A tarefa de decodificação consiste em encontrar o melhor sumário de acordo com os modelos estudados neste Capítulo. O desafio principal desse decodificador é condensar a informação mais relevante de um conjunto de textos, selecionando o subconjunto de sentenças que geram a melhor pontuação e mantenham a coerência do sumário final, e minimizando os custos computacionais da tarefa de busca.

A maioria dos trabalhos que envolvem tarefas de decodificação usam algoritmos gulosos (Carbonell and Goldstein, 1998; Daumé III and Marcu, 2006; Ouyang et al., 2010; McDonald, 2007) para resolver o problema de encontrar a "melhor" solução. No entanto, esses algoritmos não sempre garantem encontrar a solução ótima.

Diferente da maioria das propostas, Aker et al. (2010) propõem um modelo de decodificação usando o algoritmo $A^{*}$, que garante encontrar a solução ótima, o seja, o melhor sumário de acordo com um modelo probabilístico.

Neste trabalho, foi desenvolvido um decodificador baseado na proposta de Aker et al.(2010). Esse decodificador apresenta uma modificação em relação ao algoritmo original, a qual permite o tratamento da redundância ao construir o sumário final, usando informações da CST. Pode ser questionável o fato que se trate a redundância nesta etapa sendo que o Modelo de Coerência já aborda esse fenômeno, mas, apesar de que no Modelo de Coerência se considera a redundância nos padrões de coerência, é possível que a redundância ainda esteja presente nos sumários após a aplicação do modelo. Inclusive, se fossem consideradas as relações CST em vez de simplesmente valores 1 ou 0 , dado que são modeladas estatisticamente, pode ser que as probabilidades ainda tenham uma margem de erro que permita a presença de informação redundante nos sumários produzidos. Por esse motivo, também foi abordado o tratamento de redundância na etapa decodificação, para tentar diminuir o máximo possível a presença de informação redundante no sumário final. A seguir, descrevem-se o algoritmo original de decodificação de Aker et al. e logo a modificação proposta para o tratamento da redundância.

\subsubsection{Decodificação simples com o algoritmo $A^{*}$}

Dado um modelo aprendido, a partir do qual um conjunto de sentenças (que pertencem a um conjunto de documentos C) são pontuadas, deseja-se encontrar o subconjunto de sentenças $\mathrm{S}$ (de m elementos) que maximizem a pontuação (probabilidade) do sumário final. Em outras palavras, precisa-se encontrar a combinação de $m$ sentenças que maximizem a pontuação global. Esse problema pode ser entendido como um problema de busca em um espaço de várias possíveis soluções. Por exemplo, considere-se um conjunto de dois textos compostos de duas sentenças cada um, respectivamente: S1T1, S2T1 do Texto 1, e S1T2, S2T2 do Texto 2. Adicionalmente, considere-se que o tamanho permitido do sumário seja de apenas duas sentenças; esse cenário criaria um espaço de busca como o que está ilustrado na Figura 30. 


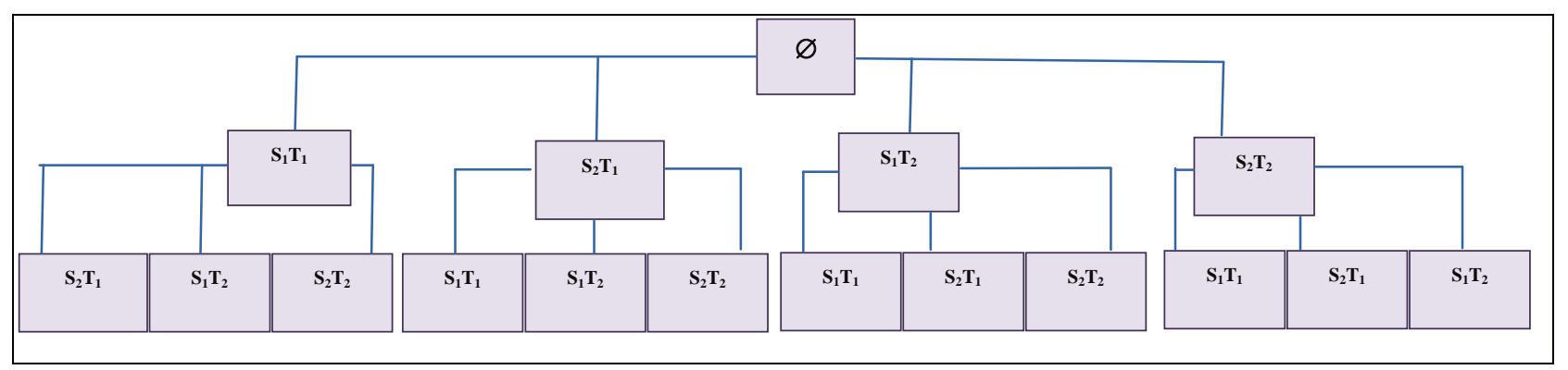

Figura 30: Espaço de busca de sentenças para decodificação

Esse espaço de busca tem várias características importantes. Primeiro, a profundidade da árvore corresponde com o número de sentenças permitidas no sumário (dois neste caso). Cada nível i da árvore corresponde a um conjunto de sub-soluções de tamanho i, por exemplo, no nível 0 existe uma única sub-solução que é o conjunto vazio $\emptyset$, que não inclui nenhuma sentença, no nível 1 são incluídas todas as sub-soluções de tamanho 1 (1 sentença), e assim por diante. Outra característica importante é que o espaço de busca é completo, por exemplo, a sub-solução $\{$ S3T1, S1T1\}e a sub-solução $\{$ S1T1, S3T1 $\}$ são consideradas caminhos diferentes no espaço de busca já que, a ordem das sentenças alterar a pontuação final, dado o Modelo de Coerência. Mas, se a coerência não estiver sendo considerada e apenas importasse a informatividade (dada pelos modelos de transformação), o espaço de busca seria incompleto, pois somente precisaria de uma sub-solução que contenha as sentenças sem importar a ordem.

A complexidade do espaço completo é maior que a complexidade do expaço incompleto. A complexidade do espaço completo é $O(\mathrm{~nm})$, em que n é o número de sentenças no conjunto de documentos, e m é o número de sentenças que devem ser incluídas no sumário de acordo com uma taxa de compressão. Dado que a taxa de compressão é normalmente dada em número de palavras, então m é um valor aproximado, calculado a partir da divisão do número de palavras permitido pela taxa de compressão e a média dos tamanhos das sentenças. A complexidade do espaço incompleto é $O(\mathrm{~nm} / 2)$, dado somente a metade das possíveis soluções é explorada.

Em um cenário real, encontrar a solução ótima pode representar um custo computacional muito alto. $\mathrm{O}$ algoritmo $\mathrm{A}^{*}$ aborda esse problema combinando o valor da pontuação de cada sentença, dado por alguma função f (neste caso seriam os modelos de transformação) e uma heurística $h$, a qual estima a pontuação adicional que seria a partir da solução atual até a solução final (o sumário). A pontuação de uma sub-solução acordo com o algoritmo A* é dada pela seguinte equação:

$$
g\left(s_{j}\right)=f\left(s_{j}\right)+h\left(s_{j}\right)
$$

É importante destacar que o cálculo da função f de uma sub-solução implica a multiplicação das pontuações das sentenças que compõem essa sub-solução (dadas pelos valores do modelo de transformação correspondente), mas, como se viu nas seções anteriores, essas multiplicações podem ser transformadas numa soma de logaritmos. Portanto, o cálculo da 
função f é dado pela soma dos valores do modelo de transformação correspondente, para cada sentença.

Aker et al. também propuseram uma heurística que simula a inserção de sentenças na sub-solução de forma gulosa. A heurística tem inicio com a soma das pontuações das sentenças (considerando-se sempre primeiro as sentenças mais bem pontuadas) até que se chegue numa sentença que ultrapasse os limites de tamanho do sumário. Quando isso acontece, se pula pra seguinte sentença melhor pontuada até achar a primeira que esteja dentro dos limites de tamanho. Quando isto acontece, multiplica-se a pontuação da sentença com a razão entre o tamanho que falta ser preenchido (ou tamanho restante) e o tamanho da sentença. Soma-se essa ponderação ao resultado da somatória feita até a sentença anterior, caso exista tal somatória (pode ser que seja a única e última sentença a ser considerada na heurística). Para ilustrar isso, considerem-se os seguintes valores obtidos por alguma função $f$ e seus correspondentes valores de 1 (em que 1 é número de palavras na sentença) para as sentenças do exemplo mostrado na Figura: S1T1 $f=6 \mathrm{l}=7, \mathrm{~S} 2 \mathrm{~T} 1 \mathrm{f}=5 \mathrm{l}=6$, S1T2 $f=3 \mathrm{l}=2$ and S2T2 $f=1 \mathrm{l}=1$. Na Figura 31, é mostrado o cálculo da heurística $h$ para uma sub-solução no espaço de busca da Figura 30, considerando um limite de 10 palavras.

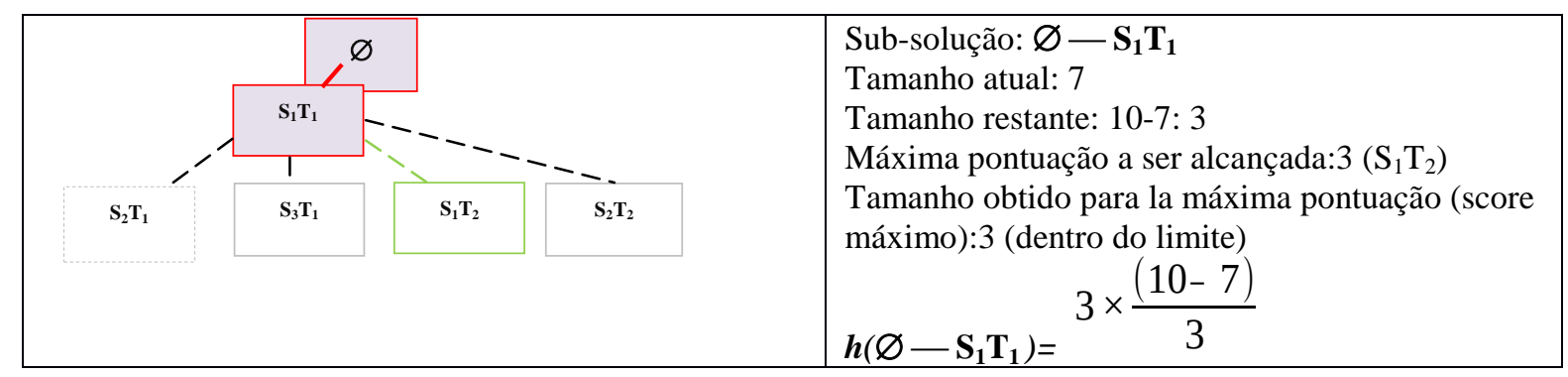

Figura 31: Exemplo de cálculo de heurística para o algoritmo A*

O valor de h é zero quando a sub-solução é o sumário final. Isso significa que a sub-solução alcançou os limites da taxa de compressão ou que estender a sub-solução, adicionando uma nova sentença, excederia o tamanho permitido pela taxa de compressão.

$\mathrm{A}^{*}$ faz uso de uma fila de prioridade $\mathrm{Q}$, que permite manter um rastreamento de todas as sub-soluções que tenham sido avaliadas até o momento, e também faz uso de uma lista ordernada de sentenças X. No topo de Q está armazenada a melhor sub-solução de acordo com a função g, descrita anteriormente. Em cada iteração, a sub-solução que se encontra no topo da fila de prioridade Q é removida e avaliada para ver se alcançou o tamanho máximo permitido ou se o valor de h é zero. Se for assim, o algoritmo termina e a sub-solução ótima é retornada, o seja, o sumário final. Se nenhuma das duas condições mencionadas é satisfeita, a sub-solução no topo da fila Q é expandida adicionando sentenças que ainda não foram incluidas naquela sub-solução. Essa expansão é representada pelos nós-filhos de uma sub-solução no grafo que representa o espaço de busca. A pontuação dada pela função g é calculada para todas as novas sub-soluções, e, de acordo com essa pontuação, elas são inseridas e ordenadas na fila Q. O algoritmo para quando a solução ótima for encontrada. $\mathrm{O}$ algoritmo de Aker et al. é mostrado no Quadro a seguir: 


\section{Algoritmo de decodificação de sumários multi-documento A* simples}

\section{Entrada:}

- Lista de sentenças: $\mathbf{x} / /$ Lista de sentenças ordenadas por score

- função de pontuação: $f($.

- função heurística: $\boldsymbol{h}($.

- Tamanho limite do sumário: $\boldsymbol{L}$

Estruturas usadas:

- Fila de Prioridade Q=[(0,Ø,IndicadordeFim) $]$

// Lista de triplas da forma: (Score da sub-sol, sentenças da sub-sol, Indicador de sol. final)

1. Enquanto $\mathrm{Q} \neq[\mathrm{]}$ fazer:

2. $\quad g, \mathbf{y}, s \leftarrow$ RemoverTopo(Q)

3. Se $s=$ T então: // Se é uma solução final então a retorna

4. retorna $y$

5. Senão:

6. Para $y_{1} \leftarrow[\max (y)+1, k]$ fazer: // buscamos inserir uma nova sentença à sub-sol. removida de $Q$

7. $\quad y^{\prime} \leftarrow \mathbf{y} U \mathbf{x}\left[y_{1}\right]$

8. Se Tamanho $\left(y^{\prime}\right) \leq \mathbf{L}$ então: // Se o tamanho da nova sub-sol. não excede o limite

9. $\quad \boldsymbol{g}^{\prime} \leftarrow \mathbf{f}\left(y^{\prime}\right)+\boldsymbol{h}\left(y^{\prime}, \mathbf{x}, l\right) / /$ Calcula-se a nova pontuação com base em $\boldsymbol{f}$ e na heurística $\boldsymbol{h}$; // I representa o tamanho da sub-sol. até o momento

10. Inserir(Q, $\left.\left(g^{\prime}, y^{\prime}, F\right)\right)$ // Inserimos a nova sub-solução de forma ordenada de acordo com $g^{\prime}$

11. Senão:

12. Se Tamanho( $\left.y^{\prime}\right)>\mathbf{L}$ e Tamanho(y') $\leq \mathbf{L}+10$ :

13. $\quad g^{\prime} \leftarrow f\left(y^{\prime}\right)+\boldsymbol{h}\left(y^{\prime}, \mathbf{x}, l\right)$

14. Inserir(Q, $\left.\left(g^{\prime}, y^{\prime}, T\right)\right)$

$15 . \quad$ Senão:

16. Inserir $(\mathrm{Q},(g, \mathbf{y}, T))$

17. fim Se

18. fim Para

19. fim Se

20. Fim Enquanto

Quadro 2: Algoritmo de decodificação A* simples

\subsubsection{Decodificação com Tratamento de Redundância usando $A^{*}$}

Para tratar a redundância no modelo de decodificação, foram usadas as relações da categoria redundância da CST. De acordo com a tipologia de relações CST, existem dois tipos de redundância: parcial e total. A redundância parcial ocorre quando somente uma parte da informação é repetitiva ou redundante, e as relações CST que a representam são Subsumption e Overlap. A redundância total ocorre quando toda a informação entre duas sentenças é redundante, sendo que as relações que representam esde tipo de redundância são: Equivalence, Identity e Summary.

O método de decodificação com tratamento de redundância desenvolvido neste trabalho consiste em penalizar as sub-soluções com redundância, eliminando-as da fila de prioridade $\mathrm{Q}$ e inserindo-as em uma segunda fila de prioridade $\mathrm{Q}_{1}$. A ordem dessas sub-soluções na fila de prioridade $\mathrm{Q}_{1}$ varia de acordo com o número e o tipo de sentenças redundantes que compõem a sub-solução. Por exemplo, as sub-soluções com maior número de informações redundantes devem aparecer depois das sub-soluções com menor número de sentenças redundantes na fila $\mathrm{Q}_{1}$. Em outras palavras, as sub-soluções com maior número redundância total devem ser penalizadas de forma que tenham posições menos privilegiadas na fila $\mathrm{Q}_{1}$ do 
que as sub-soluções que têm apenas redundâncias parciais. Para ilustração, considere-se o espaço de busca da Figura 33, na qual são mostradas as relações de redundância da CST que ocorrem entre sentenças de uma mesma sub-solução.

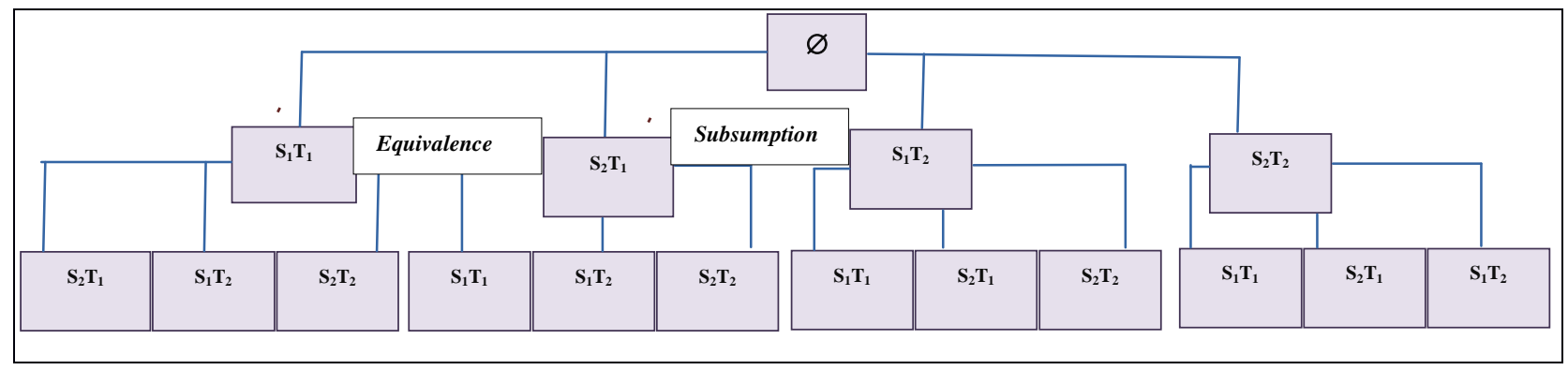

Figura 32: Espaço de busca com informações semântico-discursivas

Nesse exemplo, as sub-soluções (S1T1, S2T2) e (S2T1, S2T2) têm informações redundantes, mas a sub-solução (S1T1, S2T2) tem redundância total, enquanto (S2T1, S2T2) têm apenas redundância parcial, por isso, ela deveria ter mais prioridade em Q1 do que (S1T1, S2T2), como se mostra na Figura 33 a seguir:

\begin{tabular}{|c|c|}
\hline$\left\{S_{2} T_{1}, S_{2} T_{2}\right\}$ & $\left\{S_{1} T_{1}, S_{2} T_{2}\right\}$ \\
\hline
\end{tabular} Figura 33: Exemplo de fila de prioridade para sub-soluções com redundância

Para conseguir que a redundância total seja mais penalizada que a redundância parcial, e que isso se veja refletido na ordenação da fila Q1, simplesmente se mantém um contador com a soma das pontuações das sentenças redundantes, sendo que, as sentenças parcialmente redundantes são penalizadas com 0.5 sobre sua pontuação original e as sentenças que são totalmente redundantes são penalizadas com 1.0 sobre sua pontuação original. Finalmente, para cada sub-solução a pontuação dada por f é calculada normalmente e logo se diminui esse valor com o valor do contador para sentenças redundantes parciais e de sentenças redundantes totais.

A estratégia de manter as sub-soluções redundantes em outra fila de prioridade é que, caso a fila $\mathrm{Q}$ fique vazia e não tenha se atingido o limite permitido do sumário, então será necessário começar a expandir a segunda fila de prioridade Q1. Nota-se que, caso comece a se expandir a fila Q1, sempre se dará preferência às soluções que tenham menor quantidade de redundância, já que as soluções que tem mais redundância total serão mais penalizadas e, portanto, estarão localizadas depois das sentenças menos redundantes na fila de prioridade Q1. Deste modo tenta-se evitar ao máximo, a presença de elementos redundantes no sumário final.

Nessa abordagem, a heurística é calculada com o mesmo critério que o algoritmo original de Aket et al., mas o valor de $f$ (caso se chegue a utilizar a fila Q1) é considerando as penalizações das sentenças redundantes como descrito acima. $\mathrm{O}$ algoritmo dessa nova abordagem é mostrado no Quadro a seguir: 
Algoritmo de decodificação de sumários multi-documento A* com Tratamento de Redundância

Entrada:

- Lista de sentenças: $\mathbf{x}$

- função de pontuação: $f($.

- função heurística: $\boldsymbol{h}($.

- Tamanho limite do sumário: $\boldsymbol{L}$

Estruturas usadas:

- Fila de Prioridade $\mathbf{Q}=[(\mathbf{0 , \varnothing , I n d i c a d o r d e F i m )}]$

1. Enquanto $Q \neq[]$ fazer:

2. $g, \mathbf{y}, s \leftarrow$ RemoverTopo(Q)

3. Se $s=$ T então: // Se é uma solução final então a retorna

4. retorna $y$

5. Senão:

6. Para $y_{1} \leftarrow[\max (y)+1, k]$ fazer: // buscamos inserir uma nova sentença à sub-sol.

7. $\quad y^{\prime} \leftarrow \mathbf{y ~ U ~ x}\left[y_{1}\right]$

8. $\quad \mathrm{R} \leftarrow$ BuscaRedundância( $\left(y^{\prime}\right)$ // Busca se a solução tem sentenças redundantes

9. Se Tamanho $\left(y^{\prime}\right) \leq \mathrm{L}$ então: // Se o tamanho da nova sub-sol não excede o limite

10. Se $\mathrm{R}==$ Sim então: // O seja é uma solução com redundância

11. RedTotal $\leftarrow \operatorname{CalcRedTotal}\left(y^{\prime}\right) / /$ Soma das pontuações das sentenças com Red Total

12. RedParcial $\leftarrow$ CalcRedParcial $\left(y^{\prime}\right) / /$ Soma das pontuações das sents. com Red Parcial

13. $\quad \boldsymbol{g}^{\prime} \leftarrow \boldsymbol{f}\left(y^{\prime}\right)-\mathbf{0 . 5} *$ RedParcial - RedTotal $+\boldsymbol{h}\left(y^{\prime}, \mathrm{x}, l\right)$

14. $\quad \operatorname{Inserir}\left(\mathrm{Q}_{1},\left(g^{\prime}, y^{\prime}, T\right)\right)$

15. Senão:

16. $\quad \boldsymbol{g}^{\prime} \leftarrow \boldsymbol{f}\left(y^{\prime}\right)+\boldsymbol{h}\left(y^{\prime}, \mathrm{x}, l\right)$

17. Inserir $\left(\mathrm{Q},\left(g^{\prime}, y^{\prime}, T\right)\right)$

18. Senão:

19. $\quad$ Se Tamanho $\left(y^{\prime}\right)>\mathbf{L}$ e Tamanho $\left(y^{\prime}\right) \leq \mathbf{L}+10$ :

20. Se $\mathrm{R}==$ Sim então:

21. $\quad$ RedTotal $\leftarrow$ CalcRedTotal $\left(y^{\prime}\right)$

22. RedParcial $\leftarrow$ CalcRedParcial $\left(y^{\prime}\right)$

23. $\quad \boldsymbol{g}^{\prime} \leftarrow \boldsymbol{f}\left(y^{\prime} \mid \mathrm{x}\right)-\mathbf{0 . 5} *$ RedParcial - RedTotal $+\boldsymbol{h}\left(y^{\prime}, \mathrm{x}, \boldsymbol{l}\right)$

24. Inserir $\left(\mathrm{Q}_{1},\left(g^{\prime}, y^{\prime}, T\right)\right)$

$25 . \quad$ Senão:

26. $\quad \boldsymbol{g}^{\prime} \leftarrow \boldsymbol{f}\left(y^{\prime} \mid \mathrm{x}\right)+\boldsymbol{h}\left(y^{\prime}, \mathrm{x}, l\right)$

27. $\quad \operatorname{Inserir}\left(\mathrm{Q},\left(g^{\prime}, y^{\prime}, T\right)\right)$

28. Senão:

29. $\quad \operatorname{Inserir}(\mathrm{Q},(g, \mathbf{y}, T))$

30. fim Se

31. fim Se

32. fim Para

33. fim Se

34. Fim Enquanto

// Segundo bloco Enquanto : Chega-se neste bloco quando Q fica vazío e não se retornou nenhuma solução então se processa $\mathrm{Q}_{1}$ 


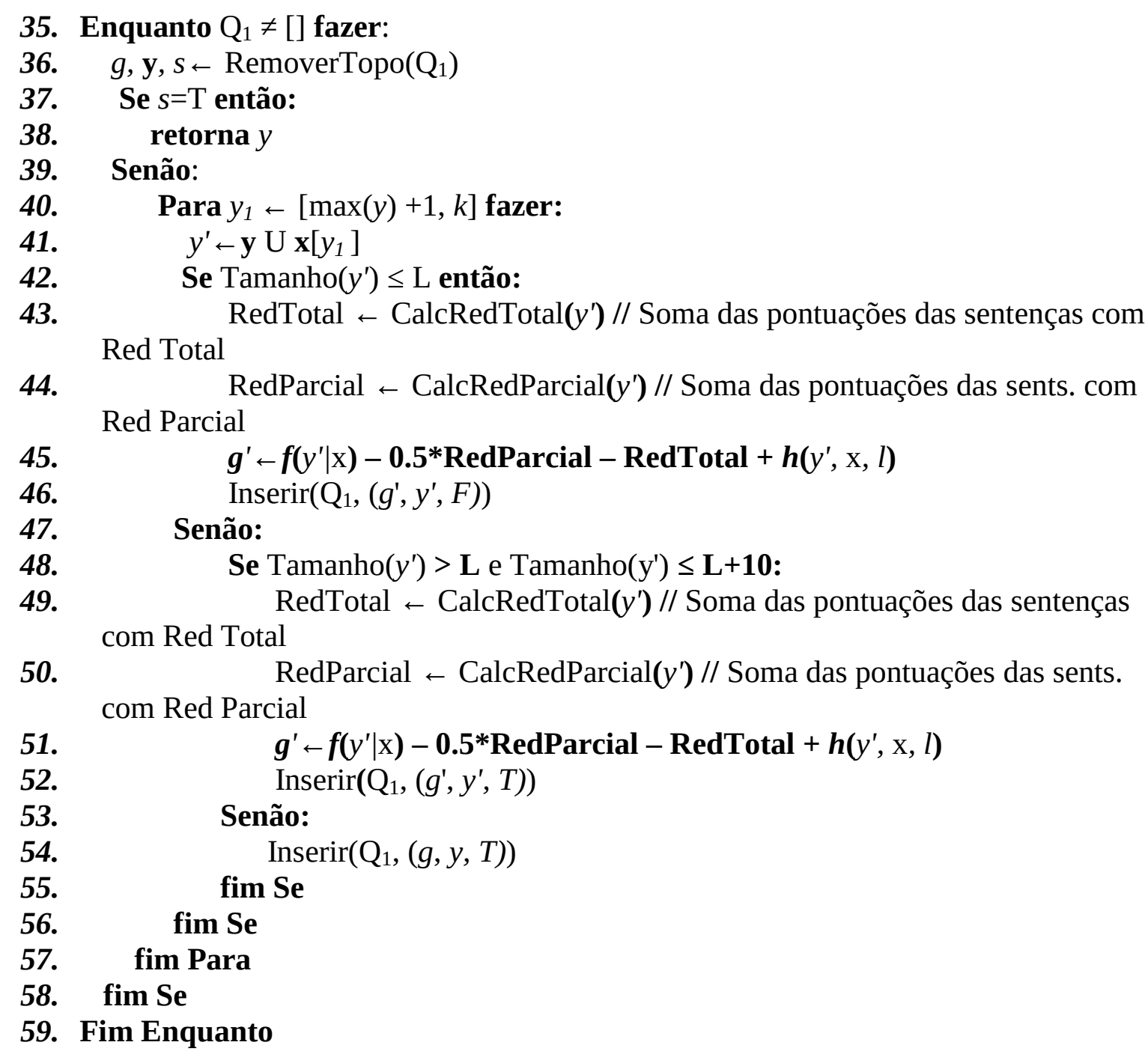

Quadro 3: Algoritmo de decodificação A* com tratamento de redundância

\subsubsection{Modelo de Coerência e Decodificação}

Como foi mencionado em seções anteriores, o Modelo de Coerência pode ser aplicado de duas formas. Uma como parte da modelagem gerativa (veja-se a Equação na Subseção 5.2.3), em que $\mathrm{P}(\mathrm{S})$ é combinado com $\mathrm{P}(\mathrm{C} \mid \mathrm{S})$ para obter a probabilidade da sentença, o que representa a pontuação da sentença usada na função $f$ no decodificador. Nesse caso, cada sub-solução é considerada um "sumário" para fins de computar $\mathrm{P}(\mathrm{S})$ nesse estágio da decodificação.

Essa abordagem pode ter algumas desvantagens já que, ao integrar muitos atributos para determinar a importância de uma sentença, o resultado pode degradar e não produzir sumários bons. Por esse motivo, considerou-se outra abordagem, que é aplicada após a fase de decodificação. Nessa abordagem o Modelo de Coerência funciona como um seletor do sumário mais coerente entre um conjunto de sumários bons em termos da informatividade do conteúdo, os quais foram selecionados pelo decodificador. 
Para poder realizar essa seleção com o Modelo de Coerência, é necessário modificar o decodificador de forma que, em vez de retornar a melhor solução (o topo da fila Q quando tenha atingido o limite de tamanho), retornam-se as top 10 melhores soluções da fila $\mathrm{Q}$, o seja, o algoritmo é modificado para parar quando as 10 primeiras posições da fila $\mathrm{Q}$ atingem os limites de tamanho permitido para o sumário. Após o algoritmo ter retornado as 10 primeiras soluções da fila Q, calcula-se o Modelo de Coerência para todas elas, e, a solução que obtiver a maior pontuação de acordo com o modelo é o sumário final.

Ao se usar decodificador com tratamento de redundância, aplica-se a mesma metodologia que a descrita no paragrafo anterior, com a exceção de que, caso o tamanho da fila Q (m) seja menor que 10, então se começa a explorar a fila Q1, a qual vai se decodificando até que os 10-m primeiros elementos de Q1 tenham atingido os limites de tamanho do sumário. Desse modo, obtêm-se as 10 melhores soluções do processo de decodificação com tratamento de redundância, nas quais é aplicado o Modelo de Coerência para determinar qual é o melhor sumário.

\subsubsection{Resumo do Capítulo e outros modelos relacionados}

Neste Capítulo, foi detalhado o desenvolvimento de cada um dos componentes da modelagem gerativa no esquema Noisy-Channel: Canal Ruidoso - $\mathrm{P}(\mathrm{C} \mid \mathrm{S})$, para esse componente, foram apresentados três modelos de transformação, os quais foram desenhados para capturar padrões de seleção de conteúdo de sumários multidocumento via diversos atributos superficiais e profundos que descrevem a historia gerativa de um sumário multidocumento; Qualidade do Sumário - $\mathrm{P}(\mathrm{S})$, neste componente foi desenvolvido um Modelo de Coerência que combina o Modelo de Entidades e a informações discursivas da CST e da RST; finalmente, foi desenvolvido um decodificador que, combinando $\mathrm{P}(\mathrm{C} \mid \mathrm{S})$ e $\mathrm{P}(\mathrm{S})$, encontra o melhor sumário para um conjunto de textos $\mathrm{P}(\mathrm{S} \mid \mathrm{C})$.

Além desses modelos, foram explorados também outros modelos discriminativos em Jorge et al. (2011), onde basicamente foram aplicados os mesmos atributos, mas em métodos de aprendizado discriminativo como SVM e árvores de decisão. Esses métodos mostraram bons resultados, sendo que os atributos relacionados com informações semântico-discursivas da CST se mostraram mais discriminativos. Nesse trabalho, não foram usados atributos com base na RST.

Além desses modelos todos, também foram explorados outros modelos e técnicas cujo desenvolvimento não progrediu, seja por falta de tempo, complexidade ou porque os resultados preliminares mostraram que não era adequado continuar aprofundando nessa linha. Um modelo que começou a ser explorado e ficou inconcluso foi um em que apenas considerou-se informações da CST, mas não simplesmente em nível de sentença senão também em nível dos parágrafos. A hipótese subjacente a esse modelo era que, ao selecionar conteúdo para um sumário, antes de considerar as informações micro (sentenças) era importante considerar as informações macro (parágrafos), já que as sentenças que compõem um sumário multidocumento teriam maior tendência de pertencer a parágrafos mais relevantes. Desse modo, além de considerar probabilidades do tipo $\mathrm{P}\left(\right.$ Redundância $\left.=\mathrm{N}_{\mathrm{Red}} \mid \mathrm{SSi}\right)$ também eram consideradas probabilidades do tipo $\mathrm{P}(\mathrm{Par}-\mathrm{Red}=$ 
$\mathrm{N}_{\text {Red }} \mathrm{SSi}$ ), o seja, a probabilidade de que um paragrafo que contêm uma sentença de sumário gere $\mathrm{N}_{\mathrm{Red}}$ sentenças via o atributo de Redundância, isso é, que as sentenças contidas nele gerem $\mathrm{N}_{\mathrm{Red}}$ redundâncias. Com isso, o modelo privilegiaria sentenças que viessem de parágrafos altamente discutidos no conjunto de textos. Resultados prévios de este modelo mostraram uma leve melhoria sobre o modelo que apenas usava informações da CST. Por falta de tempo, a investigação mais detalhada deste modelo foi abandonada. 


\section{Avaliação}

Neste Capítulo, apresentam-se e discutem-se os resultados das avaliações dos métodos desenvolvidos neste trabalho. Em princípio, iremos discutir os resultados do Modelo de Coerência no contexto da tarefa de classificação de sumários coerentes e incoerentes. $\mathrm{Na}$ sequência, apresentar-se-ão os resultados de cada um dos métodos de transformação dadas as variações na aplicação do Modelo de Coerência (MC) (durante o processo de decodificação e após o processo de decodifição) e as duas variações do Decodificador (DEC) (com e sem tratamento de redundância). Na Figura 34 a seguir, mostra-se um esquema dos grupos de resultados que serão apresentados e discutidos nas seguintes seções deste Capítulo.

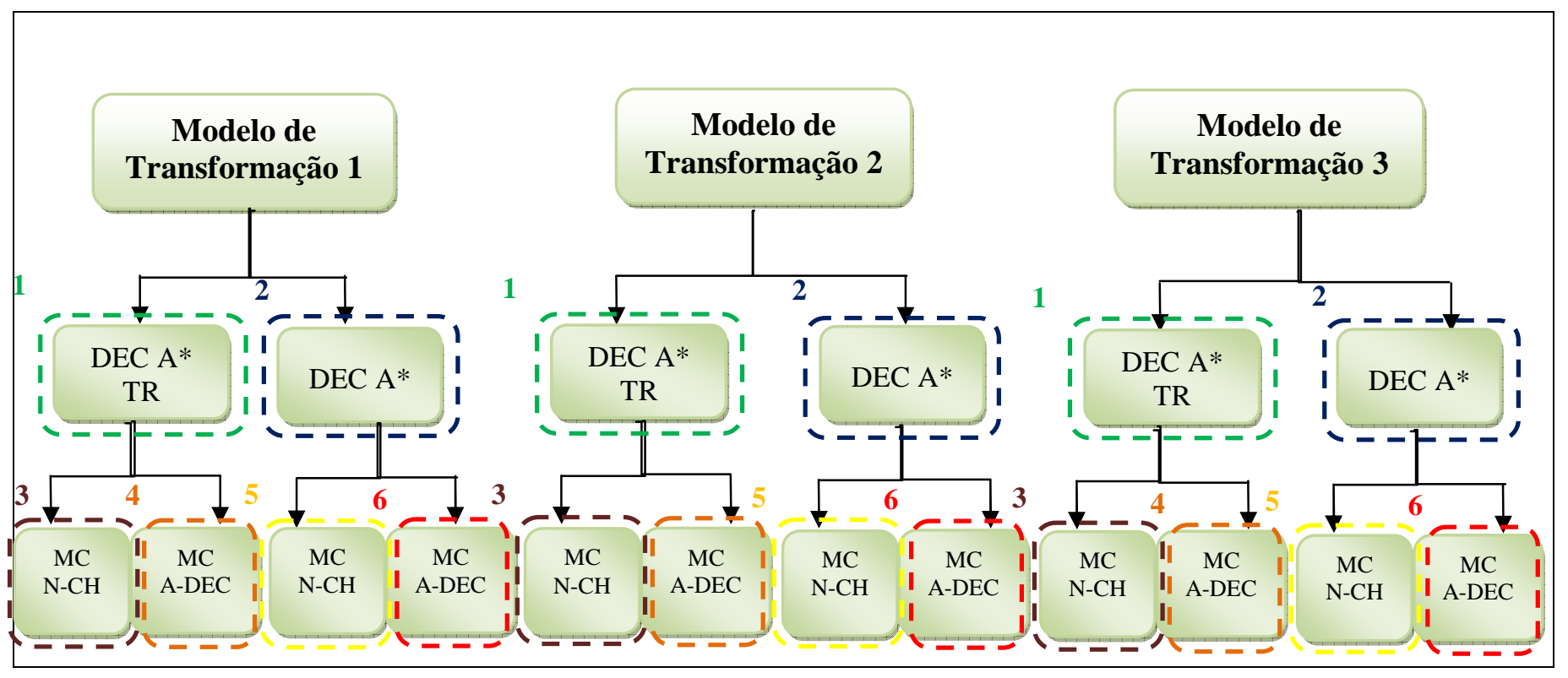

Figura 34: Esquema de experimentos realizados para a modelagem gerativa

De acordo com a Figura 34, foram realizados em total 6 experimentos para cada modelo de transformação, que correspondem a todos os filhos de um nó (do modelo de transformação). Para cada modelo de transformação (nível 1), cada nível na hierarquia da Figura 34 indica o incremento de alguma variação nos experimentos. Por exemplo, para o modelo de transformação 1 , no $2^{\text {do }}$ nível da hierarquia encontram-se os experimentos DEC A*TR e DEC $A^{*}$, indicados pelos números 1 e 2 respectivamente. O experimento correspondente ao 
número 1 indica os resultados do teste do modelo de transformação 1 com o decodificador com base no algoritmo $\mathrm{A}^{*}$ e o método de tratamento de redundância proposto; já o experimento 2 indica os resultados do teste do modelo 1 com o decodificador $A^{*}$ simples, sem nenhum tratamento de redundância. Para o mesmo modelo de transformação 1 , tem-se, no $3^{\circ}$ nível, os experimentos 3, 4, 5 e 6 . O experimento 3 indica os resultados do teste com decodificador $\mathrm{A}^{*}$ com tratamento de redundância e a incorporação do Modelo de Coerência no modelo Noisy-Channel, o seja, durante o processo de decodificação; o experimento 4 indica os resultados do teste com decodificador $A^{*}$ com tratamento de redundância e a incorporação do Modelo de Coerência após a decodificação; o experimento 5 indica os resultados do teste com o decodificador $\mathrm{A}^{*}$ sem tratamento de redundância e a incorporação do Modelo de Coerência no modelo Noisy-Channel; finalmente, o experimento 6 indica os resultados do teste com o decodificador $\mathrm{A}^{*}$ sem tratamento de redundância e a incorporação do Modelo de Coerência após a decodificação. Esse mesmo esquema combinatório é aplicado aos outros dois modelos de transformação.

Além dos três modelos de transformação, propuseram-se três variações a esses modelos: (i) um modelo gerativo contendo apenas informações profundas (RST e CST), (ii) um modelo contendo apenas informações discursivas monodocumento (RST) e (iii) um modelo apenas contendo informações semântico-discursivas mulidocumento (CST). Os resultados desses modelos são analisados sobre o mesmo esquema de variações que os outros três modelos de transformação.

O objetivo de fazer todas essas variações e avaliá-las separadamente é observar o impacto de cada um dos componentes desenvolvidos. Por exemplo, objetiva-se saber o impacto dos atributos de cada modelo sem considerar a presença do Modelo de Coerência (experimentos correspondentes aos números 1 e 2). Visa-se também, conhecer o impacto do Modelo de Coerência como parte do modelo Noisy-Channel e o impacto fora dele, após a decodificação. Por esse motivo, os resultados foram avaliados em três blocos, um para analisar o impacto dos atributos dos modelos, outro para analisar o impacto do decodificador e o outro para analisar o impacto do Modelo de Coerência.

Finalmente, todas as variações dos métodos propostos foram comparadas com dois métodos estatísticos gerativos do estado da arte: TopicSum e HierSum (Haghighi e Vanderwende, 2009). Além disso, os métodos propostos neste trabalho também foram comparados com os sumarizadores existentes para o português do Brasil.

\subsection{Modelo de Coerência na Classificação de Sumários coerentes e incoerentes}

Para avaliar o desempenho do Modelo de Coerência reproduziu-se o mesmo esquema de avaliação de Barzilay e Lapata (2008). Para o treinamento e teste dos modelos, foram utilizados como base os 50 extratos multidocumento do córpus CSTNews, e, para cada um destes 50 extratos, foram geradas 20 possíveis permutações das sentenças dos mesmos sumários, com o objetivo de ter sumários incoerentes na base de dados para o aprendizado. No total, obtiveram-se 1000 pares de vetores de atributos $(50 * 20)$, correspondentes ao par: sumário coerente e o outro incoerente (sumário permutado). Cada um desses pares 
representa uma instância em um processo de aprendizado usando o pacote SVMLight (Ref), que implementa uma versão do algoritmo SVM voltado para resolver problemas de ranque. De fato, o objetivo do aprendizado dado esse cenário é criar um modelo capaz de ranquear adequadamente um par de sumários (coerente e incoerente), sendo que o sumário coerente deve estar mais bem ranqueado que o sumário incoerente.

Foram produzidos 5 tipos de vetores de atributos correspondentes: ao modelo original de entidades, ao modelo que combina a grade de entidades e a matriz de relações CST, ao modelo de grade de entidades e a matriz de categorias CST, ao modelo grade de entidades e a matriz de informação booleana da CST, e finalmente, o modelo de entidades e a matriz de informação booleana da CST e RST.

Para cada um desses modelos, foi montado um esquema de aprendizado 10-fold cross validation para o treinamento e teste dos modelos. A acurácia foi calculada para cada fold como o valor resultante de dividir o número de vezes que o modelo ranqueou corretamente o par (extrato humano - extrato permutado) pelo número total de pares. Os resultados desses experimentos são mostrados na Tabela 24, a seguir:

Tabela 24: Resultados do Modelo de Coerência para classificação de sumários

\begin{tabular}{|c|c|c|c|c|}
\hline $\begin{array}{c}\text { Modelo } \\
\text { Entidades }\end{array}$ & $\begin{array}{c}\text { Modelo Entidades e } \\
\text { Matriz Relações } \\
\text { CST }\end{array}$ & $\begin{array}{c}\text { Modelo Entidades e } \\
\text { Matriz Categorias } \\
\text { CST }\end{array}$ & $\begin{array}{c}\text { Modelo de } \\
\text { Entidades e Matriz } \\
\text { Booleana CST }\end{array}$ & $\begin{array}{c}\text { Modelo de } \\
\text { Entidades e Matriz } \\
\text { Booleana CST e } \\
\text { RST }\end{array}$ \\
\hline $73,654 \%$ & $68,344 \%$ & $73,224 \%$ & $81,396 \%$ & $79,039 \%$ \\
\hline
\end{tabular}

Como pode ser observado, o modelo que obteve melhor acurácia foi o Modelo de Entidades combinado com a Matriz Booleana CST, que superou o Modelo de Entidades original. O Modelo Booleano CST e RST também supera o Modelo de Entidades original, apesar da acurácia dele ser um pouco inferior ao Modelo Booleano de CST só. Como foi discutido anteriormente, os modelos que incluem muitos atributos, como o Modelo de Relações CST ou Modelo de Categorias CST, têm um desempenho baixo. A acurácia deles foi bem inferior ao Modelo Booleano; de fato, o Modelo de Relações CST teve um desempenho inferior ao Modelo de Entidades original, inclusive.

Como o desempenho dos Modelos das Matrizes booleanas CST e CST-RST foi muito similar, fez-se um experimento em que somente se preencheu a Matriz Booleana com informações da RST, o seja, cada célula da matriz foi preenchida com 1 ou 0 , caso houvesse ou não uma relação RST. Fez-se isso com o objetivo de verificar quanta informação realmente relevante para identificar coerência em sumários. O resultado desse experimento mostrou um $80 \%$ de acurácia, um valor muito próximo ao Modelo da Matriz Booleana CST. Aplicou-se o teste estatístico T com 95\% de confiança e os resultados dos Modelos de Matrizes Booleanas CST e booleanas CST-RST não mostraram diferencia significativa. Isso significaria que as informações CST e RST conseguem modelar bem os atributos de sumários coerentes. Apesar disso, também se pode considerar que, se os experimentos fossem realizados em uma base de dados maior, que incluísse mais extratos humanos 
coerentes, poderia se perceber melhor a capacidade da CST de modelar mais adequadamente a coerência em sumários multidocumento.

$\mathrm{O}$ teste estatístico $\mathrm{T}$ também foi aplicado para cada par de métodos avaliados $\mathrm{e}$ verificou-se que os resultados são estatisticamente significativos com um 95\% de confiança.

Esses experimentos confirmaram a hipótese de que o conhecimento discursivo da CST permite modelar melhor a coerência em sumários multidocumento do que o Modelo de Entidades original, em que somente se consideram informações sintáticas das entidades nas transições de sentenças.

Com base nesses resultados prévios, incorporou-se o melhor desses modelos na modelagem gerativa para sumários multidocumento, ou seja, incorporamos o modelo híbrido do Modelo de Entidades e o Modelo de informações booleanas da CST. Os resultados da incorporação desse modelo serão discutidos em seções posteriores

\subsection{Impacto dos Atributos nos Modelos de Transformação}

A seguir é mostrada a Tabela dos três modelos de transformação (MT1,MT2 e MT3) e mais três variações dos atributos: somente profundos (MTProf: CST e RST), somente RST (MTRST) e somente CST (MTCST). Em princípio, esses resultados são mostrados a partir de uma decodificação com tratamento de redundância e sem aplicar o Modelo de Coerência, apenas para observar o comportamento dos atributos nos modelos (experimentos correspondentes ao número 1 de acordo com a Figura 34).

Tabela 25: Resultados da medida Rouge para Modelos de Transformação com tratamento de redundância na decodificação, sem modelo de Coerência

\begin{tabular}{|l|c|c|c|c|c|c|}
\hline \multirow{2}{*}{ Modelo } & \multicolumn{3}{|c|}{ Rouge-1 } & \multicolumn{3}{c|}{ Rouge-2 } \\
\cline { 2 - 7 } & $\begin{array}{c}\text { Cobertur } \\
\mathrm{a}\end{array}$ & Precisão & $\begin{array}{c}\text { Medida- } \\
\mathrm{F}\end{array}$ & Cobertura & Precisão & Medida-F \\
\hline MT1 & $\mathbf{0 , 2 4 9 8}$ & $\mathbf{0 , 2 6 7 9}$ & 0,2555 & $\mathbf{0 , 0 9 6 2}$ & 0,1042 & 0,0987 \\
\hline MT2 & $\mathbf{0 , 2 5 5 9}$ & 0,2813 & 0,2648 & $\mathbf{0 , 1 0 5 3}$ & 0,1162 & 0,1090 \\
\hline MT3 & 0,2328 & 0,2628 & 0,2439 & 0,0886 & 0,1035 & 0,0943 \\
\hline MTProf & $\mathbf{0 , 2 6 2 3}$ & $\mathbf{0 , 2 7 9 4}$ & $\mathbf{0 , 2 6 8 1}$ & 0,0855 & 0,0908 & 0,0873 \\
\hline MTRST & $\mathbf{0 , 3 4 5 3}$ & $\mathbf{0 , 3 5 3 4}$ & $\mathbf{0 , 3 4 8 2}$ & 0,1463 & 0,1487 & 0,1469 \\
\hline MTCST & 0,2582 & 0,2791 & 0,2651 & 0,0926 & 0,1035 & 0,0964 \\
\hline
\end{tabular}

Pode-se observar vários dados interessantes na Tabela. Em princípio, observa-se uma melhoria do modelo de transformação 1 para o modelo de transformação 2, sendo que o primeiro considera apenas informações superficiais e o segundo apresenta informações profundas discursivas monodocumento. Isso indicaria que o incremento destas informações profundas às informações superficiais ajudaria a capturar melhor os padrões de seleção de conteúdo em sumários multidocumento, que é uma das hipóteses deste trabalho. No entanto, do modelo de transformação 2 para o modelo de transformação 3, que incrementa 
informações CST, não se observa nenhuma melhoria, também não é observada melhoria do modelo de transformação 1 para o modelo de transformação 3. Isso condiz com os resultados observados entre os modelos: profundo, CST e RST, dos quais é o modelo RST o que obtêm melhores resultados, inclusive melhores que todos os outros modelos de transformação. Isso indicaria que, na modelagem gerativa multidocumento, a saliência das informações monodocumento capturariam melhor as decisões de seleção de conteúdo de sumários multidocumento, e se complementariam melhor com os atributos superficiais, do que os atributos baseados em CST.

Uma questão importante é que, apesar da CST ter sido desenhada para modelar os fenômenos multidocumento, esta não parece ter sido a mais adequada para capturar padrões de seleção de conteúdo entre vários textos. Isso se pode dever ao fato de que muitas vezes os humanos resolvem fazer um sumário tendo como guia um único documento da coleção, apenas. Isso implicaria que as informações discursivas monodocumento tem mais probabilidade de modelar os fenômenos que estejam acontecendo no processo de sumarização. Outro aspecto a considerar é que também é possível que, apesar dos sumários humanos serem compostos por sentenças que vem de vários textos, estas sentenças podem não ter relações CST entre si, o que acabaria privilegiando o uso de informações discursivas monodocumento, as quais têm mais chance de ocorrer em um sumário, já que informações de núcleo e satélite sempre ocorrem, no entanto, informações CST nem sempre vão ocorrer. Para esses resultados, foi decidido medir o grau de confiança dos resultados mais relevantes segundo a hipótese de que o incremento de informações profundas às informações superficiais levaria a capturar melhor as decisões de seleção de conteúdo. Para isso, foi aplicado o teste estatístico t para verificar a relevância estatística dos três modelos, entre os modelos de transformação 1 e 2 , entre os modelos 2 e 3 e entre os modelos 1 e 3 . Os resultados mostram que há uma significância estatística com um valor de confiança de $95 \%$. Com base em isso, podemos dizer que os resultados são um bom indício de que uma modelagem gerativa que combina atributos profundos e superficiais é capaz de capturar adequadamente as decisões de seleção de conteúdo para sumários multidocumento. A seguir são mostrados três sumários automáticos que refletem os resultados mostrados na Tabela 25. Esses sumários foram extraídos do Cluster 24, em que se relata os eventos dos jogos panamericanos. 


\section{Sumário Modelo de Transformacão 1}

A brasileira Joana Costa ficou com a quinta posição, com $4 \mathrm{~m} 20$ e mostrou, mais uma vez, neste Pan do Rio, que a pressão de competir em casa pode prejudicar os atletas.

Este recorde deve ser quebrado nesta edição dos Jogos.

Já o bronze pertence à cubana Yarisley Silva, com a marca de 4,30m.

O bronze vai para a cubana Yarisley Silva.

Após começar muito bem, saltando com segurança até os 4m, Joana começou a ter problemas na corrida de aproximação já nos $4 \mathrm{~m} 10$, mostrando nervosismo e até desistindo de saltos no meio do caminho.

\section{Sumário Modelo de Transformacão 2}

A brasileira Joana Costa ficou com a quinta posição, com $4 \mathrm{~m} 20$ e mostrou, mais uma vez, neste Pan do Rio, que a pressão de competir em casa pode prejudicar os atletas.

A medalha de prata ficou com a americana April Steiner, com a marca de $4 \mathrm{~m} 40$ e o bronze foi para a cubana Yarisley Silva, com $\mathbf{4 m 3 0}$.

Após começar muito bem, saltando com segurança até os $4 \mathrm{~m}$, Joana começou a ter problemas na corrida de aproximação já nos $4 \mathrm{~m} 10$, mostrando nervosismo e até desistindo de saltos no meio do caminho.

\section{Sumário Modelo de Transformacão 3}

Outros atletas brasileiros já sentiram essa pressão da torcida, como foi o caso das meninas do vôlei, que entregaram o ouro a Cuba, no tie break e dos atletas da ginástica artística, que cometeram seguidos erros, claramente, por nervosismo.

A brasileira Joana Costa ficou com a quinta posição, com $4 \mathrm{~m} 20$ e mostrou, mais uma vez, neste Pan do Rio, que a pressão de competir em casa pode prejudicar os atletas.

Após começar muito bem, saltando com segurança até os 4m, Joana começou a ter problemas na corrida de aproximação já nos $4 \mathrm{~m} 10$, mostrando nervosismo e até desistindo de saltos no meio do caminho.

\section{Extrato Humano}

A brasileira Fabiana Murer conquistou o primeiro ouro do atletismo para o Brasil, nesta segundafeira, na prova de salto com vara.

Com a marca de 4m60, Fabiana não só venceu a prova, como também estabeleceu o novo recorde pan-americano, $20 \mathrm{~cm}$ mais alto do que a antiga marca de $4 \mathrm{~m} 40$. A medalha de prata ficou com a americana April Steiner, com a marca de $4 \mathrm{~m} 40$ e o bronze foi para a cubana Yarisley Silva, com $4 \mathrm{~m} 30$.

Após confirmar a medalha de ouro, Fabiana tentou, ainda, bater o próprio recorde sul-americano de $4 \mathrm{~m} 66$ em três tentativas de saltar 4m68, mas não conseguiu.

A brasileira Joana Costa ficou com a quinta posição, com $4 \mathrm{~m} 20$ e mostrou, mais uma vez, neste Pan do Rio, que a pressão de competir em casa pode prejudicar os atletas.

Figura 35: Exemplo de Sumários produzidos pelos modelos de transformação 
Nota-se da Figura 35 em diante, que o Modelo de Transformação 2 é de fato o que representa melhor a seleção de conteúdo do extrato humano (informação ressaltada em negrito). Apesar disso, nenhum dos três modelos conseguiu identificar a informação principal do assunto que é a vitória da Fabiana Murer. No entanto, para o sumário produzido pelo modelo que apenas inclui RST, este cenário muda completamente, como se observa na Figura 36 a seguir.

\section{Sumário Modelo de Transformaç̃o RST}

Após começar muito bem, saltando com segurança até os 4m, Joana começou a ter problemas na corrida de aproximação já nos 4m10, mostrando nervosismo e até desistindo de saltos no meio do caminho.

A medalha de prata ficou com a americana April Steiner, com a marca de $4 \mathrm{~m} 40$ e o bronze foi para a cubana Yarisley Silva, com $4 \mathrm{~m} 30$.

A brasileira Fabiana Murer conquistou o primeiro ouro do atletismo para o Brasil, nesta segundafeira, na prova de salto com vara.

Figura 36 : Sumário produzido pelo modelo de transformação RST

Apesar de que foi observado que a RST é um atributo que consegue modelar bem a seleção de conteúdo, e por isso o modelo de RST (o que se vê refletido nos resultados deste modelo frente aos outros) foi bem na medida rouge, o fato que os outros modelos não estejam c eonseguindo pegar as informações principais pode-se dever também a influencia do tratamento de redundância aplicado ou a ausência do Modelo de Coerência. O impacto destes componentes será discutido nas seções seguintes.

\subsection{Impacto do Modelo de Coerência na Modelagem Gerativa}

Nesta seção, mostra-se os resultados para os mesmos modelos somente que incorporando o Modelo de Coerência i) como parte do esquema Noisy-Channel, tal como descrito no Capítulo 5, e ii) como um componente aplicado após o processo de decodificação. A seguir, é mostrada a Tabela 26 dos mesmos modelos de transformação mostrados na Tabela 25, só que com as variações correspondentes do Modelo de Coerência. Na Tabela, os modelos que têm os sufixos "MC", indicam à incorporação do modelo de coerência no esquema NoisyChannel, e os modelos que tem os sufixos "MCAD" indicam a aplicação do modelo de coerência após o processo de decodificação. Os resultados mostrados na Tabela 26 correspondem aos experimentos indicados com os números 3 e 4, abaixo dos nós correspondentes à decodificação com tratamento de redundância. 
Tabela 26: Resultados da medida Rouge para os modelos de transformações com as variações do Modelo de Coerência

\begin{tabular}{|l|c|c|c|c|c|c|}
\hline \multirow{2}{*}{ Modelo } & \multicolumn{3}{|c|}{ Rouge-1 } & \multicolumn{3}{c|}{ Rouge-2 } \\
\cline { 2 - 7 } & $\begin{array}{c}\text { Cobertur } \\
\text { a }\end{array}$ & Precisão & $\begin{array}{c}\text { Medida- } \\
\text { F }\end{array}$ & Cobertura & Precisão & Medida-F \\
\hline MT1 & 0,2498 & 0,2679 & 0,2555 & 0,0962 & 0,1042 & 0,0987 \\
\hline MT1-MC & $\mathbf{0 , 2 7 9 3}$ & $\mathbf{0 , 3 2 1 1}$ & $\mathbf{0 , 2 9 5 6}$ & $\mathbf{0 , 1 2 2 8}$ & $\mathbf{0 , 1 4 2 9}$ & $\mathbf{0 , 1 3 0 7}$ \\
\hline MT1-MCAD & $\mathbf{0 , 3 0 5 5}$ & $\mathbf{0 , 3 2 8 0}$ & $\mathbf{0 , 3 1 2 7}$ & $\mathbf{0 , 1 3 8 2}$ & $\mathbf{0 , 1 4 6 7}$ & $\mathbf{0 , 1 4 0 8}$ \\
\hline MT2 & 0,2559 & 0,2813 & 0,2648 & 0,1053 & 0,1162 & 0,1090 \\
\hline MT2-MC & $\mathbf{0 , 2 9 2 4}$ & $\mathbf{0 , 3 3 5 4}$ & $\mathbf{0 , 3 0 9 3}$ & 0,1324 & 0,1537 & 0,1408 \\
\hline MT2-MCAD & $\mathbf{0 , 3 1 2 0}$ & $\mathbf{0 , 3 3 2 5}$ & $\mathbf{0 , 3 1 8 4}$ & 0,1442 & 0,1525 & 0,1467 \\
\hline MT3 & 0,2328 & 0,2628 & 0,2439 & 0,0886 & 0,1035 & 0,0943 \\
\hline MT3-MC & $\mathbf{0 , 2 9 2 2}$ & $\mathbf{0 , 3 3 0 4}$ & $\mathbf{0 , 3 0 6 5}$ & 0,1225 & 0,1373 & 0,1278 \\
\hline MT3-MCAD & $\mathbf{0 , 2 3 8 2}$ & $\mathbf{0 , 2 7 3 4}$ & $\mathbf{0 , 2 5 0 9}$ & 0,0931 & 0,1084 & 0,0988 \\
\hline MTProf & 0,2623 & 0,2794 & 0,2681 & 0,0855 & 0,0908 & 0,0873 \\
\hline MTProf-MC & $\mathbf{0 , 3 0 1 9}$ & $\mathbf{0 , 3 4 2 7}$ & $\mathbf{0 , 3 1 7 1}$ & 0,1336 & 0,1516 & 0,1402 \\
\hline MTProf-MCAD & $\mathbf{0 , 2 9 7 6}$ & $\mathbf{0 , 2 9 7 8}$ & $\mathbf{0 , 2 9 6 5}$ & 0,1258 & 0,1231 & 0,1239 \\
\hline MTRST & $\mathbf{0 , 3 4 5 3}$ & $\mathbf{0 , 3 5 3 4}$ & $\mathbf{0 , 3 4 8 2}$ & 0,1463 & 0,1487 & 0,1469 \\
\hline MTRST-MC & $\mathbf{0 , 2 7 7 9}$ & $\mathbf{0 , 3 1 2 8}$ & $\mathbf{0 , 2 9 1 2}$ & 0,1192 & 0,1350 & 0,1253 \\
\hline MTRST-MCAD & $\mathbf{0 , 3 4 3 0}$ & $\mathbf{0 , 3 4 1 5}$ & $\mathbf{0 , 3 4 0 7}$ & 0,1540 & 0,1506 & 0,1515 \\
\hline MTCST & 0,2582 & 0,2791 & 0,2651 & 0,0926 & 0,1035 & 0,0964 \\
\hline MTCST-MC & $\mathbf{0 , 2 8 6 1}$ & $\mathbf{0 , 3 2 7 3}$ & $\mathbf{0 , 3 0 2 0}$ & 0,1095 & 0,1263 & 0,1158 \\
\hline MTCST-MCAD & $\mathbf{0 , 2 8 0 3}$ & $\mathbf{0 , 2 7 7 4}$ & $\mathbf{0 , 2 7 7 6}$ & 0,1141 & 0,1120 & 0,1124 \\
\hline
\end{tabular}

Em geral, observa-se que o Modelo de Coerência tem um impacto positivo na modelagem gerativa em termos de medida rouge, pois, na maioria dos resultados, a incorporação do Modelo de Coerência produz uma melhoria dos resultados em relação aos resultados da Tabela 25, em que se mostravam os resultados dos modelos de transformação sem a aplicação do Modelo de Corência. Uma dificuldade ao analisar o impacto do Modelo de Coerência é que, os efeitos do Modelo de Coerência não seriam detectados pela medida rouge. Apesar disso, observa-se uma influência positiva do Modelo de Coerência na seleção de conteúdo, nas duas formas em que ele foi incorporado.

Outro aspecto difícil de concluir é qual das formas de incorporação do Modelo de Coerência é melhor, se a incorporação do Modelo de Coerência após o processo de decodificação ou a incorporação no Noisy-Channel, ou seja, durante o processo de decodificação. Em princípio, pode-se observar que todas as variantes que envolvem CST nos modelos de transformação (MTCST, MTProf e MT3) têm melhor desempenho com a incorporação do Modelo de Coerência no esquema Noisy-Channel, do que com a incorporação após decodificação. Isso pode resultar do fato que a incorporação no Noisy-Channel implica alterar a probabilidade das sentenças antes de serem selecionadas para compor o sumário, influenciando a seleção de conteúdo. Em outras palavras, o Modelo de Coerência interfere no desempenho modelo 
de transformação. Dado que os modelos que envolvem CST não são os que modelam melhor as decisões de seleção de conteúdo (de acordo com os resultados mostrados na seção anterior), pode ser que a interferência do Modelo de Coerência represente uma melhora.

Por outro lado, a incorporação do Modelo de Coerência após o processo de decodificação não interfere diretamente no modelo de transformação, preservando mais a essência do modelo de transformação. No caso dos modelos de transformação que tiveram melhor desempenho sem Modelo de Coerência (MT2 e MTRST), a incorporação do Modelo de Coerência após o processo de decodificação gerou resultados ainda melhores. Para verificar a significância estatística dos dados obtidos aplicou-se o teste-t para os modelos que obtiveram os melhores resultados com as variações do Modelo de Coerência: modelo de transformação 2 (MT2, MT2-MC e MT2-MCAD), modelo de informações profundas (MTProf, MTProf-MC, MTProf-MCAD) e o modelo RST (MTRST,MTRST-MC,MTRSTMCAD). Nesse caso, o teste-t foi aplicado para todas as combinações de pares em cada método e se observou que há significância estatística com 95\% de confiança em cada caso.

Como foi discutido anteriormente, a medida rouge não é a forma mais adequada para avaliar o impacto do Modelo de Coerência. De fato, visa-se em trabalhos futuros realizar uma avaliação mais focada para medir quantos e quais aspectos de coerência de sumários multidocumento foram tratados corretamente pelo modelo proposto. Pelo momento, além da rouge só será mostrado um exemplo da evolução de um sumário com a aplicação das variações do Modelo de Coerência. No caso, exemplificaremos essa evolução com as variações do MT2 no mesmo exemplo das Figuras 35 e 36.

\section{Sumário MT2}

A brasileira Joana Costa ficou com a quinta posição, com 4m20 e mostrou, mais uma vez, neste Pan do Rio, que a pressão de competir em casa pode prejudicar os atletas.

A medalha de prata ficou com a americana April Steiner, com a marca de $4 \mathrm{~m} 40$ e o bronze foi para a cubana Yarisley Silva, com $4 \mathbf{m} 30$.

Após começar muito bem, saltando com segurança até os $4 \mathrm{~m}$, Joana começou a ter problemas na corrida de aproximação já nos $4 \mathrm{~m} 10$, mostrando nervosismo e até desistindo de saltos no meio do caminho.

\section{Sumário MT2-MC}

A atleta norte-americana provou que a disputa seria acirrada, já que bateu a marca de $4,40 \mathrm{~m}$, mesmo com as vaias da torcida local.

O bom salto da brasileira colocou pressão sobre a norte-americana, que falhou em sua primeira tentativa no salto de $4,40 \mathrm{~m}$.

Outros atletas brasileiros já sentiram essa pressão da torcida, como foi o caso das meninas do vôlei, que entregaram o ouro a Cuba, no tie break e dos atletas da ginástica artística, que cometeram seguidos erros, claramente, por nervosismo. 


\section{Sumário MT2-MCAD}

Após confirmar a medalha de ouro, Fabiana tentou, ainda, bater o próprio recorde sul-americano de $4 \mathrm{~m} 66$ em três tentativas de saltar 4m68, mas não conseguiu.

Após começar muito bem, saltando com segurança até os $4 \mathrm{~m}$, Joana começou a ter problemas na corrida de aproximação já nos $4 \mathrm{m10}$, mostrando nervosismo e até desistindo de saltos no meio do caminho.

A brasileira Fabiana Murer conquistou o primeiro ouro do atletismo para o Brasil, nesta segundafeira, na prova de salto com vara.

O bronze vai para a cubana Yarisley Silva.

É a $29^{\mathrm{a}}$ medalha para o Brasil no Pan.

Figura 37: Exemplos de sumários produzidos com os modelos de transformação e as variações do Modelo de Corência

Pode-se notar claramente que a evolução desses sumários refletem muitas das discussões feitas anteriormente. Em princípio, observa-se que as duas variações do Modelo de Coerência afetam o conteúdo do sumário. No entanto, no modelo MT2-MC percebe-se que essa alteração do conteúdo é mais radical em relação ao sumário produzido sem Modelo de Coerência (MT2). Já no modelo MT2-MCAD, ainda são preservadas algumas informações relevantes do sumário MT2. Além disso, observa-se um impacto na ordenação das informações, explicitando uma sequência relativamente razoável dos eventos. A partir dos resultados obtidos com o Modelo de Coerência e suas variações, pode-se indicar que o Modelo de Coerência tem um impacto positivo na modelagem gerativa da SAM.

A seguir serão mostrados os resultados para a decodificação sem tratamento de redundância, e discutido o impacto desse tratamento.

\subsection{Impacto do tratamento de redundância na decodificação}

Nesta seção, mostra-se os resultados das variações para a decodificação sem o tratamento de redundância e seu impacto na informatividade e coerência textual. Para isso, exploram-se os resultados correspondentes a todas as variações abaixo dos nós indicados pelo número 2 na Figura 34, ou seja, todas as variações indicadas pelos números 5 e 6 . A seguir, é mostrada a Tabela 27 com os resultados dessas variações. 
Tabela 27: Resultados da medida rouge para os modelos de transformação, com as variações do Modelo de Coerência, sem tratamento de redundância

\begin{tabular}{|l|c|c|c|c|c|c|}
\hline \multirow{2}{*}{ Modelo } & \multicolumn{3}{|c}{ Rouge-1 } & \multicolumn{3}{c|}{ Rouge-2 } \\
\cline { 2 - 7 } & Cobertura & Precisão & Medida-F & Cobertura & Precisão & Medida-F \\
\hline MT1 & 0,2542 & 0,2696 & 0,2611 & 0,1029 & 0,1088 & 0,1056 \\
\hline MT1-MC & 0,2288 & 0,2636 & 0,2431 & 0,07387 & 0,0831 & 0,0776 \\
\hline MT1-MCAD & 0,2345 & 0,2560 & 0,2440 & 0,0979 & 0,1041 & 0,1006 \\
\hline MT2 & 0,2660 & 0,2838 & 0,2736 & 0,1077 & 0,1123 & 0,1095 \\
\hline MT2-MC & $\mathbf{0 , 2 6 1 7}$ & $\mathbf{0 , 3 1 3 9}$ & $\mathbf{0 , 2 8 3 2}$ & 0,1113 & 0,1318 & 0,1196 \\
\hline MT2-MCAD & 0,2464 & 0,2800 & 0,2615 & 0,0959 & 0,1087 & 0,1017 \\
\hline MT3 & 0,2021 & 0,2218 & 0,2108 & 0,0693 & 0,0785 & 0,0734 \\
\hline MT3-MC & 0,2430 & 0,3133 & 0,2707 & 0,0924 & 0,1245 & 0,1052 \\
\hline MT3-MCAD & 0,2278 & 0,2486 & 0,2369 & 0,0912 & 0,0981 & 0,0942 \\
\hline MTProf & 0,2697 & 0,2727 & 0,2701 & 0,1061 & 0,1045 & 0,1048 \\
\hline MTProf-MC & 0,2524 & 0,2912 & 0,2687 & 0,0976 & 0,1110 & 0,1032 \\
\hline MTProf-MCAD & 0,2713 & 0,2799 & 0,2749 & 0,0960 & 0,0990 & 0,0973 \\
\hline MTRST & 0,3055 & 0,3181 & 0,3108 & 0,1327 & 0,1371 & 0,1345 \\
\hline MTRST-MC & $\mathbf{0 , 2 7 3 6}$ & $\mathbf{0 , 2 9 9 7}$ & $\mathbf{0 , 2 8 3 3}$ & 0,1113 & 0,1217 & 0,1150 \\
\hline MTRST-MCAD & 0,3327 & 0,3431 & 0,3371 & 0,1422 & 0,1449 & 0,1433 \\
\hline MTCST & 0,2563 & 0,2692 & 0,2619 & 0,0864 & 0,0903 & 0,0881 \\
\hline MTCST-MC & 0,2832 & 0,3301 & 0,2982 & 0,1225 & 0,1402 & 0,1266 \\
\hline MTCST-MCAD & 0,2686 & 0,2717 & 0,2701 & 0,1052 & 0,1033 & 0,1045 \\
\hline
\end{tabular}

Em princípio, a partir desses resultados, pode-se verificar que, em termos do impacto dos atributos usados nos modelos, mantém-se o mesmo padrão que nos resultados com tratamento de redundância, isto é, o modelo de transformação 2 apresenta uma melhora em relação ao modelo de transformação 1, o modelo de transformação 3 decai em relação aos dois modelos anteriores, o modelo RST é o que apresenta melhores resultados em relação a todos os outros modelos, os modelos que envolvem conhecimento da CST tendem a perder frente aos modelos que não usam CST. Da mesma forma, percebe-se que o impacto do Modelo de Coerência mantêm quase os mesmos padrões nas suas variações.

Em relação ao tratamento da redundância, pode-se observar vários padrões. De um modo geral, é possível notar que a decodificação sem tratamento de redundância tem melhores resultados em termos de rouge para a maioria das variações do que a decodificação com tratamento de redundância. Isso pode resultar do fato de que o método de tratamento de redundância proposto nesta tese é muito radical. Em princípio, o método corta as sub-soluções que envolvem qualquer tipo de redundância, colocando-as em uma segunda fila de prioridade, a qual muitas vezes nunca chega a ser processada. Dado que muitas das sub-soluções terão pouca redundância e mesmo assim serão excluídas da fila de prioridade, pode ser que boas soluções estejam sendo sacrificadas e em consequência a chance de identificar a solução ótima (ou mais próxima do conceito "ótimo") esteja sendo diminuída. 
Outro detalhe importante a ser notado é que a decodificação com tratamento de redundância tende a piorar com o uso da versão do Modelo de Coerência no Noisy-Channel, em relação ao modelo de transformação sem Modelo de Coerência e sem tratamento de redundância. Já foi observado nas variações mostradas nas seções anteriores que esse tipo de incorporação do Modelo de Coerência afeta diretamente na seleção de conteúdo, e, dado que na decodificação sem tratamento de redundância se exploram mais sub-soluções, então pode ser que com o Modelo de Coerência incorporado dessa forma essas sub-soluções tenham piorado.

A seguir, na Figura 38, são mostrados dois sumários gerados pelo modelo de transformação 2 com e sem tratamento de redundância. Esses sumários correspondem ao Cluster 8 do córpus CSTNews e relatam a participação da equipe masculina de vôlei brasileiro na Liga Mundial. As informações redundantes estão destacadas em negrito.

\section{Sumário MT2 sem tratamento de redundância}

Entretanto, os campeões olímpicos tiveram tranquilidade para se recuperar e fechar o set por 25 a 22 em um bloqueio.

Amanhã, as equipes voltam a se enfrentar, às $12 \mathrm{~h} 30$ (horário de Brasília), no mesmo local, com acompanhamento ao vivo do Terra Esportes.

No terceiro, mesmo com vários reservas como o levantador Marcelinho e Samuel, os brasileiros conseguiram fechar a partida com tranquilidade.

\section{Sumário MT2 com tratamento de redundância}

Amanhã, as equipes voltam a se enfrentar, às $12 \mathrm{~h} 30$ (horário de Brasília), no mesmo local, com acompanhamento ao vivo do Terra Esportes.

No terceiro, mesmo com vários reservas como o levantador Marcelinho e Samuel, os brasileiros conseguiram fechar a partida com tranquilidade.

Portugal e Argentina - que duelam duas vezes neste final de semana, em Portugal - completam a chave.

Os finlandeses estão na terceira colocação, com três vitórias e quatro derrotas.

Figura 38: Exemplo de sumários produzidos pelos modelos de transformação sem usar tratamento de redundância na decodificação

Na seguinte seção serão comparados os melhores modelos com os modelos do estado da arte HierSum e TopicSum.

\subsection{Modelagem Gerativa e outros métodos estatísticos}

Neste trabalho foram implementados os modelos baseados em modelagem de tópicos HierSum e TopicSum, os quais foram escolhidos para avaliação por serem o referencial de comparação da maioria de modelos gerativos do estado da arte, de acordo com o 
levantamento bibliográfico do Capítulo 3. Esses algoritmos foram aplicados para os 50 clusters do córpus CSTNews. Os 50 sumários produzidos foram avaliados com a medida rouge, da mesma forma que os modelos gerativos desenvolvidos neste trabalho. Os resultados dos modelos implementados são comparados com o modelo de transformação 2 com tratamento de redundância e o Modelo de Coerência aplicado após decodificação(MT2MCAD), que é o modelo híbrido (atributos profundos e superficiais) com melhores resultados (com base na medida rouge) e modelo RST com tratamento de redundância e Modelo de Coerência após decodificação (MTRST-MCAD) que é o modelo de transformação que obteve melhor resultado de todos os modelos estudados neste trabalho. A seguir a Tabela 28 resume os resultados destes modelos

Tabela 28: Resultados da medida rouge para os métodos do estado da arte

\begin{tabular}{|l|c|c|c|c|c|c|}
\hline \multirow{2}{*}{ Modelo } & \multicolumn{3}{|c|}{ Rouge-1 } & \multicolumn{3}{c|}{ Rouge-2 } \\
\cline { 2 - 7 } & Cobertura & Precisão & Medida-F & Cobertura & Precisão & Medida-F \\
\hline TopicSum & 0,2753 & 0,2991 & 0,2842 & 0,1132 & 0,1225 & 0,1165 \\
\hline HierSum & 0,3302 & 0,3103 & 0,3190 & 0,1878 & 0,1767 & 0,1814 \\
\hline MT2-MCAD & $\mathbf{0 , 3 1 2 0}$ & $\mathbf{0 , 3 3 2 5}$ & $\mathbf{0 , 3 1 8 4}$ & 0,1442 & 0,1525 & 0,1467 \\
\hline MTRST-MCAD & $\mathbf{0 , 3 4 3 0}$ & $\mathbf{0 , 3 4 1 5}$ & $\mathbf{0 , 3 4 0 7}$ & 0,1540 & 0,1506 & 0,1515 \\
\hline
\end{tabular}

Apesar de não ser o objetivo principal deste trabalho superar o valor de rouge dos modelos do estado da arte, pode-se dizer com satisfação que os principais modelos desenvolvidos e suas principais variações se mostram competitivos aos métodos importantes do estado da arte. Mais ainda, os métodos propostos nesta tese têm a vantagem de que, ao serem instanciados no esquema Noisy-Channel, é possível separar os componentes de decodificação e Modelo de Coerência dos modelos de transformação, isso permite analisar as implicâncias e o impacto de cada um desses componentes na sumarização. Em particular, tratar separadamente o Modelo de Coerência dos modelos de transformação permite modelar e tratar aspectos da qualidade e coerência nos sumários, enquanto os modelos de transformação se focam na seleção de conteúdo. Diferentemente dessa abordagem, os modelos do estado da arte apenas exploram distribuições de palavras em uma certa quantidade de tópicos sem explorar os vários fenômenos que acontecem na sumarização multidocumento, e que, eventualmente, guia a construção dos sumários de forma mais inteligente. Para confirmar a significância estatística dos resultados, foi aplicado o teste-t para cada par de modelos da Tabela. O teste-t mostrou que os resultados são significativos estatisticamente com $95 \%$ de confiança.

\subsection{Modelagem Gerativa e outros sumarizadores para Português}

Como foi estudado em seções anteriores, existem outros sumarizadores multidocumento para textos em português. Os principais sumarizadores são o CSTSumm (Jorge e Pardo, 2010), RSumm e CNSumm (Ribaldo et al., 2012) e o método que combina CST e RST de Cardoso(2014), o qual chamaremos método RC como explicitado no trabalho da autora. A 
seguir, a Tabela 29 resume a medida rouge desses sumarizadores e logo comparam-se os resultados com os resultados dois modelos gerativos desenvolvidos neste trabalho.

Tabela 29: Resultados da medida rouge para sumarizadores do estado da arte em Português

\begin{tabular}{|l|c|c|c|c|c|c|}
\hline \multirow{2}{*}{ Modelo } & \multicolumn{3}{|c|}{ Rouge-1 } & \multicolumn{3}{c|}{ Rouge-2 } \\
\cline { 2 - 7 } & Cobertura & Precisão & Medida-F & Cobertura & Precisão & Medida-F \\
\hline \multirow{2}{*}{ MT2-MCAD } & $\mathbf{0 , 3 1 2 0}$ & $\mathbf{0 , 3 3 2 5}$ & $\mathbf{0 , 3 1 8 4}$ & 0,1442 & 0,1525 & 0,1467 \\
\hline MTRST-MCAD & $\mathbf{0 , 3 4 3 0}$ & $\mathbf{0 , 3 4 1 5}$ & $\mathbf{0 , 3 4 0 7}$ & 0,1540 & 0,1506 & 0,1515 \\
\hline RC & 0,4374 & 0,4511 & 0,4419 & 0,2571 & 0,2630 & 0,2586 \\
\hline CSTSumm & 0,3557 & 0,4472 & 0,3864 & 0,1917 & 0,2339 & 0,2059 \\
\hline RSumm & 0,3517 & 0,5472 & 0,4346 & 0,3028 & 0,4186 & 0,3434 \\
\hline
\end{tabular}

Com base na Tabela 29 observa-se que os métodos para português têm melhor valor rouge que os modelos gerativos. Isso era esperado, pois os modelos gerativos são inferidos e produzem sumários com base em valores estatísticos. Os outros métodos para o Português são baseados em regras pré-definidas, que em principio podem ter melhor desempenho que os modelos baseados em dados estatísticos. Mas a vantagem dos modelos estatísticos, além de permitir extrair o conhecimento a partir de dados reais, é que esses modelos podem ser estendidos e treinados em córpus maiores, o que produziria modelos mais precisos e com resultados mais próximos do humano. Em particular, neste trabalho há a satisfação de observar que os modelos gerativos têm valores rouge próximos dos métodos baseados em regras pré-definidas, o que significaria que se os modelos gerativos fossem treinados em córpus maiores, o desempenho deles poderia ser afetado positivamente, podendo chegar a superar os métodos do estado da arte para o português. A seguir, o Capítulo de Considerações finais desta tese. 


\section{Capítulo}

\section{Considerações Finais}

Neste trabalho de doutorado, foi apresentada a primeira modelagem gerativa para SAM com base no esquema Noisy-Channel. Foram apresentados três modelos de transformação incrementais, que combinam atributos superficiais e atributos profundos, os quais modelam alguns dos principais fenômenos envolvidos no processo de sumarização. Também foi apresentado um Modelo de Coerência para SAM, que integra o modelo de entidades e a informação discursiva da CST e RST. Finalmente, foi desenvolvido um decodificador baseado no algoritmo $A^{*}$ e capaz de tratar a redundância usando informações fornecidas pela CST.

Os modelos gerativos foram treinados e testados no córpus CSTNews e avaliados com base na medida rouge. Os resultados obtidos foram analisados e comparados com os métodos estatísticos do estado da arte: TopicSum e HierSum (Haghighi e Vanderwende, 2009). Também foram comparados com os métodos do estado da arte em português CSTSumm (Jorge e Pardo, 2010), RSumm e CNSumm (Ribaldo et al., 2012) e RC (Cardoso, 2014). Esses resultados confirmaram a tese principal: a modelagem gerativa para SAM, formulada a partir de atributos superficiais e profundos, permite a produção de sumários informativos. Outra hipótese confirmada é que o uso da informação discursiva (CST e RST) tem um impacto positivo no modelo de coerência para sumários multidocumento. Os resultados obtidos foram satisfatórios em relação aos métodos estatísticos do estado da arte: HierSum e TopicSum. Esses resultados mostraram que a modelagem gerativa incremental gera melhores resultados. Apesar dos modelos gerativos não terem superado os métodos para o português, os quais não são estatísticos, eles têm resultados muito próximos.

\subsection{Contribuições}

A principal contribuição deste trabalho é a definição e formalização estatística de uma história gerativa para SAM, a partir de atributos superficiais e profundos, permitindo identificar a influência deles no processo de geração de um sumário multidocumento. Em princípio, essa historia gerativa é instanciada em três modelos de transformação, os quais permitem explorar a história gerativa de três formas diferentes: a partir de informações extraídas da superfície textual, a partir de informações da superfície textual e de informações de discurso (profundas) que destacam a saliência das informaçãoes de textos individuais, e, 
finalmente, a partir de informações superficiais e profundas mono e multidocumento. Este trabalho constitui um dos primeiros trabalhos em investigar métodos para extrair automaticamente modelos de SAM para textos em português, a partir de córpus de textos e seus correspondentes sumários.

Outra contribuição importante é a realização de uma das primeiras pesquisas na construção de um Modelo de Coerência para sumários multidocumento. Em particular, para modelar a coerência em SAM, foram desenvolvidos três métodos que incorporam informação da CST no Modelo de Entidades em diferentes níveis: relações completas, categorias das relações e informações booleanas (presença ou ausência de relações CST). Isso permitiu analisar a influência dessas informações na modelagem de padrões de coerência para sumários multidocumento.

Em relação à decodificação, tem se contribuído com o desenvolvimento de um método de decodificação baseado no algoritmo de busca $A^{*}$ que permite realizar o tratamento de redundância durante o processo de decodificação, identificando as informações redundantes e descartando-as.

O esquema de modelagem gerativa integra vários componentes: modelos de transformação, Modelo de Coerência e decodificador, o que constitui uma pesquisa inédita que estuda o impacto desses componentes no processo de seleção e organização das informações que compõem um sumário.

Em termos de recursos, uma contribuição importante é a anotação do córpus CSTNews com base na teoria RST. Esse processo de anotação foi documentado e formalizado em Cardoso et al. (2011).

Como resultado das pesquisas realizadas neste doutorado tem-se publicações em congressos da área e áreas relacionadas: STIL (Jorge e Pardo, 2011a; Jorge e Pardo, 2011b), ENIA (Jorge et al. , 2011), ToRPorEsp (Diaz et al., 2014), BRACIS (Jorge et al., 2014) e a revista Information Processing and Managment (Maziero et al., 2014).

\subsection{Limitações}

Uma das principais limitações neste trabalho diz respeito ao córpus CSTNews, que é o único córpus para textos em português com vários recursos que permitem a investigação de métodos de SAM. Alguns desses recursos são: diversas camadas de anotações para grupos de textos relacionados, extratos automáticos e humanos, abstracts humanos, alinhamentos, entre outros. Uma das desvantagens do córpus CSTNews é ser muito pequeno, pois contém apenas 50 clusters de textos e em média 3 documentos por cluster. Para investigações que envolvem Aprendizado de Máquina, o conjunto de dados fornecido por esse córpus representa uma base de dados muito pequena. Por exemplo, para o treinamento do Modelo de Coerência, isso gerou um problema, já que não existiam suficientes dados para representar a presença de relações CST nos sumários o que impedia modelar adequadamente os padrões de coerência nos sumários. No caso dos modelos de transformação, o fato de ter poucos extratos humanos impediu ter uma quantidade significativa de relações multidocumento que permitissem modelar os padrões de seleção de conteúdo com base nos fenômenos multidocumento. De fato, isso gerou uma tendência sobre os modelos que usam 
este tipo de informações. Um indício claro disso é o desempenho dos modelos de transformação que usam atributos baseados na CST, pois tais modelos tiveram pior desempenho que os modelos que usavam informações discursivas monodocumento.

Recentemente, o córpus CSTNews foi enriquecido com novos sumários (extratos e abstracts) (Diaz et al., 2014), incrementando 5 abstracts e 5 extratos por cada cluster de textos. Isso permitiria melhorar o desempenho de muitos métodos de sumarização que dependem desse conhecimento para produzir ou avaliar sumários multidocumento. Mesmo assim, é necessário o aumento de clusters de textos com seus correspondentes recursos (extratos, abstracts, alinhamentos e anotações) .

Outra limitação observada ao longo do desenvolvimento deste trabalho é a falta estudos prévios sobre coerência em sumários multidocumento. Como foi dito no Capítulo anterior, a rouge não é a melhor forma de avaliar o impacto de um Modelo de Coerência para sumários multidocumento. De fato, seria interessante poder medir a coerência em sumários multidocumento com base em determinados aspectos que indiquem se a organização das informações de um sumário multidocumento segue, realmente, um padrão coerênte. Do mesmo modo, uma boa investigação desses aspectos permitiria formular modelos de coerência mais eficientes.

\subsection{Trabalhos Futuros}

A partir desta pesquisa de doutorado foi possível encontrar muitos outros cenários a serem investigados no futuro. Em princípio, dado o incremento de sumários disponíveis no córpus CSTNews, os modelos desenvolvidos neste trabalho poderiam ser treinados e testados novamente, visando uma possível melhora no desempenho.

Em termos de modelos de transformação, poderiam ser retomadas algumas das pesquisas iniciadas neste trabalho e que ficaram inconclusas. Em princípio, pode-se retomar a investigação do modelo que considera a informação dos parágrafos na história gerativa, mencionado na última seção do Capítulo 5. Também seria interessante explorar outras formas de incluir mais níveis de informação em relação à hierarquia da estrutura textual, pois isso pode trazer informação relevante para a modelagem da história gerativa. Outras considerações importantes nos modelos de transformação seriam a inclusão de outros atributos na modelagem da historia gerativa. Alguns desses atributos poderiam ser, por exemplo, aspectos, informações sintáticas ou os sub-tópicos com base na anotação de (Cardoso, 2014).

No que diz respeito ao Modelo de Coerência, um assunto que foi pouco explorado neste trabalho, e que deve ser tratado com mais profundidade no futuro, é a avaliação do impacto do Modelo de Coerência na modelagem gerativa. Para isso, poder-se-ia estudar em mais detalhe os atributos da coerência textual no cenário da SAM. Uma vez fornecido esse cenário, seria possível realizar uma avaliação humana dos sumários produzidos, com base em todos os critérios/ atributos que tivessem sido estudados, e assim, seria possível determinar quais aspectos/atributos conseguem ser bem tratados (e quais não) no Modelo de Coerência. 
Em relação à decodificação, poder-se-ia propor uma modificação ao tratamento da redundância que não envolva penalizar sub-soluções completas, mas apenas sentenças. Também poderiam-se explorar outros métodos de decodificação que sejam mais baratos computacionalmente.

Finalmente, outro tema interessante para trabalho futuro seria a integração modelos de tópicos (conhecimento que usam a maioria dos métodos estatísticos do estado da arte) com os atributos estudados neste trabalho, e avaliar a influencia de cada um deles. 


\section{Referências Bibliográficas}

Afantenos, S.D.; Doura, I.; Kapellou, E.; Karkaletsis, V. (2004). Exploiting CrossDocument Relations for Multi-document Evolving Summarization. In the Proceedings of SETN, pp. 410-419.

Afantenos, S.D. (2007). Reflections on the Task of Content Determination in the Context of Multi-Document Summarization of Evolving Events. In Recent Advances on Natural Language Processing. Borovets/Bulgaria.

Agresti, A. (1996). An Introduction to Categorical Data Analysis. John Wiley and Sons, Inc.

Aker, A.; Cohn, T. e Gaizauskas, R. (2010). Multi-document summarization using A* search and discriminative training. In the Proceedings of the 2010 Conference on Empirical Methods in Natural Language Processing. pp. 482-491, Massachusets/USA.

Aker, A.; Cohn, T. e Gaizauskas, R. (2012). Redundancy reduction for multi-document summarization using $\mathrm{A}^{*}$ search and discriminative training. $1^{\text {st }}$ Workshop on Automatic Text Summarization of the Future. Castelo/Espanha.

Aleixo, P. e Pardo, T.A.S. (2008). CSTNews: Um Córpus de Textos Journalísticos Anotados segundo a Teoria Discursiva CST ( Cross-Document Structure Theory ). Série de Relatórios Técnicos do Instituto de Ciências Matemáticas e de Computação, Universidade de São Paulo, no. 326. São Carlos-SP.

Allan, J. (1996). Automatic Hipertext Linking Type. In Proceedings of Hypertext. Washington D.C./USA

Barzilay, R. e Mckeown, K.R. (2005). Sentence fusion for multidocument news summarization. Journal of Computational Linguistics, Mit Press Cambridge.

Baum,L. e Petrie, T. (1966). Stastical inference for probabilistic functions of finite state Markov chains. Ann Math. Statist. pp. 1554-1563.

Baxendale, P. (1958). Machine-made index for technical literature - an experiment. IBM Journal of Research Development.

Blei, D. M., Ng, A. Y. e Jordan, M. I. (2003). Latent Dirichlet Allocation. Journal of Machine Learning Research, 3, 993-1022.

Brown, P. E.; Pietra, S. A. D.; Pietra, V. J. D.; Mercer, R. L. (1993). The Mathematics of Statistical Machine Translation: Parameter Estimation. Computational Linguistics, Vol. 16, N. 2, pp. 79-85.

Camargo, R.T. (2013). Investigação de estratégias de sumarização humana multidocumento. Dissertação de Mestrado. Programa de Pós-graduação em Linguística, Universidade Federal de São Carlos.

Carbonell, J. e Goldstein, J. (1998). The use of MMR, diversity-based reranking for reordering documents and producing summaries. In the Proceedings of ACM-SIGIR. Melbourne/Australia.

Cardoso, P.C.F. (2014). Exploração de métodos de sumarização automática multidocumento com base em conhecimento semântico-discursivo. Tese de doutorado. Instituto de Ciências Matemáticas e de Computação, Universidade de São Paulo. São Carlos-SP. 
Cardoso, P.C.F.; Maziero, E.G.; Jorge, M.L.C.; Seno, E.M.R.; Di Felippo, A.; Rino, L.H.M.; Nunes, M.G.V.; Pardo, T.A.S. (2011). CSTNews - A Discourse-Annotated Córpus for Single and Multi-Document Summarization of News Texts in Brazilian Portuguese. In the Proceedings of the 3rd RST Brazilian Meeting, pp. 1-18. Cuiabá/Brazil.

Carlson, L. and Marcu, D. (2001). Discourse Tagging Reference Manual. Technical Report ISI-TR-545. University of Southern, California.

Carlson, L; Marcu, D.; Okurowski, M.E. (2003). Building a Discourse-Tagged Córpus in the Framework of Rhetorical Structure Theory. In J.V. Kuppevelt and R. Smith (eds.), Current Directions in Discourse and Dialogue, pp. 85-112. Kluwer Academic Publishers.

Chuang, W.T. e Yang, J. (2000). Extracting sentence segments for text summarization: a machine learning approach. In the Proceedings of the 23rd Annual International ACM SIGIR Conference on Research and Development in Information Retrieval, pp. 152159. Athens/Greece.

Conroy, J. M. e O'leary, D. P. (2001). Text summarization via Hidden Markov models. In Proceedings of SIGIR '01, pp. 406-407, New York/ USA.

Cover,T.M. e Hart, P.E. (1967). Nearest Neighbor Pattern Classification. In IEEE Transactions on Information Theory, IT-13(1):21--27. Hong Kong/ China.

Dang, H. T. (2008). Overview of the tac 2008 opinion question answering and summarization tasks. In Proceedings of TAC 2008.

Daumé III, H. and Marcu, D. (2002). A noisy-channel model for document compression. In the Proceedings of the Conference of the Association for Computational Linguistics, pp. 449-456.

Daumé III, H. e Marcu, D. (2005). Bayesian Multidocument Sumarization at MSE. In Workshop on Multilingual Sumarization Evaluation.

Daumé III, H. e Marcu, D. (2006). Bayesian query-focused summarization. In the Proceedings 21st International Conference on Computational Linguistics and the 44th annual meeting of the Association for Computational Linguistics - ACL. Sydney/Australia.

Dempster, A., Laird, N., and Rubin, D. (1977). Maximum likelihood from incomplete data via the EM algorithm. Journal of the Royal Statistical Society, Series B, 39(1): pp.1-38.

Du, P., Guo, J., Zhang, J., and Cheng, X. (2010). Manifold ranking with sink points for update summarization. In Proceedings of CIKM2010.

Duda, R. O. e Hart, P. E. (1973). Pattern Classification and Scene Analysis. John Wiley Sons Inc.

Edmundson, H. P. (1969). New Methods in automatic extracting. Journal of the ACM, Vol. 16, pp. 264-285.

Esuli, A. e Sebastiani, F. (2006). Sentiwordnet: A publicly available lexical resource for opinion mining. In In Proceedings of the 5th Conference on Language Resources and Evaluation, LREC06, pages 417-422. 
Everitt, B.S. e Hand, D.J. (1981). Finite Mixture Distributions. Chapman and Hall. London.

Fisher, R. (1990). Statistical Methods, Experimental Design and Scientific Inference. Oxford University Press.

Gantz, J. e Reinsel, D. (2011). Extracting Value from Chãos. International Data Corporation iView.

George, H. J. e Pat, L.(1995) Estimating Continuous Distributions in Bayesian Classifiers. In: Eleventh Conference on Uncertainty in Artificial Intelligence, San Mateo.

Goldberg, D. E. (1989). Genetic Algorithms in Search, Optimization and Machine Learning. Kluwer Academic Publishers, Boston, MA.

Good, I.J. (1953). The Population frequencies of species and the estimation of population parameters. Biometrika, 40, pp.16-264.

Grosz, B. e Sidner, C. (1986). Attention, Intentions, and the Structure of Discourse. Computational Linguistics, Vol. 12, N. 3.

Haghighi, A. and Vanderwende, L. (2009). Exploring content models for multi-document summarization. In the Proceedings of Human Language Technologies: The 2009 Annual Conference of the North American Chapter of the Association for Computational Linguistics- NAACL. pp.362-370. Boulder/Colorado.

Hebb, D.O. (1949). The organization of behavior. New York: Wiley \& Sons

Hennig L.; Umbrath W.; Wetzker R. (2008). An Ontology-Based Approach to Text Summarization. In the Proceedings of the International Conference on Web Intelligence and Intelligent Agent Technology - IEEE/WIC/ACM, pp.291-294. Sydney/Australia.

$\mathrm{Hu}, \mathrm{M}$. e Liu, B. (2004). Mining and summarizing customer reviews. In Proceedings of the Tenth ACM SIGKDD International Conference on Knowledge Discovery and Data Mining, KDD '04, pages 168-177, New York/USA.

Hunt, E. B., Marin, J. e Stone, P. J. (1966). Experiments in induction. New York: Academic Press.

Jeffreys, H. (1948). Theory of Probability. Second edition, Oxford: Clarendon Press.

Jelinek, F. e R. Mercer (1985). Probability Distribution Estimation from Sparse Data. IBM Technical Disclosure Bulletin, v. 28, pp.2591-2594.

Jordan, M.P. (1992). An Integrated Three-Pronged Analysis of a Fund-Raising Letter. In W.C. Mann and S.A. Thompson (eds.), Discourse Description: Diverse Linguistic Analyses of a Fund-Raising Text, pp. 171-226.

Jorge, M.L.C. e Pardo, T.A.S. (2009). Content Selection Operators for Multidocument Summarization based on Cross-document Structure Theory. In the Proceedings of the 7th Brazilian Symposium in Information and Human Language Technology - STIL, pp. 1-8. September 8-10, São Carlos/SP, Brazil.

Jorge, M.L.C. e Pardo, T.A.S. (2010). Experiments with CST-based Multidocument Summarization. In the Proceedings of the ACL Workshop TextGraphs-5: Graph-based Methods for Natural Language Processing, pp. 74-82. July 16, Uppsala/Sweden. 
Jorge, M.L.C.; Agostini, V.; Pardo, T.A.S. (2011). Multi-document Summarization Using Complex and Rich Features. In Anais do VIII Encontro Nacional de Inteligência Artificial, pp. 1-12. July 19-22, Natal/RN, Brazil.

Junqua, J.C. e Haton, J.P. (1995). Robustness in Automatic Speech Recognition: Fundamentals and Applications. Kluwer Academic Publishers.

Kehler, A. (2002). Coherence, Reference and the Theory of Grammar. CSLI Publications.

Knight, K. and Marcu, D. (2002). Summarization beyond sentence extraction: A probabilistic approach to sentence compression. Artificial Intelligence, V. 139, N.1, pp. 91-107.

Kullback, S. e Leibler, R.A. (1951). "On Information and Sufficiency". Anals of Mathematical Statistics 22 (1): pp. 79-86.

Kupiec, J.; Pedersen, J.; Chen, F. (1995). A trainable document summarizer. In the Proceedings of the 18th ACMSIGIR Conference on Research \& Development in Information Retrieval, pp. 68-73. Washington/USA.

Larocca N., Freitas, J. e Kaestner A.A. (2002). Automatic Text Summarization Using a Machine Learning Approach. In the Proceedings of the 16th Brazilian Symposium on Artificial Intelligence, pp. 205-215. Recife/Brazil.

Leite, D.S. e Rino, L. H. M. (2006). Selecting a Feature Set to Summarize Texts in Brazilian Portuguese. In: J.S. Sichman and H. Coelho, Advances in Artificial Intelligence. IBERAMIA/SBIA'2006. Ribeirão Preto /Brazil.

Lerman, K., Blair,G. S. e McDonald, R. (2009). Sentiment summarization: Evaluating and learning user preferences. In Proceedings of the 12th Conference of the European Chapter of the Association for Computational Linguistics, EACL '09, p. 514-522, Stroudsburg/USA.

Li, W., Wei, F., Lu, Q., e He, Y. (2008). PNR2: Ranking sentences with positive and negative reinforcement for query-oriented update summarization. In Proceedings of COLING2008.

Li, J. e Sujian, L. (2013). A Novel Feature-based Bayesian Model for Query Focused Multi-document Summarization. Transactions of the Association of Computational Linguistics.

Lin, C.Y. (1999). Training a selection function for extraction. In Proceedings of CIKM '99, pages 55-62, New York/ USA.

Lin, C.Y. e Hovy, E. (1997). Identifying topics by position. In Proceedings of the Fifth conference on Applied Natural Language Processing, pages 283-290. San Francisco/ USA.

Luhn, H. P. (1958). The automatic creation of literature abstracts. IBM Journal of Research and Development, Vol. 2, pp. 159-165.

Mani, I. (2001). Automatic Summarization. John Benjamins Publishing Co., Amsterdam

Mani, I. e Bloedorn, E. (1997). Multi-document summarization by graph search and matching. In the Proceedings of the $14^{\text {th }}$ National Conference on Artificial Intelligence (AAAI), pp. 622-628. American Association for Artificial Intelligence. 
Mani, I. e Bloedorn, E. (1998). Machine Learning of Generic and User-Focused Summarization. In the Proceedings of the Fifteenth National Conference on AI (AAAI98) pp. 821-826. Winsconsin/USA.

Mani, I. e Maybury, M. T. (1999). Advances in automatic text summarization. MIT Press, Cambridge, MA.

Mani, I.; Therese, F.; David H.; Gary Klein; Beth S.; Lynette Hirschman. (1999). The TIPSTER Summac Text Summarization Evaluation. In Proceedings of EACL-99. Bergen/Norway.

Mann, W.C. and Thompson, S.A. (1987). Rhetorical Structure Theory: A Theory of Text Organization. Technical Report ISI/RS-87-190.

Marcu, D. (1998). To build text summaries of high quality, nuclearity is not sufficient. In the Working Notes of the AAAI-98 Spring Symposium on Intelligent Text Summarization. Stanford/CA. .

Marcu, D. (2000). The Theory and Practice of Discourse Parsing and Summarization. The MIT Press. Cambridge, Massachusetts.

Maziero, E.G. and Pardo, T.A.S. (2009). Automatização de um Método de Avaliação de Estruturas Retóricas. In the Proceedings of the RST Brazilian Meeting, pp. 1-9. September 10, São Carlos/SP, Brazil.

Maziero, E.G.; Jorge, M.L.C.; Pardo, T.A.S. (2010). Identifying Multidocument Relations. In the Proceedings of the 7th International Workshop on Natural Language Processing and Cognitive Science - NLPCS, pp.60-69. Madeira/Portugal.

McCulloch,W.S. e Pitts, W. (1943). A logical calculus of the ideas immanent in nervous activity. Bull. Math. Biophysics, 5:115-133.

McKeown, K. e Radev, D.R. (1995). Generating summaries of multiple news articles. In the Proceedings of the $18^{\text {th }}$ Annual International ACM-SIGIR Conference on Research and Development in Information Retrieval, pp. 74-82, Seattle/WA.

McKeown, K. e Radev, D.R. (1998). Generating natural language summaries from multiple on-line sources. Computational Linguistics, Vol. 24, N. 3, pp. 469-500.

McKeown, K.; Barzilay, R.; Evans, D.; Hatzivassiloglou, V.; Klavans, J.L.; Nenkova, A.; Sable, C.; Schiffman, B.; Sigelman, S. (2002). Tracking and summarizing news on a daily basis with Columbia's Newsblaster. In the Proceedings of the Human Language Technology Conference.

Mihalcea, R. and Tarau, P. (2005). An Algorithm for Language Independent Single and Multiple Document Summarization. In the Proceedings of the International Joint Conference on Natural Language Processing (IJCNLP). Korea.

Mitchell, T. (1997). Machine Learning. McGraw-Hill, New York.

Nenkova, A. (2005). Automatic text summarization of newswire: Lessons learned from the document understanding conference. In Proceedings of AAAI 2005. Pittsburgh/ USA.

Ng., A. e Jordan, M. (2002). On Discriminative vs. Generative classifiers: A comparison of logistic regression and Naive Bayes. Neural Information Processing Systems. 
O'Donnell, M. (1997). Variable-Length On-Line Document Generation. In the Proceedings of the 6th European Workshop on Natural Language Generation. Duisburg/Alemnaha.

Ono, K.; Sumita, K.; Miike, S. (1994). Abstract generation based on rhetorical structure extraction. In the Proceedings of the International Conference on Computational Linguistics (Coling-94). Kyoto/Japão.

Osborne, M. (2002). Using maximum entropy for sentence extraction. In Proceedings of the ACL'02 Workshop on Automatic Summarization, pages 1-8, Morristown/USA.

Otterbacher, J.C.; Radev, D.R. e Luo, A. (2002). Revisions that improve cohesion in multi-document summaries: a preliminary study. In the Proceedings of the Workshop on Automatic Summarization, pp. 27-36. Philadelphia/USA.

Ouyang, Y.; Li, W.; Lu, Q. e Zhang, R. (2010). A study on position information in document summarization. In the Proceedings of the 23rd International Conference on Computational Linguistics: Posters, pp. 919-927. Beijin/China.

Paice, C. D. (1981). The automatic generation of literature abstracts: an approach based on the identification of self-indicating phrases. In: Information Retrieval Research. Butterworth \& Co.

Pang, B. e Lee, L. (2008). Opinion mining and sentiment analysis. Found. Trends Inf. Retr., 2(1-2): pp.1-135.

Pardo, T.A.S. e Rino, L.H.M. (2002). DMSumm: Review and Assessment. In E. Ranchhod and N. J. Mamede (eds.), Advances in Natural Language Processing, pp. 263-273 (Lecture Notes in Artificial Intelligence 2389). Springer-Verlag/Germany.

Pardo, T.A.S.; Rino, L.H.M. e Nunes, M.G.V. (2003). GistSumm: A Summarization Tool Based on a New Extractive Method. In N.J. Mamede, J. Baptista, I. Trancoso, M.G.V. Nunes (eds.), 6th Workshop on Computational Processing of the Portuguese Language - Written and Spoken - PROPOR (Lecture Notes in Artificial Intelligence 2721), pp. 210-218. Faro/Portugal.

Pardo, T.A.S. (2005). GistSumm- GIST SUMMarizer: Extensões e Novas Funcionalidades. Série de Relatórios do NILC. NILC-TR-05-05, p.8. São CarlosSP/Fevereiro.

Pardo, T.A.S (2006). SENTER: Um Segmentador Sentencial Automático para o Português do Brasil. Série de Relatórios do NILC. NILC-TR-06-01. São CarlosSP/Brasil.

Quinlan, J.R. (1992). C4.5 Programs for Machine Learning. San Mateo, CA: Morgan KaufmannVA.

Radev, D.R. (2000). A common theory of information fusion from multiple text sources, step one: Cross-document structure. In the Proceedings of the 1st ACL SIGDIAL Workshop on Discourse and Dialogue. Hong Kong.

Radev, D.R.; Jing, H. e Budzikowska, M. (2000). Centroid-based summarization of multiple documents: sentence extraction, utility-based evaluation and user studies. In the Proceedings of the ANLP/NAACL Workshop, pp. 21-29.

Radev, D.R.; Blair-Goldensohn, S.; Zhang, Z. (2001a). Experiments in single and multidocument summarization using MEAD. In the Proceedings of the First Document Understanding Conference. New Orleans/LA. 
Radev, D.R.; Blair-Goldensohn, S.; Zhang, Z.; Raghavan, R.S. (2001b). Newsinessence: A system for domain-independent, real-time news clustering and multi-document summarization. In the Proceedings of Human Language Technology Conference. San Diego/CA.

Radev, D.R.; Weigu, R.; Zhang, Z. (2001c). WebInEssence: A Personalized Web-Based multi-document Summarization and Recomendation System.

Reiter, E. and Dale, R. (2000). Building Natural Language Generation Systems. Cambridge University Press.

Ribaldo, R.; Akabane, A.T.; Rino, L.H.M.; Pardo, T.A.S. (2012). Graph-based Methods for Multi-document Summarization: Exploring Relationship Maps, Complex Networks and Discourse Information. In the Proceedings of the 10th International Conference on Computational Processing of Portuguese (LNAI 7243), pp. 260-271. April 17-20, Coimbra, Portugal.

Rino, L.H.M.; Pardo, T.A.S.; Silla Jr., C.N.; Kaestner, C.A. e Pombo, M. (2004). A Comparison of Automatic Summarization Systems for Brazilian Portuguese Texts. In the Proceedings of the 17th Brazilian Symposium on Artificial Intelligence - SBIA (Lecture Notes in Artificial Intelligence 3171), pp. 235-244. São Luis/Brazil.

Rosenblatt, F. (1958), The Perceptron: A Probabilistic Model for Information Storage and Organization in the Brain. Cornell Aeronautical Laboratory, Psychological Review, v65, No. 6, pp. 386-408.

Russell, S.J.; Norvig, P.; Canny, J.F.; Malik, J. e Edwards, D.D. (1995) Artificial intelligence: a modern approach. Prentice hall Englewood Cliffs, NJ.

Salton, G. (1988). Term-Weighting Approaches in Automatic Text Retrieval. Information Processing and Management, v24 n5 p513-23.

Schilder, F. e Kondadadi, R. (2008). FastSum: Fast and Accurate Query-based Multidocument Summarization. In Proceedings of the 46th meeting of the Association for Computational Linguistics. Ohio/USA.

Seno, E. R. M.; Rino, L. H. M. (2005). Summarizing RST trees focusing on referential chains: A case of study. In: Anais do III Workshop em Tecnologia da Informação e da Linguagem Humana - TIL'2005. pp. 1-10. Porto Alegre/Brazil.

Shannon, C.E. (1948), A Mathematical Theory of Communication. Bell System Technical Journal, 27, pp. 379-423.

Sparck Jones, K. (1972). A statistical interpretation of term specificity and its application in retrieval. Journal of Documentation Volume 28 Number 1, pp. 11-21. Cambridge.

Sparck Jones, K. (2007). Automatic summarising: a review and discussion of the state of the art. Technical Report UCAM-CL-TR-679. University of Cambridge.

Svore, K., Vanderwende, L., e Burges, C. (2007). Enhancing single-document summarization by combining RankNet and third-party sources. In Proceedings of the EMNLP-CoNLL, pp. 448-457.

Tan, P.N., Steinbach, M. e Kumar, V. (2006). Introduction to Data Mining. Pearson Education, Inc. 
Trigg, R. (1983). A Network-Based Approach to Text Handling for the Online Scientific Community. PhD. Thesis. University of Maryland Technical Report, TR-1346. College Park MD

Trigg, R.; Weiser, M. (1986). TEXTNET: A Network-Based Approach to Text Handling. In ACM Transactions on Office Information Systems, Volume 6.

Uzêda, V.R.; Pardo, T.A.S.; Nunes, M.G.V. (2009). A comprehensive summary informativeness evaluation for RST-based summarization methods.International Journal of Computer Information Systems and Industrial Management Applications IJCISIM, Vol. 1, pp. 188-196.

Vapnik, V. (1995). The Nature of Statistical Learning Theory. Springer-Verlag.

Wan, X., Yang, J. (2006). Improved affinity graph based multi-document summarization. In the Proceedings of HLT-NAACL2006, pp.181-184. New York/USA.

Wan, X. (2008). An Exploration of Document Impact on Graph-Based Multi-Document Summarization. In the Proceedings of the 2008 Conference on Empirical Methods in Natural Language Processing. Honolulu/Hawai.

Wang, D. and Li, T. (2010). Document update summarization using incremental hierarchical clustering. In Proceedings of CIKM2010.

Witbrock, M. and Mittal, V. (1999). Ultra-summarization: A statistical approach to generating highly condensed nonextractive summaries. In the Proceedings of the 22nd International Conference on Research and Development in Information Retrieval (SIGIR-99), Poster Session, Berkeley, CA, 1999, pp. 315-316.

Zhang, Z.; Goldenshon, S.B. e Radev, D.R. (2002). Towards CST-Enhanced Sumarization. In Proceedings of the 18th National Conference on Artificial Intelligence (AAAI-2002). Edmonton/Canadá. 


\title{
APÊNDICE A - Relações CST refinadas para a anotação do córpus CSTNews
}

\author{
Nome da Relação: Identity \\ Direcionalidade: Nula \\ Restrições: As sentenças devem ser idênticas \\ Comentários:
}

Nome da Relação: Equivalence
Direcionalidade: Nula
Restrições: As sentenças apresentam o mesmo conteúdo, mas expresso de forma
diferente
Comentários:

Nome da Relação: Summary

Direcionalidade: $\mathrm{S} 1 \leftarrow \mathrm{S} 2$

Restrições: S2 apresenta o mesmo conteúdo que S1, mas de forma mais compacta.

Comentários: Summary é um tipo de equivalence, mas summary deve haver diferença significativa de tamanho entre as sentenças.

\section{Nome da Relação: Subsumption}

Direcionalidade: $\mathrm{S} 1 \rightarrow \mathrm{S} 2$

Restrições: S1 apresenta as informações contidas em S2 e informações adicionais.

Comentários: S1 contém X e Y, S2 contém X.

\section{Nome da Relação: Overlap}

Direcionalidade: Nula

Restrições: S1 e S2 apresentam informações em comum e ambas apresentam informações adicionais distintas entre si.

Comentários: S1 contém X e Y, S2 contém X e Z.

\section{Nome da Relação: Historical background}

Direcionalidade: $\mathrm{S} 1 \leftarrow \mathrm{S} 2$

Restrições: S2 apresenta informações históricas sobre algum elemento presente em S1.

Comentários: O elemento elaborado em S2 deve ser o foco de S2; se forem apresentadas informações repetidas, considere outra relação (por exemplo, overlap). 
Nome da Relação: Follow-up

Direcionalidade: $\mathrm{S} 1 \leftarrow \mathrm{S} 2$

Restrições: S2 apresenta acontecimentos que acontecem após os acontecimentos em S1; os acontecimentos em S1 e em S2 devem ser relacionados e ter um espaço de tempo relativamente curto entre si.

Comentários:

Nome da Relação: Elaboration

Direcionalidade: $\mathrm{S} 1 \leftarrow \mathrm{S} 2$

Restrições: S2 detalha/refina/elabora algum elemento presente em S1, sendo que S2 não deve repetir informações presentes em $\mathrm{S} 1$.

Comentários: $\mathrm{O}$ elemento elaborado em $\mathrm{S} 2$ deve ser o foco de $\mathrm{S} 2$; se forem apresentadas informações repetidas, considere outra relação (por exemplo, overlap).

Nome da Relação: Contradiction

Direcionalidade: Nula

Restrições: S1 e S2 divergem sobre algum elemento das senteças.

Comentários:

Nome da Relação: Citation

Direcionalidade: $\mathrm{S} 1 \leftarrow \mathrm{S} 2$

Restrições: $\mathrm{S} 2$ cita explicitamente informação proveniente de $\mathrm{S} 1$.

Comentários: Dada a natureza desta relação, ela não pode co-ocorrer com relações de redundância total.

Nome da Relação: Attribution

Direcionalidade: $\mathrm{S} 1 \leftarrow \mathrm{S} 2$

Restrições: S1 e S2 apresentam informação em comum e S2 atribui essa informação a uma fonte/autoria presente em S1.

Comentários: Dada a natureza desta relação, ela não pode co-ocorrer com relações de redundância total.

Nome da Relação: Modality

Direcionalidade: $\mathrm{S} 1 \leftarrow \mathrm{S} 2$

Restrições: S1 e S2 apresentam informação em comum e em S2 a fonte/autoria da informação é indeterminada/relativizada/amenizada

Comentários: Dada a natureza desta relação, ela não pode co-ocorrer com relações de redundância total. 
Nome da Relação: Indirect speech

Direcionalidade: $\mathrm{S} 1 \leftarrow \mathrm{S} 2$

Restrições: S1 e S2 apresentam informação em comum; S1 apresenta essa informação em discurso direto e $\mathrm{S} 2 \mathrm{em}$ discurso indireto.

Comentários:

Nome da Relação: Translation

Direcionalidade: Nula

Restrições: S1 e S2 apresentam informação em comum em línguas diferentes.

Comentários: 


\section{APÊNDICE B - Relações RST para a anotação do córpus CSTNews}

Obs.: Nas definições o Núcleo é representado por $\mathbf{N}$ e o Satélite é representado por $\mathbf{S}$

\begin{tabular}{l}
\hline Nome da relação: ANTITHESIS \\
\hline Restrições sobre N: o escritor julga N válido \\
Restrições sobre S: não há \\
Restrições sobre N+S: N e S estão em contraste; por causa da aparente \\
incompatibilidade, não se pode julgar N e $\mathrm{S}$ válidos ao mesmo tempo; a compreensão de \\
S e da incompatibilidade entre $\mathrm{N}$ e $\mathrm{S}$ faz o leitor aceitar melhor $\mathrm{N}$ \\
Efeito: o leitor aceita melhor N
\end{tabular}

Nome da relação: ATTRIBUTION

Restrições sobre N: N apresenta uma expressão, fala ou pensamento de alguém ou algo

Restrições sobre $\mathbf{S}$ : $\mathrm{S}$ apresenta alguém ou algo que produz $\mathrm{N}$

Restrições sobre $\mathbf{N}+\mathbf{S}$ : $\mathbf{S}$ e $\mathrm{N}$ indicam, respectivamente, a fonte de uma mensagem e a mensagem

Efeito: o leitor é informado sobre a mensagem e sobre quem ou o que a produziu

Nome da relação: BACKGROUND

Restrições sobre N: o leitor não compreenderá suficientemente $\mathrm{N}$ antes de ler $\mathrm{S}$

Restrições sobre S: não há

Restrições sobre $\mathbf{N}+\mathbf{S}$ : $\mathbf{S}$ aumenta a habilidade do leitor em compreender algum elemento em $\mathrm{N}$

Efeito: a habilidade do leitor para compreender $\mathrm{N}$ aumenta

Nome da relação: CIRCUMSTANCE

Restrições sobre N: não há

Restrições sobre S: apresenta uma situação (realizável)

Restrições sobre $\mathbf{N}+\mathbf{S}$ : S provê uma situação na qual o leitor pode interpretar $\mathrm{N}$

Efeito: o leitor reconhece que $\mathrm{S}$ provê uma situação na qual $\mathrm{N}$ deve ser interpretado

\section{Nome da relação: COMPARISON}

Restrições sobre N: apresenta uma característica de algo ou alguém

Restrições sobre $\mathbf{S}$ : apresenta uma característica de algo ou alguém comparável com o que é apresentado em $\mathrm{N}$

Restrições sobre $\mathbf{N}+\mathbf{S}$ : as atributos de $\mathrm{S}$ e $\mathrm{N}$ estão em comparação

Efeito: o leitor reconhece que $\mathrm{S}$ é comparado a $\mathrm{N}$ em relação a certas atributos 
Nome da relação: CONCESSION

Restrições sobre N: o escritor julga $\mathrm{N}$ válido

Restrições sobre $\mathbf{S}$ : o escritor não afirma que $S$ pode não ser válido

Restrições sobre $\mathbf{N}+\mathbf{S}$ : o escritor mostra uma incompatibilidade aparente ou em potencial entre $\mathrm{N}$ e $\mathrm{S}$; o reconhecimento da compatibilidade entre $\mathrm{N}$ e $\mathrm{S}$ melhora a aceitação de $\mathrm{N}$ pelo leitor

Efeito: o leitor aceita melhor $\mathrm{N}$

\section{Nome da relação: CONCLUSION}

Restrições sobre N: não há

Restrições sobre $\mathbf{S}$ : $\mathrm{S}$ baseia-se no que é apresentado em $\mathrm{N}$

Restrições sobre $\mathbf{N}+\mathbf{S}$ : $\mathbf{S}$ apresenta um fato concluído a partir da interpretação de $\mathrm{N}$

Efeito: o leitor reconhece que $\mathrm{S}$ é uma conclusão produzida devido à interpretação de $\mathrm{N}$

\section{Nome da relação: CONDITION}

Restrições sobre N: não há

Restrições sobre $\mathbf{S}$ : S apresenta uma situação hipotética, futura ou não realizada

Restrições sobre $\mathbf{N}+\mathbf{S}$ : a realização de $\mathbf{N}$ depende da realização de $\mathrm{S}$

Efeito: o leitor reconhece como a realização de $\mathrm{N}$ depende da realização de $\mathrm{S}$

\section{Nome da relação: ELABORATION}

Restrições sobre N: não há

Restrições sobre $S$ : não há

Restrições sobre $\mathbf{N}+\mathbf{S}$ : $\mathbf{S}$ apresenta detalhes adicionais sobre a situação ou algum elemento de $\mathrm{N}$

Efeito: o leitor reconhece S como apresentando detalhes adicionais sobre N

\section{Nome da relação: ENABLEMENT}

Restrições sobre N: apresenta uma ação do leitor não realizada

Restrições sobre $S$ : não há

Restrições sobre $\mathbf{N}+\mathbf{S}$ : a compreensão de $\mathbf{S}$ pelo leitor aumenta sua habilidade para realizar a ação em $\mathrm{N}$

Efeito: a habilidade do leitor para realizar a ação em $\mathrm{N}$ aumenta

\section{Nome da relação: EVALUATION}

Restrições sobre N: não há

Restrições sobre $\mathbf{S}$ : não há

Restrições sobre $\mathbf{N}+\mathbf{S}$ : $\mathbf{S}$ se relaciona a $\mathrm{N}$ pelo grau de avaliação positiva do escritor por $\mathrm{N}$

Efeito: o leitor reconhece que $\mathrm{S}$ avalia $\mathrm{N}$ e reconhece o valor que ele atribui 
Nome da relação: EVIDENCE

Restrições sobre $\mathbf{N}$ : o leitor poderia não acreditar em $\mathrm{N}$ de forma satisfatória para o escritor

Restrições sobre S: o leitor acredita em $\mathrm{S}$ ou o achará válido

Restrições sobre $\mathbf{N}+\mathbf{S}$ : a compreensão de $\mathrm{S}$ pelo leitor aumenta sua convicção em N Efeito: a convicção do leitor em $\mathrm{N}$ aumenta

\begin{tabular}{|l|}
\hline Nome da relação: EXPLANATION \\
Restrições sobre N: apresenta um evento ou situação \\
Restrições sobre $\mathbf{S}$ : não há \\
Restrições sobre $\mathbf{N}+\mathrm{S}: \mathrm{S}$ explica como e/ou porque o evento ou situação apresentado \\
em $\mathrm{N}$ ocorre ou veio a ocorrer \\
Efeito: o leitor reconhece que $\mathrm{S}$ é a razão para $\mathrm{N}$ ou que $\mathrm{S}$ explica como N ocorre \\
\hline
\end{tabular}

Nome da relação: INTERPRETATION

Restrições sobre N: não há

Restrições sobre S: não há

Restrições sobre $\mathbf{N}+\mathbf{S}$ : $\mathbf{S}$ apresenta um conjunto de ideias que não é expresso em $\mathbf{N}$ propriamente, mas derivado deste

Efeito: o leitor reconhece que $\mathrm{S}$ apresenta um conjunto de ideias que não é propriamente expresso no conhecimento fornecido por $\mathrm{N}$

\section{Nome da relação: JUSTIFY}

Restrições sobre N: não há

Restrições sobre $\mathbf{S}$ : não há

Restrições sobre $\mathbf{N}+\mathbf{S}$ : a compreensão de $\mathrm{S}$ pelo leitor aumenta sua prontidão para aceitar o direito do escritor de apresentar $\mathrm{N}$

Efeito: a prontidão do leitor para aceitar o direito do escritor de apresentar $\mathrm{N}$ aumenta

\section{Nome da relação: MEANS}

Restrições sobre N: uma atividade

Restrições sobre $S$ : não há

Restrições sobre $\mathbf{N}+\mathbf{S}$ : $\mathbf{S}$ apresenta um método ou instrumento que faz com que a realização de $\mathrm{N}$ seja mais provável

Efeito: o leitor reconhece que o método ou instrumento em $\mathrm{S}$ faz com que a realização de $\mathrm{N}$ seja mais provável

Nome da relação: MOTIVATION

Restrições sobre N: uma ação volitiva não realizada

Restrições sobre S: não há 
Restrições sobre $\mathbf{N}+\mathbf{S}$ : a compreensão de $\mathrm{S}$ motiva a realização de $\mathrm{N}$

Efeito: o leitor reconhece que $\mathrm{S}$ motiva a realização de $\mathrm{N}$

Nome da relação: NON-VOLITIONAL CAUSE

Restrições sobre N: apresenta uma ação não volitiva

Restrições sobre $S$ : não há

Restrições sobre $\mathbf{N}+\mathbf{S}$ : $\mathbf{S}$ apresenta uma situação que pode ter causado $\mathrm{N}$; sem $\mathrm{S}$, o leitor poderia não reconhecer o que causou a ação em $\mathrm{N} ; \mathrm{N}$ é mais central para a satisfação do objetivo do escritor do que $S$

Efeito: o leitor reconhece a situação apresentada em S como a causa da ação apresentada em $\mathrm{N}$

\section{Nome da relação: NON-VOLITIONAL RESULT}

Restrições sobre N: não há

Restrições sobre $\mathbf{S}$ : apresenta uma ação não volitiva

Restrições sobre $\mathbf{N}+\mathbf{S}$ : $\mathbf{N}$ apresenta uma situação que pode ter causado $\mathrm{S}$; sem $\mathbf{N}$, o leitor poderia não reconhecer o que causou a ação em $\mathrm{S} ; \mathrm{N}$ é mais central para a satisfação do objetivo do escritor do que $S$

Efeito: o leitor reconhece a situação apresentada em $\mathrm{N}$ como a causa da ação apresentada em $\mathrm{S}$

\section{Nome da relação: OTHERWISE}

Restrições sobre N: apresenta uma situação não realizada

Restrições sobre $\mathbf{S}$ : apresenta uma situação não realizada

Restrições sobre $\mathbf{N}+\mathbf{S}$ : a realização de $\mathrm{N}$ impede a realização de $\mathrm{S}$

Efeito: o leitor reconhece que a realização de $\mathrm{N}$ impede a realização de $\mathrm{S}$

\section{Nome da relação: PARENTHETICAL}

Restrições sobre N: não há

Restrições sobre S: apresenta informação extra relacionada a $\mathbf{N}$ que não está expressa no fluxo principal do texto

Restrições sobre $\mathbf{N}+\mathbf{S}$ : $\mathbf{S}$ apresenta informação extra relacionada a $\mathrm{N}$, complementado $\mathrm{N}$; S não pertence ao fluxo principal do texto

Efeito: o leitor reconhece que $\mathrm{S}$ apresenta informação extra relacionada a $\mathrm{N}$, complementando $\mathrm{N}$

\section{Nome da relação: PURPOSE}

Restrições sobre N: apresenta uma ação

Restrições sobre $\mathbf{S}$ : apresenta uma situação não realizada

Restrições sobre $\mathbf{N}+\mathbf{S}$ : $\mathbf{S}$ apresenta uma situação que pode realizar $\mathrm{N}$

Efeito: o leitor reconhece que a atividade em $\mathrm{N}$ pode ser iniciada por meio de $\mathrm{S}$ 
Nome da relação: RESTATEMENT

Restrições sobre N: não há

Restrições sobre S: não há

Restrições sobre $\mathbf{N}+\mathbf{S}$ : $\mathbf{S}$ se relaciona a $\mathrm{N}$; ambos apresentam conteúdo comparável; $\mathrm{N}$ é mais importante para a satisfação do objetivo do escritor

Efeito: o leitor reconhece que S expressa o mesmo conteúdo de N, mas de forma diferente

Nome da relação: SOLUTIONHOOD

Restrições sobre N: não há

Restrições sobre $\mathbf{S}$ : apresenta um problema

Restrições sobre $\mathbf{N}+\mathbf{S}$ : N é uma solução para o problema em $\mathbf{S}$

Efeito: o leitor reconhece $\mathrm{N}$ como uma solução para o problema em

Nome da relação: SUMMARY

Restrições sobre N: não há

Restrições sobre $S$ : não há

Restrições sobre $\mathbf{N}+\mathbf{S}$ : $\mathrm{S}$ apresenta o conteúdo de $\mathrm{N}$ resumido

Efeito: o leitor reconhece $\mathrm{S}$ como um resumo do conteúdo de $\mathrm{N}$

\begin{tabular}{|l|}
\hline Nome da relação: VOLITIONAL CAUSE \\
\hline Restrições sobre N: apresenta uma ação volitiva ou uma situação que poderia surgir de \\
uma ação volitiva \\
Restrições sobre $\mathbf{S}$ : não há \\
Restrições sobre N+S: S apresenta uma situação que pode ter acarretado o fato do \\
agente da ação volitiva em $\mathrm{N}$ ter realizado a ação; sem $\mathrm{S}$, o leitor poderia não \\
reconhecer a motivação da ação; N é mais central para a satisfação do objetivo do \\
escritor do que $S$ \\
Efeito: o leitor reconhece a situação apresentada em S como a causa da ação \\
apresentada em
\end{tabular}


Nome da relação: VOLITIONAL RESULT

Restrições sobre N: não há

Restrições sobre $\mathbf{S}$ : apresenta uma ação volitiva ou uma situação que poderia surgir de uma ação volitiva

Restrições sobre $\mathbf{N}+\mathbf{S}$ : $\mathbf{N}$ apresenta uma situação que pode ter acarretado o fato do agente da ação volitiva em $\mathrm{S}$ ter realizado a ação; sem $\mathrm{N}$, o leitor poderia não reconhecer a motivação da ação; $\mathrm{N}$ é mais central para a satisfação do objetivo do escritor do que $\mathrm{S}$

Efeito: o leitor reconhece a situação apresentada em N como a causa da ação

apresentada em

Nome da relação: CONTRAST

Restrições sobre os Ns: não mais do que dois Ns; as situações nos Ns são (a) compreendidas como similares em vários aspectos, (b) compreendidas como diferentes em vários aspectos e (c) comparadas em relação a uma ou mais dessas diferenças

Efeito: o leitor reconhece as similaridades e diferenças resultantes da comparação sendo feita

Nome da relação: JOINT

Restrições sobre os Ns: não há

Efeito: não há

Nome da relação: LIST

Restrições sobre os Ns: itens comparáveis apresentados nos Ns

Efeito: o leitor reconhece como comparáveis os itens apresentados

Nome da relação: SAME-UNIT

Restrições sobre os Ns: os Ns apresentam informações que, juntas, constituem uma única proposição

Efeito: o leitor reconhece que as informações apresentadas constituem uma única proposição; separadas, não fazem sentido

Nome da relação: SEQUENCE

Restrições sobre os Ns: as situações apresentadas nos Ns são realizadas em sequência Efeito: o leitor reconhece a sucessão temporal dos eventos apresentados 
